\title{
Perspectiva de la competitividad agrícola y turística en la provincia de Sabana Centro, Cundinamarca - Colombia
}
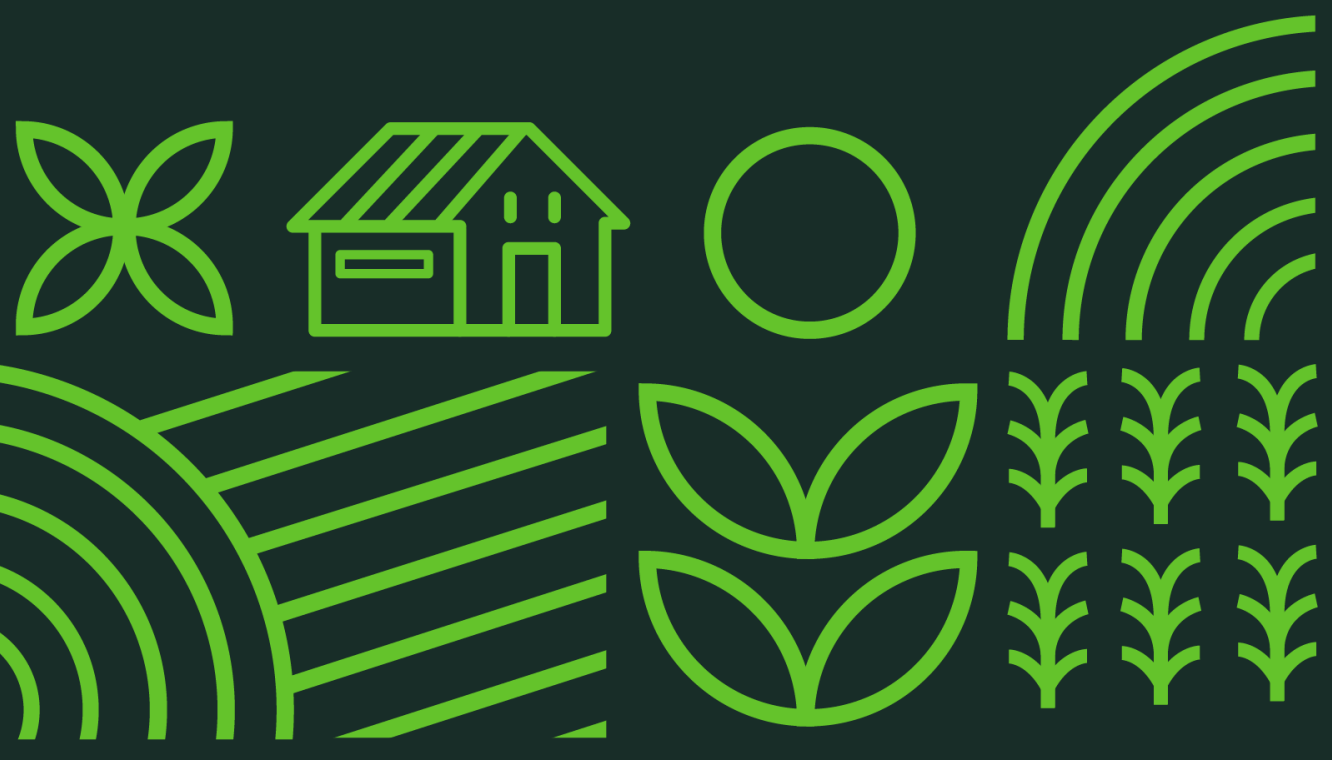

Editorial 


\section{Perspectiva de la competitividad agrícola y turística}

\section{en la provincia de Sabana Centro, Cundinamarca - Colombia}

Olga Marina García Norato. Jairo Alonso Ávila Moreno. Ana María Balcázar Daza. Luz Deisy Flórez Espinal.

Diana Patricia Gutiérrez. Yudy Marlén Bonilla Bonilla. José Zacarías Mayorga Sánchez. 
García Norato, O. M. \& Ávila Moreno, J. A.

Perspectiva de la competitividad agrícola y turística en la provincia sabana centro, Cundinamarca- Colombia.

Editorial de la Universidad de Cundinamarca. 2021.

Fusagasugá.

$221 \mathrm{p}$.

ISBN: 978-958-5195-04-2
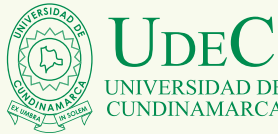

UNIVERSIDAD DE CUNDINAMARCA

\section{Dr. Adriano Muñoz Barrera}

Rector

Dra. María Eulalia Buenahora

\section{Ochoa}

Vicerrectora Académica

\section{Dr. Jaime Augusto Porras}

Jiménez

Director de Investigación

Universitaria

\section{Dr. Félix Gregorio Rojas \\ Bohórquez}

Decano Facultad de la Ciencias Administrativas, Económicas y Contables

\section{(i) Editorial UCundinamarca}

(c) Universidad de Cundinamarca, 2021

Primera Edición, 2021

Facultad de Ciencias Administrativas, Económicas y Contables.

Programa de Contaduría Pública

Coordinadores:

Olga Marina García Norato

Jairo Alonso Ávila Moreno

\section{Editorial:}

Dirección editorial: Jaime Augusto Porras Jiménez

Editor: Rosemberg del Carpio López Juarez

Corrección de estilo: Yesid Castiblanco Barreto

Diseño editorial: Paula Karina Martínez Camelo

Registro digital: Ana Milena Bejarano Torres

Dirección de Investigación

Universidad de Cundinamarca

www.ucundinamarca.edu.co

editorial@ucundinamarca.edu.co

Diagonal 18 No. 20 - 29

Fusagasugá - Cundinamarca

ISBN: 978-958-5195-04-2 


\section{Autores: \\ Olga Marina García Norato Jairo Alonso Ávila Moreno Ana María Balcázar Daza Luz Deisy Flórez Espinal \\ Diana Patricia Gutiérrez \\ Yudy Marlén Bonilla Bonilla José Zacarías Mayorga Sánchez}

\section{DERECHOS RESERVADOS:}

Prohibida la reproducción total o parcial de este libro, sin permiso previo y por escrito de los titulares del copyright.

Los conceptos aquí expresados son responsabilidad exclusiva de sus autores y no necesariamente representan la posición oficial de la Universidad de Cundinamarca.

No comercial: no puede utilizar esta obra con fines comerciales de ningún tipo. Tampoco puede vender esta obra bajo ningún concepto ni publicar estos contenidos en sitios web que incluyan publicidad de cualquier tipo.

El presente libro es derivado de un compendio de resultados de investigación de los siguientes proyectos: 1.- seguridad alimentaria y competitividad agrícola de la provincia de Sabana centro Cundinamarca Colombia 2.- medición de productividad y gestión del conocimiento al sector agrícola de Cundinamarca.

En cuanto a la información consignada en el presente documento, fue revisada y evaluada por pares evaluadores externos doble ciego con el fin de garantizar una valoración crítica e imparcial sobre la calidad de los manuscri- tos; por lo cual los autores fueron informados sobre las recomendaciones dadas por los pares para realizar los respectivos cambios y/o ajustes del caso, para finalmente ser aprobados por el Consejo Editorial de la Universidad de Cundinamarca. 


\section{Índice}

10

\section{Capítulo 1}

Competitividad del sector agrícola de Sabana Centro, Cundinamarca, un acercamiento desde la teoría.

Introducción.

1.1 Marco teórico de la competitividad.

1.2 Marco conceptual.

1.3 Estado del arte.

Conclusión.

Referencias.

\section{5}

\section{Capítulo 2}

Retos de la competitividad agrícola de la provincia Sabana Centro, Cundinamarca, Colombia. Caso: papa, maíz y lechuga.

Introducción.

2.1 Metodología.

2.2 Contexto económico y social provincia Sabana Centro, Cundinamarca.

2.3 Modelo propuesto para la medición de la competitividad sector agrario Sabana Centro de Cundinamarca. Caso: maíz, papa y hortalizas.

2.4 Retos y estrategias para mejorar la competitividad agrícola. 
Conclusión.

Referencias.

\section{8}

\section{Capítulo 3}

Análisis del emprendimiento turístico en los municipios de Chía y Cajicá 2019-2020. Propuesta metodológica.

Introducción.

3.1 Estado del arte.

3.2 Metodología.

3.3 Desarrollo de la investigación.

Conclusión.

Referencias.

\section{0}

\section{Capítulo 4}

El microcrédito, una alternativa para el desarrollo biotecnológico del agro colombiano.

Introducción.

4.1 Marco teórico 198

4.2 Metodología 204

4.3 Resultados 205

Conclusión.

Referencias. 


\section{Lista de tablas}

Tabla 1. Conceptos de competitividad

Tabla 2. Atributos para la ventaja competitiva de una nación: condiciones y requerimientos para el sector agropecuario

Tabla 3. Variables e indicadores de la medición de la competitividad de los productores agrícolas

Tabla 4. Puntajes pilares ICD

Tabla 5. Rendimiento cultivos de hortalizas, papa y maíz en Sabana Centro

Tabla 6. Salida EViews regresión

Tabla 7. Efecto de aumento en la producción en Sabana Centro, Cundinamarca, en el PIB sectorial

Tabla 8. Costo, ingresos, utilidad y rentabilidad por hectárea

Tabla 9. Tabulación de algunas variables asociadas a la competitividad

Tabla 10. Variables del modelo

Tabla 11. Cantidad de créditos otorgados por actividad productiva, banca tradicional

Tabla 12. Valor total de préstamos otorgados por actividad productiva, banca tradicional

Tabla 13. Valor promedio por solicitante de préstamos otorgados por actividad productiva, banca tradicional

Tabla 14. Número de créditos y número de beneficiarios del sector microcrediticio

Tabla 15. Relación créditos banca tradicional vs. microcrédito

Tabla 16. Créditos potenciales de microcréditos de acuerdo con cifras históricas

Tabla 17. Montos de créditos potenciales de microcréditos de acuerdo con cifras históricas

Tabla 18. Promedio montos de créditos potenciales de microcréditos de acuerdo con cifras históricas 


\section{Lista de figuras}

Figura 1. Categorías, subíndices y variables

Figura 2. Elementos genéricos para la determinación de las relaciones entre competitividad y relaciones productivas

Figura 3. Distribución y uso principal del área continental de Colombia

Figura 4. Incidencia de la pobreza monetaria y de la pobreza extrema (porcentaje), total nacional 2017-2018

Figura 5. ODS en los que incide el crecimiento verde

Figura 6. Cinco ejes estructurales de la política de economía verde

Figura 7. Productividad de la tierra en países de referencia, 2013

Figura 8. Productores que reciben asistencia técnica agropecuaria en cultivos de referencia

Figura 9. Estructura del Índice de Competitividad de las Provincias de Cundinamarca (ICPC), 2018

Figura 10. Clasificación de las provincias de Cundinamarca según su etapa de desarrollo económico

Figura 11. Resultados generales ICPC 2018

Figura 12. Perfil competitivo de la provincia Sabana Centro de Cundinamarca

Figura 13. Provincias de Cundinamarca, división político-administrativa 2017

Figura 14. Tasas de crecimiento del PIB de Cundinamarca

Figura 15. PIB de Cundinamarca en miles de millones de pesos

Figura 16. Producción de hortalizas, maíz y papa en la provincia Sabana Centro

Figura 17. Áreas sembradas y cosechadas

Figura 18. Estrategias importantes para la competitividad de papa, maíz y lechuga

Figura 19. Efectos marginales e interpretación de las variables

Figura 20. Fórmulas tamaño de muestra 


\section{Lista de anexos}

Anexo 1. Encuesta de caracterización - Papa

Anexo 2. Tabulación encuesta de caracterización - Papa

Anexo 3. Encuesta de caracterización - Maíz

Anexo 4. Tabulación encuesta de caracterización - Maíz

Anexo 5. Encuesta de caracterización - Lechuga

Anexo 6. Tabulación encuesta de caracterización - Lechuga

Anexo 7. Instrumento de medición (encuesta) 


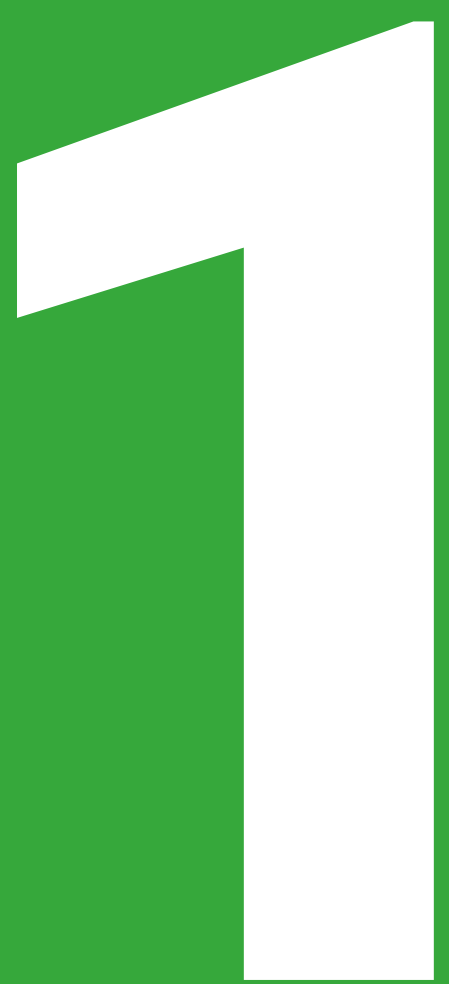

Competitividad del sector agrícola de Sabana Centro, Cundinamarca, un acercamiento desde la teoría. 


\title{
Competitividad del sector agrícola de Sabana Centro, Cundinamarca, un acercamiento desde la teoría
}

\author{
Jairo Alonso Ávila Moreno ${ }^{7}$ \\ Olga Marina García Norato ${ }^{2}$ \\ José Zacarías Mayorga Sánchez ${ }^{3}$ \\ Yudy Marlén Bonilla Bonilla ${ }^{4}$
}

\section{Introducción}

Magíster en Desarrollo Rural, especialista en Gerencia Informática, especialista en Finanzas y administrador de empresas. Docente investigador del programa de Administración de Empresas e integrante del Grupo de Investigación DOPyS. E-mail: jairo3139@yahoo.es.

2 Doctora en Historia, magíster en Desarrollo Rural, especialista en Finanzas y economista. Integrante del Grupo de Investigación ADCODER de la Universidad de Cundinamarca. E-mail: Olga.garciaudec17@gmail.com.

3 Magíster en Planeación Socioeconómica, especialista en Finanzas, Control de Gestión y Revisoría Fiscal, especialista en Docencia Universitaria, Economía Internacional y Desarrollo Económico, y economista. Director de investigación universitaria de la Universidad de Cundinamarca e integrante del Grupo de Investigación DOPyS. E-mail: jmayorgs@gmail.com.

$4 \quad$ Magíster en Ciencias Económicas, especialista en Gerencia Financiera Internacional y economista. Docente investigadora en Administración de Empresas y líder del Grupo de Investigación DOPyS de la Universidad de Cundinamarca, extensión Chía.

E-mail: yumabus@gmail.com. 
competitividad ha afectado la función que durante décadas tenía el concepto de economías basadas en localización. La ubicación de recursos en diferentes partes de los procesos de producción en el sector agrícola ha permitido un desarrollo tecnológico que ha facilitado en contexto la dinámica entre productores y consumidor final, presentando como resultado una mejor productividad. Las diferentes economías buscan acceder a mejorar la productividad con el fin de subsanar sus falencias y fortalecer su producto interno bruto (PIB), el cual es considerado como el principal indicador al medir el crecimiento de un país o región (Krugman, 2008). Cundinamarca no es la excepción a la hora de desarrollar su competitividad dado el impacto que genera en un sector como el agrario con gran potencial.

Este capítulo presenta a la comunidad académica, en primer lugar, un marco teórico sobre la competitividad; en segundo lugar, el marco conceptual; $y$, en tercer lugar, la revisión del estado del arte sobre este importante tema que determina hoy en el mundo si un país o una región entra al mercado o no. Finalmente, se establece cómo está la competitividad de la provincia de Sabana Centro en el departamento de Cundinamarca, Colombia, puesto que este capítulo es producto del proyecto titulado "Seguridad alimentaria y competitividad agrícola en la provincia de Sabana Centro, Cundinamarca, Colombia", desarrollado en conjunto por la Universidad de Cundinamarca y la Universidad Nacional. 


\subsection{Marco teórico de la competitividad}

Para hablar de competitividad se parte de dos conceptos importantes: ventaja absoluta y comparativa. El primero es propuesto por Adam Smith (1776) en su trabajo Una investigación sobre la naturaleza y causas de la riqueza de las naciones ${ }^{5}$, donde afirma que cada nación debe especializarse en producir mercancías en el menor costo medio de producción, es decir, que posean una ventaja absoluta, lo que trae consigo una eficiencia internacional (Smith, 1776).

Por su parte, David Ricardo (1818, citado por Napoleoni, 1981) plantea que, aun cuando un país no tenga ventajas absolutas en la producción de un bien, puede tener ventajas en la producción de bienes que posean un menor costo de oportunidad.

Michael Porter (1991) considera que estas dos teorías son importantes, pero establece que los tres factores que generan riqueza según lo propuesto por Smith (1776), tierra, recursos naturales y el trabajo, en la economía globalizada y competitiva, no pueden explicar por qué se da más riqueza en unos países que en otros, ya que el autor lo atribuye a la competitividad y productividad (Porter, 2007).

Otro aporte que genera inquietud en la academia y fortaleciendo lo propuesto por Ricardo y Smith, y luego de retomado el sentido de la localización por Krugman, es la idea sobre los impactos que genera la concentración de la actividad económica y cómo el desarrollo de nuevo conocimiento ayuda a impulsar los procesos productivos de los sectores. Según Maskell y Malmberg (1999), esta variable de localización puede producir un conocimiento que a su vez gene- 
re spillover entre el sector, innovando y mejorando la productividad.

Otro estudio sobre la productividad, su relación con la localización geográfica y la especialización de las actividades económicas, realizado por Feldman y Audretsch (1999), propone que la diversificación o especialización de la actividad económica puede promover de una forma efectiva el crecimiento sectorial por medio de transferencia de conocimiento y por ende generar mejoras por innovación a la productividad. Los hallazgos de este estudio, aunque divididos, mostraron que sí hay una pequeña relación entre la especialización y la localización geográfica en la productividad, pero debe estar acompañada por herramientas políticas para soportar el proceso de crecimiento del sector; también señala que las industrias que participan en el sector tienden a ubicarse en bloque con el fin de aumentar la producción y los procesos de innovación que fortalecen la productividad.

La competitividad se ha abordado por otros autores diferentes a Porter a lo largo de los años. A continuación, se presentan algunos de ellos: 
Tabla 1. Conceptos de competitividad

\begin{tabular}{|c|l|}
\hline Autor & \multicolumn{1}{|c|}{ Concepto de competitividad } \\
\hline $\begin{array}{c}\text { Michael Porter } \\
(1991)\end{array}$ & $\begin{array}{l}\text { La competitividad está determinada por la } \\
\text { productividad, definida como el valor del } \\
\text { producto generado por una unidad de trabajo } \\
\text { o de capital. La productividad es función de la } \\
\text { calidad de los productos (de la que a su vez } \\
\text { depende el precio) y de la eficiencia productiva. } \\
\text { (p. 51) }\end{array}$ \\
\hline Gerard Müller & $\begin{array}{l}\text { Es el conjunto de habilidades y condiciones } \\
\text { requeridas para el ejercicio de la competencia, la } \\
\text { cual es la lucha económica que genera rivalidad } \\
\text { entre grupos de vendedores (p. 138). }\end{array}$ \\
\hline Ivancevich \\
(1996)
\end{tabular}




\begin{tabular}{|c|l|}
\hline $\begin{array}{c}\text { Padilla y Juárez } \\
\text { (2006) }\end{array}$ & $\begin{array}{l}\text { La capacidad de introducir nuevos y mejores } \\
\text { productos, principalmente acompañados de } \\
\text { nuevas formas de organización empresarial y un } \\
\text { incremento en la capacidad productiva. Afirman } \\
\text { que esta competitividad es dinámica y es } \\
\text { sostenible en el largo plazo, y permite aumentar } \\
\text { las remuneraciones reales de los factores y los } \\
\text { niveles de vida de la población (pp. 9-10). }\end{array}$ \\
\hline $\begin{array}{c}\text { Departamento } \\
\text { Pacional de } \\
\text { (2007) }\end{array}$ & $\begin{array}{l}\text { En el conPES 3439 define la competitividad } \\
\text { regional como la capacidad de producir bienes } \\
\text { y servicios que compitan exitosamente en } \\
\text { mercados globalizados, generen crecimiento } \\
\text { sostenido en el largo plazo y contribuyan de esa } \\
\text { manera a mejorar los ingresos y la calidad de } \\
\text { vida de sus habitantes. }\end{array}$ \\
\hline
\end{tabular}

Fuente: elaboración propia.

Porter (1991) en su trabajo La ventaja competitiva de las naciones propone analizar la empresa y el sector para identificar los factores que determinan la generación de valor agregado, y si estos son sostenibles en el mediano y largo plazo. Adicional a esto, realiza un estudio a diez países para un periodo de cuatro años con el fin de entender los patrones del éxito competitivo, lo cual le permite concluir que la innovación genera niveles más altos 
de competitividad. Además, resalta que la capacidad para innovar se afecta por: (i) las condiciones de los factores; (ii) las condiciones de la demanda; (iii) las industrias relacionadas y de apoyo; y (iv) la estrategia, estructura y rivalidad de las firmas.

Porter argumenta que el tipo de cambio, el costo de la mano de obra, el balance comercial positivo, el nivel de intervención gubernamental y las tasas de interés no tienen nada que ver con la competitividad de un país, sino que se necesita es buen liderazgo tanto en el ámbito privado como en el público (Porter, 2007).

A nivel sectorial, el autor propone que "los sectores nacionales de mayor éxito comprenden grupos de firmas, no participantes aislados. Los competidores internacionales líderes (en un sector) no solo tienden a localizarse en la misma nación, sino que frecuentemente se encuentran en la misma ciudad o región dentro de la nación. Las posiciones nacionales en los sectores son sorprendentemente estables y se extienden durante muchas décadas" (Porter, 1991, p. 34). Finalmente, Porter (2007) establece cinco premisas para generar una teoría de ventaja nacional en los sectores, donde él afirma que se debe:

1. Explicar por qué las empresas de determinadas naciones eligen mejores estrategias que las de otras para competir en determinados sectores.

2. Integrar a la explicación del éxito internacional tanto el comercio como las inversiones extrajeras ${ }^{6}$.

3. Reflejar un concepto amplio de la competencia que comprenda los mercados segmentados, los productos diferenciados, las diferencias en

$\overline{6}$ Puesto que, según el autor, "muchas de las causas fundamentales de las exportaciones y de las IED resulta que son las mismas" (Porter, 2007). 
las tecnologías y en las economías de escala.

4. Reconocer la importancia de la innovación en lugar de desplazar pasivamente los recursos allí donde los rendimientos sean mayores, se debe buscar cómo aumentarlos mediante la incorporación de nuevos productos y procesos.

5. Dado que las empresas desempeñan un papel principal en el proceso de creación de la ventaja comparativa, las estrategias de estas deben ser parte integrante de una teoría de la ventaja nacional con una visión de eficiencia internacional (pp. 45-47).

Dicha competitividad se ha buscado medir en los últimos años principalmente por el Foro Económico Mundial desde 1979, para esto construyeron el Índice de Competitividad Global (ICG) que en 2018 actualizó su metodología, la cual establece doce (12) aspectos o categorías, agrupados en cuatro (4) subíndices: (i) ambiente apto; (ii) capital humano; (iii) mercados; y (iv) ecosistema de innovación.

Estas subcategorías a su vez agrupan noventa y ocho (98) variables (figura 1), midiendo así los fundamentos microeconómicos y macroeconómicos de la competitividad de los diferentes países. 
Figura 1. Categorías, subíndices y variables
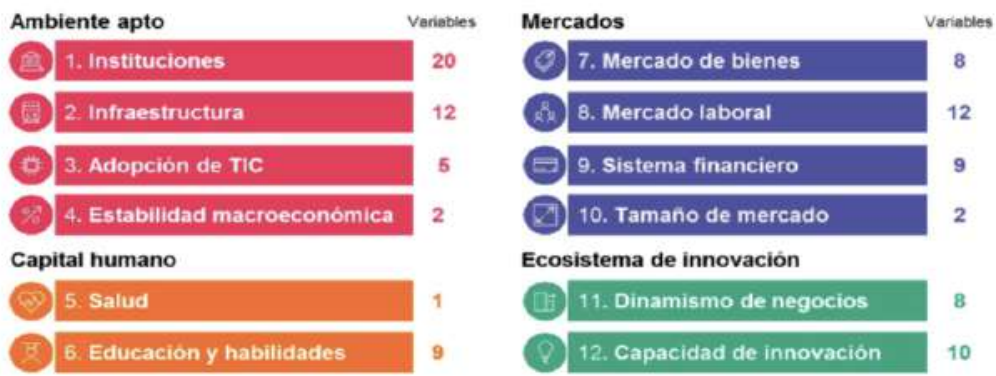

Fuente: México Competitivo (2018).

Por otro lado, las economías que deseen ser exitosas en la era 4IR necesitan:

- Ser resistentes ante las crisis financieras o desempleomasivo, por loquedebencrear mecanismos económicos para prevenir estas situaciones.

- Ser ágiles adaptándose al cambio en lugar de resistirse a él. Las empresas, los encargados de la formulación de políticas públicas y los trabajadores deberían poder adaptar rápidamente su funcionamiento y aprovechar las oportunidades para producir bienes o prestar servicios de nuevas maneras.

- Construir un ecosistema de innovación incentivándola en todos los niveles y que todos los interesados contribuyan a crear mejores condiciones para que surjan nuevas ideas que se financien y comercialicen como nuevos productos y servicios.

- Adaptarse a un enfoque centrado en el ser humano para el desarrollo económico, reconociendo el capital humano como esencial para generar prosperidad y que cualquier política que afecte 
negativamente el potencial de los factores humanos reducirá el crecimiento económico a largo plazo. Como consecuencia, la formulación de políticas deberá garantizar que la velocidad del cambio y la introducción de nuevas tecnologías se traduzcan finalmente en mejores condiciones de vida (World Forum Economic, 2019).

Porsuparte,Zegarray Valdiviaen2010 proponen un Índice de Competitividad Regional (ICR) de un país con el fin de posicionar un nuevo enfoque frente a este concepto, partiendo de "cómo en determinada región de un país se administran los recursos y capacidades para incrementar sostenidamente la productividad empresarial y el bienestar de su población". Para esto establecen determinantes de la competitividad de las regiones, a los cuales llaman pilares y son: (i) gobierno e instituciones; (ii) desarrollo económico; (iii) infraestructura productiva; (iv) capital humano; y (v) eficiencia de las empresas.

Adicional a esto, cada uno contiene cinco factores y algunas variables que permiten medir diferentes aspectos de la competitividad regional. Finalmente, concluyen que este índice es "un modelo específico desde el punto de vista estructural" y se debe componer principalmente de información estadística de fuentes secundarias, y complementarse en menor medida de información primaria proveniente de la aplicación de una encuesta a empresarios de todas las regiones del país, seleccionando de esta información los indicadores que conforman los cinco pilares que lo componen. Dichos indicadores deben pasar por un proceso de estandarización con el fin de consolidar las unidades de medida, obteniendo así tres tipos de resultados: (i) el resultado global del 
ICR; (ii) los resultados parciales del ICR para cada una de las regiones; y (iii) los resultados parciales del ICR para cada uno de los cinco pilares (Zegarra y Valdivia, 2010).

En Colombia, por su parte, se ha buscado la manera de generar y medir la competitividad del sector agrícola, a lo cual Bejarano en 1995 realizó un aporte al determinar algunos "elementos para un enfoque de la competitividad en el sector agropecuario", al igual que se denomina su trabajo. El autor realiza una aproximación metodológica, dentro de la cual identifica los elementos relevantes que permiten determinar las relaciones entre competitividad y las relaciones productivas (Bejarano, 1995, p. 40).

\section{Figura 2. Elementos genéricos para la determinación de las relaciones entre competitividad y relaciones productivas}

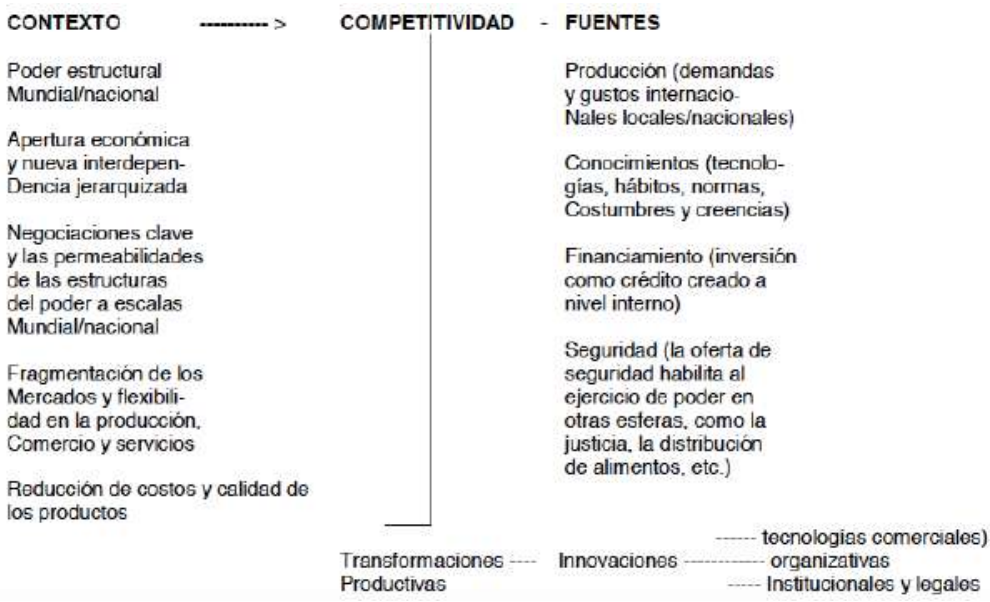


Bejarano (1995) resalta que el entorno hace referencia a los elementos que enmarcan el acceso a los mercados internacionales como asimetrías y políticas comerciales de los bloques económicos entre otros, además de los que, sin ser directamente empresariales, productivos o económicos, determinan el medioambiente de las decisiones de la empresa o del sector como las jerarquías de poder. Además, resalta que, dependiendo del nivel de análisis de la competitividad, es decir, si es nacional, sectorial o empresarial, se deben definir otros elementos del entorno a partir de sus condiciones.

También se deben identificar aspectos de la creación de ventajas competitivas que sean controlables por la empresa, puedan serlo por parte del gobierno, los que "requieren acuerdos gobierno-empresa y los que son difícilmente controlables y frente a los cuales se requiere una cierta capacidad de adaptación" (Bejarano, 1995, p. 51). Adicional a esto, presenta los atributos para la ventaja competitiva de una nación, junto con las condiciones y requerimientos para el sector agropecuario (tabla 2), a partir de una adaptación de los determinantes de la competitividad de Porter (1991) para el caso del sector en estudio. Dichos determinantes son:

- Las condiciones de los factores: la disponibilidad de factores de producción e infraestructura requerida para competir en un sector determinado, cuya jerarquización es definitiva para la eficiencia y la competitividad.

- Las condiciones de demanda, que comprenden su naturaleza a nivel nacional o internacional de los productos del sector.

- Las industrias relacionadas y de apoyo: es la 
presencia o ausencia en el país de las abastecedoras de insumos y de otras relacionadas que sean competitivas a nivel internacional.

- Estrategia, estructura y competencia entre productores que consideran las características y naturaleza de la competencia doméstica e internacional (Porter, 1991).

Tabla 2. Atributos para la ventaja competitiva de una nación: condiciones y requerimientos para el sector agropecuario

\begin{tabular}{|c|c|c|}
\hline Atributos & Condiciones & $\begin{array}{l}\text { Implicaciones o } \\
\text { requerimientos }\end{array}$ \\
\hline $\begin{array}{c}\text { Condiciones } \\
\text { factoriales }\end{array}$ & $\begin{array}{l}\text { - Ventajas } \\
\text { comparativas } \\
\text { basadas en } \\
\text { actores de } \\
\text { producción } \\
\text { especializados } \\
\text { (recurso humano } \\
\text { y base científica } \\
\text { sólida). } \\
\text { - Velocidad y } \\
\text { eficiencia en la } \\
\text { creación, mejora } \\
\text { y empleo de los } \\
\text { elementos que } \\
\text { generan ventaja } \\
\text { comparativa en } \\
\text { las actividades } \\
\text { productivas. }\end{array}$ & $\begin{array}{l}\text { - Cambio de ventajas } \\
\text { comparativas tradicionales } \\
\text { hacia ventajas } \\
\text { competitivas, lo cual } \\
\text { supone la incorporación de } \\
\text { la innovación tecnológica a } \\
\text { la producción. } \\
\text { - Necesidad de flexibilidad } \\
\text { de los sistemas de } \\
\text { generación -difusión-, } \\
\text { adopción de tecnología } \\
\text { agropecuaria y de } \\
\text { fomentar en las empresas } \\
\text { agropecuarias la demanda } \\
\text { por recursos humanos } \\
\text { calificados. }\end{array}$ \\
\hline
\end{tabular}




\begin{tabular}{|l|l|l|}
\hline $\begin{array}{l}\text { Condiciones } \\
\text { de demanda }\end{array}$ & $\begin{array}{l}\text { Interesa más } \\
\text { el carácter o la } \\
\text { naturaleza de la } \\
\text { demanda que su } \\
\text { tamaño. }\end{array}$ & $\begin{array}{l}\text { - Estímulo a la calidad } \\
\text { (mediante el uso de } \\
\text { mejoras tecnológicas } \\
\text { productivas y } \\
\text { organizacionales, entre } \\
\text { otros) y a la exigencia } \\
\text { de los compradores } \\
\text { nacionales y regionales. } \\
\text { Identificación de } \\
\text { nichos de mercado en } \\
\text { el país y la región que } \\
\text { pueden satisfacerse con } \\
\text { productos diferenciados } \\
\text { mediante la aplicación de } \\
\text { conocimientos científicos y } \\
\text { tecnológicos. }\end{array}$ \\
\hline $\begin{array}{l}\text { Actividades } \\
\text { productivas }\end{array}$ & $\begin{array}{l}\text { Presencia } \\
\text { en el país de } \\
\text { proveedores y } \\
\text { otras relacionadas } \\
\text { que sean } \\
\text { internacionalmente } \\
\text { competitivas. }\end{array}$ & $\begin{array}{l}\text { económico y tecnológico } \\
\text { de proveedores locales y } \\
\text { regionales. } \\
\text { Estímulo a la } \\
\text { elaboración de los } \\
\text { productos agropecuarios. }\end{array}$ \\
\hline
\end{tabular}




\begin{tabular}{|c|l|l|}
\hline $\begin{array}{c}\text { Estrategia, } \\
\text { estructura y } \\
\text { rivalidad de la } \\
\text { empresa }\end{array}$ & $\begin{array}{l}\text { Prácticas } \\
\text { administrativas, } \\
\text { modalidades de } \\
\text { organización y tipo } \\
\text { de educación, y } \\
\text { vocaciones que se } \\
\text { favorecen. }\end{array}$ & $\begin{array}{l}\text { - Promoción de la } \\
\text { rivalidad como elemento } \\
\text { motor de la mejora } \\
\text { dinámica y estimulador de } \\
\text { la innovación tecnológica } \\
\text { entre los productores } \\
\text { agropecuarios. } \\
\end{array}$ \\
& $\begin{array}{l}\text { Introducción de la } \\
\text { planificación estratégica } \\
\text { con énfasis en la } \\
\text { planificación tecnológica } \\
\text { en las empresas } \\
\text { agropecuarias. }\end{array}$ \\
& \\
&
\end{tabular}

Esto con el fin de fomentar las ventajas competitivas creadas en el sector, lo cual debe estar articulado con la sostenibilidad, la equidad, las políticas de desarrollo productivo y de modernización del aparato productivo (Bejarano, 1995).

\subsection{Marco conceptual}

A continuación, se presentan algunos conceptos importantes para el desarrollo de la investigación:

Competitividad. El "conjunto de instituciones, políticas y factores que determinan el nivel de productividad de un país" (World Economic Forum, 2014, p. 4).

Economías de escala. "Propiedad por la cual el costo total promedio a largo plazo disminuye conforme aumenta la cantidad producida" (Mankiw, 2016, p. 385). 
Eficiencia en el mercado de bienes. "La competencia saludable de mercado, doméstica y extranjera, es importante para incentivar la eficiencia de mercado y así la productividad empresarial, de forma que las empresas más eficientes, produciendo bienes demandados en el mercado, sean las que prosperen" (World Economic Forum, 2014, p. 7).

Externalidad. "El efecto no compensado de las acciones de una persona sobre el bienestar de un tercero, en presencia de una externalidad negativa, como la contaminación" (Mankiw, 2016, p. 836).

Índice. La Organización de las Naciones Unidas para la Alimentación y la Agricultura (FAO) define como "un conjunto agregado o ponderado de parámetros o indicadores" (CTPD, s.f.).

Indicador. La Universidad Nacional de Colombia (s.f.) define al indicador como "una expresión cualitativa o cuantitativa observable que permite describir características, comportamientos o fenómenos de la realidad a través de la evolución de una variable" (p. 11). Por otro lado, el Consejo Nacional de Evaluación de la Política de Desarrollo Social (CONEVAL, 2019)7 de México define al indicador como "una herramienta cuantitativa o cualitativa que muestra indicios o señales de una situación, actividad o resultado; brinda una señal relacionada con una única información" (párr. 1).

Innovación. Transformación de conocimiento en nuevos productos y servicios. No es un evento aislado, sino la respuesta continua a circunstancias cambian-

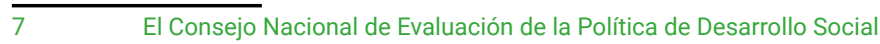
(CONEVAL) es un organismo público descentralizado de la administración pública que genera información objetiva sobre la situación política social y la medición de la pobreza en México. 
tes (Nelson, 1999).

Instituciones. Marco legal y administrativo en el que los individuos, las empresas y los gobiernos interactúan para generar riqueza" (World Economic Forum, 2014, p. 4).

Pilar. Considerados como impulsores de productividad a partir de los cuales el Foro Económico Mundial busca proveer a los diferentes países considerados en el reporte de competitividad de herramientas que les permitan a los líderes empresariales y a los encargados de la política económica identificar obstáculos y mejorar la competitividad de sus naciones (Chacón, 2015, p. 1).

Ventaja competitiva. Esta crece fundamentalmente debido al valor que una empresa es capaz de generar. El concepto de valor representa lo que los compradores están dispuestos a pagar, y el crecimiento de este valor a un nivel superior se debe a la capacidad de ofrecer precios más bajos en relación con los competidores por beneficios equivalentes o proporcionar beneficios únicos en el mercado que puedan compensar los precios más elevados. Una empresa se considera rentable si el valor que es capaz de generar es más elevado de los costos ocasionados por la creación del producto (Porter, 1985).

\subsection{Estado del arte}

Como primera medida se presenta el contexto sobre seguridad alimentaria, lo que permite destacar la importancia del sector agrícola a nivel local, regional, 
nacional e internacional. Luego, se presentan algunos trabajos que se han realizado alrededor del tema de competitividad de la región Sabana Centro de Cundinamarca en el sector agrícola.

Contexto de la seguridad agroalimentaria. Según la FAO, se espera que para el año 2050 la población mundial Ilegue a los nueve mil millones de habitantes (FAO, 2019), lo que implica el reto de aumentar la producción alimentaria en aproximadamente un 70 por ciento (FAO, 2019). Esta situación genera una oportunidad importante para Colombia, puesto que es uno de los "siete países con mayor capacidad de aumentar la producción agrícola" (Villanueva, 2018).

En Colombia se ha dado un uso importante de la tierra para la agricultura, pero de 43.1 millones de hectáreas aptas o destinadas a agricultura, únicamente $7.1 \mathrm{mi}$ llones (es decir, 6.3 \% del área nacional) se encuentran dedicadas a siembra de cultivos, las 34.4 millones restantes se han destinado a la alimentación de animales. Lo que puede considerarse poco beneficioso para el medioambiente puesto que la ganadería genera el $14.5 \%$ de las emisiones de efecto invernadero, "aumenta la degradación de los suelos, contamina agua y aire, y declina la biodiversidad de las regiones", lo cual a su vez trae consigo una oportunidad de crecimiento para el sector agrícola del país (Villanueva, 2018). 


\section{Figura 3. Distribución y uso principal del área continental de Colombia}

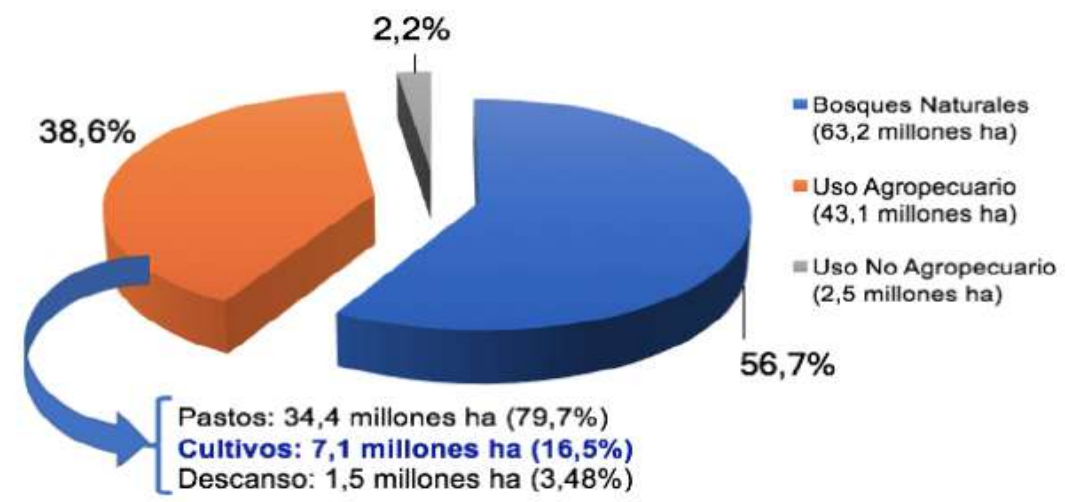

Fuente: estudios sobre la bioeconomía como fuente de nuevas industrias basadas en el capital natural de Colombia (Villanueva, 2018).

Se puede afirmar que una de las principales necesidades que el país presenta actualmente alrededor de la agricultura es la seguridad alimentaria, debido a que al proveer esta se evitan la malnutrición y desnutrición, por lo cual el Estado colombiano ha venido trabajando con la FAO en áreas determinadas como estrategias para el mejoramiento de la agricultura y la alimentación, permitiendo aportar a la erradicación de la pobreza extrema en el país, la cual todavía presenta tasas altas (figura 4). Cabe resaltar que, aunque esta situación es preocupante, se han aumentado los cultivos agrícolas a nivel nacional según lo afirma el Departamento Nacional de Planeación (DNP). 
Figura 4. Incidencia de la pobreza monetaria y de la pobreza extrema (porcentaje), total nacional 20172018

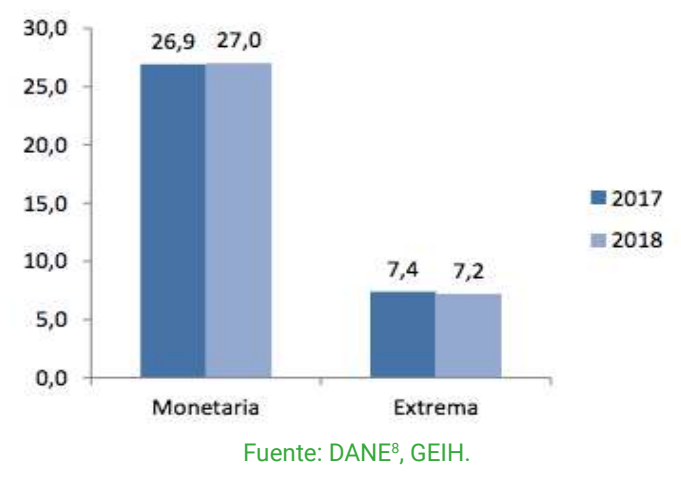

Otro aspecto importante dentro de la seguridad agroalimentaria es la vinculación del país dentro de la Organización para la Cooperación y el Desarrollo Económicos (OCDE), la cual dentro de sí contempla el crecimiento verde (CV). Para cumplir con este requisito de desarrollo sostenible, el gobierno estableció por medio del CONPES 3918 de 2018: "Estrategia para la implementación de los ODS" y del Acuerdo de París. Dicho CV incide directamente en el cumplimiento de nueve ODS e indirectamente en siete de ellos (figura 5). La política de CV busca impulsar la productividad y la competitividad del país, al tiempo que se asegura el uso sostenible del capital natural y la inclusión social, lo que evidencia la necesidad de generar cultivos más productivos, sostenibles y amigables con el medioambiente, e innovaciones que ayuden a diversi-

$8 \quad$ El Departamento Administrativo Nacional de Estadística (DANE) es la institución colombiana encargada de recopilar la información micro y macroeconómica, poblacional y social para su análisis y toma de decisiones en los entes gubernamentales. 
ficar la oferta exportadora del sector (DNP, 2018).

Figura 5. ODS en los que incide el crecimiento verde

\section{IMPACTOS DIRECTOS}

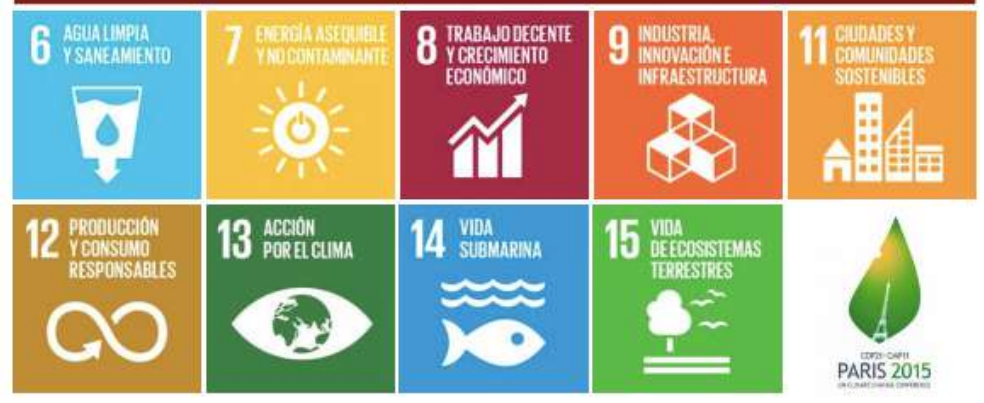

\section{IMPACTOS INDIRECTOS}

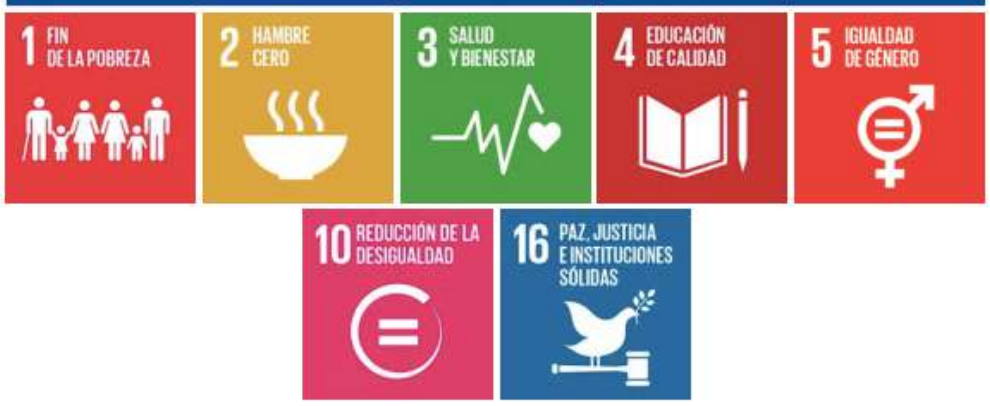

Fuente: presentación documento CONPES Política de Crecimiento Verde (2018).

Esto se evidencia de forma más precisa dentro de uno de los cinco ejes estructurales de dicha política (figura 6), el cual es el II y se denomina "Uso eficiente del capital natural y la energía en los sectores productivos". 


\section{Figura 6. Cinco ejes estructurales de la política de economía verde}

V. Marco de gobernanza para el crecimiento verde

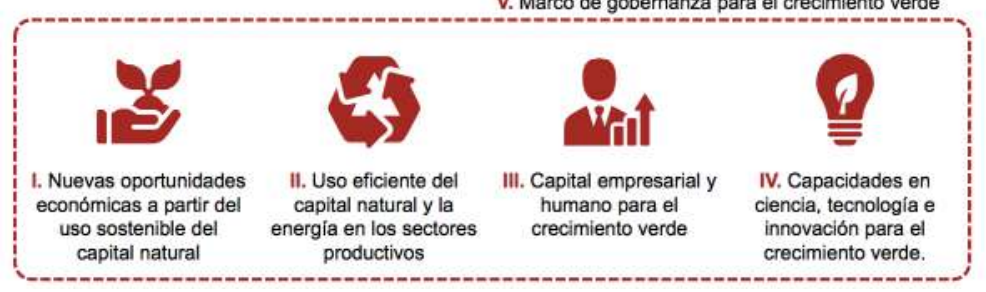

Fuente: presentación documento CONPES Política de Crecimiento Verde (2018).

Dentro de este eje se aborda como uno de los temas de especial interés la productividad del suelo, partiendo de la base que en Colombia es baja en comparación con otros países.

\section{Figura 7. Productividad de la tierra en países de referencia, 2013*}

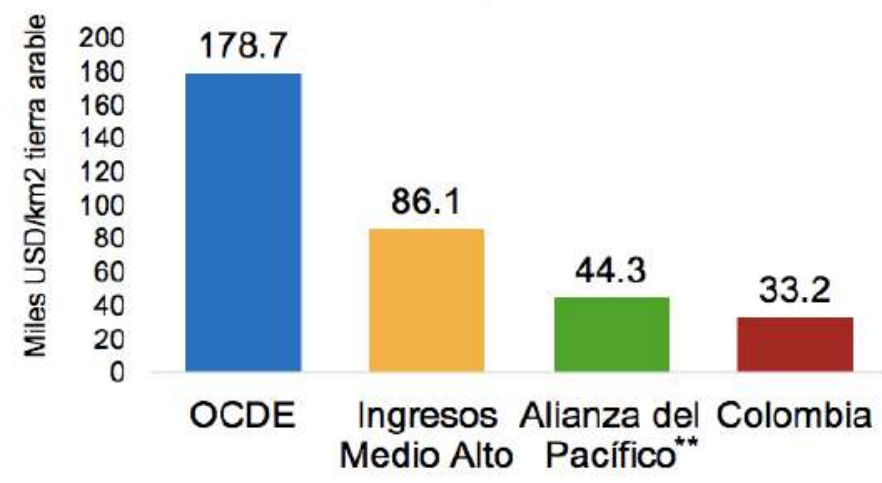

* Razón entre la producción de la agricultura y el área total cultivable con cosechas y pastoreos permanentes. La tierra 
para la agricultura se refiere a la proporción de la tierra que es arable que se encuentra con cosechas y pastoreos permanentes (Banco Mundial y FAO, 2013).

** El promedio para los países de la Alianza del Pacífico no incluye a Colombia.

Fuente: Presentación documento CONPES Política de Crecimiento Verde (2018).

Figura 8. Productores que reciben asistencia técnica agropecuaria en cultivos de referencia

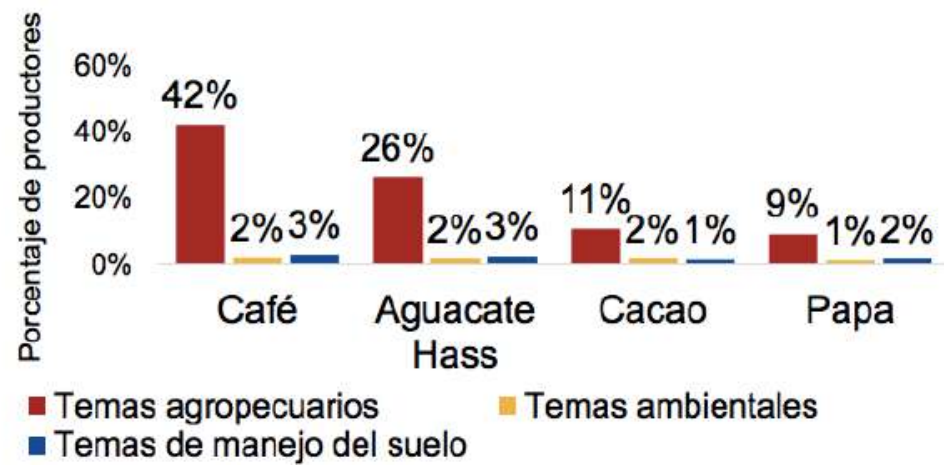

Fuente: CIAT con base en el Censo Nacional Agropecuario (2018).

Aun así, se resalta el hecho de que, respecto a 2009 , se ha incrementado en un $33.5 \%$ la inversión pública en investigación agropecuaria (DNP, 2018) y se propone como solución:

- Mejorar la productividad del suelo y el desempeño ambiental del sector agropecuario. 
- Asistencia técnica y buenas prácticas agropecuarias.

- Incorporar, en el 2019, criterios de crecimiento verde en el servicio de extensión agropecuaria en la reglamentación de la ley de innovación agropecuaria.

- Financiación: incorporar, en el 2019, criterios de crecimiento verde en la financiación de proyectos a través del Incentivo a la Capitalización Rural (ICR) y de la Línea Especial de Crédito (LEC) (DNP, 2018).

Adicional a esto, la misión de crecimiento verde (CV) identificó cuatro componentes estratégicos que se considera deben ser impulsados en el marco de un modelo de CV: (i) economía circular (manejo integral de residuos); (ii) energías renovables; (iii) aprovechamiento forestal; y (iv) bioeconomía (actividades económicas a partir de recursos de origen biológico).

Sin embargo, Finagro considera que el sector agrario está pasando por un buen momento y se espera siga creciendo dado el aumento de la demanda, en especial del mercado externo, de acuerdo con los datos proporcionados por el Fondo Internacional para Desarrollo Agrícola (FIDA), quienes afirman que la producción de alimentos en países en desarrollo como Colombia deberá duplicarse para el 2050 debido al "crecimiento del ingreso disponible de las economías emergentes, la mejora en la calidad de la dieta y el incremento en la población mundial, que alcanzará las 9000 millones de personas" (Finagro, 2019). 
Frente a lo anterior, el país puede responder dado su potencial agrícola, ya que es uno de los siete países en Latinoamérica con mayor capacidad para el desarrollo de áreas cultivables según la FAO, lo que lo llevará a convertirse en una de las grandes despensas del mundo. Adicional a esto, Finagro afirma que:

Entre 223 países en donde se evaluó el potencial de expansión del área agrícola, sin afectar el área del bosque natural, Colombia fue clasificada en el puesto 25. De los 22 millones de hectáreas cultivables que tiene el país, solo están sembradas 4.8 de ellas. Si a estas cifras se les suma el gran potencial de la altillanura colombiana para desarrollos forestales y agrícolas estimado en 3.5 millones de hectáreas, el panorama es muy prometedor. (Finagro, 2019)

Para lograr producir el $80 \%$ de la cantidad de alimentos que se requerirán para el 2050, es necesario que los países sean más productivos en las áreas de cultivos actuales y el 20 \% corresponderá a nuevas áreas, lo cual implica un desafío para la transformación del sector en Colombia, y debe generar mejoras genéticas, tecnologías de punta, agricultura de precisión, automatización, desarrollo de núcleos, economías de escala y valor agregado, y todo con enfoque de mercado (Finagro, 2019).

Adicionalmente, a nivel internacional se han realizado varios estudios, uno de ellos es el desarrollado por Ortiz, Infante y Ortega (2016), quienes proponen el Índice de Competitividad Agrícola Municipal (ICAM) para el estado de Michoacán, México. Los autores consideran que la evaluación de 
la competitividad es un instrumento importante a la hora de tomar decisiones tanto a nivel empresarial como gubernamental. El índice propuesto cuenta con seis variables y veintiún (21) indicadores, y es aplicado a los municipios del estado de Michoacán con el fin de realizar un análisis comparativo entre estos entornos de la producción agrícola. Esto les permitió identificar los que requieren atención prioritaria para mejorar la competitividad desde las variables e indicadores expuestos, lo cual es considerado por los autores como una técnica innovadora y particular.

El estudio parte de un análisis del PIB y de la importancia de la agricultura en el estudio, luego establecen las seis variables de estudio que son: (i) superficie de temporal; (ii) tecnología; (iii) organización de los productores; (iv) capacitación; (v) apoyos; y (vi) superficie asegurada, las cuales están compuestas por algunos indicadores como se puede observar en la tabla 3. Para realizar la del ICAM implementaron una técnica de proporciones y estandarización de datos $^{9}$, a partir de información obtenida en el Censo Ejidal del Instituto Nacional de Estadística, Geografía e Informática (INEGI) en 2007.

\footnotetext{
Se realiza la estandarización de las variables que conforman el índice de vulnerabilidad agrícola, normalizando los valores para convertirlos en homogéneos cuantificables entre sí de la siguiente manera:

$V N x_{1}=\frac{\left(x_{1}-x_{m}\right)}{\sigma x}$

Donde;

$V N x_{1}$ : es el valor normalizado de $x_{1}$.

$x_{1}$ : es el valor del indicador.

$x_{m}$ : es la media de la serie $x$.

$\sigma x$ : desviación estándar de la serie $x$.
} 


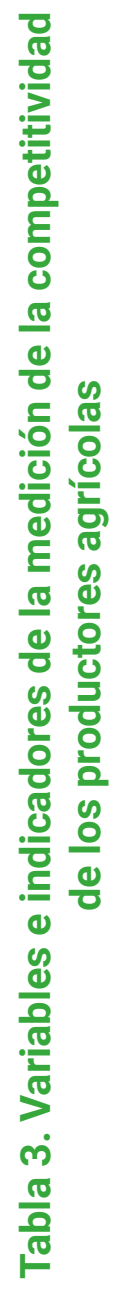

\begin{tabular}{|c|c|c|c|}
\hline 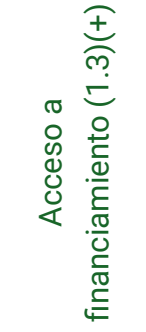 & 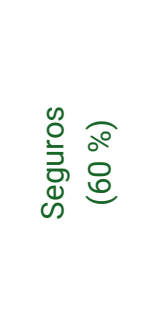 & 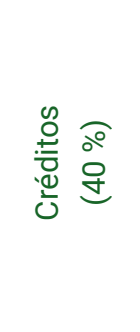 & \\
\hline 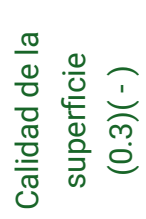 & 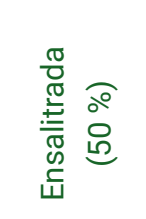 & 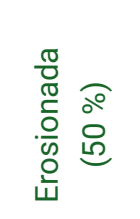 & \\
\hline 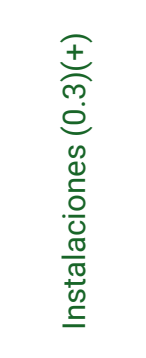 & 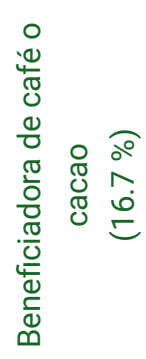 & $\begin{array}{l}\frac{\pi}{0} \\
\frac{0}{0} \\
\frac{\pi}{0} \\
\frac{0}{0} \\
\frac{0}{0} \\
\frac{0}{\frac{0}{0}} \\
\frac{0}{0} \\
0 \\
0\end{array}$ & 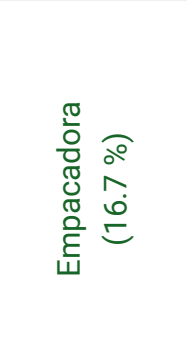 \\
\hline 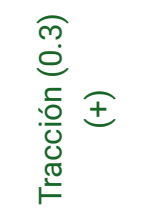 & 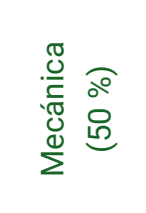 & 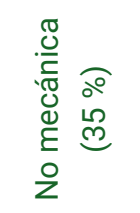 & 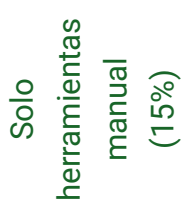 \\
\hline 윰 & 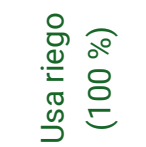 & 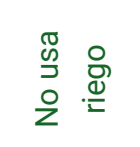 & \\
\hline 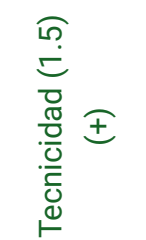 & 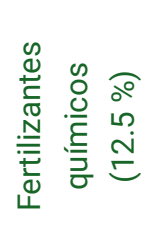 & 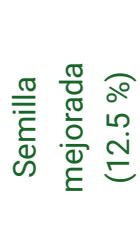 & 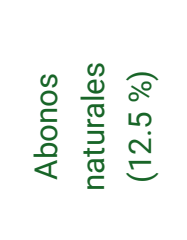 \\
\hline
\end{tabular}




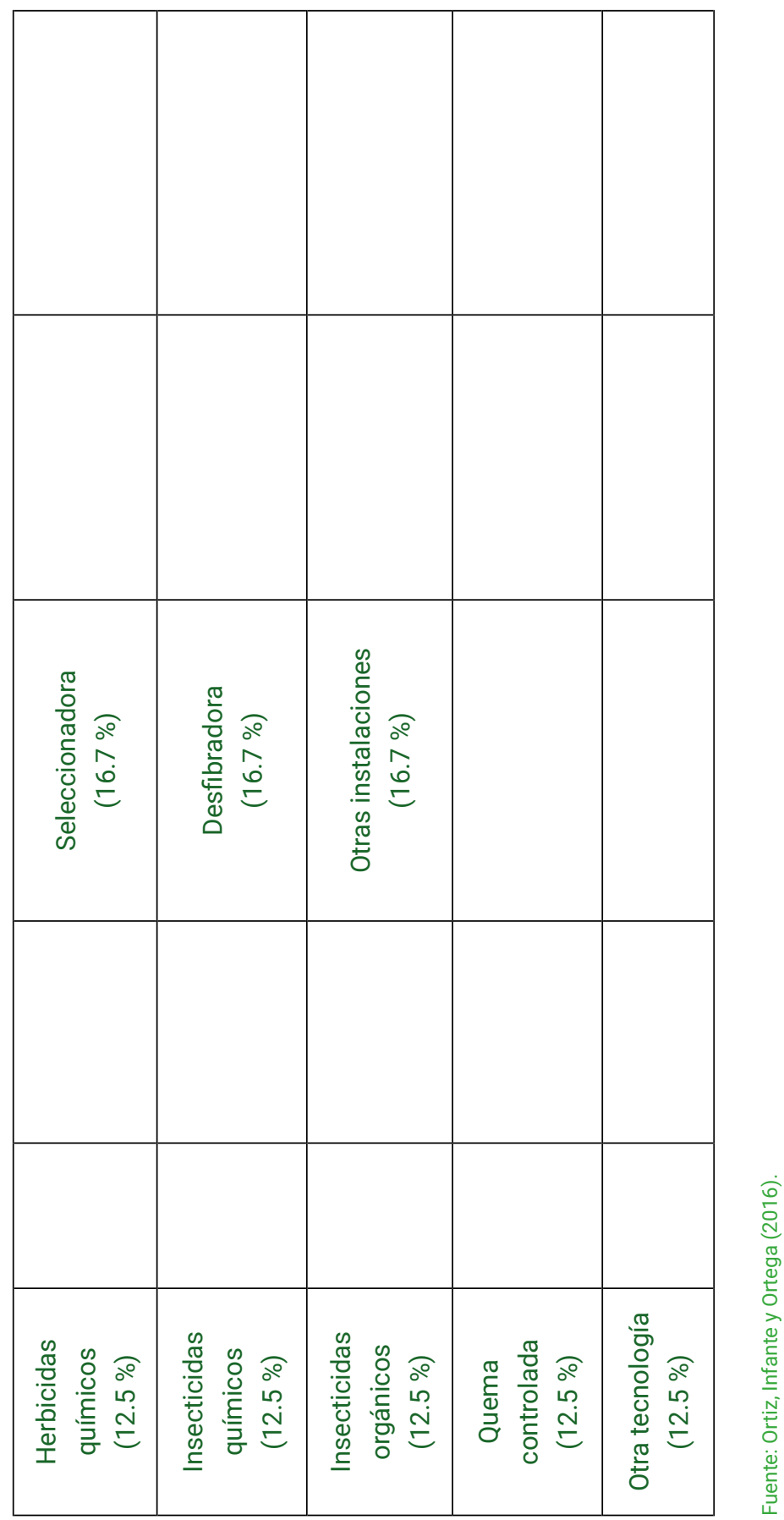


El análisis estadístico sugiere que el riego y el financiamiento son las variables con mayor importancia, aunque todas las variables hacen un aporte al desempeño del ICAM.

Para finalizar, concluyen que el ICAM es una forma alternativa de evaluar la competitividad a escala municipal, permite aprovechar la información generada por las fuentes oficiales y estadísticamente presenta fortaleza en cuanto al análisis de varianza, puesto que existe una complementariedad entre las distintas variables. También afirman que el índice presenta limitaciones que provienen del proceso de estandarización de los indicadores y su integración final, esto último debido a que la fuente de alimentación son promedios estandarizados, perdiéndose el detalle sobre diferencias internas de los productores a escala municipal (Ortiz, Infante y Ortega, 2016).

Otro estudio realizado por Durán, Mora, González y Vargas (2018), los cuales realizan un análisis del concepto de competitividad, el cual determinan como multifactorial, abarcando factores que consideran propios de Costa Rica (país en estudio) y son responsabilidad del gobierno, aspectos externos a la empresa como el mercado e internos, o propios del sistema de producción, dentro del cual define la "competitividad técnica" siendo esta

la capacidad de ofrecer un producto de excelente calidad, a bajo costo y en el volumen requerido por un mercado específico, como resultado de un manejo técnico que busque la eficiencia del trabajo, la innovación, la máxima productividad, la reducción de pérdidas y la reducción de los costos de producción. (p. 141) 
Adicional a esto, realizan un análisis de la herramienta desarrollada para cuantificar la competitividad, la cual denominan Índice de Competitividad Técnica Empresarial (ICTE) y está compuesta por doce constructos que son: (i) protección del cultivo; (ii) factor humano; (iii) gestión del suelo; (iv) nutrición del cultivo; (v) política de calidad; (vi) manejo del cultivo; (vii) control de operaciones; (viii) planificación de operaciones; (ix) relación con el ambiente; (x) políticas de innovación; (xi) infraestructura; y (xii) equipamiento.

Estos a su vez se subdividen en setenta y ocho (78) elementos, lo cual es argumentado por los autores como necesarios "para el alcance pleno de la mayor capacidad técnica de competir de una empresa con un determinado producto fresco en un mercado internacional" (Durán et al., 2018. p. 145).

La aplicación de este índice les permite concluir que "en general, entre las empresas exportadoras de productos agrícolas frescos no tradicionales existe un importante rezago tecnológico, al comparar nuestros niveles de desarrollo técnico empresarial con el ámbito mundial o incluso contra la producción bananera nacional" (Durán et al., 2018. p. 157). Adicional a esto resaltan los bajos niveles de desarrollo técnico, lo que trae consigo una baja competitividad técnica empresarial, principalmente en cuanto a los factores primarios de la producción. Lo anterior lo asocian a la ausencia de servicios estatales de apoyo técnico a la exportación y de políticas crediticias dirigidas al consumo de tecnología, sin promover antes el desarrollo técnico empresarial. La gestión del recurso humano está afectando la calidad del producto final exportado y las operaciones de la empresa, generando altos costos y debilidad en la capacidad de competir 
en el mercado internacional.

Finalmente, concluyen que existe una limitada capacidad técnica para competir de los productos agrícolas frescos no tradicionales costarricenses en el mercado internacional, dado lo anterior y sus altos costos de producción.

Enelpaís sehan realizadovarias investigaciones alrededor de la competitividad de los productos agropecuarios, siendo uno de ellos el realizado por Stellian y Danna-Buitrago (2017), la cual se realiza respecto a los productos de Estados Unidos, esto con el fin de establecer en qué medida el tratado de libre comercio (TLC) entre ambos países representa un riesgo u oportunidad para dichos productos. Para esto calculan las ventajas comparativas reveladas de Colombia dentro del TLC con Estados Unidos según el método del Centro de Estudios Prospectivos y de Información Internacional (CEPII) para 60 grupos de la Clasificación Uniforme para el Comercio Internacional (CUCI) de productos agropecuarios y sus derivados. Dicha metodología les permite concluir que Colombia no es competitivo en un nivel que le permita aprovechar las oportunidades generadas por el TLC, por lo que consideran que es necesario analizar las medidas de política económica para convertir dicho tratado en una real herramienta de crecimiento de la producción agropecuaria y, por ende, de desarrollo del país (Stellian y Danna-Buitrago, 2017).

Por su parte, la Gobernación de Cundinamarca junto con el Centro de Pensamiento en Estrategias Competitivas de la Universidad del Rosario (CEPEC) establecieron el Índice de Competitividad de las Provincias de Cundinamarca (ICPC) para el 2018, 
el cual parte de la metodología desarrollada por el Consejo Privado de Competitividad y el Centro de Pensamiento en Estrategias Competitivas de la Universidad del Rosario (2013) para el Índice Departamental de Competitividad (IDC), cuyo propósito principal es medir aspectos que inciden en el nivel de competitividad de los departamentos en Colombia. A su vez, el IDC sigue la metodología empleada por el Foro Económico Mundial para el cálculo del Índice de Competitividad Global. El ICPC mide "el desempeño competitivo de las quince provincias del departamento de Cundinamarca en función de la siguiente estructura: tres factores y diez pilares, divididos en 25 subpilares y 75 variables" (Gobernación de Cundinamarca y CEPEC, 2018, p. 13). El ICPC posee 12 pilares agrupados en tres categorías como se observa en la figura 9:

\section{Figura 9. Estructura del Índice de Competitividad de las Provincias de Cundinamarca (ICPC), 2018}

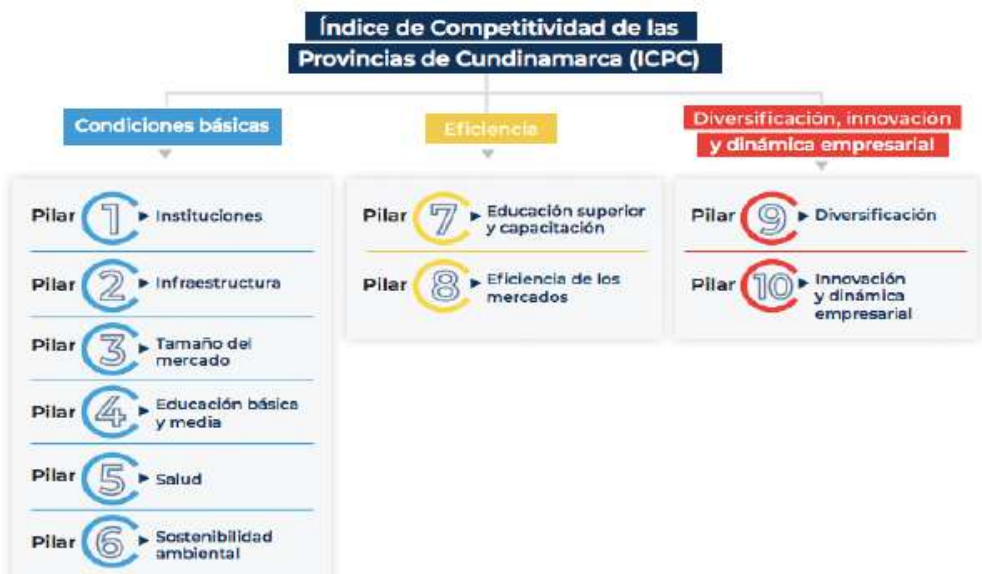

Fuente: construcción CEPEC (2018) con base en Consejo Privado de Competitividad (CPC) y CEPEC Universidad del Rosario (2017) (Gobernación de Cundinamarca y CEPEC, 2018). 
Dentro del informe donde presentan el ICPC miden el nivel de desarrollo de las provincias, las cuales se clasifican en tres etapas de acuerdo con su capacidad de generación de valor agregado (relativizado por la población) y del nivel de pobreza (según el Índice de Pobreza Multidimensional, IPM) de cada uno de los municipios que las componen. Para esto se calculó un índice agregado a partir del valor agregado per cápita y el IPM (ponderado por la población de los municipios que componen cada provincia). Se da una asignación de una ponderación de $50 \%$ al puntaje de valor agregado per cápita y de $50 \%$ al puntaje del IPM. Las provincias con un menor nivel de desarrollo hacen parte de la etapa 1 donde el índice agregado es menor a 0.33 , mientras que las que poseen un mayor desarrollo económico se clasifican en la etapa 3 y su índice agregado es mayor a 0.66 , y las que poseen un índice entre 0.33 y 0.66 se clasificaron en la etapa 2 (figura 10). En este punto es importante resaltar que la provincia Sabana Centro se encuentra en la etapa 3. 
Figura 10. Clasificación de las provincias de Cundinamarca según su etapa de desarrollo económico

\begin{tabular}{l|l|l}
\multicolumn{1}{c|}{ Etapa 1 } & \multicolumn{1}{c|}{ Etapa 2 } & \multicolumn{1}{c}{ Etapa 3 } \\
\hline Tequendama & Guavio & Sabana Centro \\
\hline Cualivá & Soacha & $\begin{array}{l}\text { Sabana } \\
\text { Occidente }\end{array}$ \\
\hline Magdalena Centro & Ubaté & \\
\hline Rionegro & Alto Magdalena & \\
\hline Medina & Sumapaz & \\
\hline Bajo Magdalena & Almeidas & \\
\hline & Oriente & \\
\hline
\end{tabular}

Esta clasificación deja ver el avance económico y social de la provincia, además, presenta el mejor puntaje en el índice (8.16 sobre 10), convirtiéndose en el territorio más competitivo del departamento de Cundinamarca. 
Figura 11. Resultados generales ICPC 2018

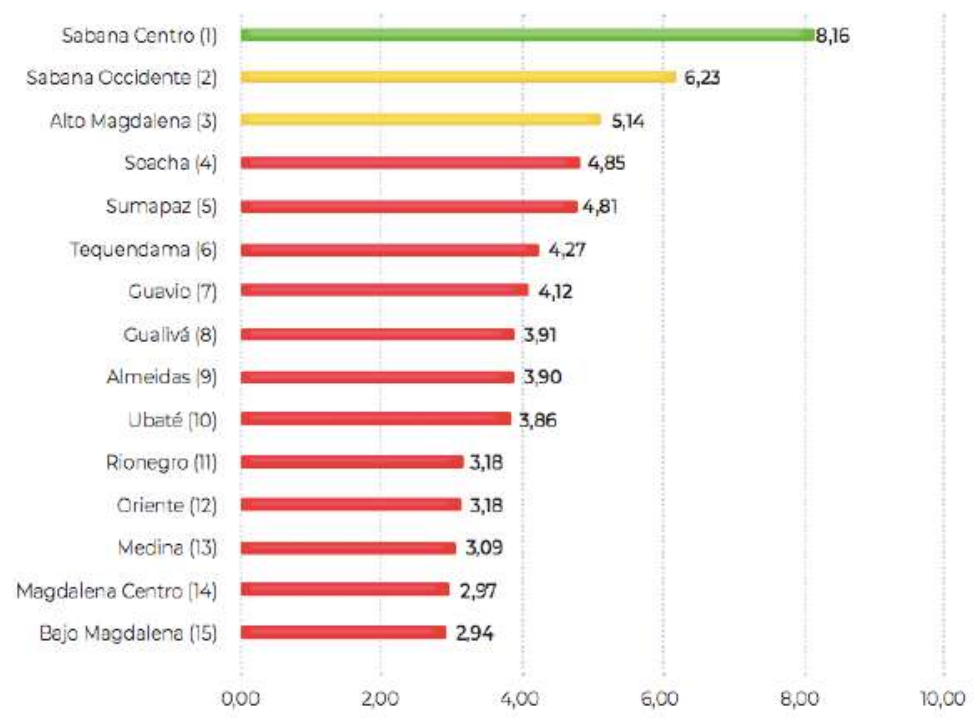

* Los colores del gráfico indican: verde = desempeño alto, amarillo

= desempeño medio y rojo = desempeño bajo (Gobernación de Cundinamarca y CEPEC, 2018).

Fuente: construcción CEPEC - Universidad del Rosario (2018) con base en CPC y CEPEC Universidad del Rosario (2017).

Este resultado nace de presentar el mejor desempeño en seis de los diez totales. Para establecer la posición dentro del ICPC, se da una puntuación de cero (0) a diez (10), siendo diez la puntuación máxima dentro de cada pilar de acuerdo con su desempeño. Los pilares donde la provincia de Sabana Centro ocupó el primer lugar son: infraestructura (8.22) tamaño del mercado (10.00), educación básica y 
media (7.50), salud (7.42), educación superior y capacitación (8.63), lo cual se atribuye a la calidad en educación superior por su desempeño en las pruebas Saber Pro, la calidad de sus docentes y de bilingüismo e innovación. También ocupó el primer lugar en el pilar de dinámica empresarial con un puntaje de 9.79. Por su parte, ocupó el segundo lugar en los pilares de instituciones con un puntaje de 7.08 , lo cual se asocia a los buenos resultados de gestión fiscal y eficacia entre otros aspectos; pilar de eficiencia de los mercados (7.19) y diversificación con 9.11 puntos. En el pilar de sostenibilidad ambiental ocupó el puesto doce (12) con 5.35 puntos (Gobernación de Cundinamarca y CEPEC, 2018, pp. 26-35). A continuación, se presenta el resumen del ICPC:

Sabana Centro

Cabecera:

Zipaquirá

506.654

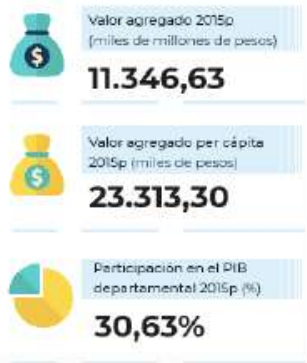

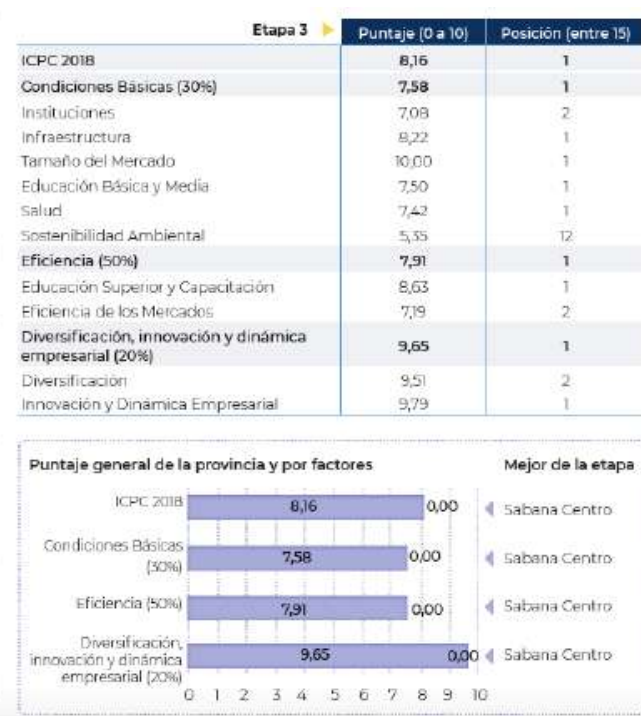




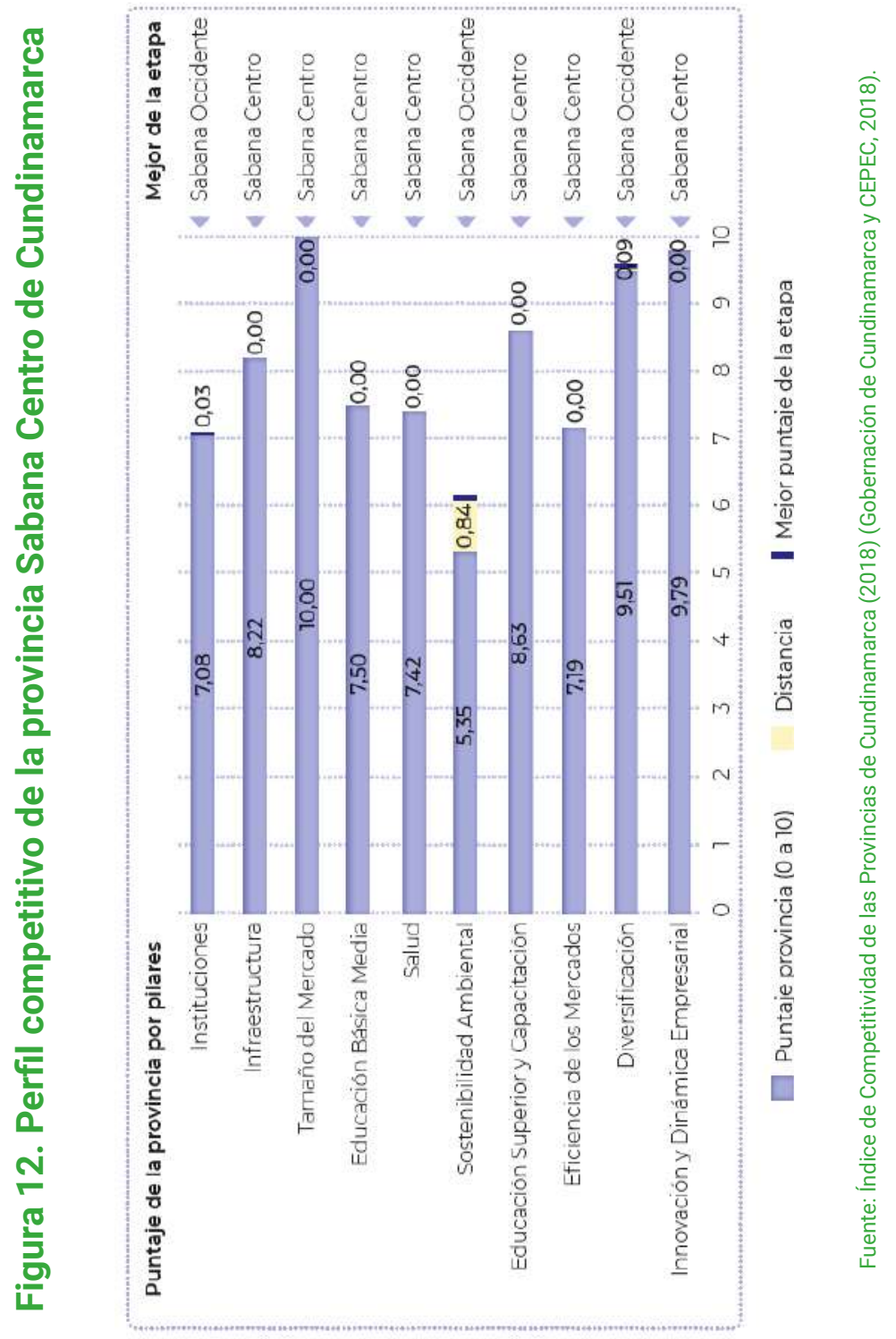


Adicional a esto, la Gobernación de Cundinamarca junto con el Programa de las Naciones Unidas para el Desarrollo (PNUD) realiza la primera línea base de los Objetivos de Desarrollo Sostenible a nivel provincial de Cundinamarca, por medio de lo cual buscan fortalecer las capacidades de las instituciones locales con el fin de que puedan identificar, monitorear, hacer seguimiento y evaluar los indicadores ODS; que permita a las diferentes entidades territoriales "establecer acciones concretas para la reducción y cierre de brechas, así como alcanzar las metas a mediano plazo de los ejercicios de planeación estratégica como son los planes de desarrollo, las políticas públicas, proyectos estratégicos regionales, entre otros" (Gobernación de Cundinamarca y PNUD, 2018, p. 13).

Además de esto, la provincia aglomera un alto porcentaje dentro del departamento de personas en el sector urbano con un $13 \%$ y en el rural con $5.83 \%$ (Gobernación de Cundinamarca y PNUD, 2018, p.26). Finalmente, deja ver un avance en los indicadores de pobreza junto con la provincia de Sabana Occidente y los municipios La Calera (Guavio) y Cota (Sabana Centro) (Gobernación de Cundinamarca y PNUD, 2018, p. 78).

De acuerdo con el Ministerio de Agricultura y Desarrollo Rural, se identificó que, entre los años 2007 y 2013 , se redujo en $36 \%$ la cantidad de hectáreas cultivadas en la Sabana Centro, tanto de cultivos transitorios como permanentes, lo que evidencia la transformación de las actividades económicas y los cambios en el uso de los factores productivos como el suelo (Universidad de la Sabana, 2014-2015). 


\section{Conclusión}

Es importante resaltar que la nueva metodología del Índice de Competitividad Global 4.0 parte de la idea original del profesor Klaus Schwab y la orientación del profesor Xavier Sala-i-Martin de la Universidad de Columbia; el GCl 4.0 se ha venido desarrollando desde 2015 dada la necesidad de actualizarlo por "la combinación de los efectos continuos de la Gran Recesión de 2008 y el ritmo acelerado de la Cuarta Revolución Industrial (4IR)" (World Economic Forum, 2016). Según el Foro Económico Mundial, la recesión dejó como enseñanza que las crisis financieras pueden tener efectos duraderos en la productividad reduciendo la trayectoria de crecimiento a largo plazo.

Los autores afirman que desarrollar un índice de competitividad regional para un país constituye un gran esfuerzo que permite construir una herramienta que apoye su desarrollo. Bejarano (1995) afirma que se deben agrupar de manera operacional las variables que permiten estimular los determinantes de la competitividad en tres grandes campos: (i) inversión en externalidades; (ii) criterios de reconversión productiva; y (iii) el carácter de la intervención pública.

Dentro de este contexto, la provincia de Sabana Centro para 2017 tiene una población de $63 \%$ en edad de trabajar y un $37 \%$ es potencialmente dependiente, es decir, son niños y adultos mayores, lo cual deja ver que se ha dado un avance en la reducción de la pobreza por el aumento de la fuerza laboral. Aun así, se requieren inversiones estratégicas en capital humano acompañadas de políticas que permitan avanzar más en lo económico, social y en el fortalecimiento institucional disminuyendo el desempleo (Gobernación de 
Cundinamarca y PNUD, 2018).

En definitiva, son pocos los estudios realizados alrededor de la creación de un índice de competitividad en el sector agrícola de la Sabana Centro de Cundinamarca. Si bien existe el ICPC, este es para toda la región sin discriminar los sectores económicos, y cuando se aborda el sector agrícola en la región, no se encontraron a la fecha trabajos específicos enfocados en la competitividad de este. 


\section{Referencias}

Bejarano, J. (1995). Elementos para un enfoque de la competitividad en el sector agropecuario. Colección de Documentos IICA Serie Competitividad No. 3.

Chacón, F. (2015). Índice de Competitividad Global. Universidad de Costa Rica.

Departamento Administrativo Nacional de Estadística [DANE]. (2019). Comunicado de prensa. Pobreza monetaria 2018. https://www.dane.gov.co/ files/investigaciones/condiciones_vida/ pobreza/2018/cp_pobreza_monetaria_18.pdf Departamento Nacional de Planeación [DNP]. (2018). Documento CONPES Política de Crecimiento Verde. https://colaboracion.dnp. gov.co/CDT/Prensa/Presentaci\%C3\%B3n\%20 Pol\%C3\%ADtica\%20de\%20Crecimiento\%20 Verde.pdf

(2006). Documento CONPES 3439 Institucionalidad y principios rectores de política para la competitividad y productividad. http://www.colombiacompetitiva.gov.co/snci/ Documents/Conpes-3439-2006.pdf

Durán, A., Mora, D., González, M., y Vargas, G. (2018). Nivel de competitividad de las empresas exportadoras de productos agrícolas no tradicionales de Costa Rica. Agronomía Costarricense, 42(2), 141-158. 
Feldman, M., y Audretsch, D. (1999). Innovation in cities: Science-based diversity, specialization and localized competition. European Economic Review, 43(2), 409-429. https://doi. org/10.1016/S0014-2921(98)00047-6

Fondo para el Financiamiento del Sector Agropecuario [Finagro]. (2019). El momento del agro. https:// www.finagro.com.co/noticias/el-momentodel-agro

Gobernación de Cundinamarca y Centro de Pensamiento en Estrategias Competitivas [CEPEC]. (2018). Índice de competitividad para las provincias de Cundinamarca, ICPC - 2018. Gobernación de Cundinamarca y CEPEC.

Gobernación de Cundinamarca y Programa de las Naciones Unidas para el Desarrollo [PNUD]. (2018). Línea base Objetivos de Desarrollo Sostenible, departamento de Cundinamarca - Colombia. Gobernación de Cundinamarca y Provincias Gobernación de Cundinamarca.

México. Consejo Nacional de Evaluación de la Política de Desarrollo Social [CONEVAL] ¿Qué son los indicadores de los programas de desarrollo social? Boletín de monitoreo. https:// www.coneval.org.mx/Informes/boletin coneval/boletin_monitoreo_02_2013/nota5. html\#: :text=CONEVAL,cual\%20puede $\% 20$ ser\%20informaci\%C3\%B3n\%20relevante. 
Müller, G. (1995). El caleidoscopio de la competitividad. Revista de la CEPAL, 56, 137-140.

Napoleoni, C. (1981). Fisiocracia, Smirth, Ricardo, Marx. Oikos Tau S.A. Ediciones.

Nelson, B. (1999). 1001 ways to take initiative at work. Workman Publishing Company-

Objetivos de Desarrollo Sostenible [ODS]. (2019).

Hambre Cero en Colombia. https://www.ods. gov.co/es/objetivos/hambre-cero

Organización de las Naciones Unidas para la Agricultura y la Alimentación [FAO]. (2019). FAO en Colombia. Programas en Colombia. http://www.fao.org/colombia/programas-yproyectos/es/

Ortiz, C., Infante, Z., y Ortega, P. (2016). El ICAM como propuestademedicióndecompetitividadagrícola municipal en Michoacán. Red Internacional de Investigadores en Competitividad.

Padilla, R. y Juárez, M. (2006). Efectos de la capacitación en la competitividad de la industria manufacturera. CEPAL.

Porter, M. (1991). La ventaja competitiva de las naciones. Vergara.

(2007). La ventaja competitiva de las naciones. Harvard business review, 85(11), 6995.

Stellian, R., y Danna-Buitrago, J. (2017). Competitividad de los productos agropecuarios colombianos 
en el marco del tratado de libre comercio con los Estados Unidos: análisis de las ventajas comparativas. Revista de la CEPAL, (122), 139163.

Smith, A. (1776). Investigación de la naturaleza y causas de la riqueza de las naciones. Alianza.

Ten Kate, A. (1995). La competitividad y factores que lo determinan.

Universidad Nacional de Colombia. (s.f.). Manual de indicadores de proceso del sistema de mejor gestión - UN SIMEGE. http://www. cienciasagrarias.bogota.unal.edu.co/sites/ default/files/IMGS/Guia_indicadores.pdf

Villanueva, D. (2018). Estudios sobre la bioeconomía como fuente de nuevas industrias basadas en el capital natural de Colombia. DNP; Universidad Eafit.

World Economic Forum. (2016). ¿Qué es la competitividad? https://es.weforum.org/ agenda/2016/10/que-es-la-competitividad/

(2014). The Global Competitiveness Report: 2014-2015. World Economic Forum (WEF). http://www.weforum.org/ reports?filter[type]=Annual\%20Reports

Zegarra, L., y Valdivia, C. (2010). Un índice regional de competitividad para un país. Revista de la CEPAL, (102), 69-86. 


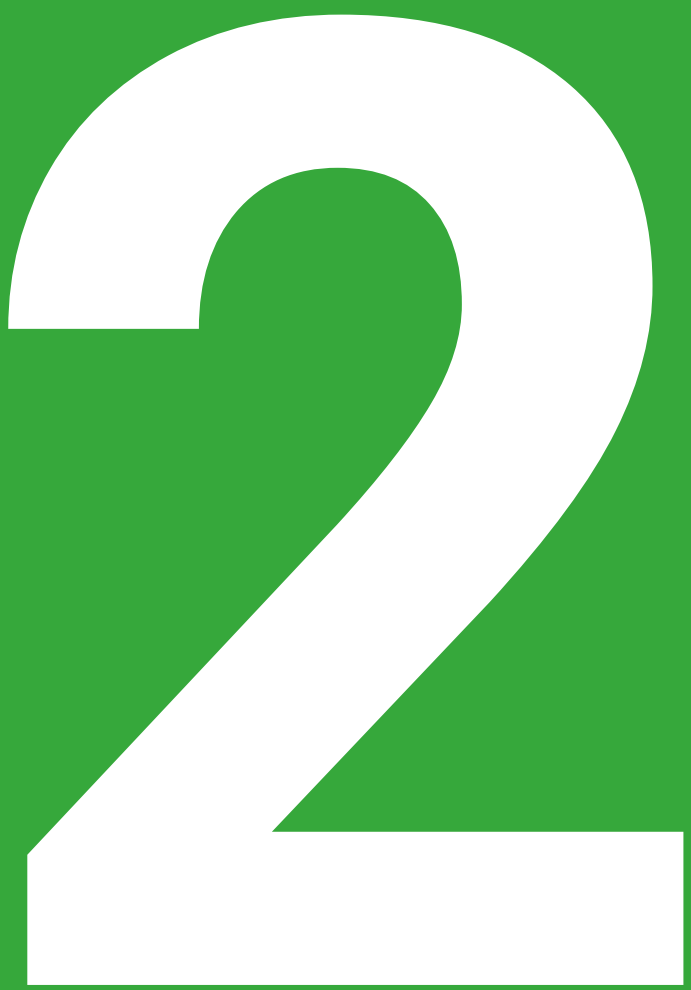

Retos de la competitividad agrícola de la provincia Sabana Centro,

Cundinamarca, Colombia Caso: papa, maíz y lechuga 


\title{
Retos de la competitividad agrícola de la provincia Sabana Centro, Cundinamarca, Colombia Caso: papa, maíz y lechuga
}

\author{
Jairo Alonso Ávila Moreno ${ }^{10}$ \\ Olga Marina García Norato ${ }^{11}$ \\ Diana Patricia Gutiérrez Mejía ${ }^{12}$ \\ Ignacio Gómez Roldán ${ }^{13}$
}

\section{Introducción}

\section{El presente artículo muestra los resultados de la investigación denominada "Seguridad alimentaria y competitividad agrícola de la provincia de Sabana Centro, Cundinamarca, Colombia" y desarrollada en}

\footnotetext{
10 Administrador de empresas de la Universidad Externado de Colombia, especialista en Gerencia Informática, especialista en Finanzas y magíster en Desarrollo Rural de la Universidad Pedagógica y Tecnológica de Colombia -UPTC. Docente investigador de la Universidad de Cundinamarca. E-mail: jalonsoavila@ucundinamarca.edu. co.

11 Economista de la Universidad Santo Tomás de Bucaramanga, especialista en Finanzas, magíster en Desarrollo Rural y doctora en Historia de la Universidad Pedagógica y Tecnológica de Colombia -UPTC, sede Tunja. Docente investigadora de la Universidad de Cundinamarca. E-mail: omgarcia@ucundinamarca.edu.co.

12 Economista de la Universidad Nacional de Colombia, magíster en Ciencias Económicas de la Universidad Santo Tomás y estudiante de doctorado en Desarrollo Local y Cooperación Internacional de la Universidad Politécnica de Valencia, España. E-mail: diagu@upv.edu.es.

13 Doctor en Análisis Económico de la Universidad Nacional de Educación a Distancia (UNED), magíster en Economía de la Universidad Nacional de Colombia, especialista en Evaluación Social de Proyectos de la Universidad de los Andes y economista de la Pontificia Universidad Javeriana. Docente de la Dirección de Investigación de la Universidad de Cundinamarca y miembro de los Grupos de Investigación ADCUN de la UDEC. E-mail: ignacio.gomez19@gmail.com.
} 
la provincia de Sabana Centro del departamento de Cundinamarca, Colombia. Se propone una forma de medir la competitividad del sector agrícola en esta región, para lo cual se utilizó metodología mixta, partiendo de la productividad de la papa, el maíz y las hortalizas en el sector a nivel regional. Se utiliza como herramienta un modelo econométrico que toma como insumo datos obtenidos del Departamento Administrativo Nacional de Estadística (DANE) y las Evaluaciones Agropecuarias Municipales (EVA). Se realizó trabajo de campo que permitió efectuar un análisis descriptivo y es la base para la propuesta específica para la medición de la competitividad en el sector. En el primer apartado se presenta la metodología específica utilizada, coherentemente con el capítulo 1 que trata la "Competitividad del sector agrícola de Sabana Centro, Cundinamarca, un acercamiento desde de la teoría", donde se establece el referente teórico -insumo principal- para el desarrollo de esta investigación. En el segundo apartado de este capítulo se presentan los principales resultados partiendo de una contextualización de la región y sector objeto de estudio, luego, se presenta la contribución de la producción del maíz, la papa y las hortalizas de Sabana Centro de Cundinamarca dentro del PIB agrícola nacional. Para finalizar, se analizan los resultados obtenidos mediante los datos arrojados por las encuestas junto con la propuesta de medición de la competitividad, dando paso a la discusión y las conclusiones. 


\subsection{Metodología}

La investigación se desarrolla a partir de un acercamiento metodológico cualitativo y cuantitativo, con carácter inductivo a partir del contexto económico y social, que permitieron identificar las condiciones de competitividad agrícola en la región en estudio. En primer lugar, se realizó la revisión documental en bases indexadas con el fin de establecer el contexto. A partir de los datos tomados de bases oficiales como el DANE y las EVA, se estableció la significancia de los tres cultivos objeto de estudio por medio de una regresión lineal múltiple bajo Mínimos Cuadrados Ordinarios (MCO). Luego, se realizó el trabajo de campo, en el cual se aplicaron 118 encuestas a los cultivadores de papa, maíz y lechuga de los municipios de Tenjo, Tabio, Cajicá, Zipaquirá, Cogua y Nemocón, con el fin de identificar los hábitos productivos, formación productiva de los productores, acceso a tecnología, cultura emprendedora, innovación, visión empresarial y apoyo gubernamental, para así analizar de forma descriptiva las respuestas obtenidas para proponer un modelo de medición de competitividad.

\subsection{Contexto económico y social provincia Sabana Centro, Cundinamarca}

La provincia de Sabana Centro está ubicada al norte del departamento de Cundinamarca, Colombia, y la conforman once municipios: Cajicá, Chía, Cota, Gachancipá, Sopó, Tabio, Tenjo, Tocancipá, Zipaquirá (capital de provincia), Cogua y Nemocón. Además, limita al norte con la provincia de Ubaté, al sur con Bogotá, al oriente con las provincias de Almeidas y Gua- 
vio, y al occidente con las provincias de Rionegro y Sabana Occidente (figura 13). Según la caracterización económica y empresarial de la Cámara de Comercio de Bogotá (CCB), la región tiene 1062 km2, lo que representa el $4.5 \%$ del área total del departamento de Cundinamarca (CCB, 2019).

Figura 13. Provincias de Cundinamarca, división político-administrativa 2017

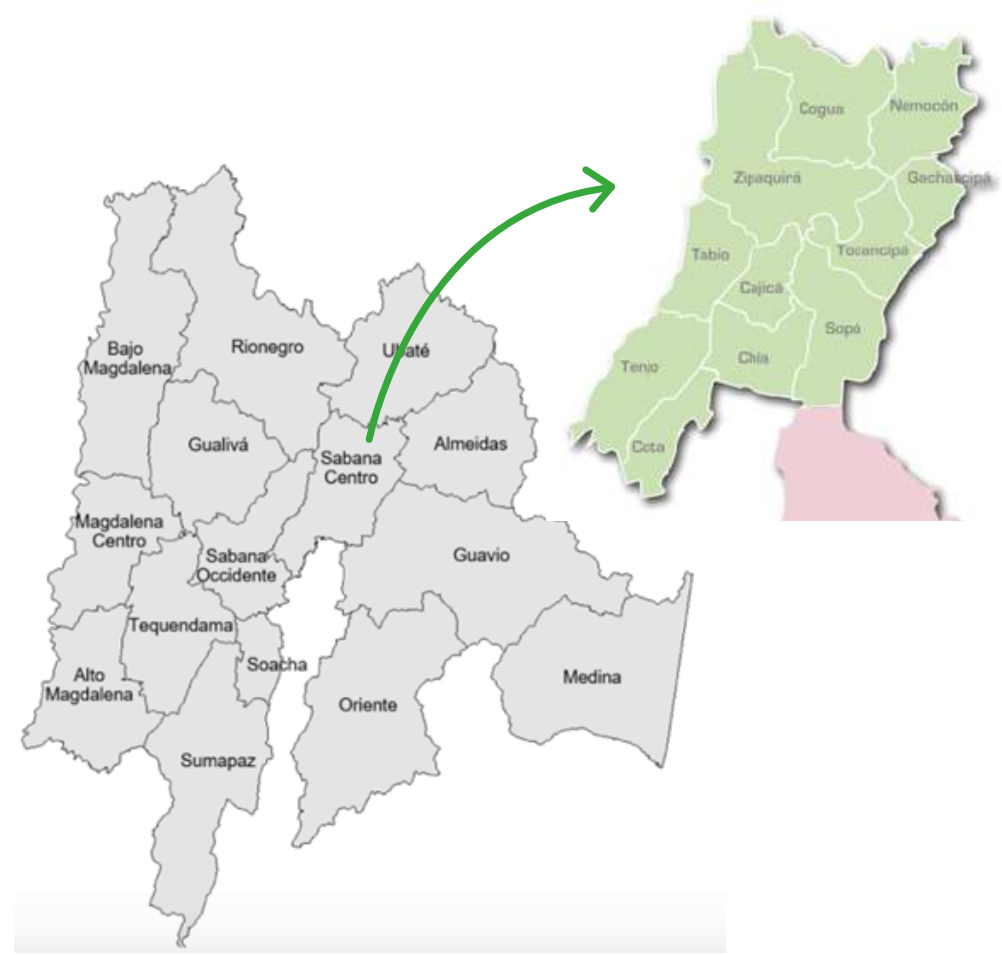

Fuente: PNUD, elaboración proyecto Transformando Colombia: Objetivos de Desarrollo Sostenible (CCB, 2019).

Dentro de este contexto, la provincia de Sabana Centro para 2017 posee el 63 \% de su población 
en edad de trabajar y un $37 \%$ es dependiente, es decir, son niños y adultos mayores. No obstante, las reducciones en la pobreza requieren inversiones estratégicas en capital humano acompañadas de políticas que permitan avanzar en más logros económicos, sociales y en el fortalecimiento institucional que contribuyan a disminuir el desempleo (Gobernación de Cundinamarca y PNUD, 2018). La provincia aglomera un alto porcentaje de personas dentro del departamento, la cual se distribuye de la siguiente forma: en el sector urbano con un $13 \%$ y en el rural con 5.83 \% (Gobernación de Cundinamarca y PNUD, 2018). En general, se deja ver un avance para superar los indicadores de pobreza junto con la provincia de Sabana Occidente y los municipios La Calera (Guavio) y Cota (Sabana Centro) (Gobernación de Cundinamarca y PNUD, 2018).

De acuerdo con el Ministerio de Agricultura y Desarrollo Rural, se identificó que, entre los años 2007 y 2013 , se redujo en $36 \%$ la cantidad de hectáreas cultivadas en la Sabana Centro, tanto de cultivos transitorios como permanentes, lo cual evidencia la transformación de las actividades económicas y los cambios en el uso de los factores productivos como el suelo (Universidad de la Sabana, 2016).

El nivel de desarrollo de las provincias se encuentra en la etapa tres, es decir, que hace parte del grupo con mayor desarrollo económico y su índice agregado es mayor a 0.66. Se presenta alto puntaje en el índice de competitividad del departamento con un valor de 8.16 sobre 10 , siendo el territorio más competitivo de Cundinamarca (Gobernación de Cundinamarca y Centro de Pensamiento en Estrategias Competitivas (CEPEC), 2018, p. 17). 
Tabla 4. Puntajes pilares ICD

\begin{tabular}{|l|r|}
\hline \multicolumn{1}{|c|}{ Pilar } & Puntaje \\
\hline Infraestructura & 8.22 \\
\hline Tamaño del mercado & 10.00 \\
\hline Educación básica y media & 7.50 \\
\hline Salud & 7.42 \\
\hline Educación superior y capacitación & 8.63 \\
\hline Dinámica empresarial & 9.79 \\
\hline Instituciones & 7.08 \\
\hline Eficiencia de los mercados & 7.19 \\
\hline Diversificación & 9.11 \\
\hline Sostenibilidad ambiental & 5.35 \\
\hline
\end{tabular}

Fuente: Gobernación de Cundinamarca y CEPEC (2018).

En cuanto al crecimiento del PIB, se establece una tendencia negativa de la tasa de crecimiento para el periodo 2007-2018, aunque ha sido positiva, es decir, que aumentado la producción del departamento. 
Figura 14. Tasas de crecimiento del PIB de Cundinamarca

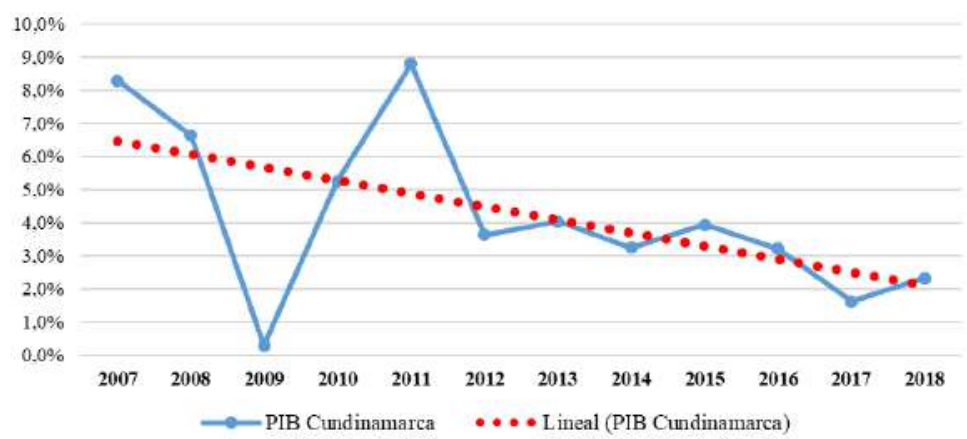

Fuente: elaboración propia a partir del DANE (2019).

Se observa que, aunque la tasa de crecimiento del PIB departamental ha venido disminuyendo, este sigue creciendo y también los cultivos en estudio, como se presentó en la figura 14, lo cual permite establecer que estos contribuyen positivamente al crecimiento del PIB. 
Figura 15. PIB de Cundinamarca en miles de millones de pesos*

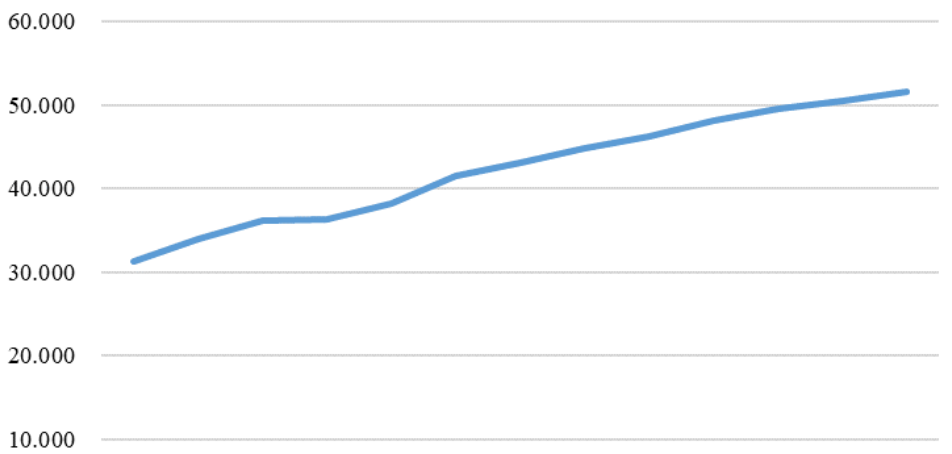

* A precios constantes de 2015 por encadenamiento.

Fuente: elaboración propia a partir del DANE (2019).

En cuanto a la tasa de crecimiento en la provincia de Sabana Centro de Cundinamarca para los cultivos objeto de estudio, se presenta en los últimos años una tendencia a la baja. Si bien la tasa de crecimiento del maíz es la que más ha caído, lo cual no quiere decir que la producción en toneladas haya caído también, todas en general poseen un comportamiento similar, lo que permite identificar una afectación sobre el PIB departamental, cuya tasa también ha disminuido para el periodo 2006-2018 (figura 14). Aun así, la producción establecida en toneladas de los cultivos ha crecido de forma discreta, como lo demuestran las toneladas producidas en la figura 16. 
Figura 16. Producción de hortalizas, maíz y papa en la provincia Sabana Centro*

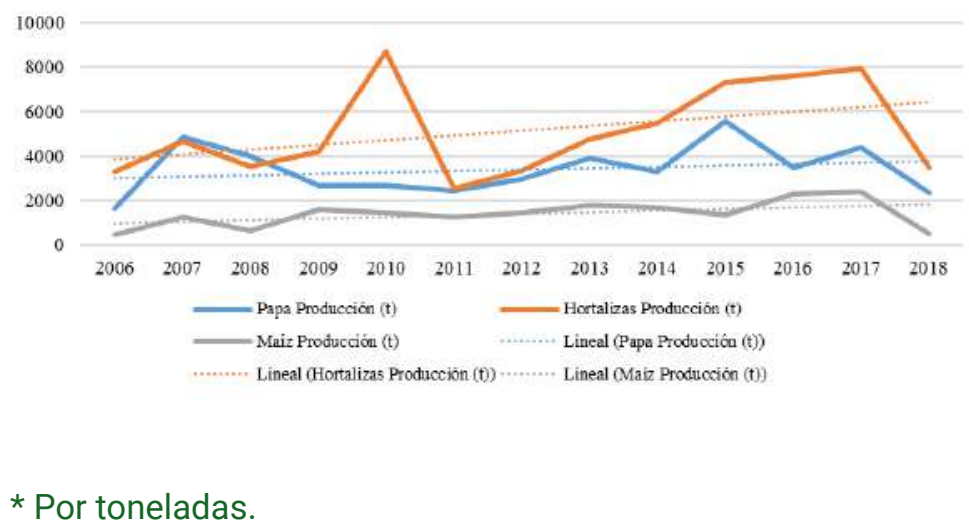

Fuente: elaboración propia a partir del DANE (2019).

Esto se puede validar dada la tasa de rendimiento (tabla 5), la cual se mide por el total producido $(t)$ por el número de hectáreas cosechadas (ha):

$$
\text { Rendimiento }=\frac{t}{h a} \quad \text { [1] }
$$

Se puede observar, para los tres tipos de cultivos, que esta es positiva, siendo la de hortalizas la mayor, lo cual se puede considerar como lógico dado el tamaño de los productos asociados a este grupo; por su parte, le sigue la papa y luego el maíz. 
Tabla 5. Rendimiento cultivos de hortalizas, papa y maíz en Sabana Centro

\begin{tabular}{|c|c|c|c|}
\hline Año & Papa & Hortalizas & Maíz \\
\hline 2006 & 2.26 & 13.42 & 1.63 \\
\hline 2007 & 3.82 & 10.45 & 1.67 \\
\hline 2008 & 2.19 & 8.82 & 0.60 \\
\hline 2009 & 1.78 & 4.65 & 1.58 \\
\hline 2010 & 1.78 & 5.34 & 1.22 \\
\hline 2011 & 0.96 & 3.43 & 1.40 \\
\hline 2012 & 1.16 & 4.38 & 1.27 \\
\hline 2013 & 1.37 & 6.27 & 1.28 \\
\hline 2014 & 2.04 & 6.53 & 1.35 \\
\hline 2015 & 2.06 & 5.12 & 1.23 \\
\hline 2016 & 2.23 & 5.73 & 2.44 \\
\hline 2017 & 2.78 & 5.39 & 2.76 \\
\hline 2018 & 2.87 & 4.46 & 0.91 \\
\hline Promedio & 2.10 & 6.46 & 1.49 \\
\hline
\end{tabular}

Con el fin de complementar la información se presenta el comportamiento del número de áreas sembradas y cosechadas, las cuales presentan una tendencia de aumento, aunque en 2018 presentó una gran caída, esta se puede asociar a los fenómenos climáticos presentados. 
Figura 17. Áreas sembradas y cosechadas*

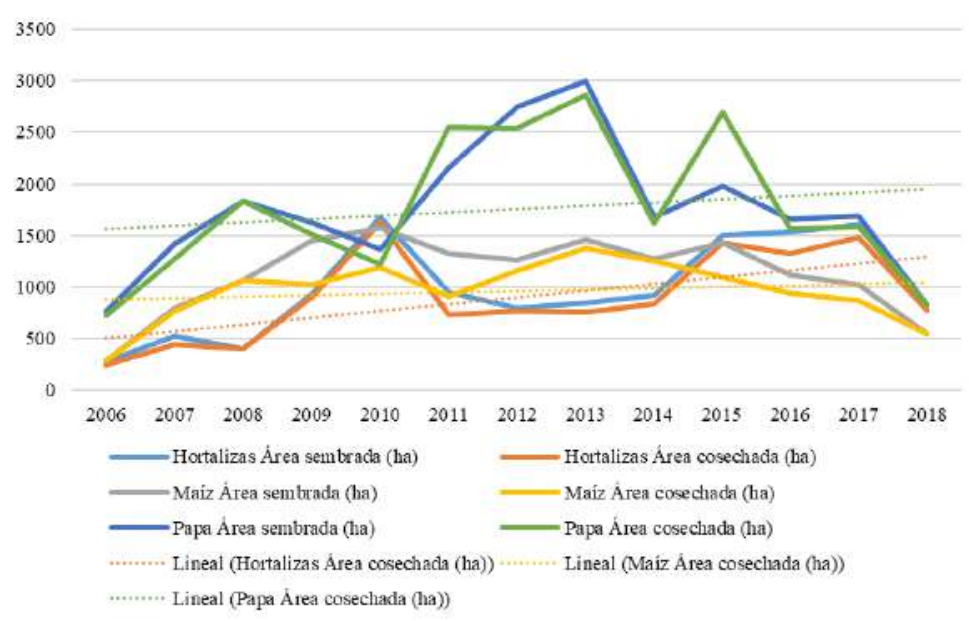

* En hectáreas.

Fuente: elaboración propia a partir del DANE y Evaluaciones Agropecuarias Municipales (EVA).

Dado lo anterior, se propone establecer si la producción de las hortalizas, el maíz y la papa tienen un efecto sobre el PIB sectorial a nivel nacional, por lo que se propone realizar una regresión que permita establecer si la producción de estos en la Sabana Centro de Cundinamarca es significativa, por lo que se plantea la siguiente ecuación:

$$
P I B_{S_{t}}=\beta_{1} p h_{t}+\beta_{2} p m_{t}+\beta_{3} p p_{t}+\varepsilon_{t}
$$

Donde:

$P I B_{S}$ : es el valor del PIB sectorial para el periodo $t$, para este caso se tomó el rubro de: cultivos 
agrícolas transitorios y permanentes; propagación de plantas; actividades de apoyo a la agricultura y la ganadería, y posteriores a la cosecha, explotación mixta y caza ordinaria, y mediante trampas y actividades de servicios conexas.

$p h_{t}:$ es la producción de hortalizas en el periodo $t$ $p m_{t}$ : es la producción de maíz en el periodo $t$, $p p_{t}$ : es la producción de papa en el periodo $t_{\mathrm{y}}$ $\varepsilon_{t}:$ es el error.

El periodo de estudio establecido es de 2007 a 2017, a partir de lo anterior se obtiene:

\section{Tabla 6. Salida EViews regresión}

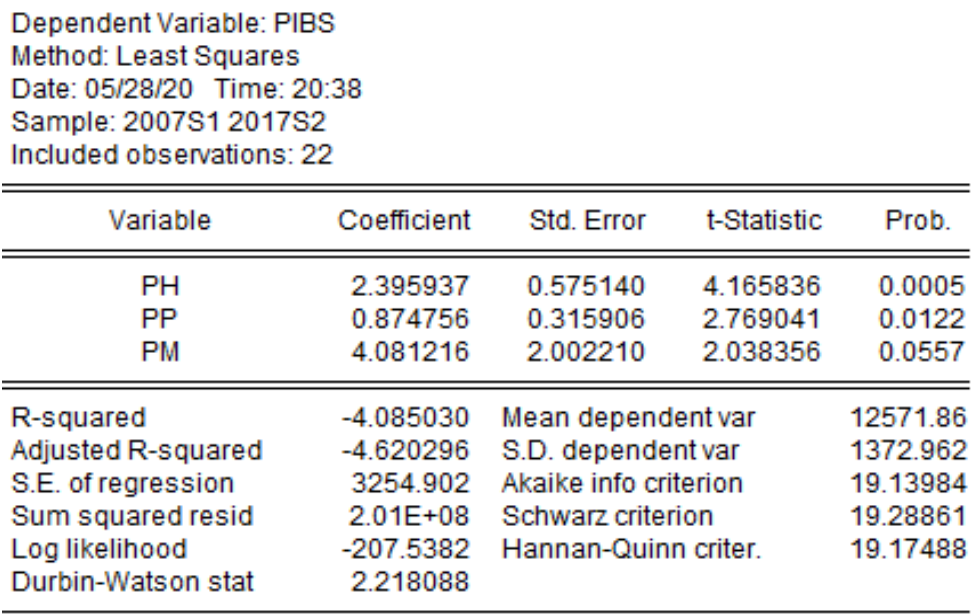


Se puede concluir que existe evidencia estadística para rechazar $H_{0}$ :

$H_{0}: \hat{\beta}=0$

$H_{a}: \hat{\beta} \neq 0$

Dado que a una significancia del 90, 95 y del $99 \%$, con una probabilidad para $p h_{t}$ del 0.005 , $p m_{t}$ del 0.0122 , pero del 90 y $95 \%$ para $p p_{t}$ con una probabilidad del 0.0557. Se puede afirmar entonces que las betas estimados son estadísticamente significativos. Poseen un signo positivo, lo que deja ver una relación positiva, es decir que, en la medida que aumente la producción de hortalizas, maíz o papa, el PIB sectorial aumentará así:

Tabla 7. Efecto de aumento en la producción en Sabana Centro, Cundinamarca, en el PIB sectorial

\begin{tabular}{|c|c|}
\hline $\begin{array}{c}\text { Aumento de una } \\
\text { tonelada de producción }\end{array}$ & $\begin{array}{c}\text { Aumento en el PIB sectorial } \\
\text { nacional } \\
\text { (millones de pesos) }\end{array}$ \\
\hline Hortalizas & 2.39 \\
\hline Papa & 0.87 \\
\hline Maíz & 4.08 \\
\hline
\end{tabular}


En definitiva, se puede concluir que la producción de los productos objeto de estudio tienen un efecto positivo sobre el sector a nivel nacional, lo valida la importancia de mejorar la competitividad de este, además de los impactos económicos y sociales que trae consigo.

Por su parte, el trabajo de campo permitió establecer que la lechuga es el producto que mayor rentabilidad presenta por $\mathrm{Ha}$, que oscila entre 20 y 30 millones por $\mathrm{Ha}$ (anexos 5-6), que en términos porcentuales oscila entre $100 \%$ y $150 \%$, seguido por el maíz que genera una utilidad entre $\$ 2.5$ y $\$ 3.5$ millones de utilidad por hectárea (anexos 3-4), que en términos porcentuales oscila entre $83 \%$ y $116 \%$, y, por último, la papa, que genera una utilidad entre menos \$2 y $\$ 2$ millones por hectárea (anexos 1-2), que en términos porcentuales la rentabilidad oscila entre $-20 \%$ y $20 \%$, según se puede visualizar en el cuadro 5. Por consiguiente, la lechuga es el producto con mayor nivel de competitividad, seguido por el maíz y, por último, la papa presenta el menor nivel de competitividad de los tres productos. Sin embargo, es la papa la que presenta mayores niveles de ocupación laboral por hectárea de los tres productos, según se visualiza en los datos arrojados en las encuestas.

Los encuestados manifestaron en su totalidad que en el último año no han realizado ninguna innovación, por lo que es de vital importancia fomentar la realización de estas por medio de estrategias como campañas educativas y acceso a recursos enfocados a esto. 
Tabla 8. Costo, ingresos, utilidad y rentabilidad por hectárea

\begin{tabular}{|c|c|c|c|c|}
\hline Cultivo & Costo/Ha & $\begin{array}{c}\text { Ingresos/ } \\
\mathrm{Ha}\end{array}$ & $\begin{array}{l}\text { Utilidad/ } \\
\mathrm{Ha}\end{array}$ & $\begin{array}{c}\text { Rentabilidad/ } \\
\mathrm{Ha}\end{array}$ \\
\hline Рapa & $\begin{array}{c}\text { Entre } \\
8 \text { y } 12 \\
\text { millones }\end{array}$ & $\begin{array}{c}\text { Entre } \\
8 \text { y } 12 \\
\text { millones }\end{array}$ & $\begin{array}{l}\text { Entre } \\
(-) 2 \text { y } 2 \\
\text { millones }\end{array}$ & $\begin{array}{c}\text { Entre }(-) 20 \% \\
\text { y } 20 \%\end{array}$ \\
\hline Maíz & $\begin{array}{c}\text { Entre } \\
2.5 \text { y } 3.5 \\
\text { millones }\end{array}$ & $\begin{array}{l}\text { Entre } 5 \text { y } 7 \\
\text { millones }\end{array}$ & $\begin{array}{c}\text { Entre } \\
2.5 \text { y } 3.5 \\
\text { millones }\end{array}$ & $\begin{array}{l}\text { Entre } 83 \% \text { y } \\
\quad 116 \%\end{array}$ \\
\hline Lechuga & $\begin{array}{c}\text { Entre } \\
17 \text { y } 23 \\
\text { millones }\end{array}$ & $\begin{array}{c}\text { Entre } \\
50 \text { y } 80 \\
\text { millones }\end{array}$ & $\begin{array}{c}\text { Entre } \\
20 \text { y } 30 \\
\text { millones }\end{array}$ & $\begin{array}{c}\text { Entre } 100 \% \text { y } \\
150 \%\end{array}$ \\
\hline
\end{tabular}

Fuente: elaboración propia a partir del trabajo de campo. 
Tabla 9. Tabulación de algunas variables asociadas a la competitividad

\begin{tabular}{|c|c|c|c|}
\hline Cultivo & Papa & Maíz & Lechuga \\
\hline \multicolumn{4}{|l|}{ Tipo de cultivo } \\
\hline Urbano & $0 \%$ & $5 \%$ & $0 \%$ \\
\hline Rural & $75 \%$ & $88 \%$ & $75 \%$ \\
\hline Suburbano & $25 \%$ & $7 \%$ & $25 \%$ \\
\hline \multicolumn{4}{|l|}{$\begin{array}{l}\text { Tiempo de la } \\
\text { conformación de la } \\
\text { unidad productiva }\end{array}$} \\
\hline Menos de 1 año & $25 \%$ & $5 \%$ & $25 \%$ \\
\hline De 1 a 4 años & $25 \%$ & $36 \%$ & $25 \%$ \\
\hline Más de 4 años & $50 \%$ & $59 \%$ & $50 \%$ \\
\hline \multicolumn{4}{|l|}{$\begin{array}{l}\text { Realiza análisis de } \\
\text { suelo }\end{array}$} \\
\hline Sí & $47 \%$ & $26 \%$ & $31 \%$ \\
\hline No & $53 \%$ & $74 \%$ & $69 \%$ \\
\hline \multicolumn{4}{|l|}{ Tipo de suelo } \\
\hline Arenoso & $14 \%$ & $12 \%$ & $14 \%$ \\
\hline Limoso & $34 \%$ & $30 \%$ & $34 \%$ \\
\hline Arcilloso & $9 \%$ & $8 \%$ & $9 \%$ \\
\hline Franco arenoso & $43 \%$ & $50 \%$ & $43 \%$ \\
\hline \multicolumn{4}{|l|}{ Tipo de riego } \\
\hline Goteo & $0 \%$ & $0 \%$ & $28 \%$ \\
\hline Gravedad & $35 \%$ & $5 \%$ & $0 \%$ \\
\hline Aspersión & $55 \%$ & $95 \%$ & $72 \%$ \\
\hline Otro & $10 \%$ & $0 \%$ & $0 \%$ \\
\hline
\end{tabular}




\begin{tabular}{|c|c|c|c|}
\hline $\begin{array}{c}\text { Nivel de educación } \\
\text { productor }\end{array}$ & & & \\
\hline Primaria & $62 \%$ & $71 \%$ & $45 \%$ \\
\hline Secundaria & $15 \%$ & $19 \%$ & $33 \%$ \\
\hline Técnico & $2 \%$ & $0 \%$ & $0 \%$ \\
\hline Tecnólogo & $3 \%$ & $0 \%$ & $11 \%$ \\
\hline Profesional & $5 \%$ & $5 \%$ & $0 \%$ \\
\hline Posgrado & $0 \%$ & $0 \%$ & $0 \%$ \\
\hline Ninguna & $13 \%$ & $5 \%$ & $11 \%$ \\
\hline $\begin{array}{c}\text { Innovación proceso } \\
\text { productivo }\end{array}$ & & & \\
\hline Sí & $0 \%$ & $0 \%$ & $0 \%$ \\
\hline No & $100 \%$ & $100 \%$ & $100 \%$ \\
\hline
\end{tabular}

Fuente: elaboración propia a partir del trabajo de campo.

Para finalizar, se resaltan las estrategias consideradas importantes a implementar para mejorar la competitividad del cultivo por parte de los tres grupos de encuestados (ver anexos 1-6). Para los cultivadores encuestados se establece la implementación de procesos de transformación y asociarse con otros productores como las principales estrategias para mejorar su competitividad, lo cual requiere de acompañamiento permanente por parte del gobierno local, la academia e instituciones de tipo técnico que generen apoyo para lograr los resultados esperados. 


\section{Figura 18. Estrategias importantes para la competitividad de papa, maíz y lechuga}

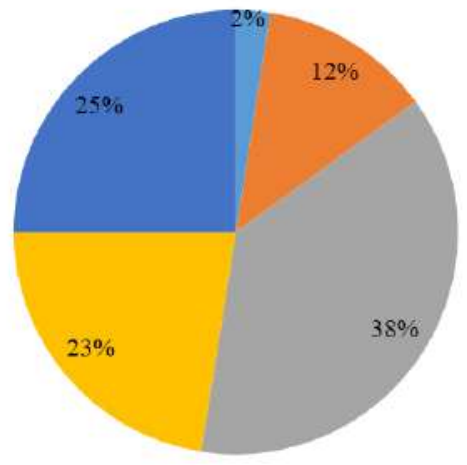

Papa

- Construir centros de acopio locales o regionales

= Asociarse con otros productores

implementar procesos de transformacion

= Mejorar la infaestructura productiva

- Incursionar en otros mercados

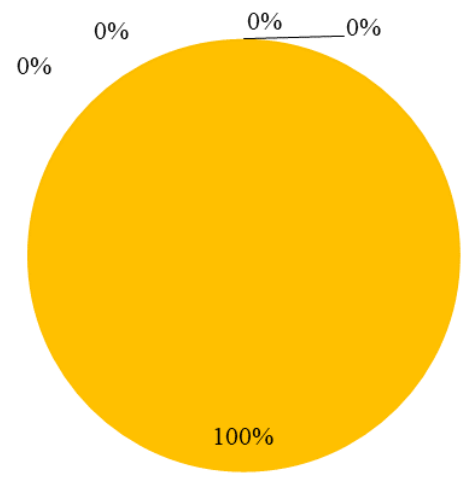

\section{Lechuga}

- Construir centros de acopio locales o regionales

- Asociarse con otros productores

- Diversificar las variedades de lechuga

- Implementar procesos de transformacion

- Incursionar en otros mercados 


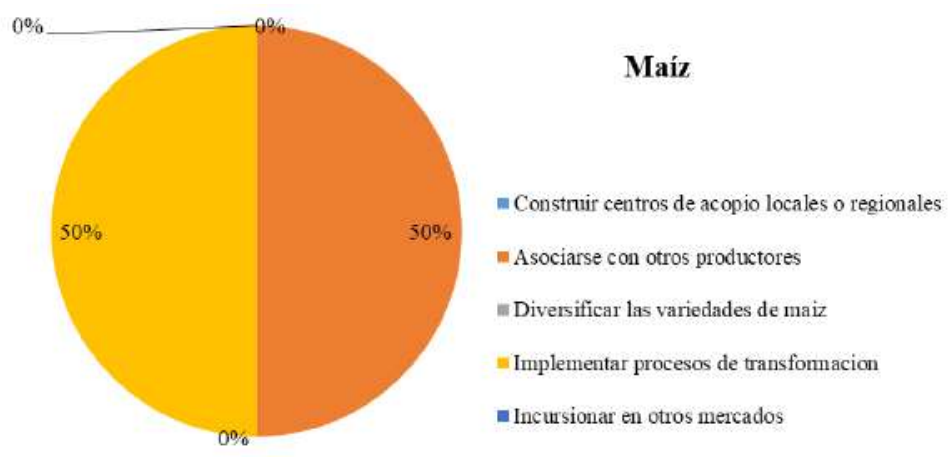

\subsection{Modelo propuesto para la medición de la competitividad sector agrario Sabana Centro de Cundinamarca. Caso: maíz, papa y hortalizas}

Cuando se desea predecir un resultado binario, por ejemplo, productivo contra no productivo, es muy recomendable utilizar regresión Logit (Greene, Ennett y Ringwalt, 1999). La característica de esta regresión radica en que la variable independiente es una variable dummy: código 0 (improductivo) o 1 (productivo) (Flores, Cruz, Rosano y Rodríguez, s.f.).

Dada la relación existente entre productividad y competitividad, para esta investigación se propone un modelo de respuesta binaria, los cuales buscan principalmente determinar la probabilidad de respuesta: 


$$
P(y=1 \mid x)=P\left(y=1 \mid x_{1}, x_{2}, \ldots, x_{k}\right)
$$

Donde $\boldsymbol{x}$ denota el conjunto total de variables explicativas (Wooldridge, 2010). Por ejemplo, para este caso, $\boldsymbol{y}$ es un indicador de competitividad del sector agrícola ${ }^{14}$ de la Sabana Centro de Cundinamarca. Por su parte, $\boldsymbol{x}$ contiene varias características individuales como el capital humano, las instituciones, la innovación entre otros factores que afectan el estado de la competitividad, incluidas variables de indicador binario o dummy sobre la participación en diferentes programas que ayudan a promover la competitividad en la región.

Según Gutiérrez, Nauzán y García (2017), el modelo Logit hace referencia a una función de distribución logística (FDL) y los coeficientes de regresión del modelo muestran un cambio en el logaritmo de probabilidad cuando alguna de las variables explicativas del modelo cambia en una unidad (Gujarati y Porter, 2010), por lo que busca dar a la variable dependiente o regresora valores entre 0 y 1 (ver ecuación 1), donde $\mathrm{P}$ es la probabilidad de obtener un valor en $\boldsymbol{y}$ dado unas variables $\boldsymbol{x}$ llamadas regresoras. Como se mencionó anteriormente, este modelo, al ser de respuesta binaria, define la probabilidad como la acumulativa de la función logística, así:

$$
P_{i}=\frac{e^{x_{j}^{\prime} \beta}}{1+e^{x_{j}^{\prime} \beta}}=\frac{1}{1+e^{-x_{j}^{\prime} \beta}}
$$


Donde se puede intuir que para $x_{j}^{\prime} \beta \rightarrow-\infty$ la probabilidad tiende a cero, $P_{i} \rightarrow 0$, y para $x_{j}^{\prime} \beta \rightarrow \infty$ la probabilidad tiende a uno, $P_{i} \rightarrow 1$ que es lo que se espera lograr (Montenegro, s.f. p. 297). El método de estimación más utilizado para el Logit es el de máxima verosimilitud, el cual garantiza eficiencia ${ }^{15}$ (Montenegro, s.f.).

A continuación, se presentan algunos componentes importantes que permiten tomar la decisión de utilizar el modelo Logit como el modelo general para la estimación del índice de competitividad del sector agrícola de la región objeto de estudio:

Figura 19. Efectos marginales e interpretación de las variables

\begin{tabular}{|c|c|}
\hline $\begin{array}{c}\text { EFECTOS } \\
\text { MARGINALES }\end{array}$ & $\frac{\partial P}{\partial X_{k}}=P(1-P) \beta_{k}$ \\
\hline $\begin{array}{c}\text { INTERPRETACIÓN DE } \\
\text { LAS VARIABLES }\end{array}$ & $\frac{P_{1}}{1-p_{i}}=\ln \left(e^{\alpha+\beta_{k} X_{k i}}\right)=\alpha+\beta_{k} X_{k i}$ \\
\hline
\end{tabular}

Según los autores, el Ratio Odds linealiza la ecuación del modelo haciendo que los valores estimados estén obligatoriamente entre 0 y 1 (Gujarati, 2009). Por su parte, los coeficientes estimados a

15 Es decir, "la varianza alcanza el límite inferior Cramer Rao" (Montenegro, s.f. p. 
través de máxima verosimilitud se interpretan como el cambio marginal de la probabilidad dado un cambio en el valor de la variable independiente (Rosales et al., 2010).

Específicamente, para esta investigación se pretende explicar la competitividad de la región en estudio como función de unas variables exógenas que le caracterizan y que se denotan por $x_{i}^{\prime}$, adicionando el término de error, el cual explica las diferencias entre los valores observados de competitividad $\boldsymbol{y}$, junto con sus valores previstos. La forma reducida para el "modelo Logit binomial" que se correrá es:

$$
P_{y=1}=\frac{e^{x_{j}^{\prime} \beta}}{1+e^{x_{j}^{\prime} \beta}}
$$

Donde el vector fila $x_{j}^{\prime}$ de variables explicativas para i-ésimo agricultor contiene las variables exógenas o independientes, e incluye una constante. Las variables de $x_{i}^{\prime}$ que hacen parte del modelo Logit de competitividad se presentan y definen a continuación (tabla 10), de los valores que tomarán se obtendrán algunas de la aplicación del instrumento de investigación y otras de bases de datos oficiales o indexadas. 


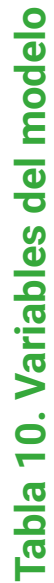

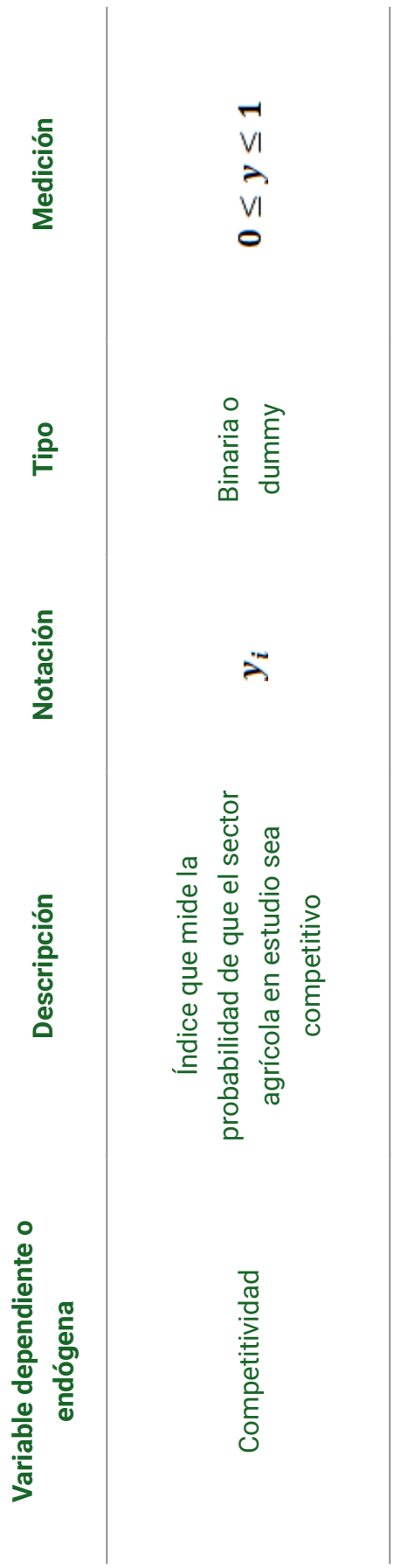




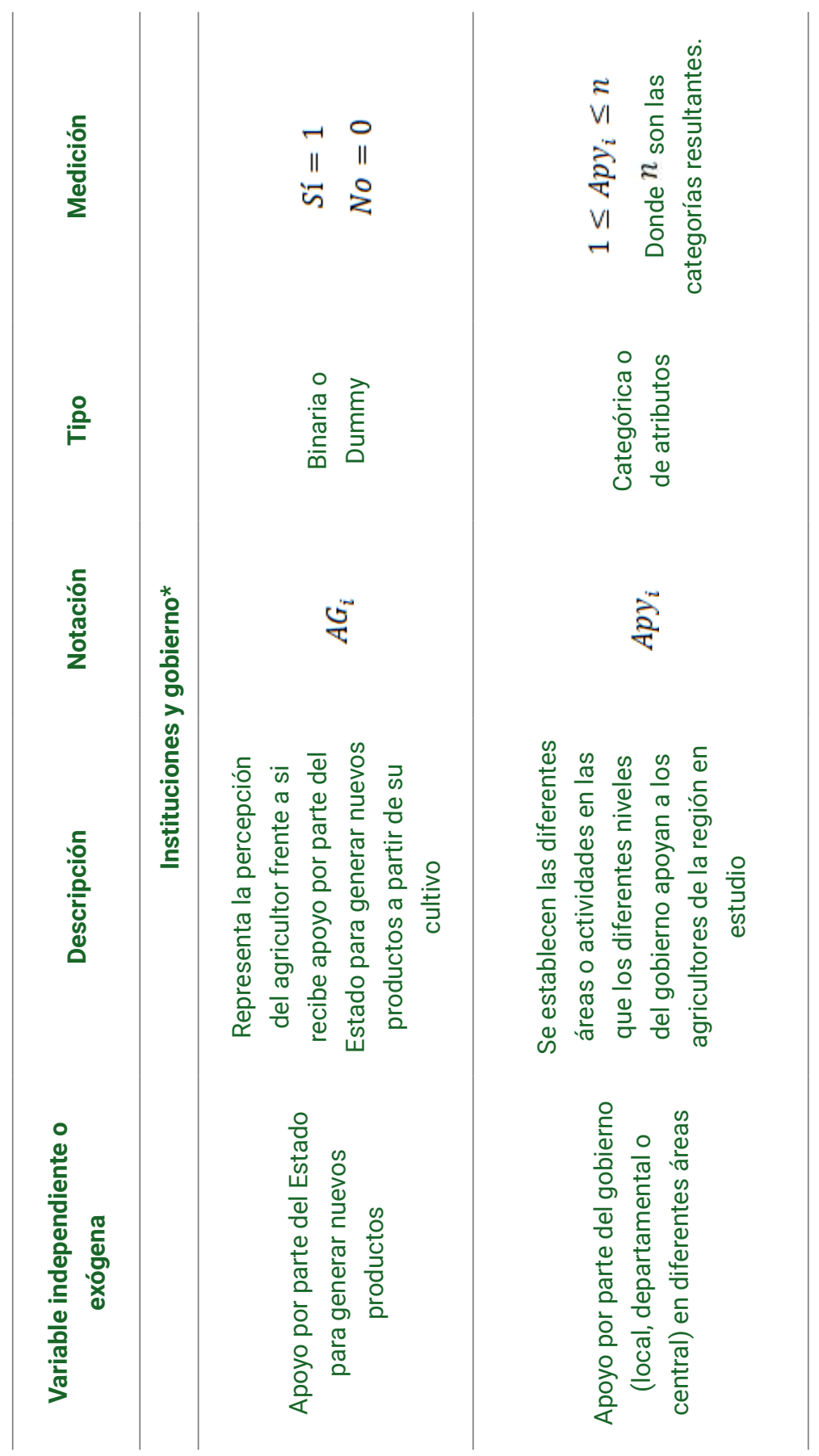




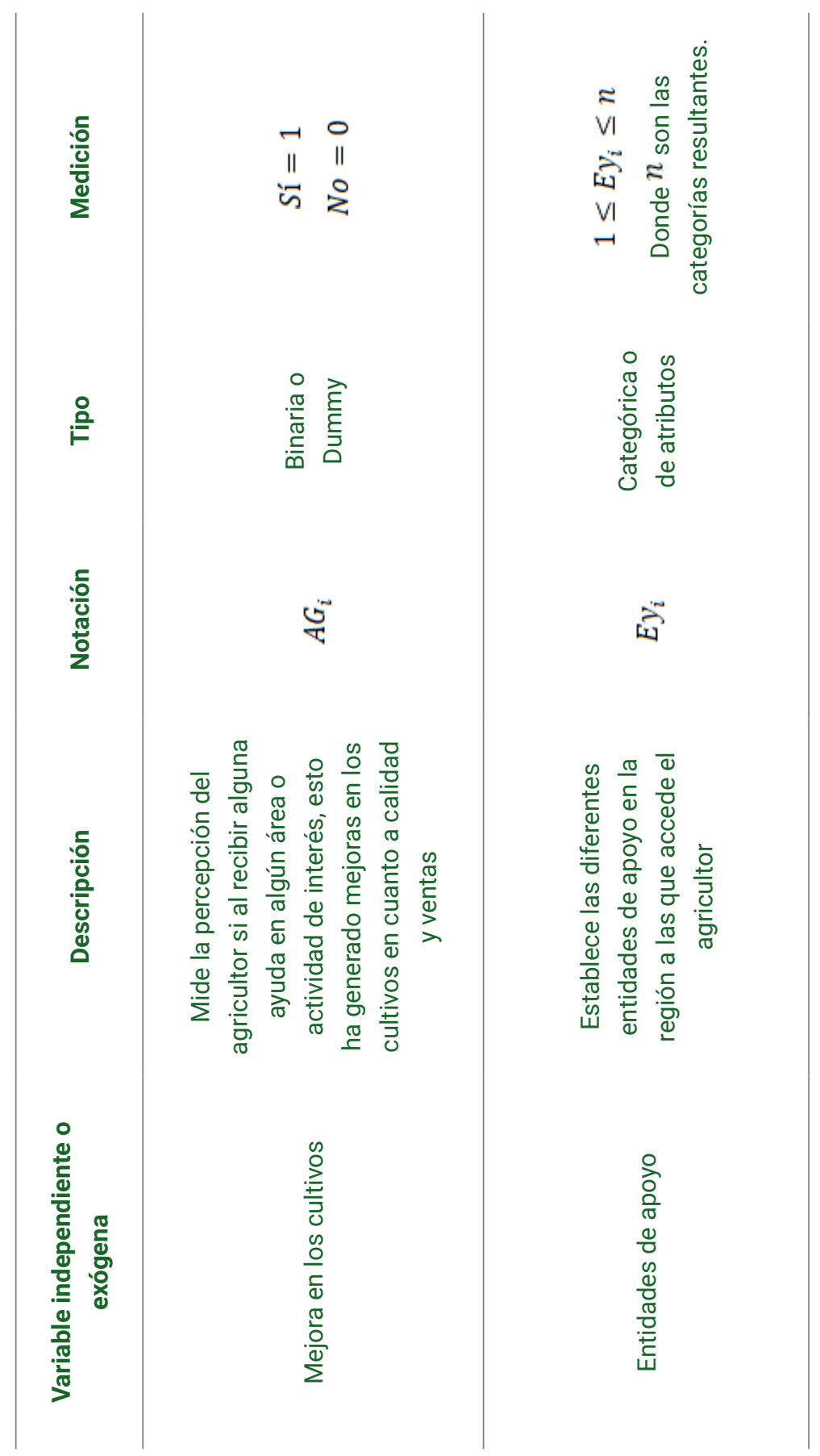




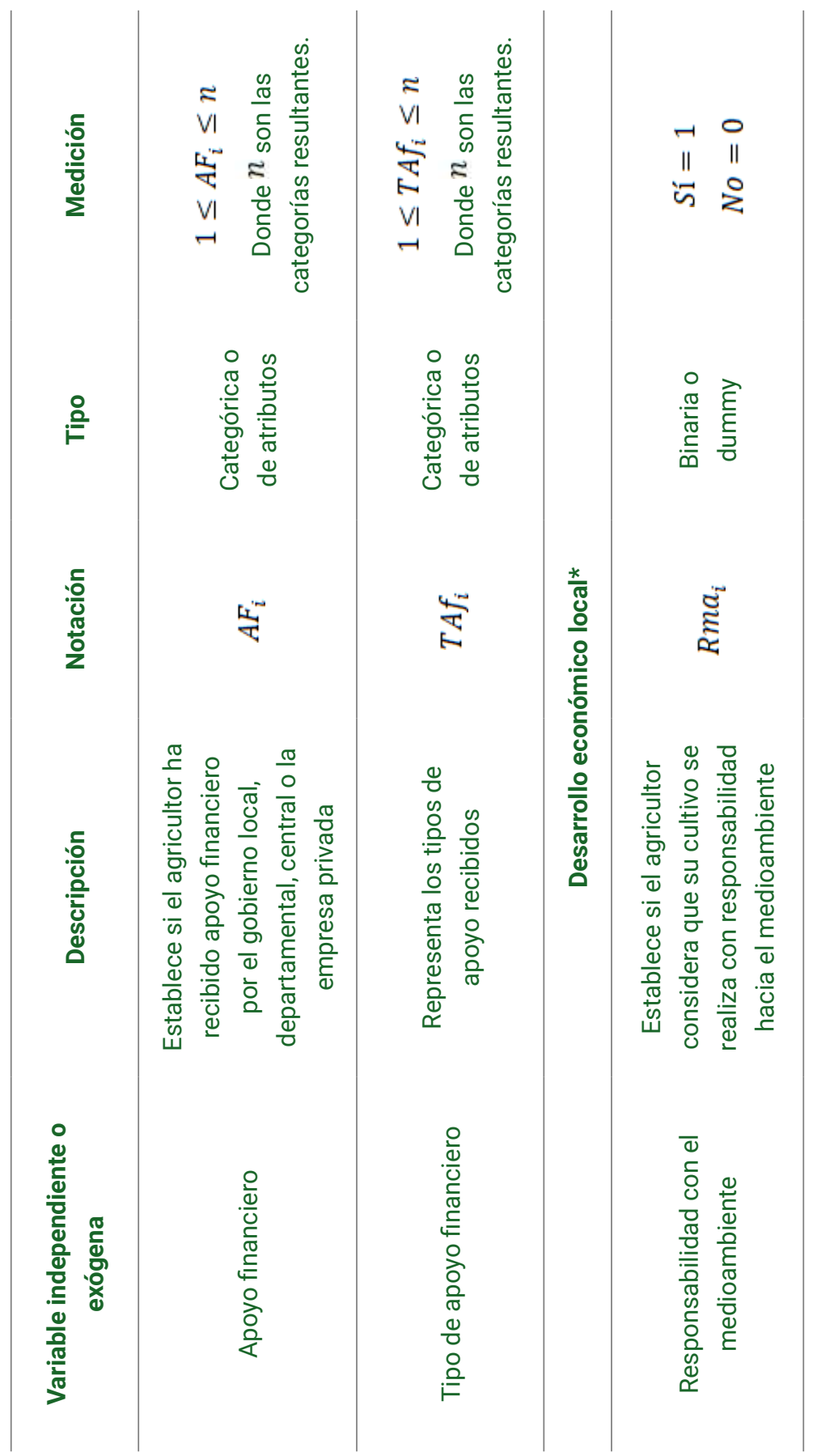




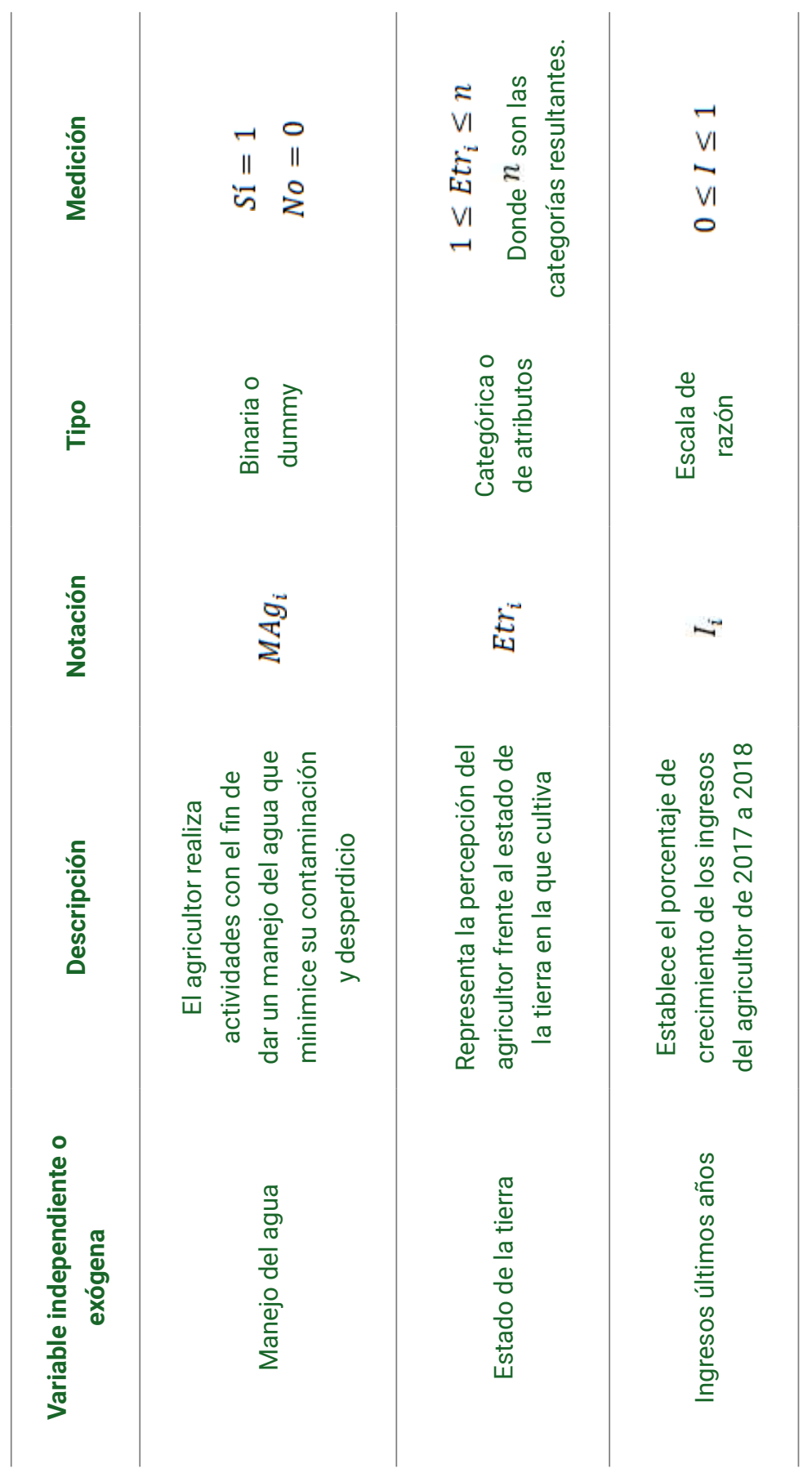




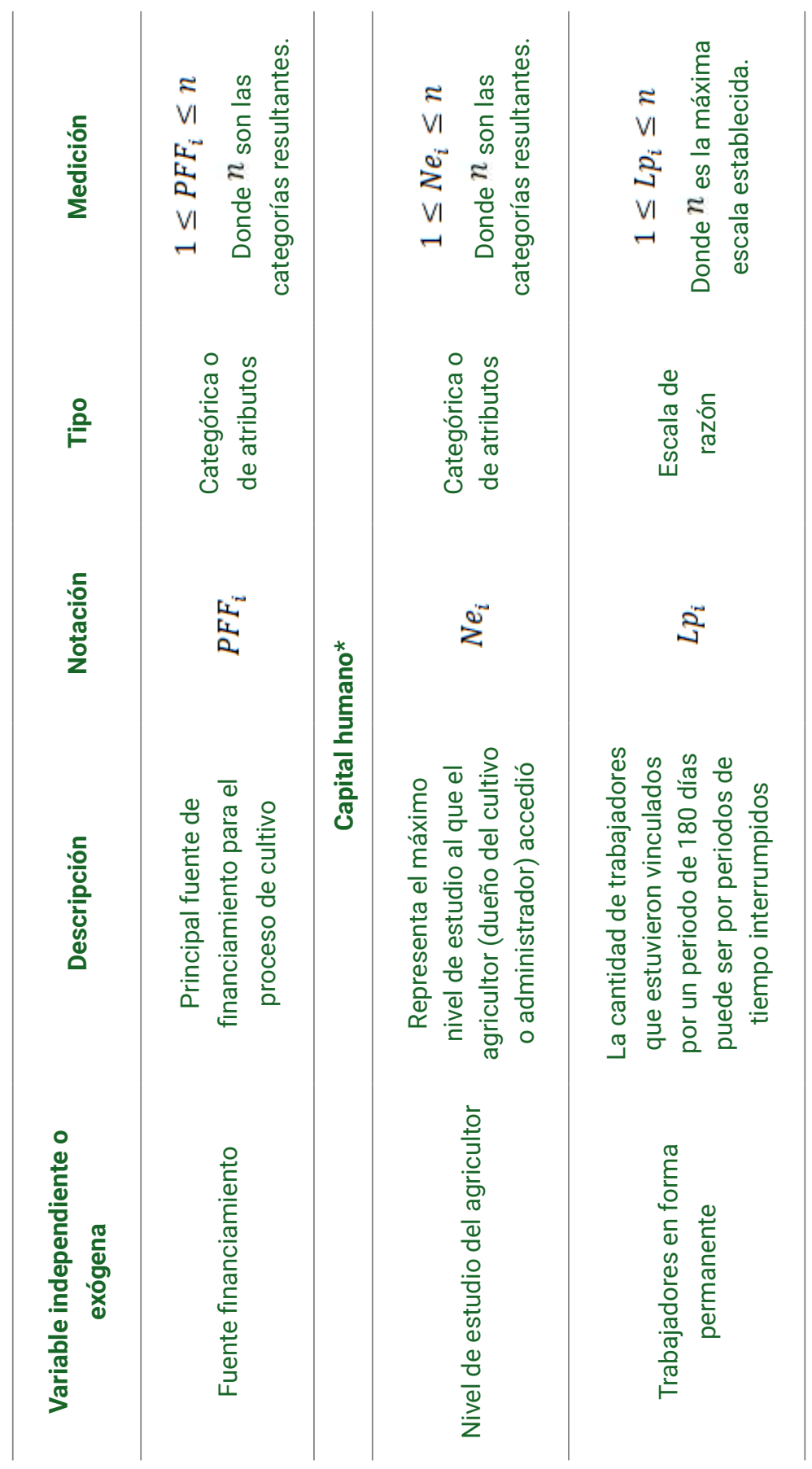




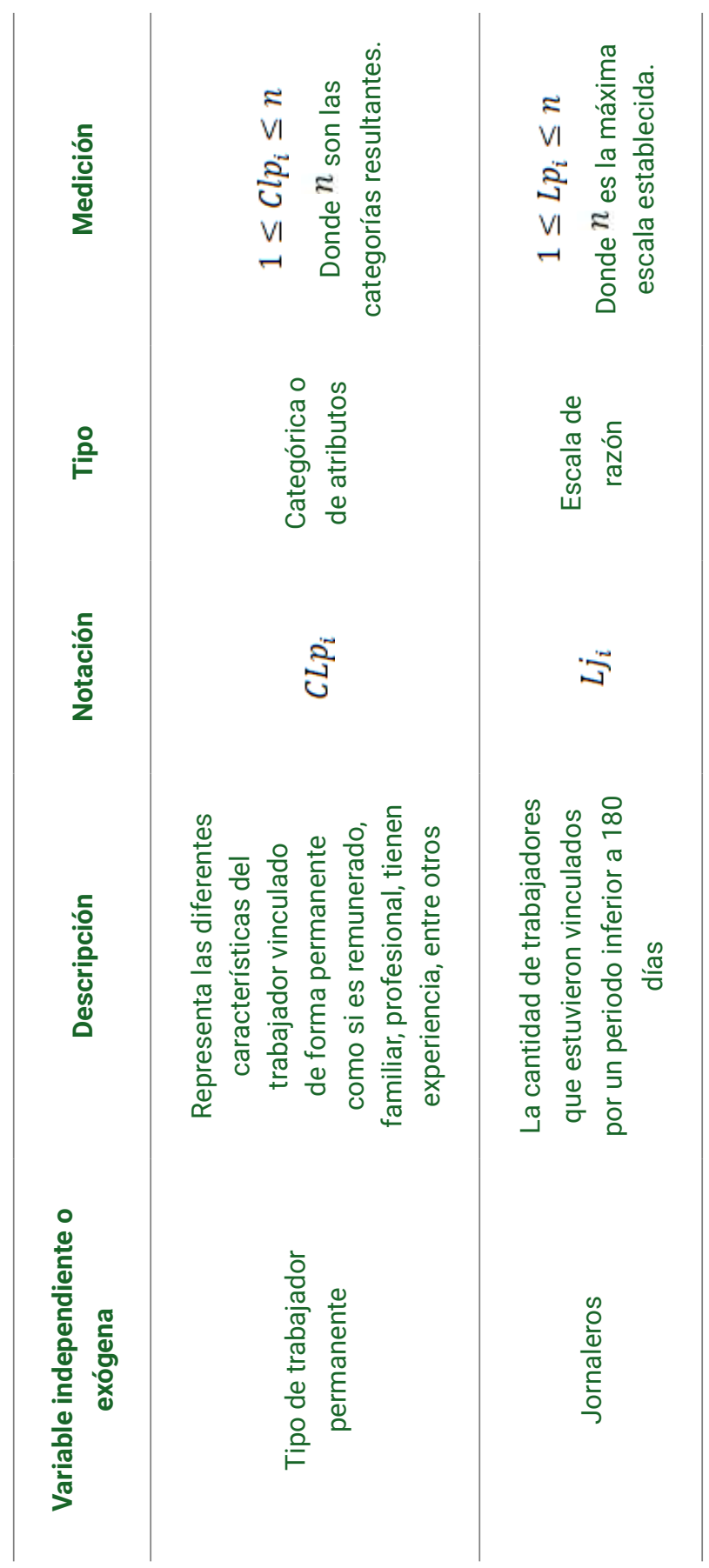




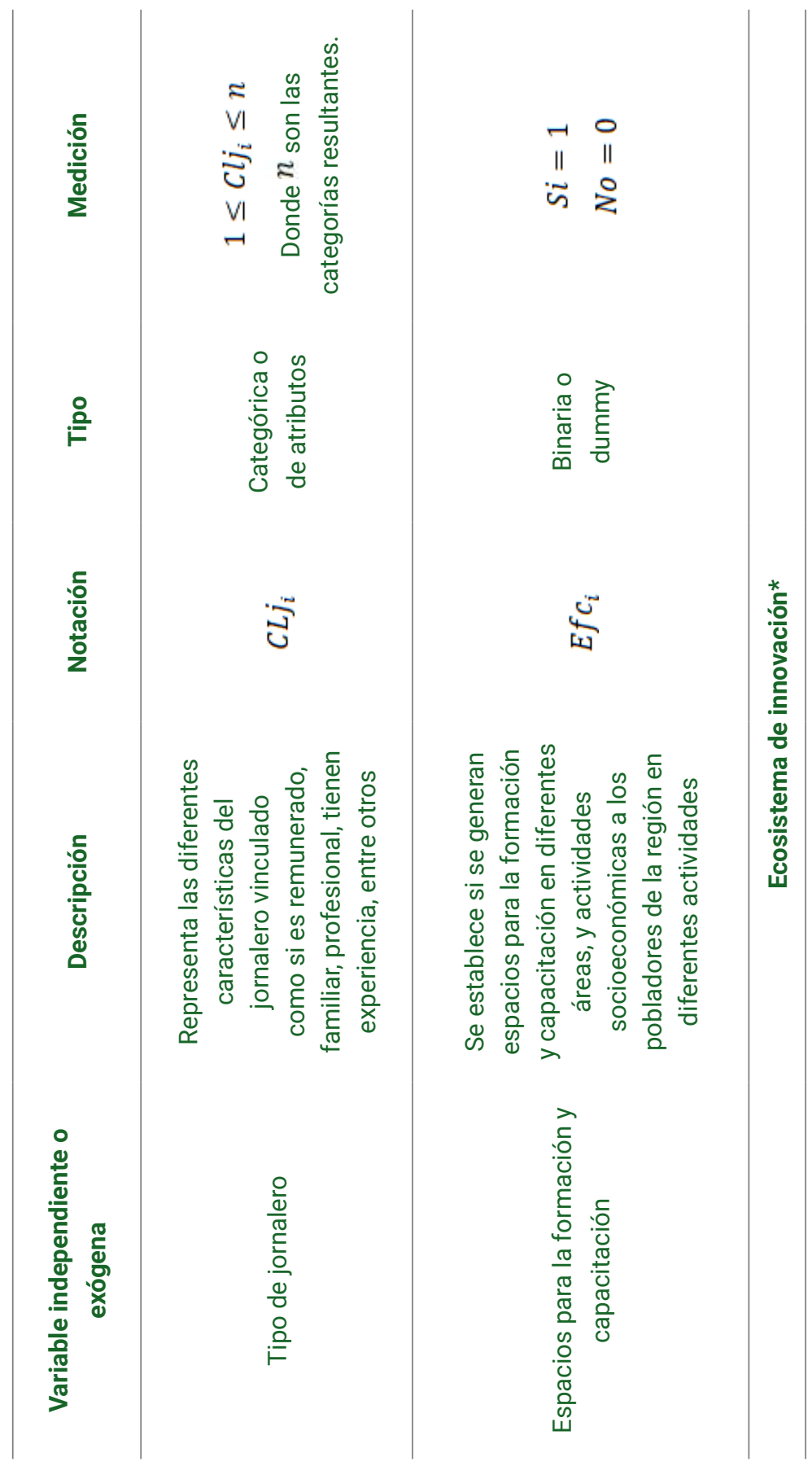




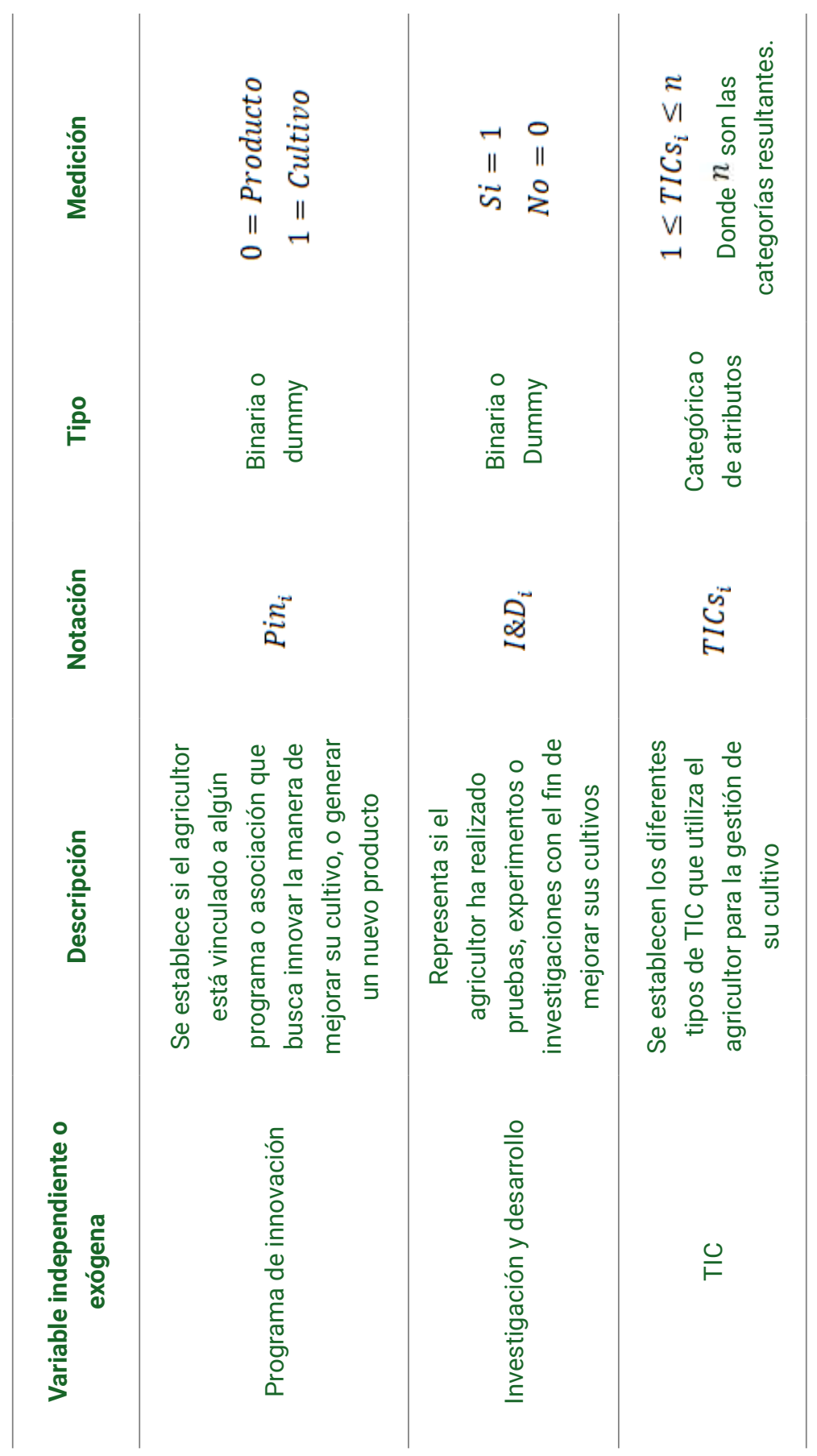




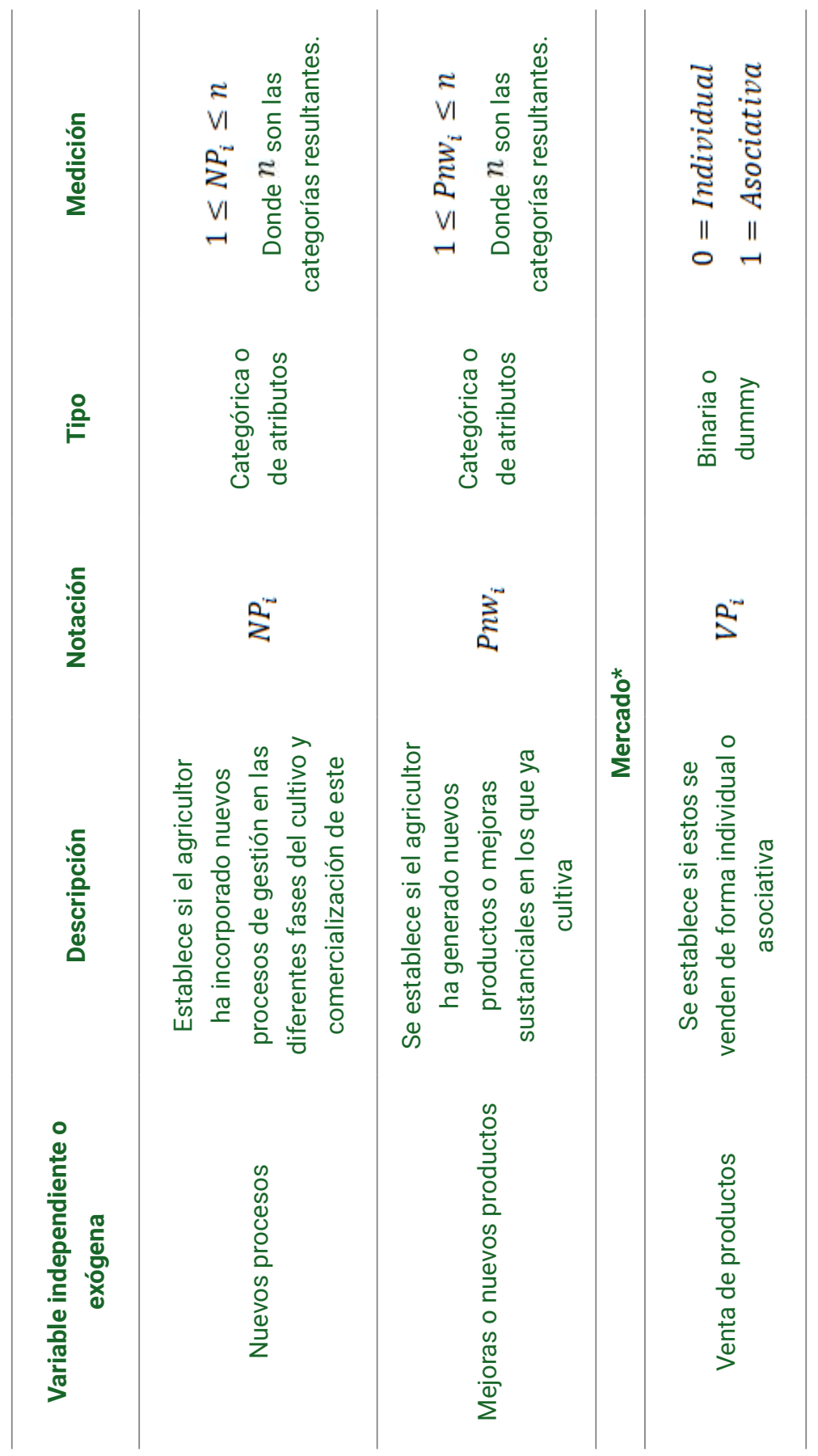




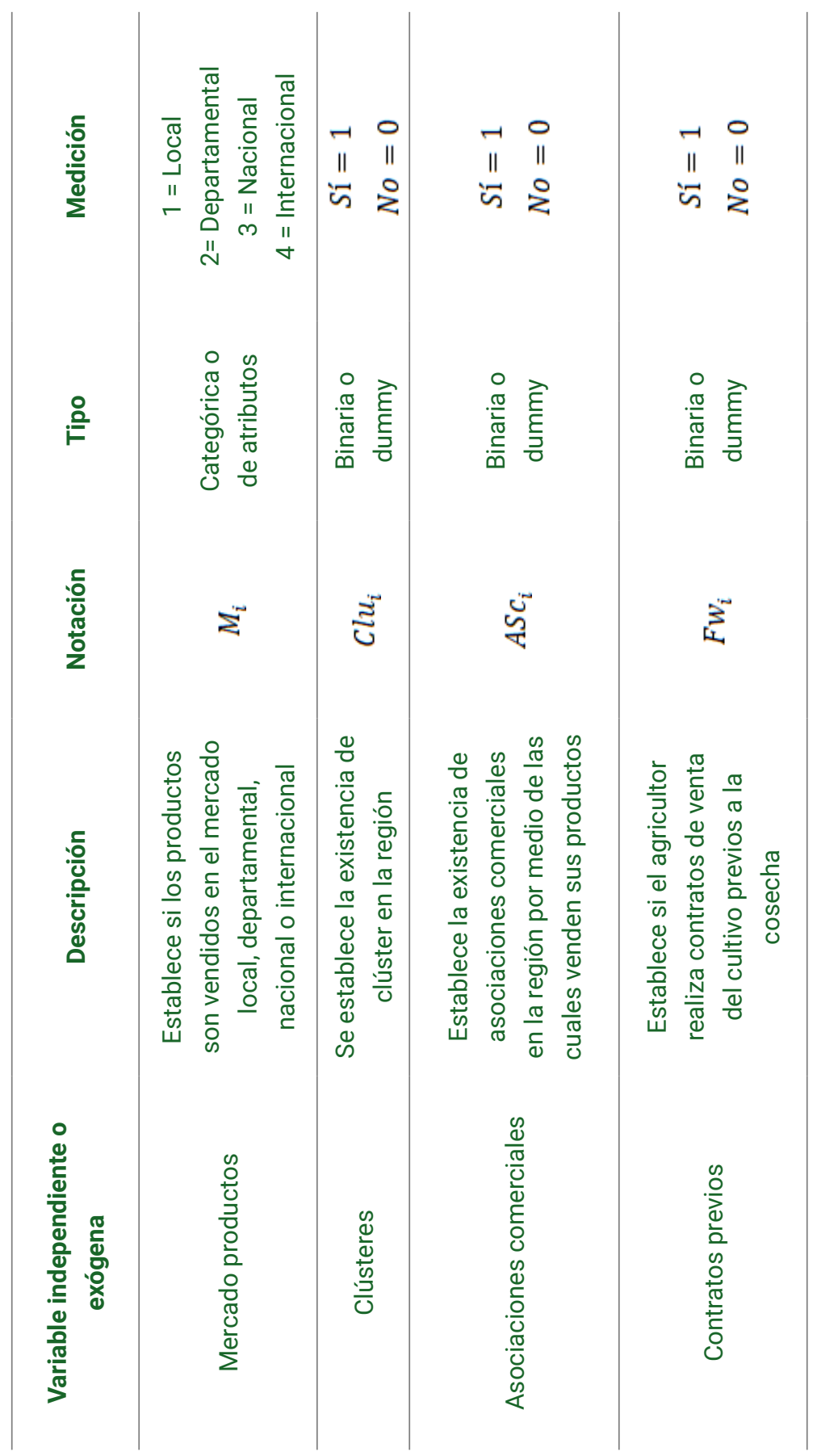




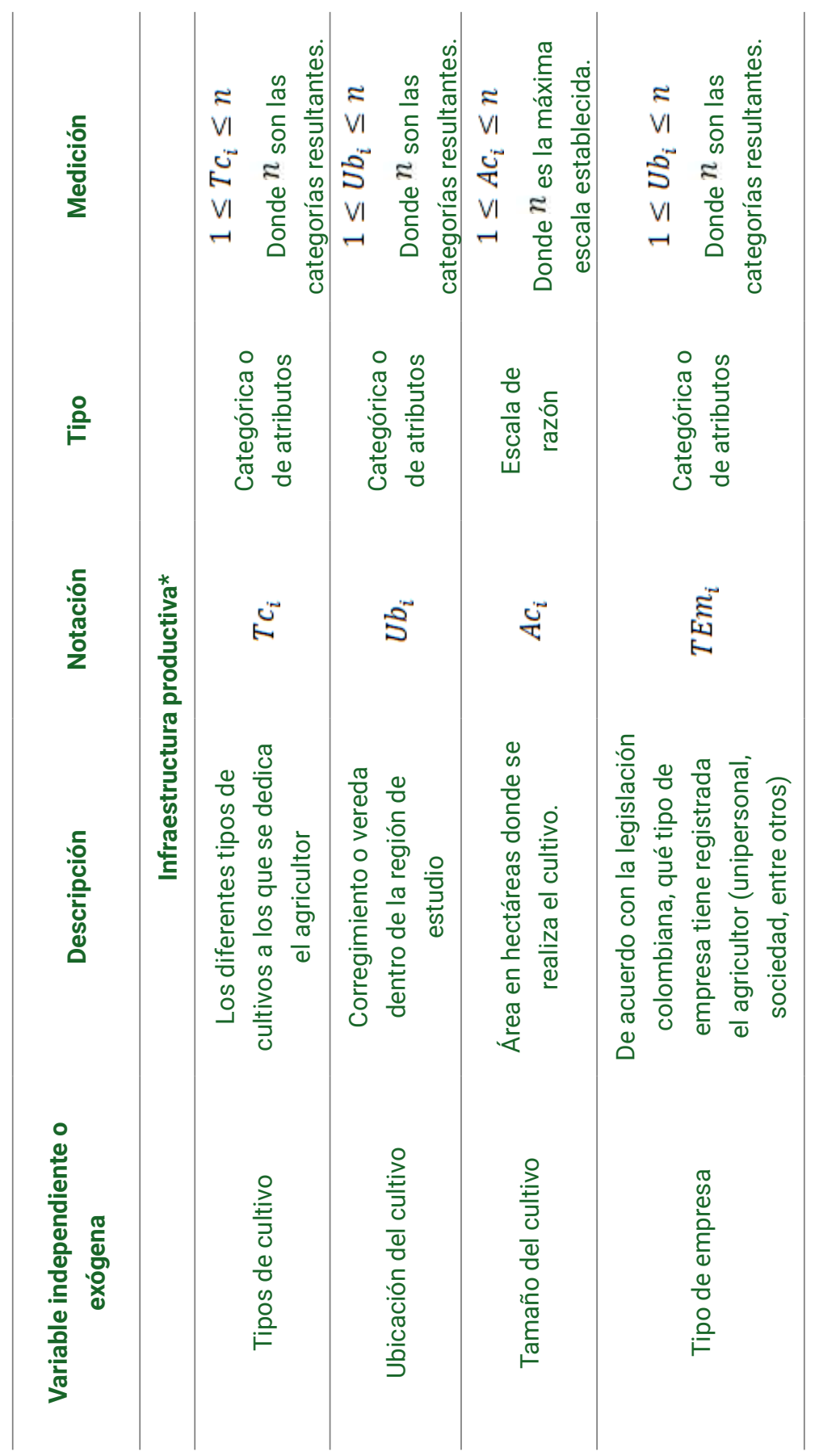




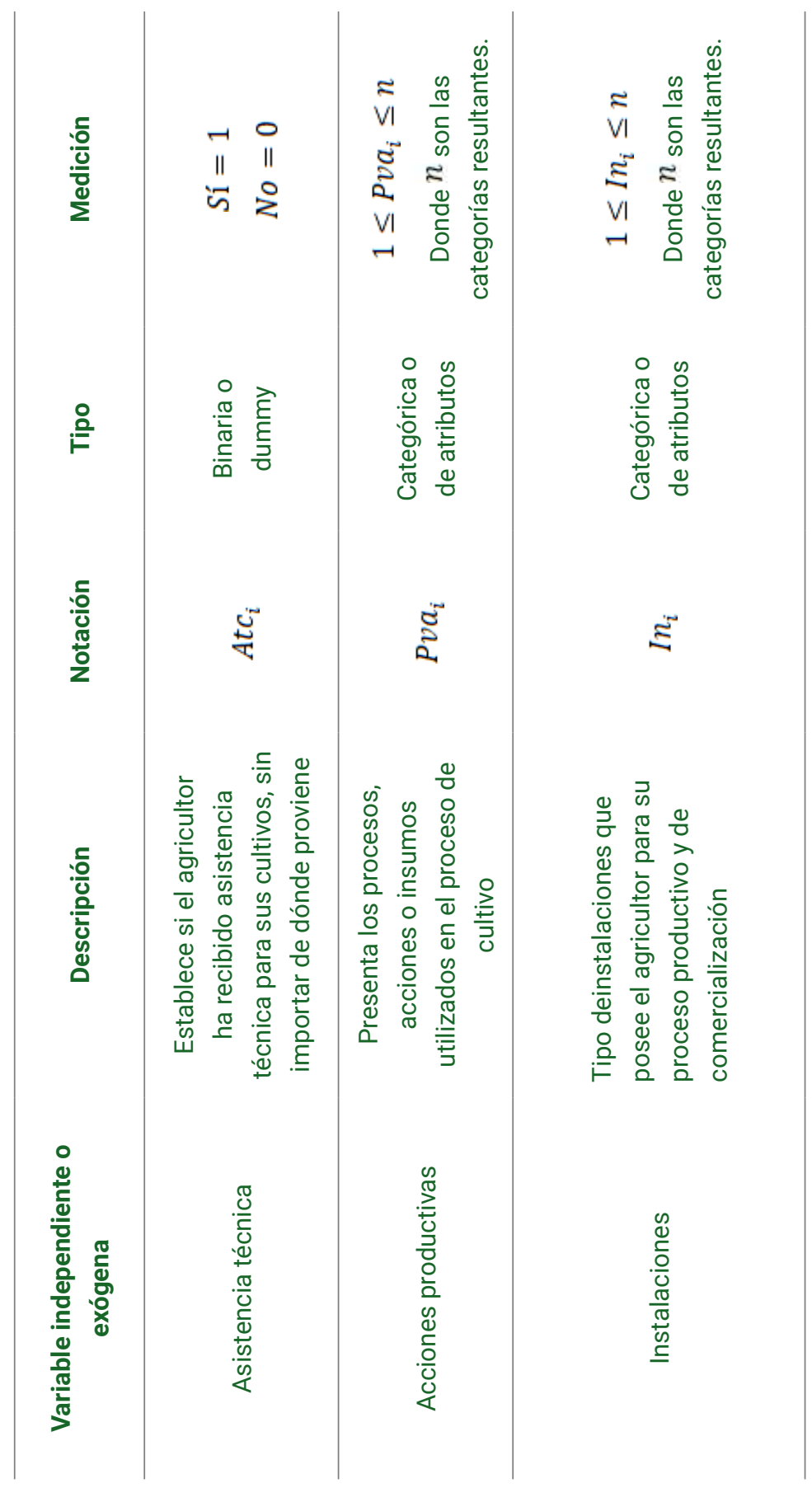




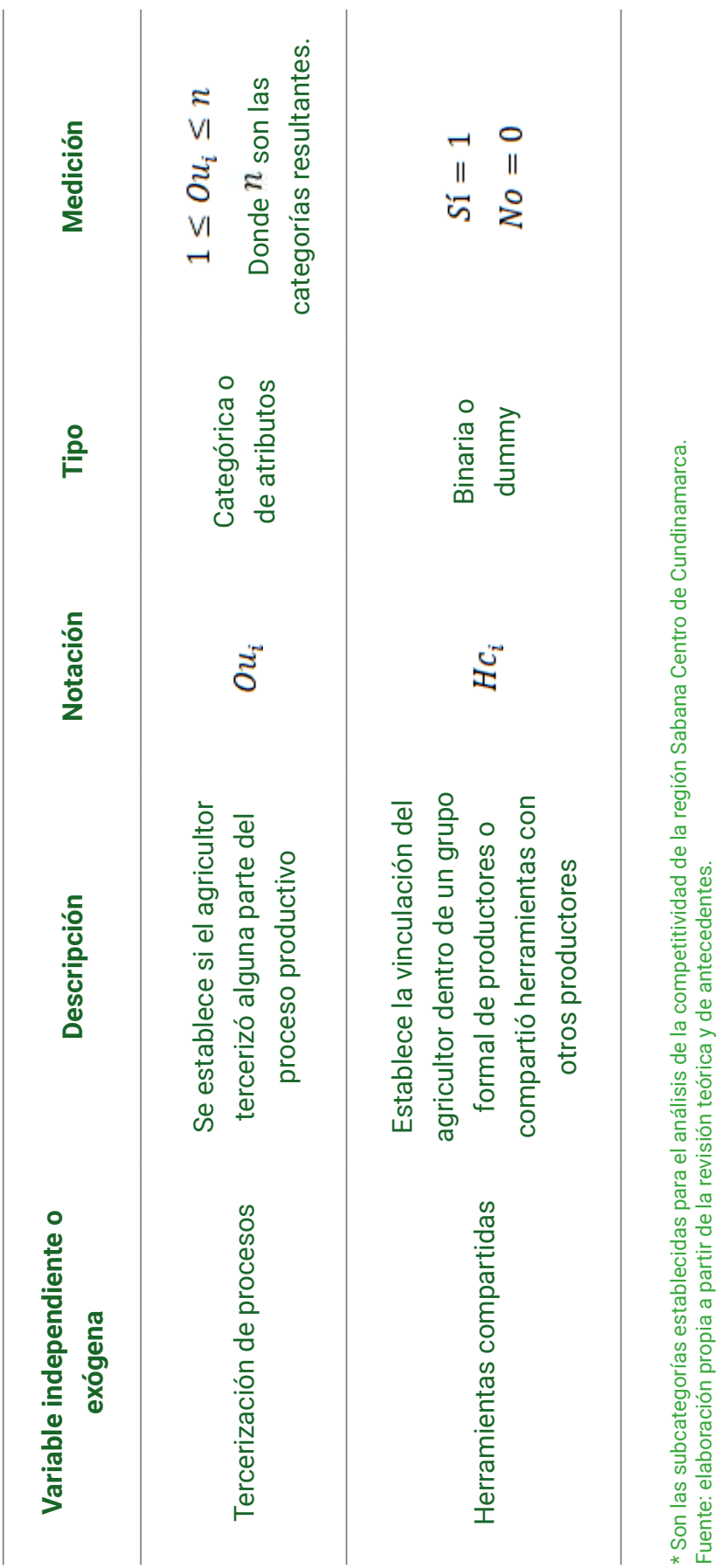


Las variables establecidas se encuentran agrupadas en seis subcategorías las cuales se definen a continuación:

Instituciones y gobierno: dentro de la cual se busca establecer la red de apoyo desde el gobierno y analizar la política pública alrededor de la competitividad de la región.

Capital humano: esta categoría involucra el nivel de educación y otras características asociadas a la cualificación y generación de competencias de los trabajadores y agricultores de la región.

Innovación: busca establecer si los agricultores están desarrollando procesos innovadores que les permitan mejorar sus cultivos o crear mejoras 0 nuevos productos.

Mercados: busca establecer la manera en que los agricultores incursionan en diferentes mercados y su alcance.

Desarrollo económico: analiza algunas variables que desde la teoría potencializan el desarrollo económico en la región, como el medioambiente.

Infraestructura productiva: establece la forma productiva que desarrollan los agricultores en la región en estudio, tomando en cuenta actividades y recursos entre otros.

Finalmente, es importante tener en cuenta que los datos que se utilizarán son de corte transversal, ya que son de un momento determinado en el tiempo, aun así, los resultados del modelo se complementarán con análisis descriptivo de diferentes variables de tipo económico y social.

Aplicación del modelo. En primer lugar, se correrán todos los modelos Logit univariados posibles 
con el fin de identificar las variables regresoras significativas en ellos. Luego, las variables que hayan resultado significativas se correrán bajo a un modelo Logit general. Es importante resaltar que se espera que este cuente con poder predictivo, es decir, que cuente con una "especificidad y sensibilidad altas de al menos el 75 \%" (Higuera y Miranda, 2014) y que cumpla con requerimientos como bondad de ajuste, análisis del $\mathrm{R}^{2}$ ajustado, entre otros.

\subsection{Retos y estrategias para mejorar la competitividad agrícola}

Desde lo establecido en la investigación y la evidencia empírica, es posible decir que el sector agrícola puede considerarse como motor de desarrollo económico y social desde la óptica gubernamental nacional y local, y como aspecto trascendental en la política de seguridad alimentaria. A partir de esto se debe:

- Establecer la necesidad de impactar la conciencia de la población, en cuanto a la importancia de cambiar la actitud frente a las tradiciones agrícolas y productivas. Se requiere una actitud de cambio de los modelos productivos tradicionales, todo mediante políticas públicas que permitan llegar a la población agricultora.

- Definir estrategias que impacten en el factor humano, generando conocimiento, habilidades y destrezas que permitan generar nuevos procesos, la adopción de nuevas tecnologías 
y una cultura de innovación y emprendimiento permanente.

- El mercado no es estático, está en constante cambio. Por eso es imperioso diseñar alternativas que permitan ampliarlo y estas deben partir de la base de la transformación.

- El potencial agrícola productivo de Colombia es inmenso y se debe aprovechar. Este aspecto permite obtener seguridad alimentaria y generar muchos puestos de trabajo.

- La producción competitiva va de la mano con una visión empresarial de la producción agrícola. Esta se puede lograr en algunos casos de manera individual, pero en la mayoría de estos se requiere la asociatividad a través de proyectos integradores que permitan alternativas innovadoras y rentables a los productores.

- El incremento de la productividad es imperativo con miras a la competitividad, pero también para contrarrestar la permanente reducción del área sembrada, ocasionada por la potrerización y por el avance cada vez mayor del urbanismo.

- Es importante rescatar el cultivo de productos de tradición en la economía nacional con miras a garantizar la seguridad alimentaria nacional. La destinación de los recursos del presupuesto nacional debe estar orientada a generar transformación de la actividad agrícola del país, esto con mayor orientación hacia procesos investigativos y proyectos integradores, más aún cuando los agricultores nacionales, según la percepción mostrada por la región Sabana Centro de Cundinamarca, no tiene la cultura de investigación e innovación. 
- Los hallazgos que se visualizan en este trabajo de investigación deben concluir en la formulación de proyectos de tipo regional que permitan integrar la población en la concepción de desarrollo territorial.

- El país debe enfocar esfuerzos y destinar recursos orientados a realizar estudios de inteligencia de mercados, esto permitiría orientar la actividad de los productores nacionales hacia aquellas que garanticen su comercialización.

- Las instituciones del Estado deben reestructurarse para que dejen de ser solo entes burocráticos para que se dediquen a orientar una verdadera política de transformación del campo colombiano.

- Se propone la implementación de un modelo de medición de la competitividad mediante un modelo probabilístico: "índice que mide la probabilidad de que el sector agrícola en estudio sea competitivo", partiendo de la creación de una base de datos que contenga los datos necesarios para la estimación de este, lo cual permitirá el conocimiento a profundidad del sector dada la importancia de este para la economía del departamento y del país. 


\section{Conclusión}

De manera general, se concluye como resultado de este proceso investigativo que el sector agrícola de la Sabana Centro del departamento de Cundinamarca presenta grandes dificultades, con miras a competir de manera certera frente a otras economías y sectores de la vida nacional. Se concluye además que la actividad agrícola ha venido perdiendo importancia en Colombia, llegando a representar solo el $9 \%$ del PIB.

Colombia tiene un gran potencial agropecuario considerándosele como el séptimo país del mundo en la oportunidad de convertirse en despensa agrícola, situación que no ha sido aprovechada adecuadamente $y$, al contrario, ha ido perdiendo en la economía nacional.

Los índices de escolaridad son preocupantes, ya que el $65.2 \%$ tiene un nivel de escolaridad primaria y el $9.5 \%$ no tiene escolaridad, lo cual dificulta cualquier proceso de transformación agropecuaria en el país.

Según datos del Ministerio de Salud del 2015, la tasa de desnutrición en Colombia es de un $9 \%$, situación que se podría evitar si se implementaran políticas para mejorar la productividad y distribución de alimentos en Colombia.

La actividad agropecuaria ha ido trasladándose de la actividad agrícola a la actividad pecuaria, representando la primera con $7.3 \%$ y la segunda con $78.2 \%$, la cual tiene implicaciones grandes en el nivel de empleo del sector rural.

Los productores nacionales tienen mayor tendencia a producir de manera individual bajo la figura de personas naturales asociadas, lo cual 
dificulta lograr economías de escala y dificulta una mayor competitividad, según los resultados del trabajo de campo.

Es de suma importancia para Colombia establecer sus niveles de competitividad tanto regional como nacional, ya que para establecer objetivos y estrategias de desarrollo es imprescindible partir de indicadores que midan el estado en que nos encontramos, los avances que vamos logrando y los retos que debemos plantearnos para lograr niveles óptimos en el país.

Las estrategias que se definan en busca de mejorar la competitividad deben partir de reconocer el estado de avance de cada una de esas categorías, las acciones necesarias para optimizarlas, los recursos requeridos para llevarlas a cabo y el compromiso adquirido por cada uno de los actores de desarrollo.

Se puede establecer mediante el análisis econométrico que la producción de hortalizas, de maíz y de papa son base importante del PIB del departamento, por lo cual es importante fortalecer el sector desde su productividad y su competitividad. A esto se propone un modelo que permita medir la competitividad del sector en la Sabana Centro del departamento de Cundinamarca, esto con el fin de involucrar variables que están contenidas dentro de otros índices de medición de competitividad, pero que se ajusten más a la realidad del sector en estudio. 


\section{Referencias}

Bejarano, J. (1995). Elementos para un enfoque de la competitividad en el sector agropecuario. Colección de Documentos IICA.

Cámara de Comercio de Bogotá [CCB]. (2019). Caracterización económica y empresarial de las provincias de cobertura de la CCB. https://bibliotecadigital.ccb.org.co/ bitstream/handle/11520/2892/6235_ caracteriz_empresarial_sabana_centro. pdf?sequence $=1$ \&isAllowed $=y$

Departamento Administrativo Nacional de Estadística [DANE]. (2014). Censo Nacional Agropecuario. DANE.

. (2016). CNA Tomo 2 - Resultados. DANE.

(2017). Encuesta Nacional Agropecuaria ENA. Boletín técnico. DANE.

. (2019). Comunicado de prensa. Pobreza monetaria 2018. https://www.dane.gov.co/ files/investigaciones/condiciones_vida/ pobreza/2018/cp_pobreza_monetaria_18.pdf Departamento Nacional de Planeación [DNP]. (2018a). Plan Nacional de desarrollo PND (2018 - 2022). Pacto por Colombia, pacto por la equidad. DNP. (2018b). Documento CONPES. Política de Crecimiento Verde. https://colaboracion.dnp. gov.co/CDT/Prensa/ Presentaci\%C3\%B3n\%20 
Pol\%C3\%ADtica\%20de\%20Crecimiento\%20 Verde.pdf

Durán, A., Mora, D., González, M., y Vargas, G. (2018). Nivel de competitividad de las empresas exportadoras de productos agrícolas no tradicionales de Costa Rica. Agronomía Costarricense, 42(2), 141-158.

Espinosa, R. (2017) Welcome to the new Marketing: Ventaja competitiva: Qué es, claves, tipos y ejemplos. https://robertoespinosa. es/2017/10/22/ventaja-competitiva-que-estipos-ejemplos

Federación Nacional de Cultivadores de Cereales [FENALCE]. (2017). Índice cerealista. FENALCE. Flores, V., Cruz, M., Rosano, G., y Rodríguez, E. (s.f.). Medición de la competitividad de los productores de limón Persa por medio de Logit, caso de los productores de Cuitláhuac Veracruz. Handbook.

Fondo para el Financiamiento del Sector Agropecuario [Finagro]. (2019). El momento del agro. https:// www.finagro.com.co/noticias/el-momentodel-agro

Furtado, C. (2002) La teoría del subdesarrollo. CEPAL. Gobernación de Cundinamarca. (2016). Plan de desarrollo de Cundinamarca (2016 - 2020), Unidos podemos más. Gobernación de Cundinamarca.

y Centro de Pensamiento en Estrategias 
Competitivas [CEPEC]. (2018). Índice de competitividad para las provincias de Cundinamarca, ICPC - 2018. Gobernación de Cundinamarca y CEPEC.

Gobernación de Cundinamarca y Programa de las Naciones Unidas para el Desarrollo [PNUD]. (2018). Línea base Objetivos de Desarrollo Sostenible, departamento de Cundinamarca - Colombia. Gobernación de Cundinamarca y Provincias Gobernación de Cundinamarca.

Greene, J.; Ennett, S. y Ringwalt, C. (1999). Prevalence and correlates of survival sex among runaway and homeless youth. American journal of public health, 89(9), 1406-1409.

Gujarati, D. (2009) Basic econometrics. McGraw-Hill Education.

y Porter, D. (2010). Econometría. McGraw-Hill. Gutiérrez, D., Nauzán, V., y García, O. (2017). Salarios de eficiencia en la aplicación de estrategias salariales para el sector petrolero en Colombia Caso: Barrancabermeja - Área Operaciones. Corporación Universitaria Iberoamericana.

Higuera, V., y Miranda, J. (2014). Las capacidades competitivas en las pequeñas y medianas empresas (PYME) exportadoras: Una aproximación desde un modelo de logit multinomial. En XLIX Asamblea Anual CLADEA 2014 "Liderando en un mundo global, Latinoamérica y Europa, nuevas conexiones". https://cladea2014.files.wordpress.com/2014/10/ paper_299.pdf

Ministerio de Salud y Protección Social [Minsalud]. 
(2015). Análisis de la situación de salud colombiana. Minsalud.

Ministerio de Agricultura y Desarrollo Rural [MADR]. (2017). Producción nacional por producto. MADR.

Montenegro, A. (s.f.). Econometría intermedia y básica.

Pontificia Universidad Javeriana.

Objetivos de Desarrollo Sostenible [ODS]. (2019).

Hambre Cero en Colombia. https://www.ods. gov.co/es/objetivos/hambre-cero

Organización de las Naciones Unidas para la Agricultura y la Alimentación [FAO]. (1996). Declaración en Roma sobre la seguridad alimentaria mundial. FAO.

(2017). Estadísticas de producción de cultivos. FAO.

(2019). FAO en Colombia. Programas en

Colombia. http://www.fao.org/colombia/ programas-y-proyectos/es/

Ortiz, C., Infante, Z., y Ortega, P. (2016). El ICAM como propuestademedicióndecompetitividadagrícola municipal en Michoacán. Red Internacional de Investigadores en Competitividad.

Rosales, R., Perdomo, J., Morales, C., y Urrego, A. (2010). Fundamentos de econometría intermedia: teoría y aplicaciones. Apuntes de clase CEDE, 1. Universidad de Los Andes.

Stellian, R., y Danna-Buitrago, J. (2017). Competitividad 
de los productos agropecuarios colombianos en el marco del tratado de libre comercio con los Estados Unidos: análisis de las ventajas comparativas. Revista de la CEPAL, (122), 139163.

Stiglitz, J. (1989). Financial Markets and Development. Oxford Review of Economic Policy, 5(4), 55-68. Universidad de La Sabana (2016). Informe de calidad de vida Sabana Centro, cómo vamos (20152016). Universidad de La Sabana.

Universidad de los Andes. (2017). Encuesta Longitudinal Colombiana -ELCA, resultados. Universidad de los Andes.

Valderrama, M. (1976). El trigo en Colombia. CIMMYT. Villanueva, D. (2018). Estudios sobre la bioeconomía como fuente de nuevas industrias basadas en el capital natural de Colombia. DNP; Universidad Eafit.

Wooldridge, J. (2010). Econometric analysis of cross section and panel data. MIT press.

Zegarra, L., y Valdivia, C. (2010). Un índice regional de competitividad para un país. Revista de la CEPAL, (102), 69-86. 


\section{Anexo 1. Encuesta de caracterización - Papa Universidad de Cundinamarca - Universidad Nacional de Colombia} Encuesta de caracterización agrícola

Objetivo: obtener información directa de las unidades productivas de papa (Solanum tuberosum) de la provincia Sabana Centro, Cundinamarca, en relación con los factores de competitividad: condiciones de los factores de producción, condiciones de la demanda, sectores relacionados y de apoyo y estrategia, estructura y rivalidad, para identificar las condiciones que requiere el cultivo para ser considerado productivo y mejorar su competitividad.

\section{Información de la encuesta}

1. Identificación de la unidad productiva

2. Entorno ocupacional

3. Oferta y demanda

4. Estructura tecnológica e innovación

\section{Contenido de la encuesta}

Instrucciones para su diligenciamiento:

Lea detenidamente las preguntas y responda de acuerdo con las características de su unidad productiva. 
Si alguna pregunta no aplica para su unidad productiva, por favor déjela en blanco.

Fecha (dd/mm/aaaa):

Hora de inicio:

Hora de finalización:

Encuestador:

I. Identificación de la unidad productiva

1. Nombre de la unidad productiva:

2. Altura del predio: MSNM

3. Dirección:

4. NIT:

5. Nombre del representante legal:

6. Nombre de la persona entrevistada:

7. Cargo:

8. Teléfonos:

9. Dirección electrónica:

10. Tipo de sociedad:

11. Municipio: 
12. El cultivo es:
a. Urbano ( )
b. Rural ()
c. Suburbano ( )

13. El tiempo de conformación de la unidad productiva es de (señale con una $\mathrm{x}$ ):
a. Menos de 1 año ()
b. Entre 1 y 4 años ()
c. Más de 4 años ()
d.

14. El área del cultivo sembrada (en ha) es de:
a. $0-1$ has
b. 1-5 has
c. 5-10 has
d. De 10-20 has
e. Superior a 20 has
( )
()

( )

( )

15. El área cosechada del cultivo (en ha) es de:
a. $0-1$ has
b. $1-5$ has
c. $5-10$ has
d. De 10-20 has
( )
e. Superior a 20 has
( )

( )

( )

16. La producción (ton/ha ciclo) del cultivo es:
a. $0-1$ ton
b. 1-5 ton
c. $5-10$ ton
d. De 10-20 ton
e. Superior a 20 ton

( )

17. ¿Cuál es la periodicidad de la producción de papa en su parcela? 

a. De 0-1 mes
b. De 1-3 meses
c. De 3-6 meses
d. De 6 meses a un año
e. Otro ()

18. Para la caracterización del suelo de su unidad productiva utiliza:
a. Análisis de suelo
b. Ninguna
( )

( )

19. ¿Cada cuánto tiempo realiza la caracterización del suelo en su unidad productiva?
a. Cada 1-3 años
b. Cada 3-5 años
( )
c. Cada 5-10 años
d. No realiza

( )

20. El tipo de suelo de su unidad productiva es:
a. Suelo arenoso
b. Suelo limoso
c. Suelo arcilloso
d. Suelo franco arenoso
e. Otro. ¿Cuál?

21. ¿Cuáles son los criterios mediante los cuales fertiliza?
a. Análisis de suelos
b. Ciclos ya estandarizados ()
c. Situación climática
d. A juicio del cultivador
e. Otro. ¿Cuál?

22. ¿Cuáles son los criterios del uso de agroquímicos?

a. Experiencia 

b. A calendario
c. Incidencia y severidad
( )
d. Por evaluación agronómica
e. Cuidado y preservación ambiental
f. Otro. ¿Cuál?

23. ¿Cuáles son los productos más utilizados para el control de plagas y enfermedades en el cultivo?
a. Fungicidas
b. Herbicidas
c. Insecticidas
()
d. Nematicidas
e. Control orgánico

f. Otro. ¿Cuál?

24. ¿Cuáles son los fertilizantes más utilizados para las etapas de crecimiento, desarrollo y producción en el cultivo?
a. Fertilizantes químicos
b. Fertilizantes de origen orgánico
c. Otro. ¿Cuál?

25. ¿Utiliza en su cultivo productos orgánicos?
a. Sí
( ) ¿Cuál?

b. No ( )

26. ¿Qué tipo de agua utiliza en su cultivo?
a. Agua lluvia
b. Agua de acueducto
c. Agua propia
d. Reservorios
e. Distrito de riego
f. Otro. ¿Cuál?

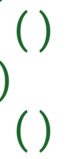


27. ¿Qué tipo de riego utiliza en su cultivo?
a. Por goteo
b. Por aspersión ( )
c. Por gravedad ()
d. Otro. ¿Cuál?

28. ¿Tiene mecanismos implementados para el manejo de aguas residuales de origen agrícola?
a. Sí
( ) ¿Cuál?
b. No
( )

29. ¿Tiene mecanismos implementados para el manejo de cuencas?
a. Sí
( ) ¿Cuál?
b. No
( )

30. ¿Cuál es el uso dado a los envases de agroquímicos utilizados en las prácticas de cultivo?
a. Reutilizados
b. Reciclados
c. Desechados dentro del cultivo
d. Incinerados
e. Otro. ¿Cuál?

II. Entorno ocupacional

31. ¿Cuál es el tiempo en horas a la semana destinado por el productor en la unidad productiva?
a. 5-10 horas
b. 11-15 horas
c. $16-20$ horas
d. Otro. ¿Cuál?

( ) 
32. ¿Qué otro tipo de actividad laboral realiza el productor?
a. Comerciante
b. Agricultor
c. Profesional dependiente
d. Profesional independiente
e. Otro. ¿Cuál?

( )

33. ¿Cuál es el porcentaje de ingresos aportados por la unidad aqrícola?

a. Del $1 \%$ al $25 \%$

b. Del $26 \%$ al $50 \%$

c. Del $51 \%$ al $75 \%$

d. Del $76 \%$ al $100 \%$

34. ¿Cuál es el porcentaje de ingresos aportados por otras actividades laborales?

a. Del $1 \%$ al $25 \%$

b. Del $26 \%$ al $50 \%$

c. Del $51 \%$ al $75 \%$

d. Del $76 \%$ al $100 \%$

35. Escolaridad del productor:
a. Primaria
b. Secundaria
c. Técnico
d. Tecnólogo
e. Profesional
f. Posgrado
g. Ninguno

36. ¿Tiene empleados en su cultivo?
a. Sí
b. No
()
() 
37. El número de trabajadores de la unidad productiva, incluyendo todas las sedes, es (señale con una $\mathrm{x}$ ):
a. 1-2 trabajadores
b. 3-5 trabajadores
c. 6-10 trabajadores
d. Superior a 11 trabajadores

( )

( )

( )

( )

38. ¿Qué tipo de vinculación tiene para la mayoría de los empleados en su cultivo?

a. Tiempo completo

b. Medio tiempo

c. Prestación de servicios

d. Por jornal

e. Otro. ¿Cuál?

39. Diligencie el siguiente cuadro indicando frente a cada uno de los procesos misionales su nivel educativo, sus principales funciones y el número de trabajadores, según sean permanentes 0 temporales: 


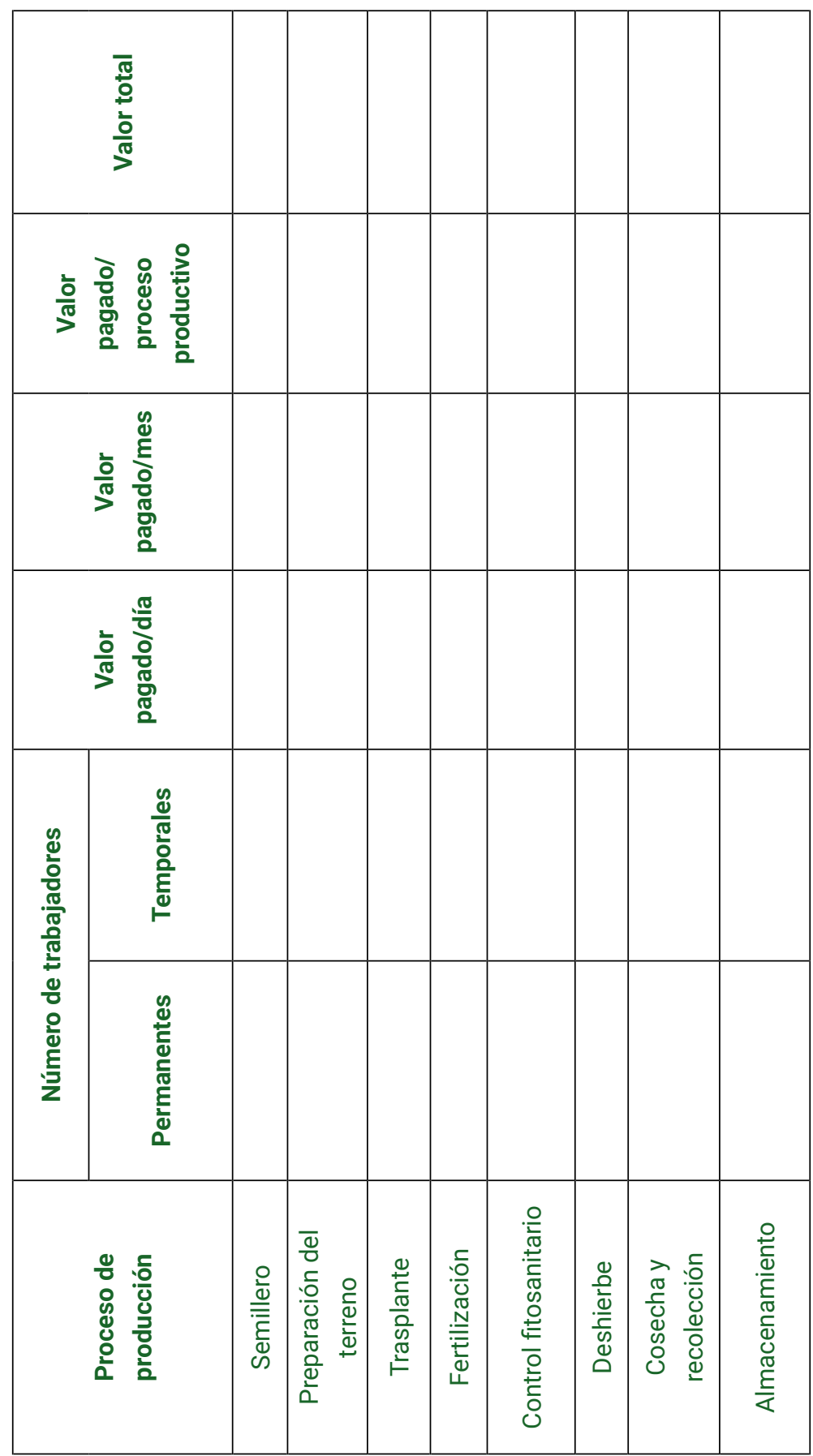



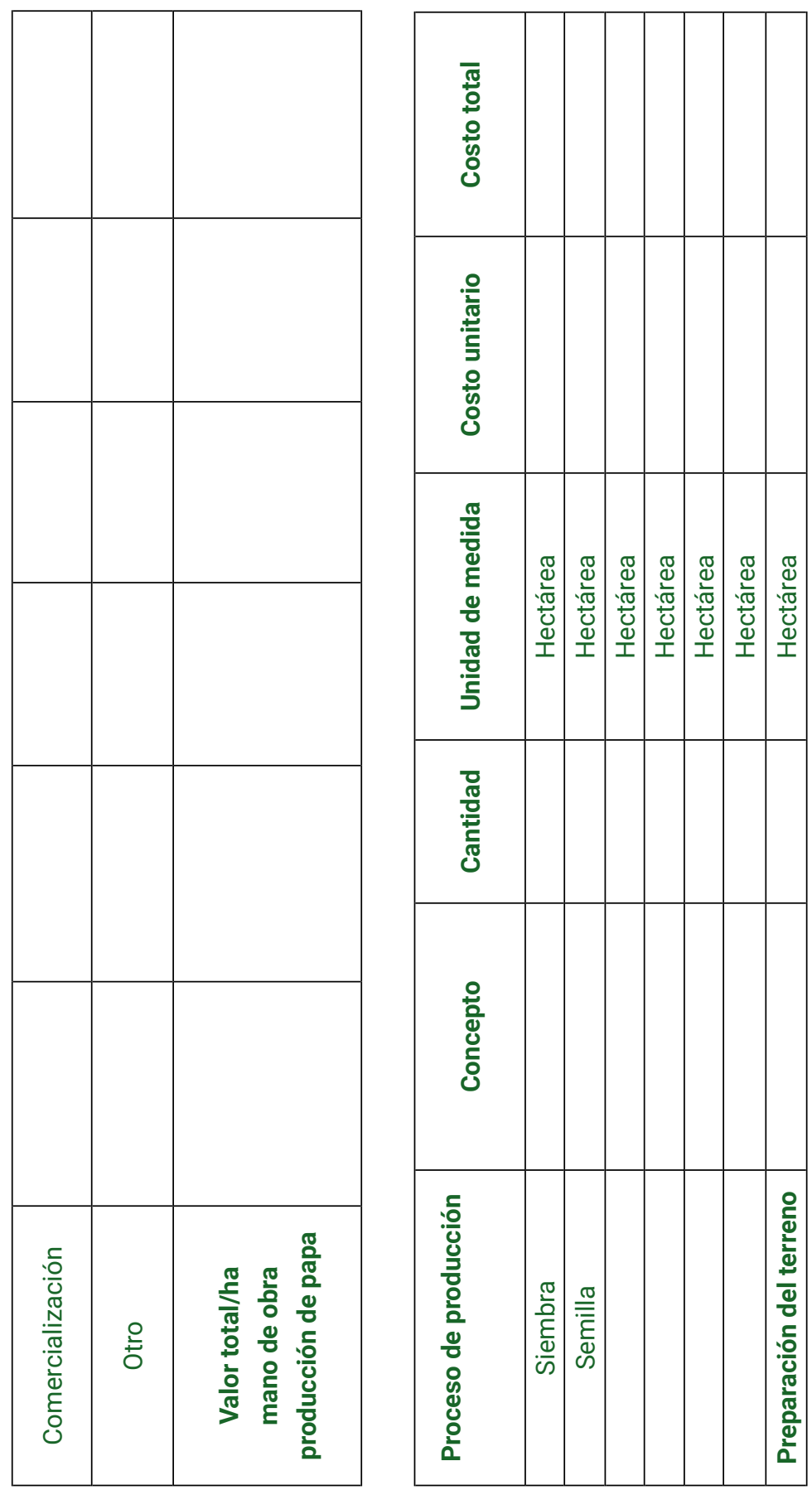


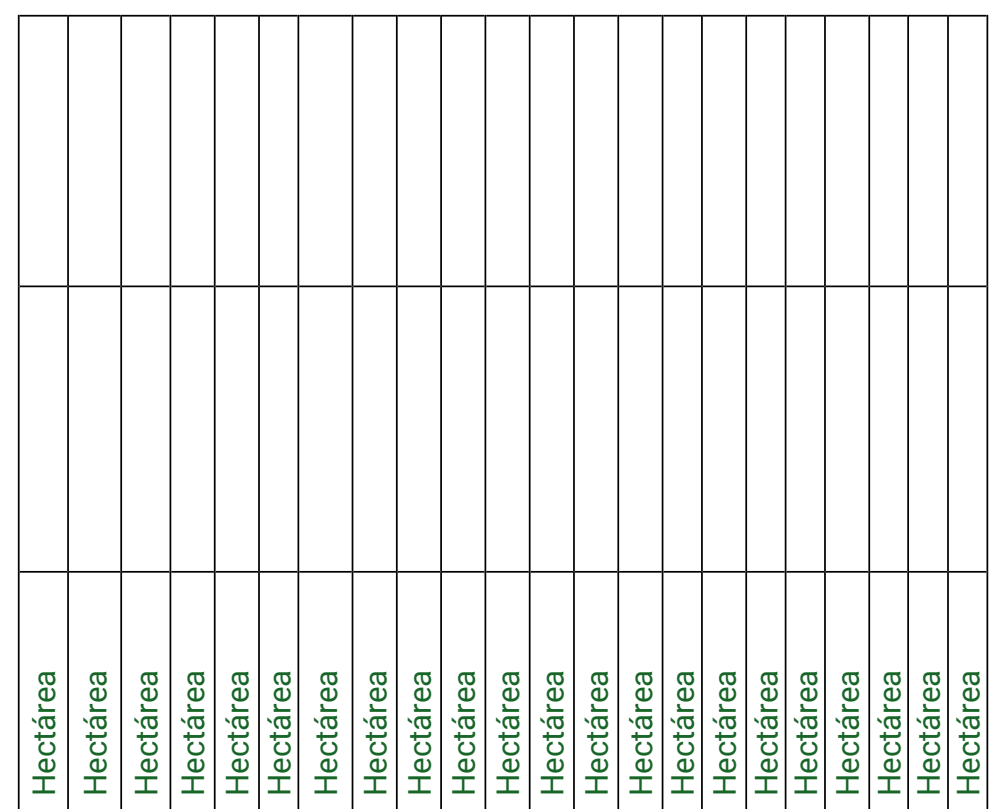

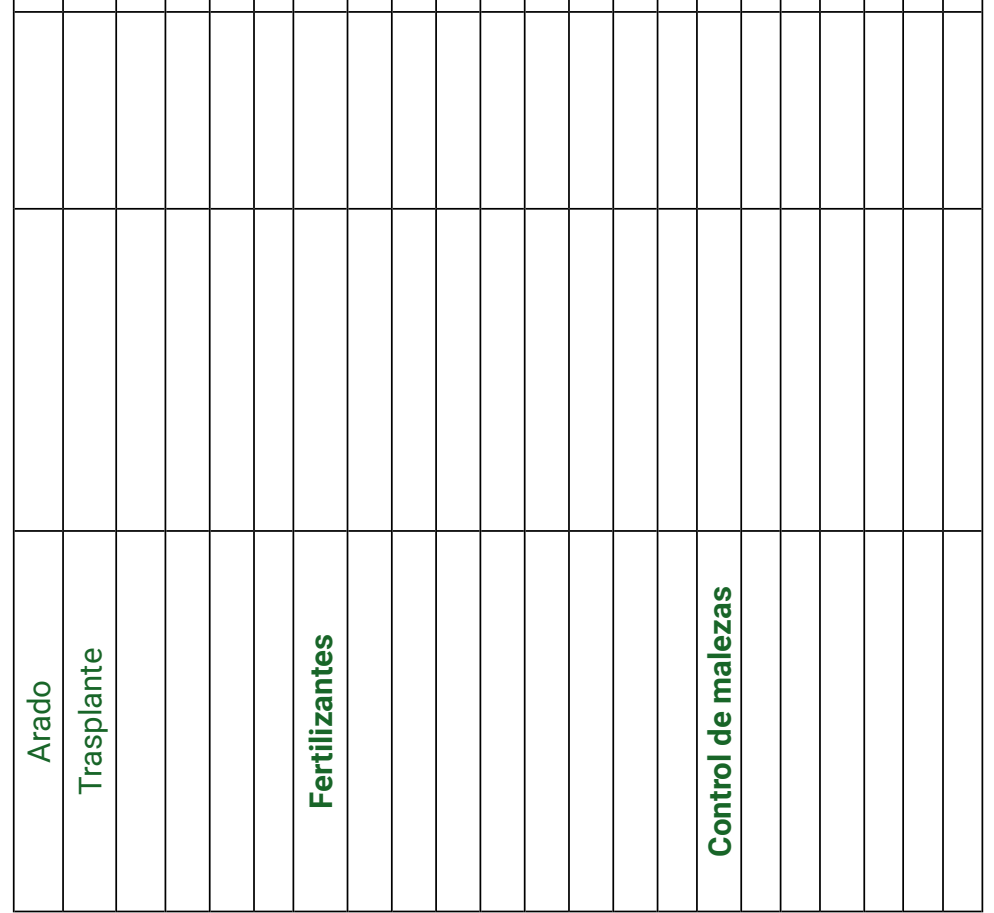




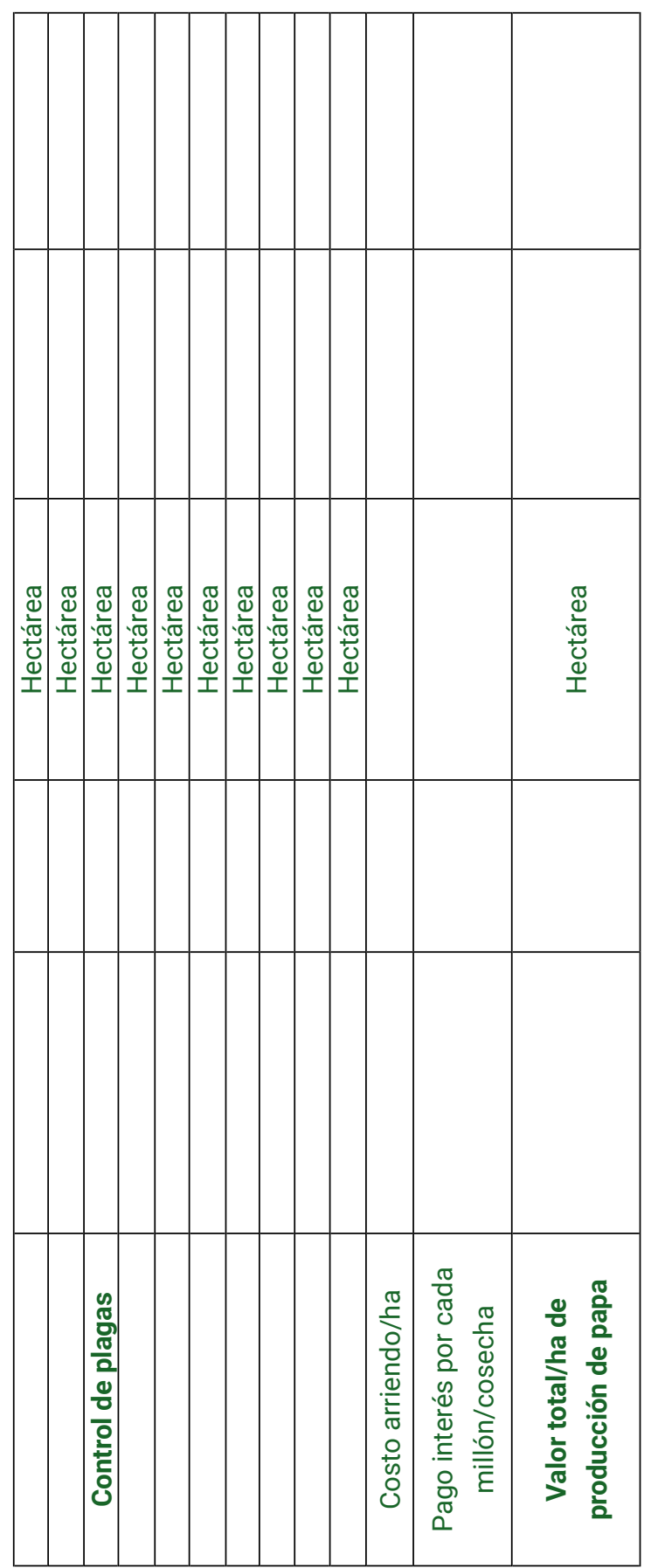


40. Si el terreno es propio, ¿sabe usted cuál es el costo de arriendo de una hectárea de tierra en su vereda o región?

41. Total costo por hectárea (39 y 40):

42. Si usted usa crédito, ¿qué entidad o particular le presta dinero? ¿A qué interés? $\%$

43. ¿Cuáles son los gastos promedio mensuales en el sostenimiento de su hogar?

a. Luz/mes:

b. Agua/mes:

c. Gas/mes:

d. Mercado/mes:

e. Otro. ¿Cuál? Valor /mes:

Total:

44. ¿Qué nivel educativo tienen los trabajadores vinculados en su proceso productivo?
a. Primaria
b. Secundaria
c. Técnico
d. Tecnólogo
e. Profesional
()
f. Posgrado
g. Ninguno 
45. ¿Está capacitado el personal del cultivo para realizar las actividades?
a. Todos
b. La gran mayoría ()
c. Algunos
d. Ninguno

46. La capacitación del personal es:

a. Dada en el cultivo por otros trabajadores ( )

b. Dada en el cultivo por el productor ( )

c. Se contratan capacitadores

d. Otro. ¿Cuál?

47. ¿En qué actividades considera que se requiere capacitación?
a. Producción ()
b. Mercadeo ()
c. Fluctuación de precios
d. Poscosecha ()
e. Financiamiento ()
f. Otro. ¿Cuál?

\section{III.Visión empresarial}

48. ¿Tiene proyecciones de ampliar el volumen de producción en su cultivo?
a. Sí
b. No
c. ¿En qué área?

49. ¿Cuáles considera que son las prioridades 
estratégicas con miras a mejorar la competitividad?

a. Minimizar el uso de agroquímicos

b. Aumentar la productividad de los empleados mediante reconocimientos, incentivos o bonificaciones

c. Conformar formas asociativas

d. Realizar préstamos para aumentar el volumen de producción

e. Invertir en investigación y desarrollo

f. Realizar transformación del producto

g. Otro. ¿Cuál?

50. ¿Qué tipo de transformación le gustaría realizar en su producto?

a. Transformación del producto

b. Transformación del proceso productivo

c. Nuevas formas de presentación del producto

d. No visualiza ninguna 

c. Facilitar infraestructura y dotar de equipos ( )
d. Dotarlo de un seguro de cosecha ()
e. Otro ( )

53. ¿Cuál cree usted que son los principales factores que afectan el producto en materia de competitividad?
a. Baja productividad
b. Mercados limitados
()
()
c. Tasa de cambio
d. Producción limpia
e. Baja o nula transformación
f. Baja calidad del producto
g. Falta de agremiación
h. Precio de los insumos agrícolas ( )
i. Falta de agua
j. Importación del producto
k. Bajos volúmenes de producción
I. Otro. ¿Cuál?

54. ¿Lleva registros contables de su actividad agrícola?
a. Sí
b. No
( ) ¿Por qué?

\section{5. ¿Aproximadamente a cuánto ascienden las} ventas por ciclo de producción en su cultivo/ha?

a. Entre $\$ 100.000-\$ 5.000 .000$

b. Entre $\$ 5.000 .000-\$ 10.000 .000$

c. Entre $\$ 10.000 .000-\$ 20.000 .000$

d. Más de $\$ 20.000 .000$ ¿Cuánto? 
56. ¿De cuánto es el costo de producción en su cultivo?

a. Por planta:

b. Por ha/ciclo productivo:

57. ¿Aproximadamente a cuánto ascienden los costos por ha/ciclo productivo en su cultivo?

a. Entre $\$ 1.000 .000-\$ 4.000 .000$

b. Entre $\$ 4.000 .000-\$ 6.000 .000$

c. Entre $\$ 6.000 .000-\$ 10.000 .000$

d. Más de $\$ 10.000 .000$ ¿Cuánto?

58. ¿Cuál es la frecuencia de siembra del cultivo de papa en su unidad productiva?
a. Bimestral
b. Trimestral
c. Semestral
d. Anual
e. Otro

59. ¿Cuáles son los criterios en los que se basa para manejar distintos precios de venta?
a. Venta al por mayor - Plaza
b. Cercanía a centros de consumo
c. Forma de pago
d. Pago anticipado
e. Pago diferido
f. Otro. ¿Cuál? 
60. ¿A qué mercado están dirigidos los productos que desarrolla su unidad productiva?
a. Local
b. Nacional
c. Internacional

61. ¿A quién le vende su producto con mayor frecuencia?

a. Plaza de mercado local/nacional ()

b. Cadenas de supermercados o instituciones públicas/privadas

c. Intermediarios satélites

d. Empresas transformadoras

e. Otro. ¿Cuál?

62. ¿Dónde comercializa el producto?
a. En el predio
b. En el mercado del pueblo
c. En plazas nacionales
d. En mercados internacionales
e. Otro. ¿Cuál?

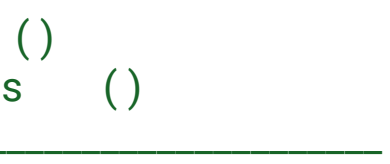

63. ¿Conoce los procesos o requerimientos para poder exportar papa?
a. Sí
b. No

64. ¿Comercializa su producto en el mercado internacional?
a. Sí
( )
b. No 
65. Si comercializa en el mercado internacional, especifique en cuáles regiones:

a. Comunidad Andina de Naciones (CAN) ()

b. Mercosur

c. Centroamérica y el Caribe

d. EE. UU. y Canadá

e. Unión Europea

f. Asia

g. África

h. Oceanía

i. Otro. ¿Cuál?

66. El acceso a los mercados internacionales le implica (seleccione máximo 5 opciones y clasifíquelas, teniendo en cuenta que cinco es la mayor puntuación y uno la menor):

a. Eliminar barreras fitosanitarias

b. Producción limpia

c. Transformar el producto

d. Producir grandes volúmenes

e. Producir en cualquier temporada

f. Mayor velocidad de innovación

g. Reducción de los costos de producción

h. Ampliar infraestructura física

i. Capacitación del recurso humano

j. Gestión del talento humano

k. Actualización y renovación tecnológica

1. Vincular especialistas para los procesos misionales

m. Mejorar y ampliar el portafolio de productos ( )

n. Certificar competencias laborales

o. Incorporar procesos logísticos relacionados con almacenamiento, transporte y distribución 
de los productos

p. Otro. ¿Cuál?

67. La variación de los precios de ventas en el año es:

a. Alta (los precios presentaron cambios sustanciales en los diferentes meses)

b. Normal (similar a años anteriores con precios bajos y altos según los meses)

c. Baja (los precios permanecieron estables independientemente de los meses)

68. Con su conocimiento y experiencia, ¿cuál es la oferta del producto por mes?

\begin{tabular}{|l|l|l|l|l|}
\hline & Alta & Media & Baja & $\begin{array}{c}\text { Oferta en } \\
\text { toneladas/ha }\end{array}$ \\
\hline Enero & & & & \\
\hline Febrero & & & & \\
\hline Marzo & & & & \\
\hline Abril & & & & \\
\hline Mayo & & & & \\
\hline Junio & & & & \\
\hline Julio & & & & \\
\hline Agosto & & & & \\
\hline Septiembre & & & & \\
\hline Octubre & & & & \\
\hline Noviembre & & & & \\
\hline Diciembre & & & & \\
\hline
\end{tabular}

69. ¿Pertenece su unidad productiva a una asociación o cadena productiva reconocida? 

a. Sí
( )
b. No
Si su respuesta es "sí", indique cuál:

\section{IV.Estructura tecnológica e innovación}

70. ¿Su unidad productiva cuenta con el servicio de asistencia técnica agrícola?
a. Sí
( )
b. No

71. ¿La asistencia técnica agrícola ayuda a mejorar la producción de mi unidad productiva?
a. Sí
( )
b. No
( )

72. ¿Su empresa ha sido certificada por sistemas de gestión de calidad?
a. Sí
()
b. No
Si la respuesta es "sí", indique cuáles normas:

73. ¿Han llevado a cabo procesos de certificación del recurso humano por competencias laborales?
a. Sí
b. No
Si la respuesta es "sí", indique cuáles normas: 
74. ¿Dispone su unidad productiva de marcas propias?
a. Sí
b. No
Si la respuesta es "si", indique cuáles:

75. ¿Realiza su unidad productiva actividades de investigación y desarrollo tecnológico?
a. Sí
b. No
Si la respuesta es "sí", ¿a qué se enfoca esta investigación?

76. ¿En el último año se ha introducido en la empresa o unidad productiva alguna innovación en producto 0 proceso?
a. Sí
()
b. No
()

Si la respuesta es "sí", indique cuáles productos o procesos:

78. ¿En su unidad productiva se ha establecido alguna práctica para contrarrestar la volatilidad de precios del cultivo?
a. Sí
b. No
( ) 
Si su respuesta es "sí", indique cuál:

79. ¿En su gremio se han diseñado nuevas políticas de apoyo a los productores para promover la seguridad alimentaria?
a. Sí
b. No
Si su respuesta es "sí", indique cuáles:

80. Considera que los rendimientos de su cultivo se han visto afectados en los últimos 20 años por:

a. El cambio climático

b. La erosión de los suelos

c. La fatiga de los suelos

d. Presencia de hongos, nematodos y otros

e. La urbanización acelerada de los terrenos aptos para agricultura

f. Otro. ¿Cuál?
( )

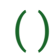

()

( )

81. ¿En la unidad productiva se han desarrollado acciones para la adaptación al cambio climático?
a. Sí
b. No

Si su respuesta es "sí", indique cuáles: 
82. ¿Qué estrategia considera importante implementar para mejorar la competitividad de la papa?

a. Construir centros de acopio locales o regionales ()

b. Asociarse con otros productores

c. Diversificar las variedades

d. Implementar proyectos de transformación del producto

e. Mejorar la infraestructura productiva

f. Incursionar en nuevos mercados

g. Otro. ¿Cuál? 


\section{Anexo 2. Tabulación encuesta de caracterización - Papa}

\section{El cultivo es:}

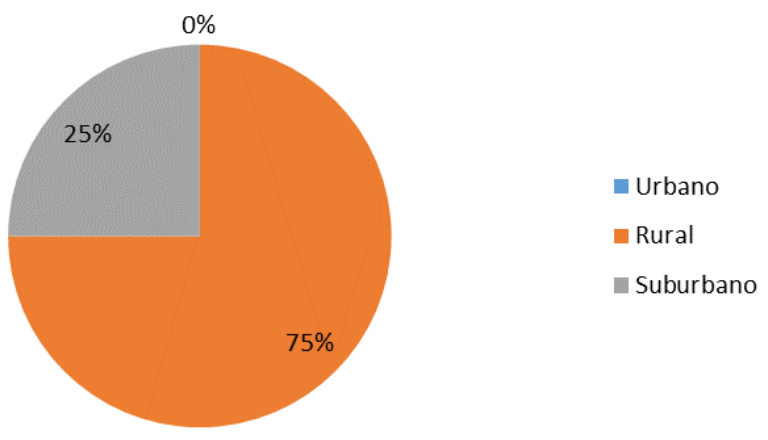

\section{El tiempo de conformación de la unidad productiva es de:}

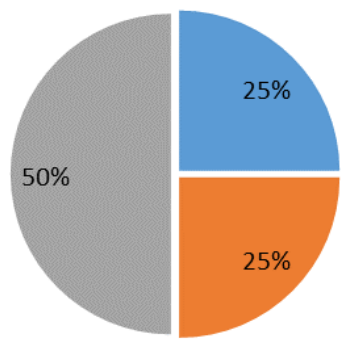

- Menos 1 año

- Entre 1 y 4 años

Mas de 4 años 
El área (ha) del cultivo sembrada es

de:

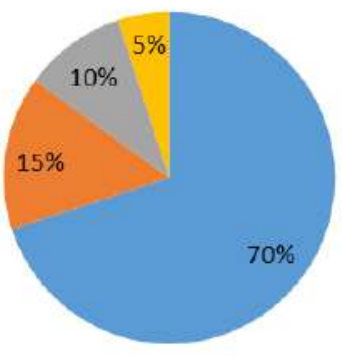

- De 0 a $1 \mathrm{Ha}$

- De 1 a $5 \mathrm{Ha}$

- De 5 a $10 \mathrm{Ha}$

$=$ De 10 a $20 \mathrm{Ha}$

El área (ha) cosechada del cultivo es de:

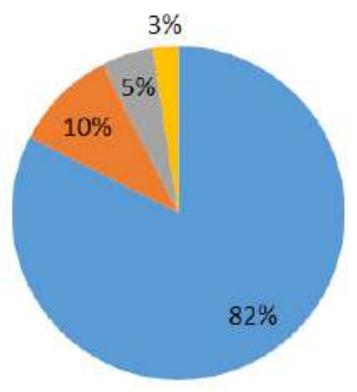

= 0 a 5 ha

= 6 a 10 ha

a 11 a 20 ha

= Sup a 21

¿Cuál es la periodicidad de la producción de papa en su parcela?

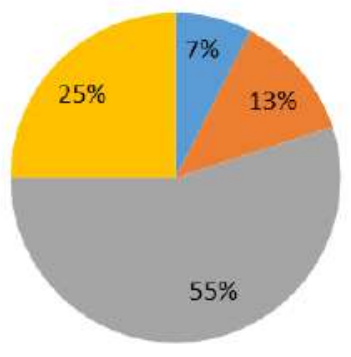




\section{Caracterización del suelo de su unidad productiva:}

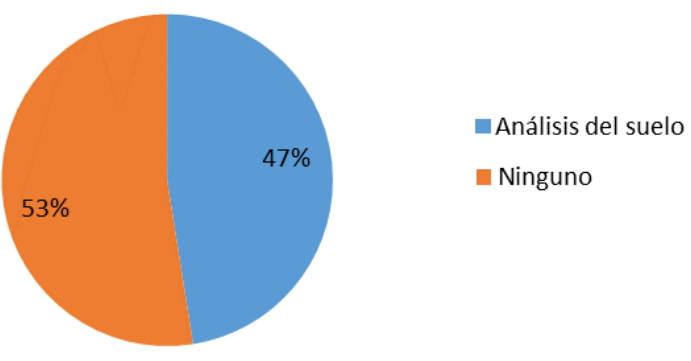

\section{¿Cada cuánto tiempo realiza la} caracterización del suelo en su unidad productiva?

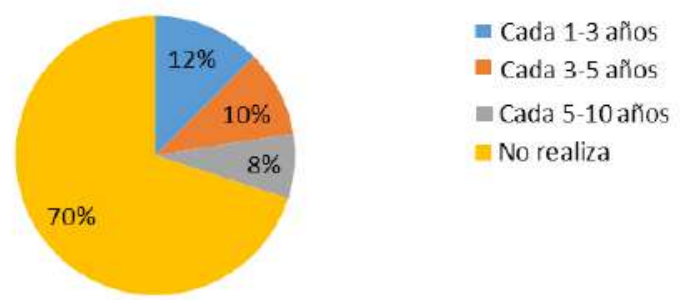

\section{El tipo de suelo de su unidad productiva es:}

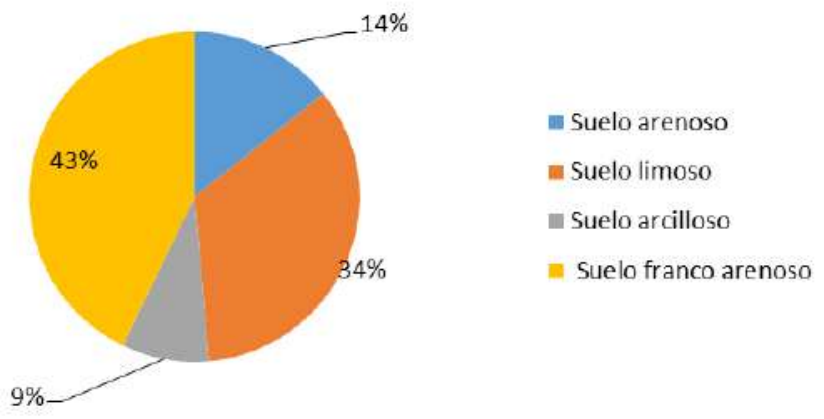




\title{
¿Cuáles son los criterios mediante los cuales usted fertiliza?
}

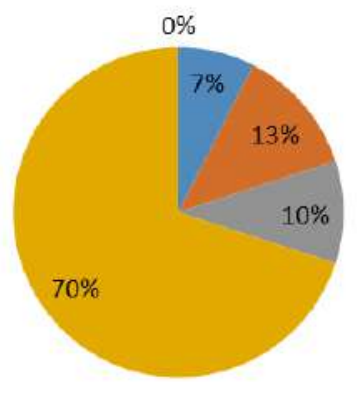

\author{
- Análisis del suelo \\ - Situación climática \\ a Ciclos estandarizados \\ a juicio del cultivador \\ motro
}

\section{¿Cuáles son los criterios de uso de} agroquímicos?

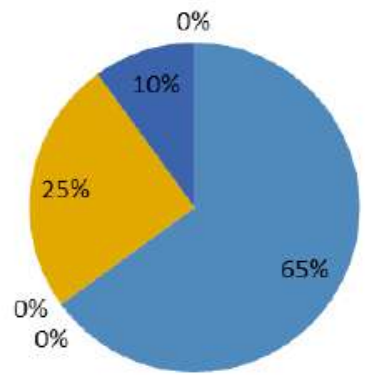

$$
\begin{aligned}
& \text { Experiencia } \\
& \text { A calendario } \\
& \text { — Incidencia y severidad } \\
& \text {-Por evaluación agronómica } \\
& \text {-Preservación ambiental } \\
& \text { =Otro }
\end{aligned}
$$

\section{¿Cuáles son los productos más} utilizados para el control de plagas y enfermedades en el cultivo?
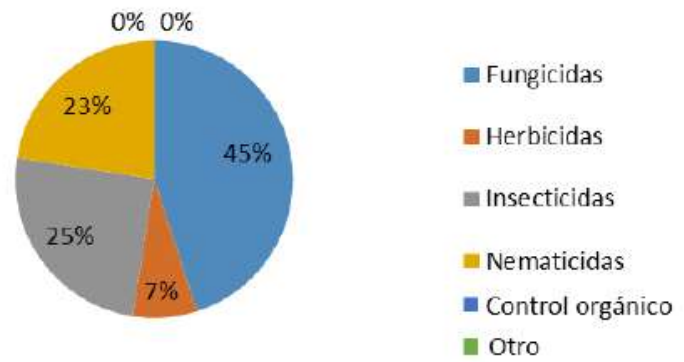
¿Cuáles son los fertilizantes más utilizados para las etapas de crecimiento, desarrollo y producción del cultivo?

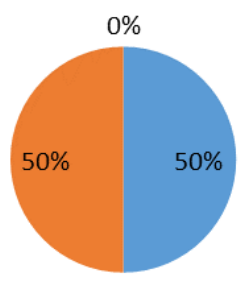

- Fertilizantes químicos

Fertilizantes de origen orgánico

n Otro

\section{¿Utiliza en su cultivo productos} orgánicos?

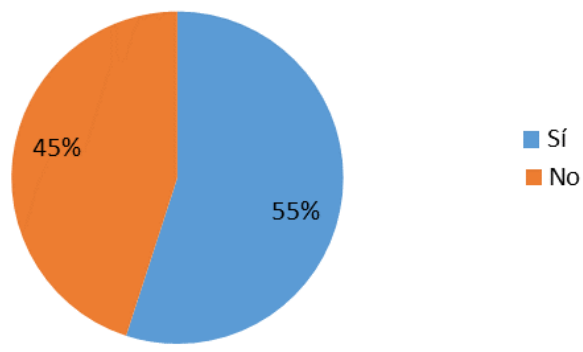

¿Qué tipo de riego utiliza en su cultivo diferente a agua lluvia?

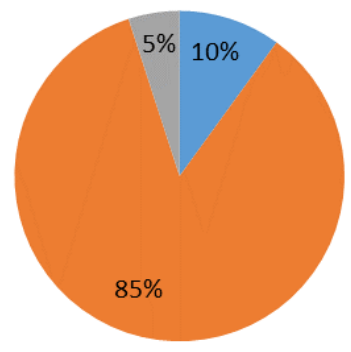

- Distritos de Riego

neservorios

Acueductos 
¿Qué sistema de riego utiliza en su

\section{cultivo?}

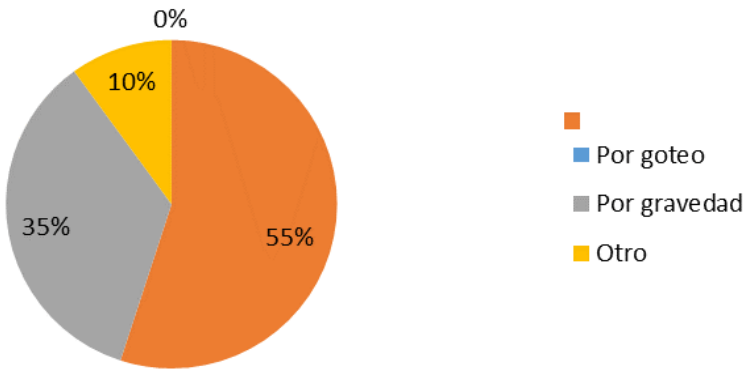

¿Tiene mecanismos implementados para el manejo de aguas residuales de origen agrícola?

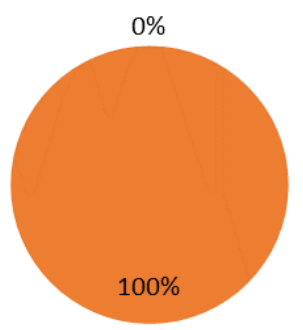

¿Tiene mecanismos implementados para el manejo de cuencas hidrográficas?

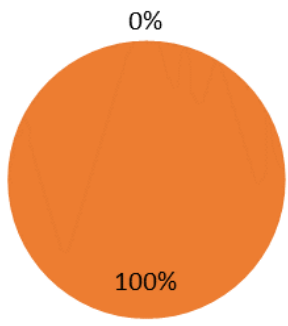


¿Cuál es el uso dado a los envases de agroquímicos utilizados en las prácticas de cultivo?

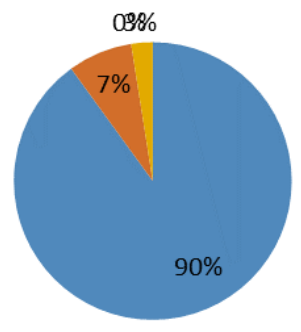

Reciclados

- Desechados dentro del cultivo

- Incinerados

Otro

¿Cuál es el tiempo en horas a la semana destinado por el productor en la unidad productiva?

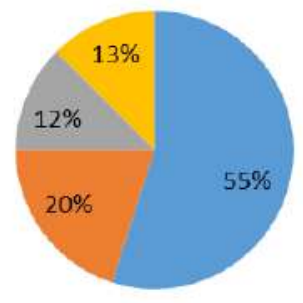

5 a 10 horas

11 a 15 horas

16 a 20 horas

atra

¿Qué otro tipo de actividad laboral realiza el productor?

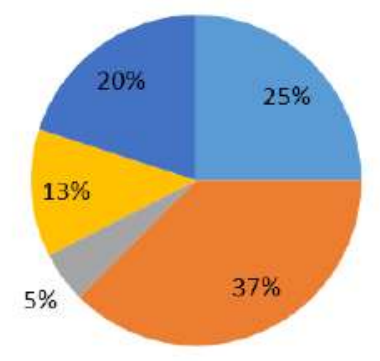

E Comerciante

- Jornalero agrícola

- Profesional dependiente

- Profesional independiente - Otras 
¿Cuál es el porcentaje de ingresos aportados por la unidad agricola?

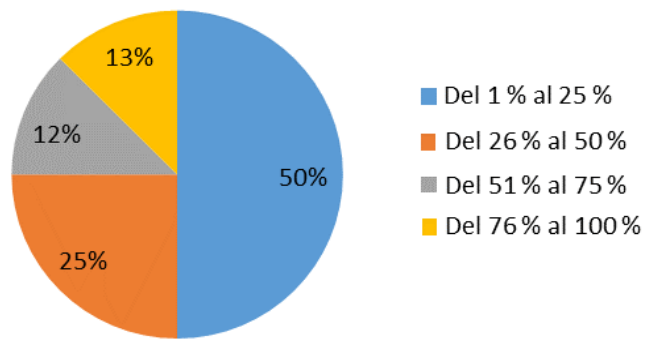

¿Cuál es el porcentaje de ingresos aportados por otras actividades laborales?

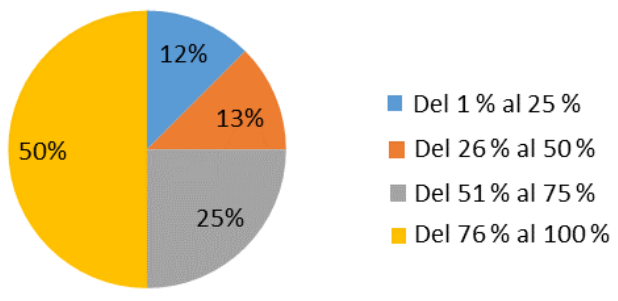

Nivel educativo de los productores:

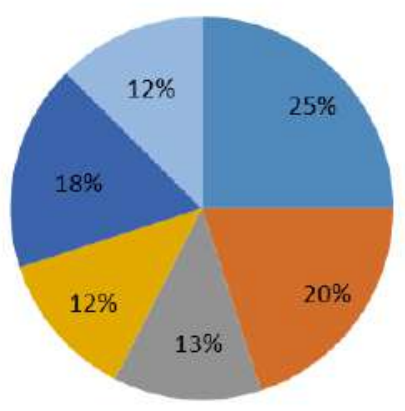

$$
\begin{aligned}
& \text { ne Primaria } \\
& \text { 포 Secundaria } \\
& \text { wécnico } \\
& \text { - Tecnólogo } \\
& \text { - Profesional } \\
& \text { - Posgrado } \\
& \text { = Ninguna }
\end{aligned}
$$


¿Tiene empleados en su cultivo?

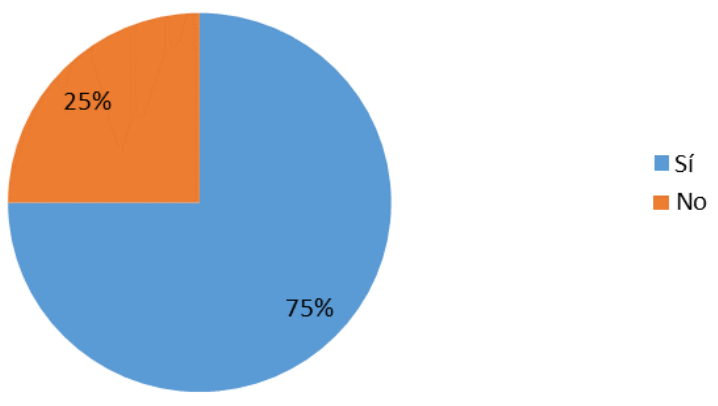

El número de trabajadores de la unidad productiva, incluyendo todas las sedes, es:

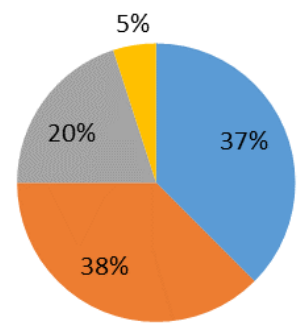

- De 1 a 2

- De 3 a 5

De 6 a 10

Superior a 11

¿Qué tipo de vinculación tiene para la mayoría de empleados de su cultivo?

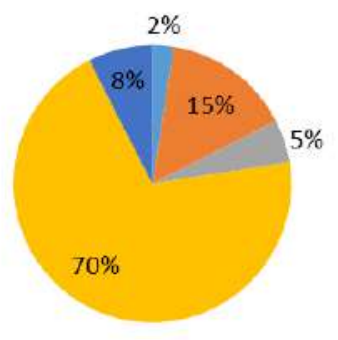

$$
\begin{aligned}
& =\text { Tiempo completo } \\
& =\text { Medio tiempo } \\
& =\text { Por jornal } \\
& =\text { Prestación de servicios } \\
& =\text { Otro }
\end{aligned}
$$




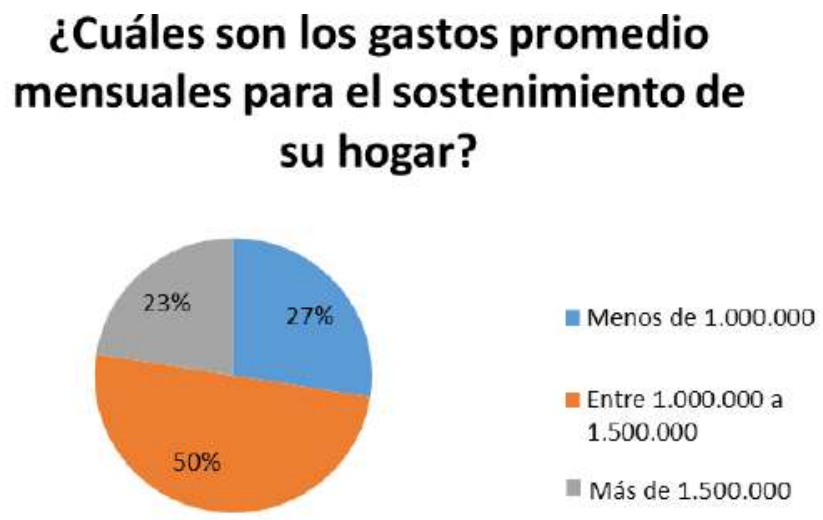

¿Qué nivel educativo tienen los trabajadores vinculados en su proceso productivo?

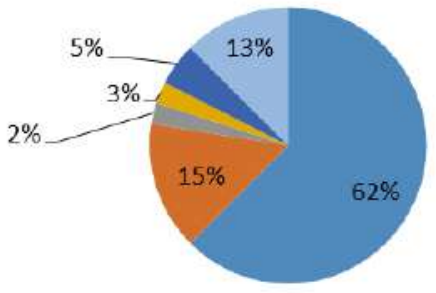

Erimaria

- Secundaria

¿Está capacitado el personal de cultivo para realizar las actividades?

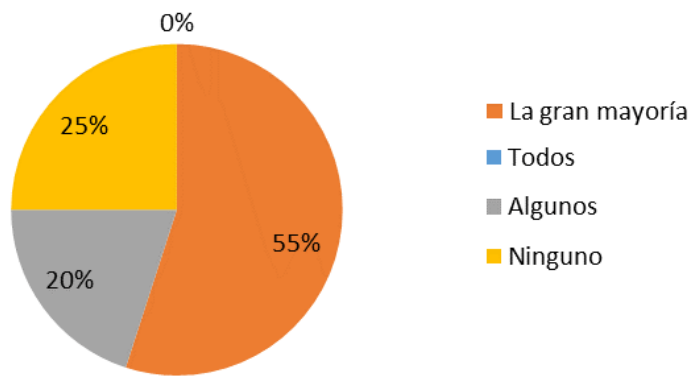




\section{La capacitación del personal es:}

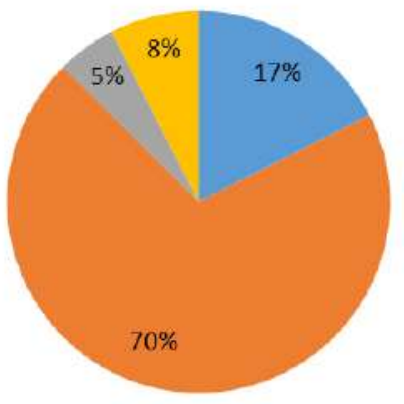

\section{- Dada en el cultivo por} otros trabajadores

= Dada en el cultivo por el productor

- Se contratan capacitadores

In Otro

\section{¿En qué actividades considera que se requiere capacitación?}

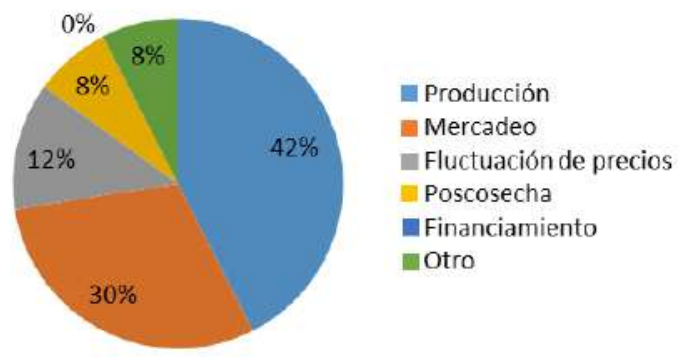

¿Tiene proyecciones de ampliar el volumen de producción en su cultivo?

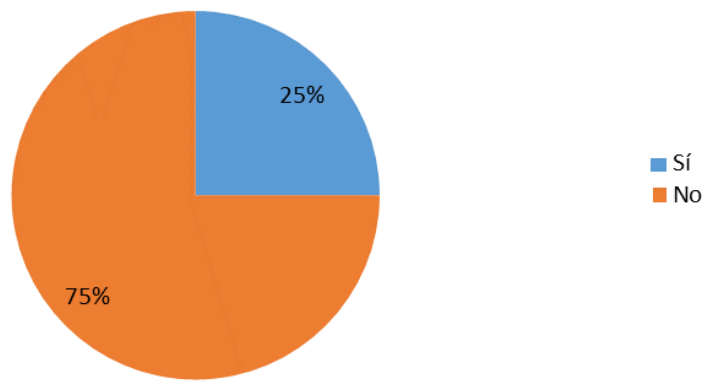


¿Cuáles considera que son las prioridades estratégicas con miras a mejorar la competitividad?

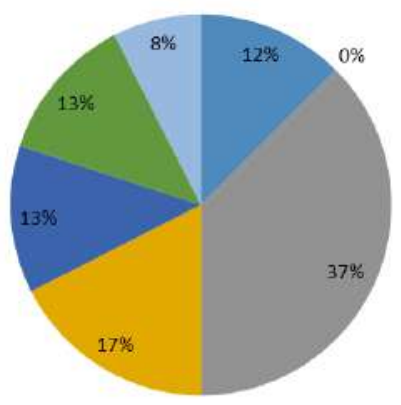

- Minimizar el precio de agroquímicos

= Aumentar productividad de los empleados mediante reconocimientos

in Conformar formas asociativas

inealizar préstamos para aumentar el volumen de producción

Envertir en investgación y desarrollo

ERealizar transformación de producto

Eotro

\section{¿Recibe incentivos del gobierno para desarrollar esta actividad?}

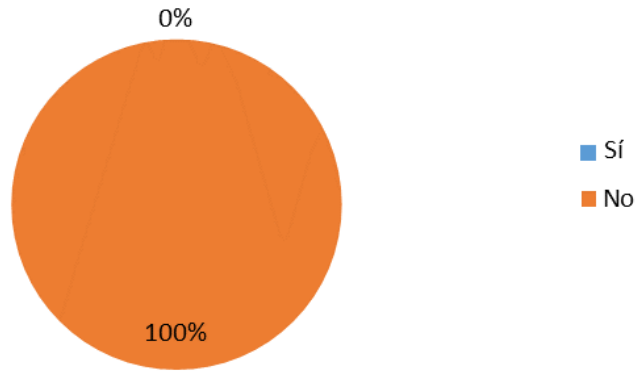

¿Qué tipo de transformación requiere para mejorar su competitividad?

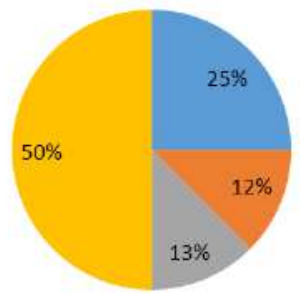

w Transformación del producto

- Transformación del proceso productivo

II Nuevas formas de presentación del producto

mo visualiza ninguna 
¿Qué incentivos considera usted que debería dar el gobierno para desarrollar mejor su actividad y mejorar su rentabilidad?

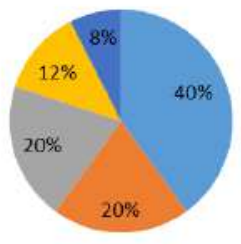

Disminución de precios de los agroquímicos - Prestar asesoría técnica

- Dotar de infraestructura y equipos

- Dotar de seguros de cosecha

= Otros

¿Cuál cree usted que son los principales factores que afectan el producto en materia de competitividad?

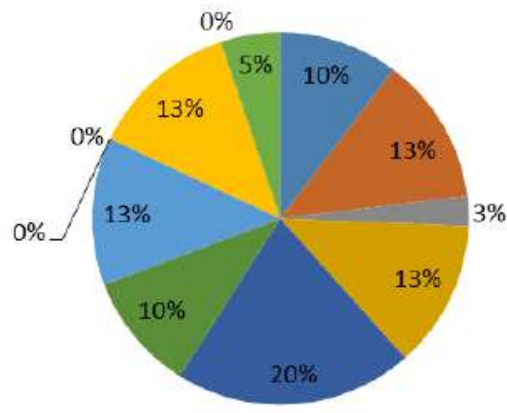

¿Lleva registros contables de su actividad agrícola?

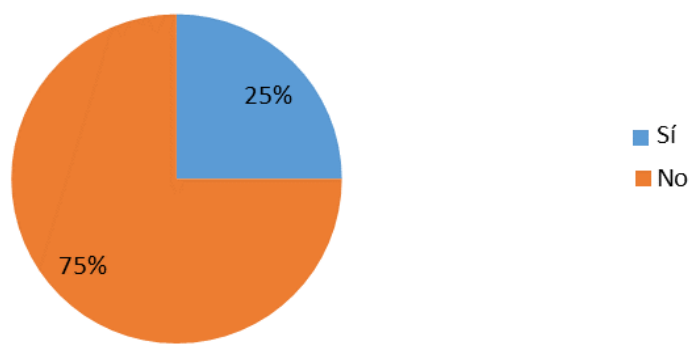


¿Aproximadamente a cuánto ascienden las ventas por ciclo de producción en su cultivo?
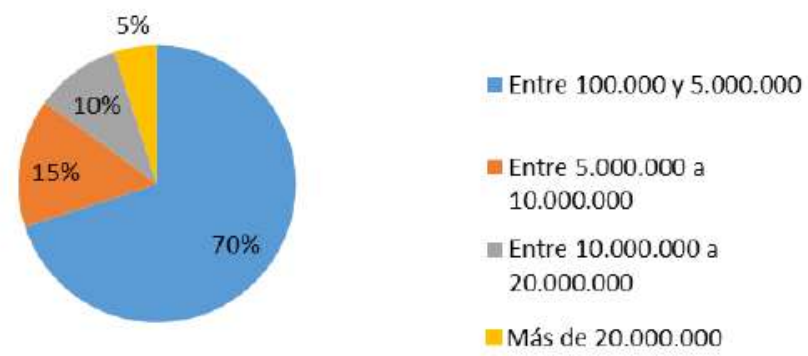

¿Cuánto es el costo de producción de su cultivo por ha?
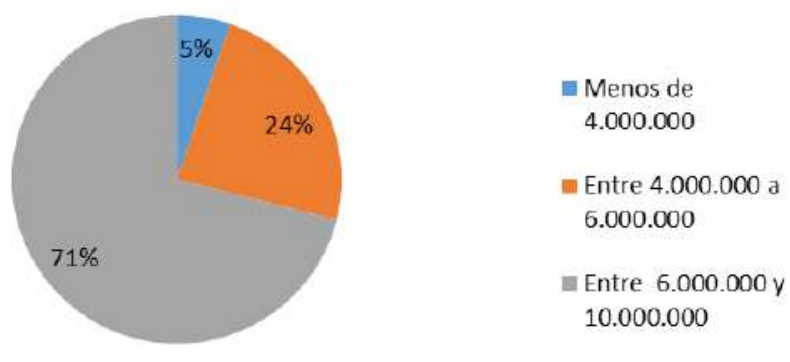

¿Cuál es la frecuencia de sembrado de papa en su unidad productiva?

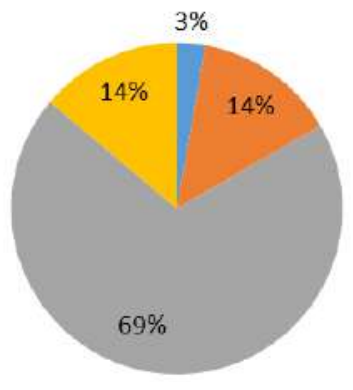

Eimestral

w Trimestral

nemestral

anual 
¿Cuáles son los criterios en los que se basa para manejar distintos precios de venta?

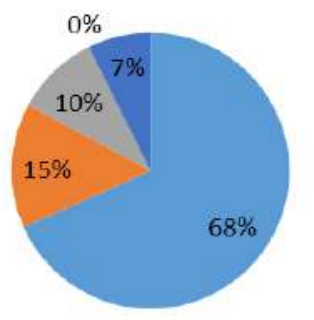

- Venta plaza al por mayor

- Cercanía a centros de consumo

narmas de pago

Otros

- Pago anticipado

¿A qué mercados están dirigidos los productos que desarrolla su unidad productiva?

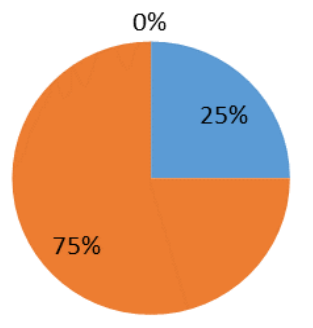

- Local

nacional

n Internacional

\section{¿A quién le vende su producto con más frecuencia?}

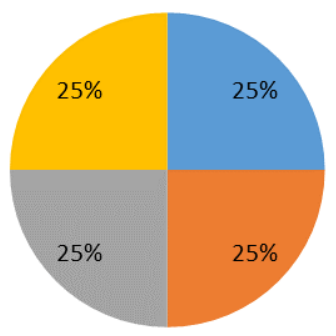

- Plaza de mercado local nacional

- Cadenas de supermercados o institucior públicas o privadas

- Intermediarios satélites

Empresas transformadoras 


\section{¿Dónde comercializa el producto?}

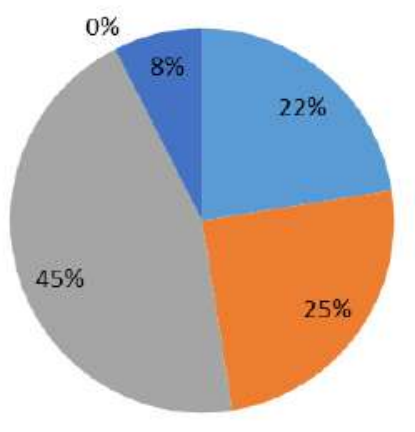

$$
\begin{aligned}
& \text { m En el predio } \\
& \text { = En el mercado del pueblo } \\
& \text { = Plazas nacionales } \\
& \text { = Mercados internacionales } \\
& \text { m Otros }
\end{aligned}
$$

\section{¿Conoce los procesos o} requerimientos para exportar papa?

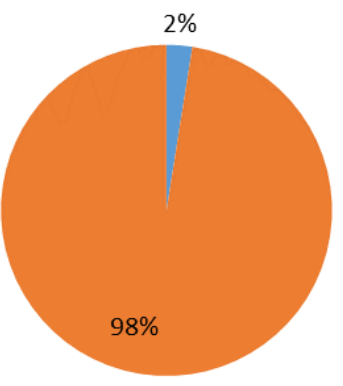
internacional?

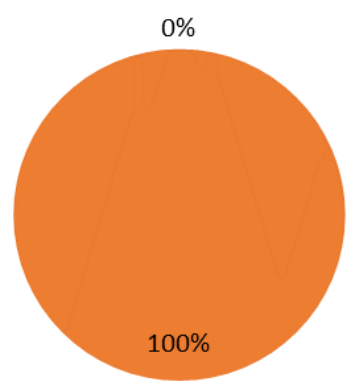


El acceso a los mercados internacionales implica:

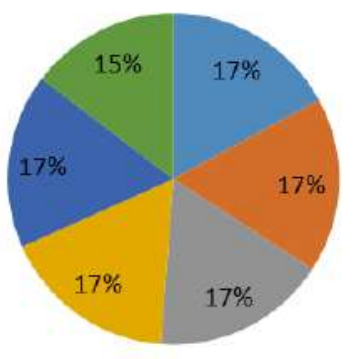

- Eliminar barreras fitosanitarias

Eroducción limpia

- Transformar el producto

- Producción grandes volúmenes

- Mayor innovación

- Ampliar portafolio de productos

La variación de precios de venta en el año es:

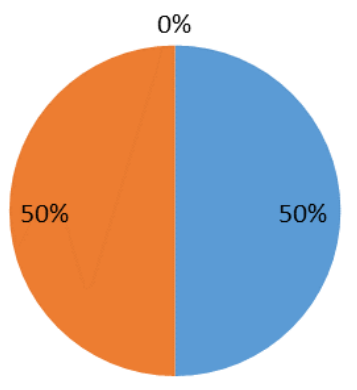

Alta

Normal

Вaja

\section{¿Pertenece su unidad productiva a una asociación o cadena productiva reconocida?}

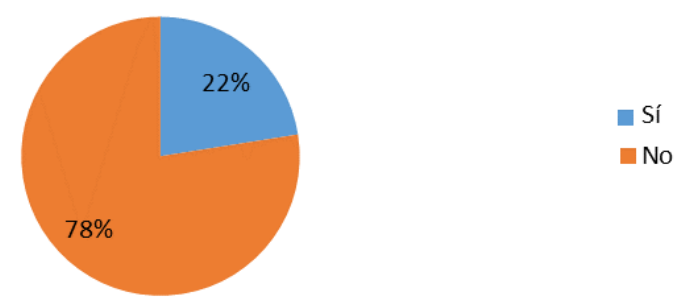


¿Su unidad productiva cuenta con el servicio de asistencia técnica agrícola?

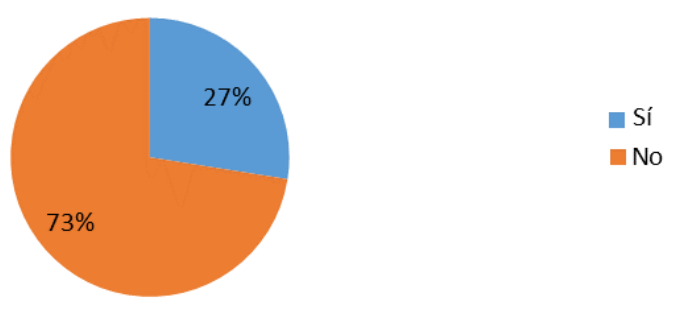

¿La asistencia técnica agrícola ayuda a mejorar la producción de mi unidad productiva?

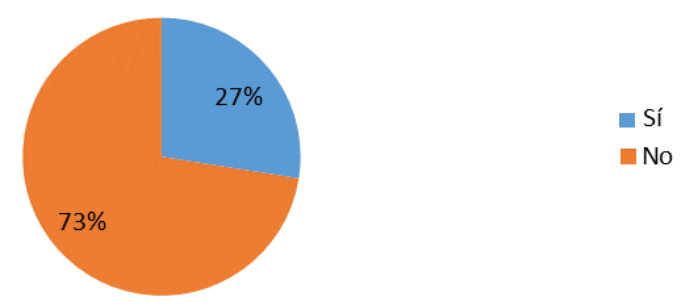

¿Su empresa ha sido certificada por sistemas de calidad?

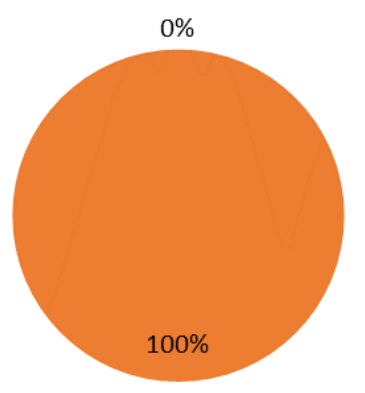




\section{¿Han llevado procesos de certificación del recurso humano por competencias laborales?}

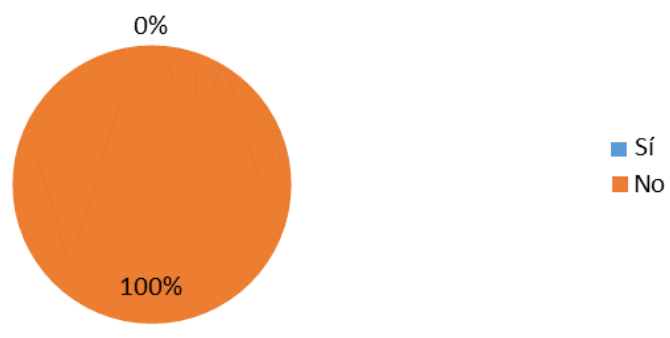

¿Dispone su unidad productiva de marcas propias?

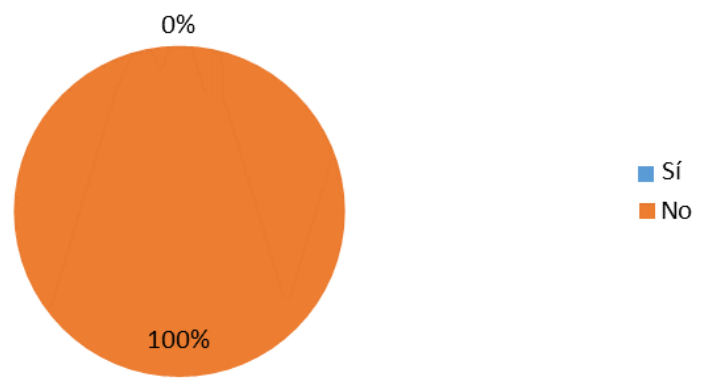

¿Realiza en su unidad productiva actividades de investigaciones y desarrollo tecnológico?

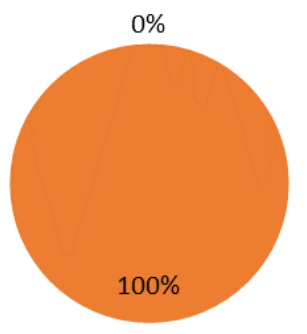


¿En el último año se ha introducido en la empresa alguna innovación en producto o proceso?

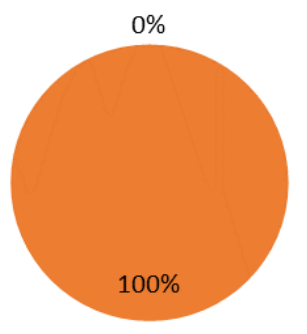

¿En su unidad productiva se ha establecido alguna práctica para contrarrestar la volatilidad de precios del cultivo?

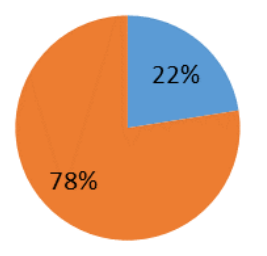

¿En su gremio se han diseñado nuevas políticas de apoyo para promover la seguridad alimentaria?

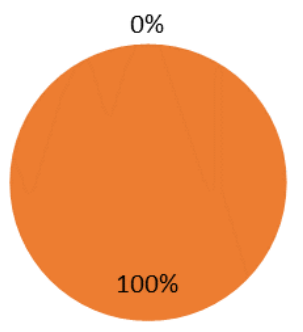




\section{¿En la unidad productiva se han desarrollado acciones para la adaptación al cambio climático?}

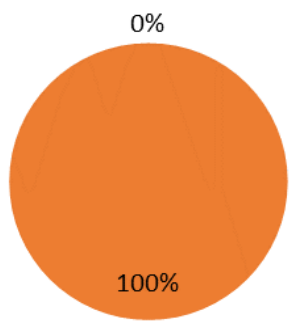

¿Qué estrategia considera importante implementar para mejorar la competitividad de la papa?

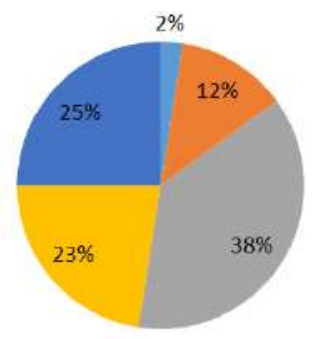

= Construir centros de acopio locales o regionales

- Asociarse con otros productores

- Implementar procesos de transformación

= Mejorar la infaestructura productiva

- Incursionar en otros mercados

Considera que los rendimientos de su cultivo se han visto afectados en los últimos años por:

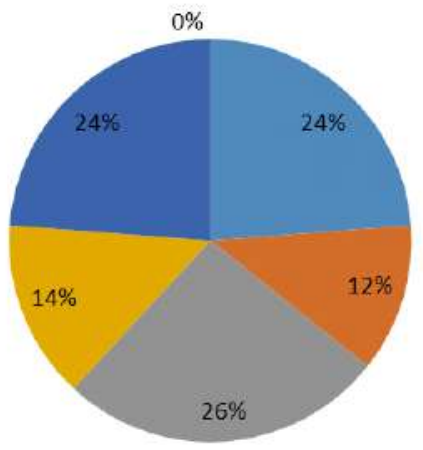

-El cambio climático

- La erosión de los suelos

- La fatiga de los suelos

- La presencia de hongos, nemátodos $y$ otros

- La urbanización acelerada de los

terrenos aptos para agricultura atro 


\section{Anexo 3. Encuesta de caracterización - Maíz Universidad de Cundinamarca- Universidad Nacional de Colombia} Encuesta de caracterización agrícola

Objetivo: obtener información directa de las unidades productivas de maíz (Zea mays) de la provincia Sabana Centro, Cundinamarca, en relación con los factores de competitividad: condiciones de los factores de producción, condiciones de la demanda, sectores relacionados y de apoyo y estrategia, estructura y rivalidad, para identificar las condiciones que requiere el cultivo para ser considerado productivo y mejorar su competitividad.

\section{Información de la encuesta}

1. Identificación de la unidad productiva

2. Entorno ocupacional

3. Oferta y demanda

4. Estructura tecnológica e innovación

\section{Contenido de la encuesta}

Instrucciones para su diligenciamiento: Lea detenidamente las preguntas y responda de acuerdo con las características de su unidad productiva.

Si alguna pregunta no aplica para su unidad productiva, por favor déjela en blanco. 
Fecha(dd/mm/aaaa):

Hora de inicio:

Hora de finalización:

Encuestador:

\section{Identificación de la unidad productiva}

1. Nombre de la unidad productiva:

2. Altura del predio: MSNM

3. Dirección:

4. NIT:

5. Nombre del representante legal:

6. Nombre de la persona entrevistada:

7. Cargo:

8. Teléfonos:

9. Dirección electrónica:

10. Tipo de sociedad:

11. Municipio:

12. El cultivo es: 

a. Urbano ( )
b. Rural ()
c. Suburbano ( )

13. El tiempo de conformación de la unidad productiva es de (señale con una $\mathrm{x}$ ):

a. Menos de 1 año ()

b. Entre 1 y 4 años ()

c. Más de 4 años ()

14. El área del cultivo sembrada (en ha) es de:

a. $0-1$ has

b. 1-5 has

c. 5-10 has

()

d. De 10-20 has ()

e. Superior a 20 has

15. El área cosechada del cultivo (en ha) es de:
a. $0-1$ has
b. $1-5$ has
c. 5-10 has
d. De 10-20 has ()
e. Superior a 20 has

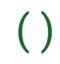

( )

( )

16. La producción (ton/ha ciclo) del cultivo es:
a. $0-1$ ton
b. 1-5 ton
c. $5-10$ ton
d. De 10-20 ton
e. Superior a 20 ton

( )

( )

17. ¿Cuál es la periodicidad de la producción de maíz en su parcela?

a. De 0-1 mes

b. De 1-3 meses 

c. De 3-6 meses
d. De 6 meses a un año ( )
e. Otro

18. Para la caracterización del suelo de su unidad productiva utiliza:

a. Análisis de suelo

b. Ninguna ( )

19. ¿Cada cuánto tiempo realiza la caracterización del suelo en su unidad productiva?
a. Cada 1-3 años ()
b. Cada 3-5 años ()
c. Cada 5-10 años ()
d. No realiza

20. El tipo de suelo de su unidad productiva es:
a. Suelo arenoso
b. Suelo limoso
c. Suelo arcilloso
d. Suelo Franco arenoso ( )
e. Otro. ¿Cuál?

21. ¿Cuáles son los criterios mediante los cuales fertiliza?
a. Análisis de suelos
b. Ciclos ya estandarizados
c. Situación climática
d. A juicio del cultivador
e. Otro. ¿Cuál?

22. ¿Cuáles son los criterios del uso de agroquímicos?

a. Experiencia 

b. A calendario
( )
c. Incidencia y severidad
d. Por evaluación agronómica ( )
e. Cuidado y preservación ambiental ( )
f. Otro. ¿Cuál?

23. ¿Cuáles son los productos más utilizados para el control de plagas y enfermedades en el cultivo?
a. Fungicidas
b. Herbicidas
c. Insecticidas
d. Nematicidas
e. Control orgánico
f. Otro. ¿Cuál?

24. ¿Cuáles son los fertilizantes más utilizados para las etapas de crecimiento, desarrollo y producción en el cultivo?
a. Fertilizantes químicos
b. Fertilizantes de origen orgánico
c. Otro. ¿Cuál?

25. ¿Utiliza en su cultivo productos orgánicos?
a. Sí

¿Cuál?

b. No ( )

26. ¿Qué tipo de agua utiliza en su cultivo?
a. Agua lluvia
b. Agua de acueducto
c. Agua propia
d. Reservorios
e. Distrito de riego 
f. Otro. ¿Cuál?

27. ¿Qué tipo de riego utiliza en su cultivo?
a. Por goteo
b. Por aspersión
c. Por gravedad ()
d. Otro. ¿Cuál?

28. ¿Tiene mecanismos implementados para el manejo de aguas residuales de origen agrícola?
a. Sí
( ) ¿Cuál?

b. No

( )

29. ¿Tiene mecanismos implementados para el manejo de cuencas?
a. Sí
( ) ¿cuál?
b. No
( )

30. ¿Cuál es el uso dado a los envases de agroquímicos utilizados en las prácticas de cultivo?
a. Reutilizados
b. Reciclados
( )
c. Desechados dentro del cultivo
d. Incinerados
e. Otro. ¿Cuál?

\section{Entorno ocupacional}

31. ¿Cuál es el tiempo en horas a la semana destinado por el productor en la unidad productiva?
a. 5-10 horas
b. 11-15 horas 

c. 16-20 horas
d. Otro. ¿Cuál?

32. ¿Qué otro tipo de actividad laboral realiza el productor?
a. Comerciante
b. Agricultor
c. Profesional dependiente
d. Profesional independiente
e. Otra. ¿Cuál?

33. ¿Cuál es el porcentaje de ingresos aportados por la unidad agrícola?

\begin{tabular}{lllll}
\hline a. Del $1 \%$ al $25 \%$ & $($ ) & b. Del $26 \%$ al $50 \%$ & () \\
\hline c. Del $51 \%$ al $75 \%$ & () & d. Del $76 \%$ al $100 \%$ & () \\
\hline 34. ¿Cuál es el porcentaje de ingresos aportados por \\
otras actividades laborales? \\
\begin{tabular}{lllll} 
a. Del $1 \%$ al $25 \%$ & () & b. Del $26 \%$ al $50 \%$ & () \\
\hline c. Del $51 \%$ al $75 \%$ & () & d. Del $76 \%$ al $100 \%$ & () \\
\hline
\end{tabular}
\end{tabular}

35. ¿Escolaridad del productor?
a. Primaria
b. Secundaria
c. Técnico
d. Tecnólogo
e. Profesional
f. Posgrado
g. Ninguna

36. ¿Tiene empleados en su cultivo?
a. Sí ( )
b. No ( ) 
37. El número de trabajadores de la unidad productiva, incluyendo todas las sedes, es (señale con una $x$ ):
a. 1-2 trabajadores
b. 3-5 trabajadores
e. 6-10 trabajadores
f. Superior a 11 trabajadores

( )

38. ¿Qué tipo de vinculación tiene para la mayoría de los empleados en su cultivo?
a. Tiempo completo
b. Medio tiempo
c. Prestación de servicios
d. Por jornal
e. Otro. ¿Cuál?

39. Diligencie el siguiente cuadro indicando frente a cada uno de los procesos misionales su nivel educativo, sus principales funciones y el número de trabajadores, según sean permanentes 0 temporales: 


\begin{tabular}{|c|c|c|c|c|c|c|c|c|c|c|c|c|}
\hline \multicolumn{2}{|c|}{$\begin{array}{l}\overline{\frac{\pi}{0}} \\
\frac{0}{2} \\
\frac{0}{\pi}\end{array}$} & & & & & & & & & & & \\
\hline \multicolumn{3}{|c|}{ 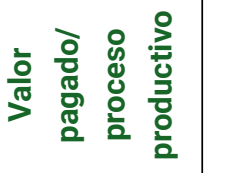 } & & & & & & & & & & \\
\hline \multicolumn{2}{|c|}{ 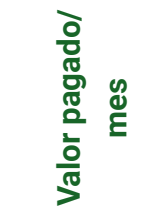 } & & & & & & & & & & & \\
\hline \multicolumn{2}{|c|}{$\frac{\frac{\pi}{\frac{\pi}{2}}}{\frac{0}{0}}$} & & & & & & & & & & & \\
\hline \multirow{2}{*}{ 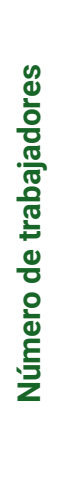 } & 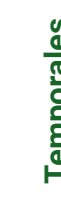 & & & & & & & & & & & \\
\hline & 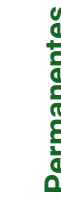 & & & & & & & & & & & \\
\hline & 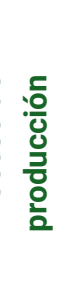 & $\begin{array}{l}\text { 웜 } \\
\overline{\bar{c}} \\
\text { c }\end{array}$ & 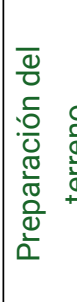 & 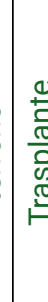 & 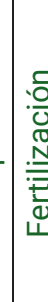 & 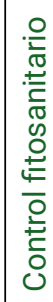 & 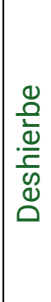 & 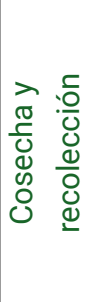 & 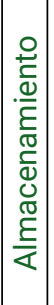 & 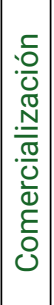 & 옴 & 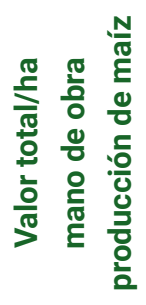 \\
\hline
\end{tabular}




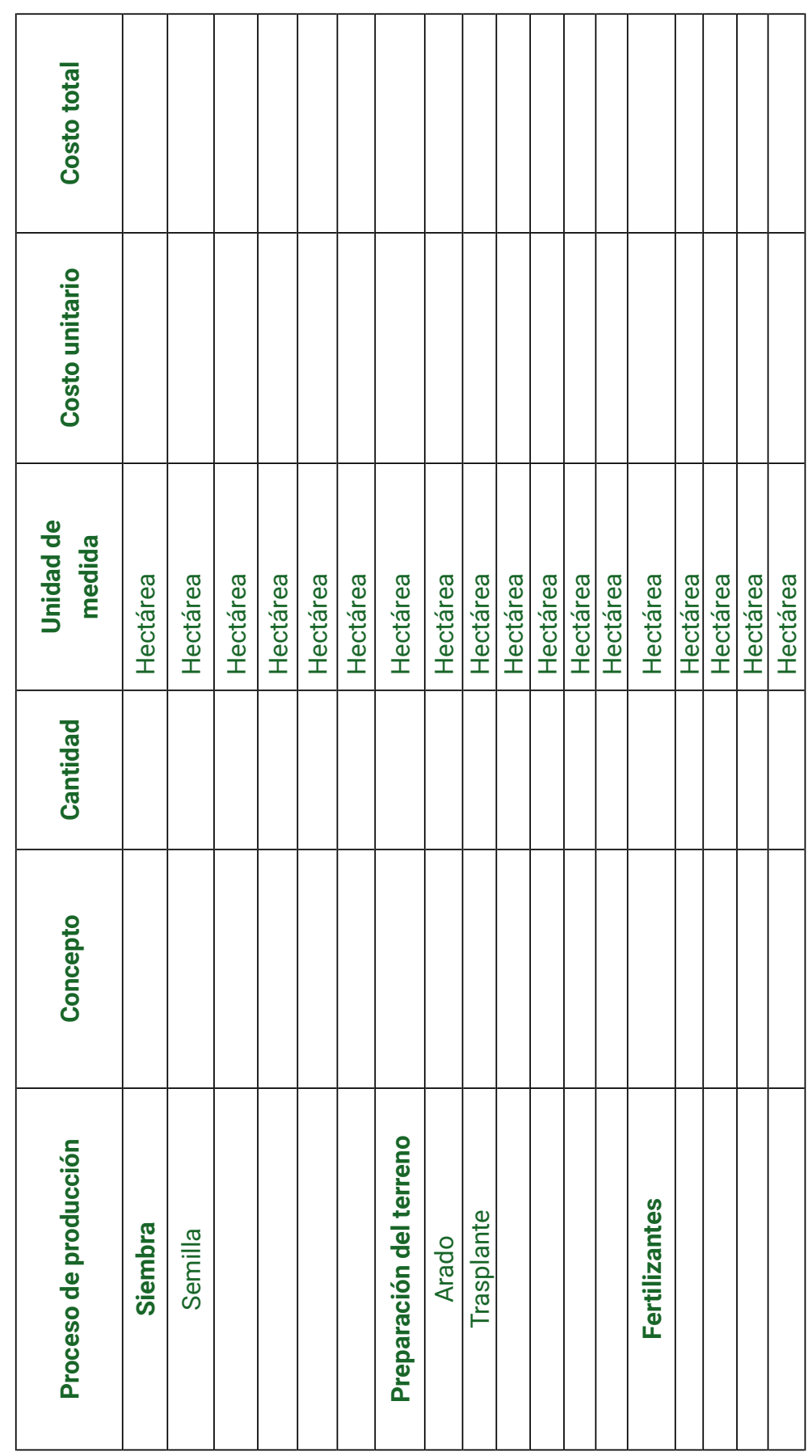




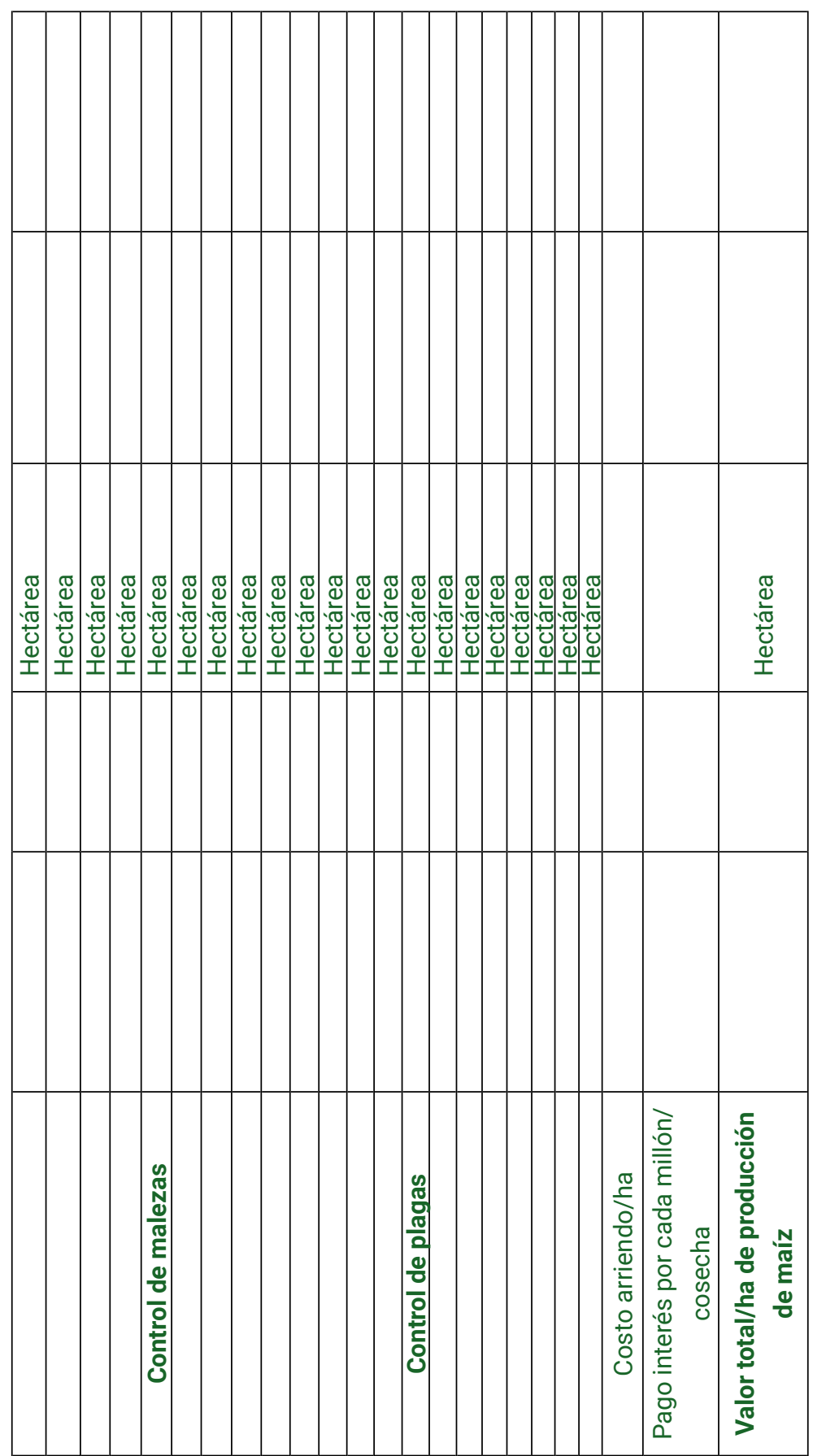


40. Si el terreno es propio, ¿sabe usted cuál es el costo de arriendo de una hectárea de tierra en su vereda o región?

41. Total costo por hectárea (39 y 40):

42. Si usted usa crédito, ¿qué entidad o particular le presta dinero? ¿A qué interés? $\%$

43. ¿Cuáles son los gastos promedio mensuales en el sostenimiento de su hogar?

a. Luz/mes:

b. Agua/mes:

c. Gas/mes:

d. Mercado/mes

e. Otro. ¿Cuál?

Valor/mes:

Total:

44. ¿Qué nivel educativo tienen los trabajadores vinculados en su proceso productivo?
a. Primaria
b. Secundaria
c. Técnico
d. Tecnólogo
e. Profesional
f. Posgrado
g. Ninguna

45. ¿Está capacitado el personal del cultivo para 
realizar las actividades?
a. Todos
()
b. La gran mayoría ()
c. Algunos
d. Ninguno

46. ¿La capacitación del personal es?
a. Dada en el cultivo por otros trabajadores ( )
b. Dada en el cultivo por el productor ( )
c. Se contratan capacitadores
d. Otro. ¿Cuál?

47. ¿En qué actividades considera que se requiere capacitación?
a. Producción
b. Mercadeo
( )
()
c. Fluctuación de precios
d. Pos cosecha
e. Financiamiento ()
f. Otro. ¿Cuál?

\section{III.Visión empresarial}

48. ¿Tiene proyecciones de ampliar el volumen de producción en su cultivo?
a. Sí
b.No
c. ¿En qué área?

49. ¿Cuáles considera que son las prioridades estratégicas con miras a mejorar la competitividad? 
a. Minimizar el uso de agroquímicos

b. Aumentar la productividad de los empleados mediante reconocimientos, incentivos 0 bonificaciones ()

c. Conformar formas asociativas

d. Realizar préstamos para aumentar el volumen de producción ()

g. Invertir en investigación y desarrollo

h. Realizar transformación del producto

i. Otra. ¿Cuál?

50. ¿Qué tipo de transformación le gustaría realizar en su producto?

a. Transformación del producto

b. Transformación del proceso productivo

c. Nuevas formas de presentación del producto

( )

d. No visualiza ninguna ( )

51. ¿Recibe incentivos del gobierno para desarrollar esta actividad?

a. Sí

¿Cuál?

b. No ( )

52. ¿Qué incentivos considera usted debería dar el gobierno para desarrollar mejor su actividad y mejorar la rentabilidad?

a. Disminuir precios de agroquímicos

b. Prestar asesoría técnica

c. Facilitar infraestructura y dotar de equipos

d. Dotarlo de un seguro de cosecha 
e. Otro

53. ¿Cuál cree usted que son los principales factores que afectan el producto en materia de competitividad?
a. Baja productividad
b. Mercados limitados
c. Tasa de cambio
d. Producción limpia
e. Baja o nula transformación
()
()
f. Baja calidad del producto
g. Falta de agremiación
h. Precio de los insumos agrícolas
i. Falta de agua

j. Importación del producto

k. Bajos volúmenes de producción ( )

I. Otro. ¿Cuál?

54. ¿Lleva registros contables de su actividad agrícola?
a. Sí
b. No
( ) ¿Por qué?

55. ¿Aproximadamente a cuánto ascienden las ventas por ciclo de producción en su cultivo/ha?

a. Entre $\$ 100.000-\$ 5.000 .000$

b. Entre $\$ 5.000 .000-\$ 10.000 .000$

c. Entre $\$ 10.000 .000$ - $\$ 20.000 .000$

d. Más de $\$ 20.000 .000$ ¿Cuánto?

56. ¿De cuánto es el costo de producción en su cultivo? 
a. Por planta:

b. Por ha/ciclo productivo:

57. ¿Aproximadamente a cuánto ascienden los costos por ha/ciclo productivo en su cultivo?
a. Entre $\$ 1.000 .000-\$ 4.000 .000$
d. Entre $\$ 4.000 .000-\$ 6.000 .000$
e. Entre $\$ 6.000 .000-\$ 10.000 .000$
f. Más de $\$ 10.000 .000$ ¿Cuánto?

58. ¿Cuál es la frecuencia de siembra del cultivo de maíz en su unidad productiva?
a. Bimestral ()
b. Trimestral ( )
c. Semestral ()
d. Anual ()
e. Otro ()

59. ¿Cuáles son los criterios en los que se basa para manejar distintos precios de venta?
a. Venta al por mayor - Plaza
b. Cercanía a centros de consumo
c. Forma de pago
d. Pago anticipado
e. Pago diferido
f. Otro. ¿Cuál?

60. ¿A qué mercado están dirigidos los productos que desarrolla su unidad productiva? 

a. Local
b. Nacional
c. Internacional ()

61. ¿A quién le vende su producto con mayor frecuencia?
a. Plaza de mercado local/nacional ( )
b. Cadenas de supermercados o instituciones públicas/privadas ()
c. Intermediarios satélites
d. Empresas transformadoras
e. Otro. ¿Cuál?

62. ¿Dónde comercializa el producto?
a. En el predio
b. En el mercado del pueblo
c. En plazas nacionales
d. En mercados internacionales
e. Otro. ¿Cuál?

63. ¿Conoce los procesos o requerimientos para poder exportar maíz?
a. Sí
b. No

64. ¿Comercializa su producto en el mercado internacional?
a. Sí
b. No () 
65. Si comercializa en el mercado internacional, especifique en cuáles regiones:
a. Comunidad Andina de Naciones (CAN) ( )
b. Mercosur
c. Centroamérica y el Caribe
d. EE. UU. y Canadá
e. Unión Europea
f. Asia
g. África
h. Oceanía

i. Otro. ¿Cuál?

66. El acceso a los mercados internacionales le implica (seleccione máximo 5 opciones y clasifíquelas, teniendo en cuenta que cinco es la mayor puntuación y uno la menor):

a. Eliminar barreras fitosanitarias

b. Producción limpia

c. Transformar el producto

d. Producir grandes volúmenes

e. Producir en cualquier temporada

f. Mayor velocidad de innovación

g. Reducción de los costos de producción

h. Ampliar infraestructura física

i. Capacitación del recurso humano

j. Gestión del talento humano

k. Actualización y renovación tecnológica

1. Vincular especialistas para los procesos misionales

m. Mejorar y ampliar el portafolio de productos

n. Certificar competencias laborales 
o. Incorporar procesos logísticos relacionados con

almacenamiento, transporte y distribución de los productos ()

p. Otro. ¿Cuál?

67. La variación de los precios de ventas en el año es:

a. Alta (los precios presentaron cambios sustanciales en los diferentes meses)

b. Normal (similar a años anteriores con precios bajos y altos según los meses)

c. Baja (los precios permanecieron estables independientemente de los meses)

68. Con su conocimiento y experiencia, ¿cuál es la oferta del producto por mes?

\begin{tabular}{|l|l|l|l|l|}
\hline & Alta & Media & Baja & $\begin{array}{c}\text { Oferta en } \\
\text { toneladas/ha }\end{array}$ \\
\hline Enero & & & & \\
\hline Febrero & & & & \\
\hline Marzo & & & & \\
\hline Abril & & & & \\
\hline Mayo & & & & \\
\hline Junio & & & & \\
\hline Julio & & & & \\
\hline Septiembre & & & & \\
\hline Octubre & & & & \\
\hline Noviembre & & & & \\
\hline Diciembre & & & & \\
\hline
\end{tabular}

69. ¿Pertenece su unidad productiva a una asociación o cadena productiva reconocida? 

a. Sí
b. No
Si su respuesta es "sí", indique cuál:

\section{IV.Estructura tecnológica e innovación}

70. ¿Su unidad productiva cuenta con el servicio de asistencia técnica agrícola?
a. Sí
( )
b. No

71. ¿La asistencia técnica agrícola ayuda a mejorar la producción de mi unidad productiva?
a. Sí
( )
b. No
( )

72. ¿Su empresa ha sido certificada por sistemas de gestión de calidad?
a. Sí
()
b. No
Si la respuesta es "sí", indique cuáles normas:

73. ¿Han llevado a cabo procesos de certificación del recurso humano por competencias laborales?
a. Sí
b. No
Si la respuesta es "sí", indique cuáles normas: 
74. ¿Dispone su unidad productiva de marcas propias?
a. Sí
b. No
Si la respuesta es "si", indique cuáles:

75. ¿Realiza su unidad productiva actividades de investigación y desarrollo tecnológico?
a. Sí
b. No
( )
Si la respuesta es "sí", ¿a qué se enfoca esta investigación?

76. ¿En el último año se ha introducido en la empresa o unidad productiva alguna innovación en producto 0 proceso?
a. Sí
b. No
( )

Si la respuesta es "sí", indique cuáles productos o procesos:

77. Teniendo en cuenta la información sobre las tendencias en su sector, su conocimiento de este y las expectativas a futuro (5-10 años), ¿cuáles tecnologías y procesos considera serán utilizados 
en su producto?

\begin{tabular}{lc}
\hline a. Uso de TIC & $($ ) \\
\hline b. Paquetes biotecnológicos & () \\
\hline c. Mecanización aqrícola & () \\
\hline d. Procesos más tecnificados & () \\
\hline e. Otros () & \\
\hline
\end{tabular}

78. ¿En su unidad productiva se ha establecido alguna práctica para contrarrestar la volatilidad de precios del cultivo?
a. Sí
( )
b. No
Si su respuesta es "sí", indique cuáles:

79. ¿En su gremio se han diseñado nuevas políticas de apoyo a los productores para promover la seguridad alimentaria?
a. Sí
b. No

Si su respuesta es "sí", indique cuáles:

80. Considera que los rendimientos de su cultivo se han visto afectado en los últimos 20 años por:
a. El cambio climático
b. La erosión de los suelos
c. La fatiga de los suelos 

d. La presencia de hongos, nematodos y otros
()
e. La urbanización acelerada de los terrenos aptos para agricultura ()
f. Otro. ¿Cuál?

81. ¿En la unidad productiva se han desarrollado acciones para la adaptación al cambio climático?
a. Sí
b. No
Si su respuesta es "sí", indique cuáles:

82. ¿Qué estrategia considera importante implementar para mejorar la competitividad del maíz?

a. Construir centros de acopio locales o regionales ()

b. Asociarse con otros productores

c. Diversificar las variedades

d. Implementar proyectos de transformación del producto ()

e. Mejorar la infraestructura productiva

f. Incursionar en nuevos mercados

g. Otro. ¿Cuál? 


\section{Anexo 4. Tabulación encuesta de caracterización - Maíz}

\section{El cultivo es:}

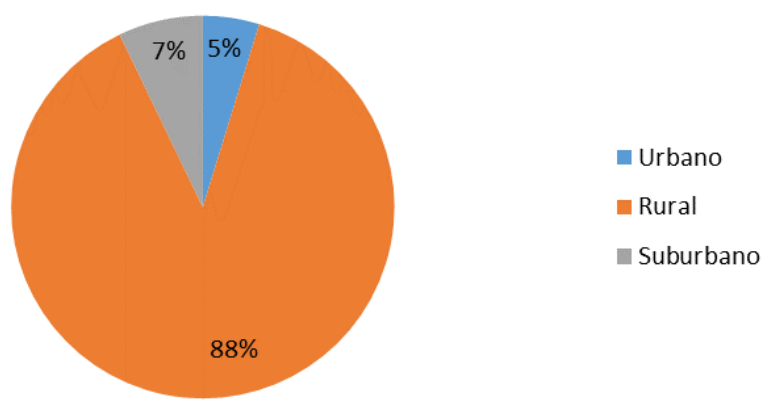

\section{El tiempo de conformación de la unidad productiva es de:}

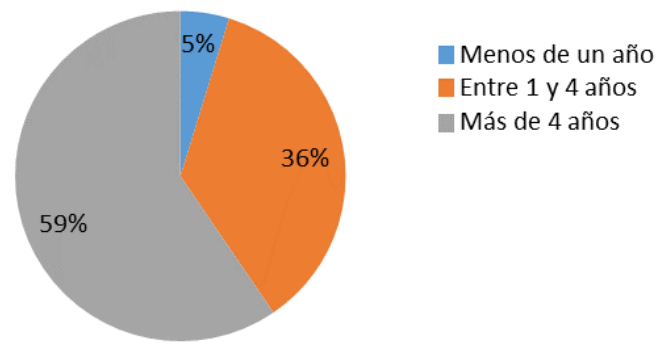




\section{El área (ha) del cultivo sembrada es}

de:

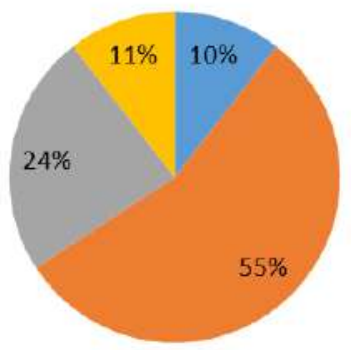

me 0 a 1 ha

De 1 a 5 ha

De 5 a 10 ha

De 10 a 20 ha

El área (ha) cosechada del cultivo es de:

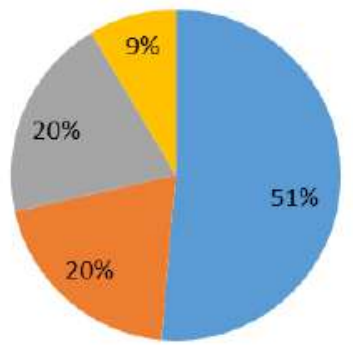

$$
\text { m } 0 \text { a } 5 \text { ha }
$$$$
\text { ㅂ. } 6 \text { a } 10 \text { ha }
$$$$
\text { iㅗㄹ } 11 \text { a } 20 \text { ha }
$$$$
\text { = Sup. a } 21 \text { ha }
$$

\section{La producción (ton/ha) es de:}

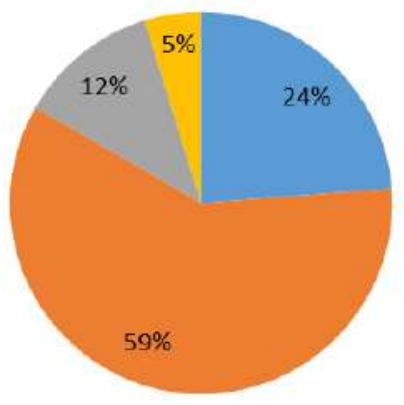


¿Cuál es la periodicidad de la producción de maíz en su parcela?

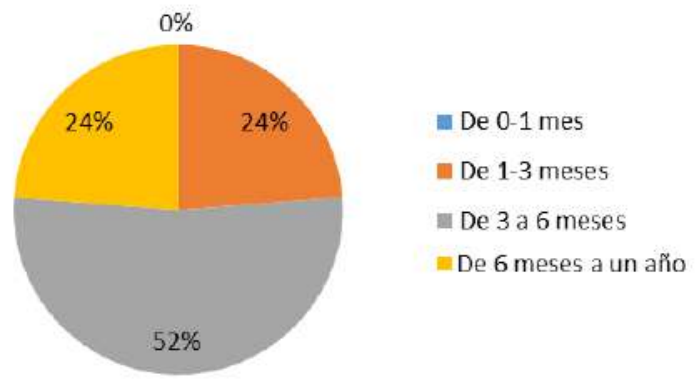

Caracterización del suelo de su unidad productiva:

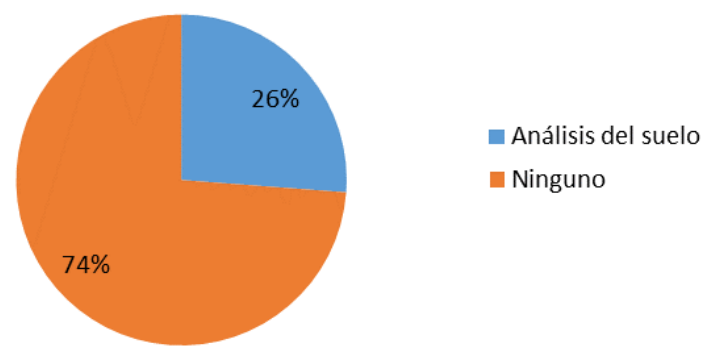

¿Cada cuánto tiempo realiza la caracterización del suelo en su unidad productiva?

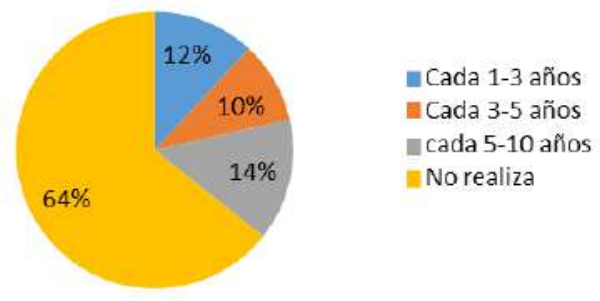




\section{El tipo de suelo de su unidad productiva es:}

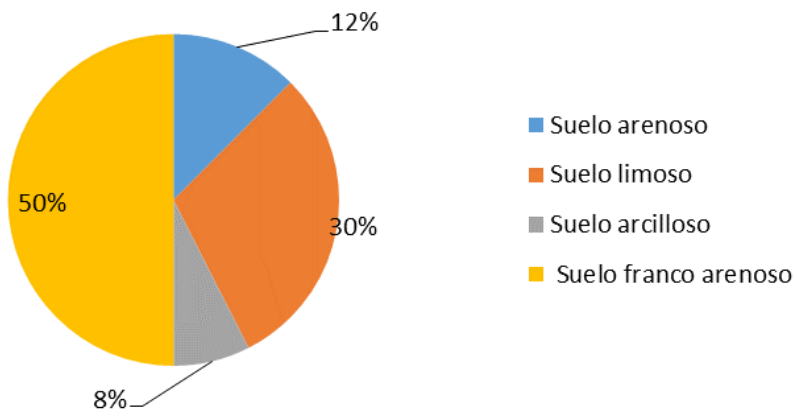

¿Cuáles son los criterios mediante los cuales usted fertiliza?

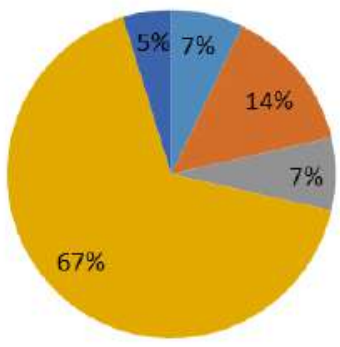

— Análisis del suelo

- Ciclos estandarizados

- Situación climática

A juicio del cultivador

nOtro

\section{¿Cuáles son los criterios del uso de agroquímicos?}

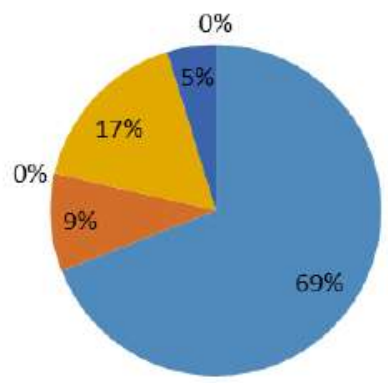

Experiencia

A calendario

- Preservación ambiental

- Incidencia y severidad

- Por evaluación agronómica notro 
¿Cuáles son los productos más utilizados para el control de plagas y enfermedades en el cultivo?

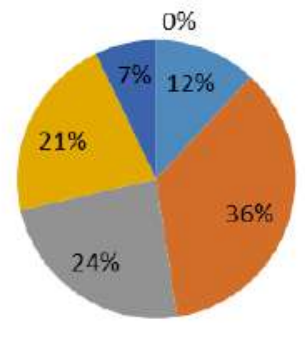

- Fungicidas

werbicidas

n Insecticidas

Nematicidas

@ Control orgánico

= Otro

¿Cuáles son los fertilizantes más utilizados para las etapas de crecimiento, desarrollo y producción del cultivo?

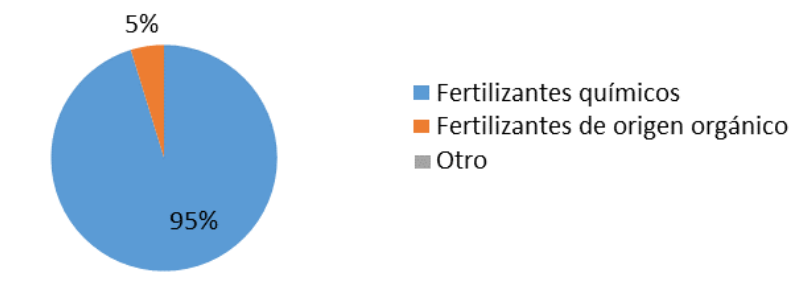

¿Utiliza en su cultivo productos orgánicos?

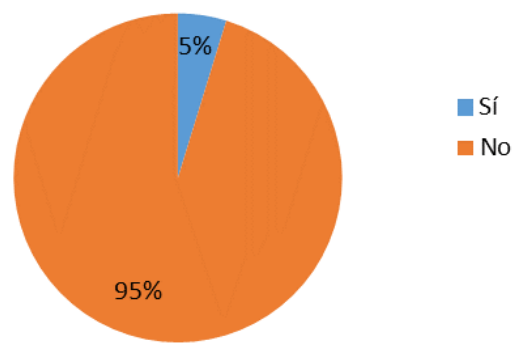


¿Qué tipo de riego utiliza en su cultivo diferente a agua lluvia?

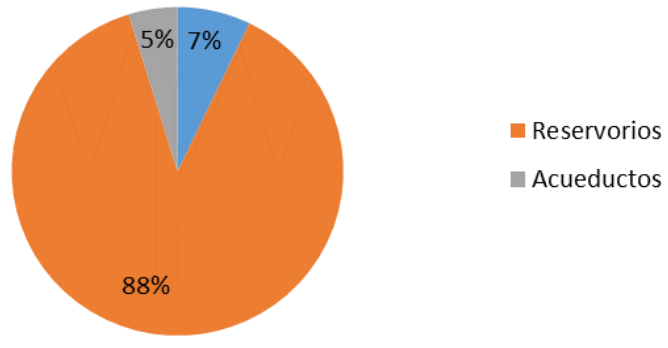

¿Qué sistema de riego utiliza en su cultivo?

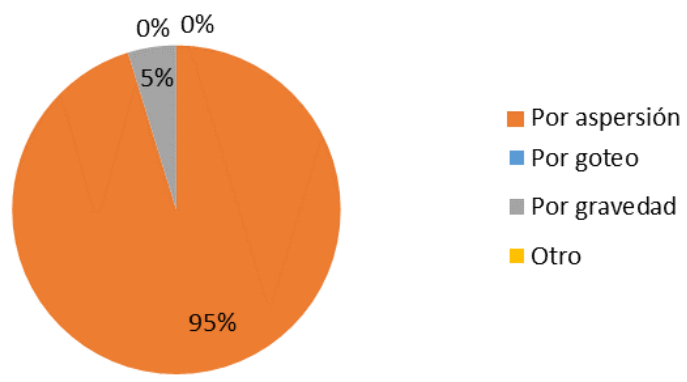

¿Tiene mecanismos implementados para el manejo de aguas residuales de origen agrícola?

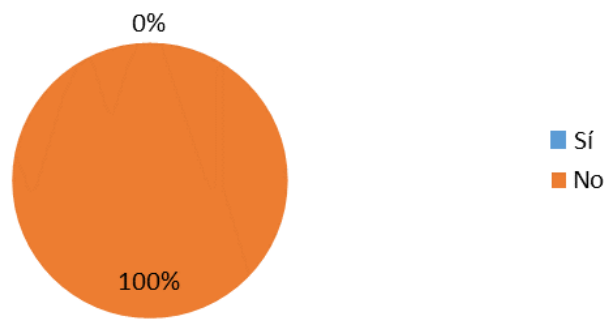


¿Tiene mecanismos implementados para el manejo de cuencas hidrográficas?

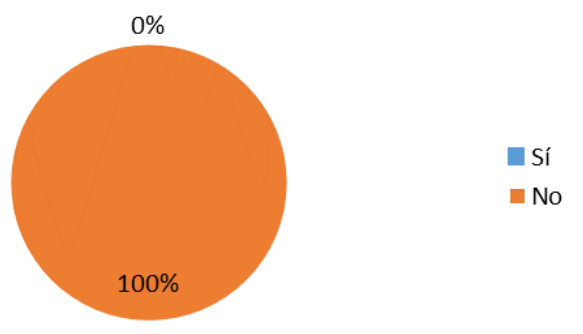

¿Cuál es el tiempo en horas a la semana destinado por el productor en la unidad productiva?

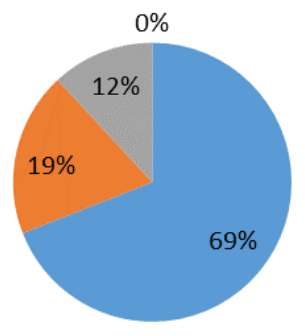

$$
\begin{aligned}
& \text { — a } 10 \text { horas } \\
& \text { De } 10 \text { a } 20 \text { horas } \\
& \text { Más de } 20 \text { horas } \\
& \text { Otra }
\end{aligned}
$$

¿Cuál es el uso dado a los envases de agroquímicos utilizados en las prácticas de cultivo?

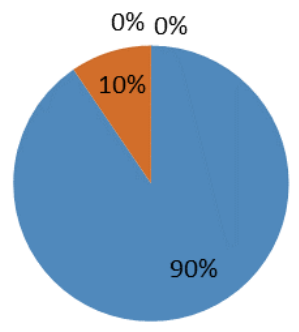

$$
\begin{aligned}
& \text { Reciclados } \\
& \text { Desechados dentro del } \\
& \text { cultivo } \\
& \text { Incinerados } \\
& \text { Otro }
\end{aligned}
$$




\title{
¿Qué otro tipo de actividad laboral realiza el productor?
}

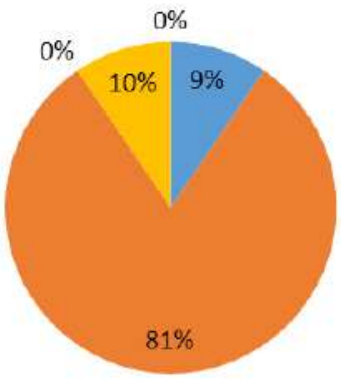

\author{
In Comerciante \\ - Jornalero agrícola \\ w Profesional dependiente \\ a Profesional independiente \\ atras
}

¿Cuál es el porcentaje de ingresos aportados por la unidad agrícola?

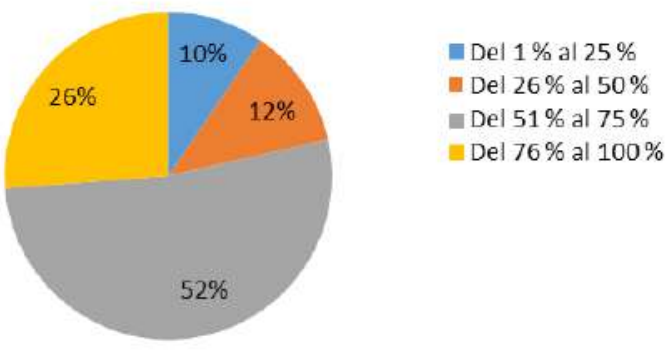

¿Cuál es el porcentaje de ingresos aportados por otras actividades laborales?

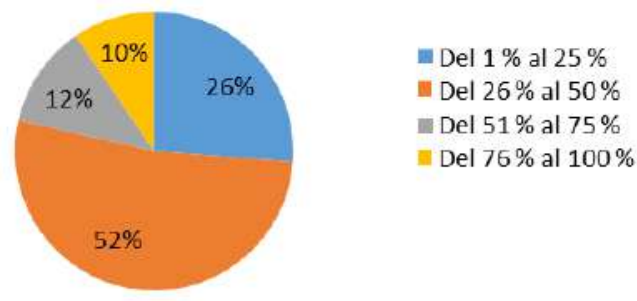


Nivel educativo de los productores:

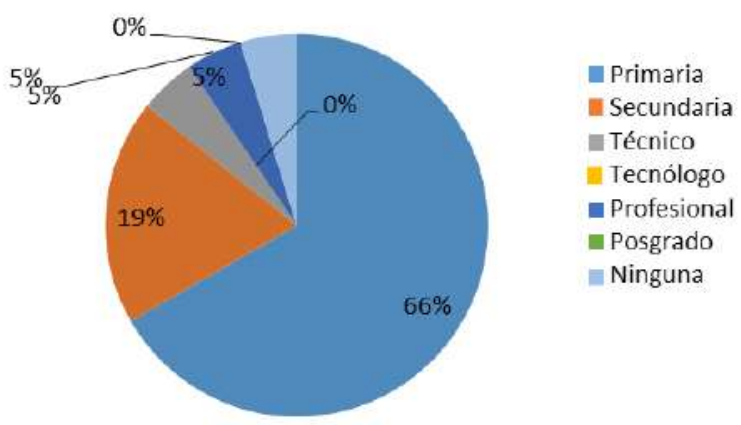

¿Tiene empleados en su cultivo?

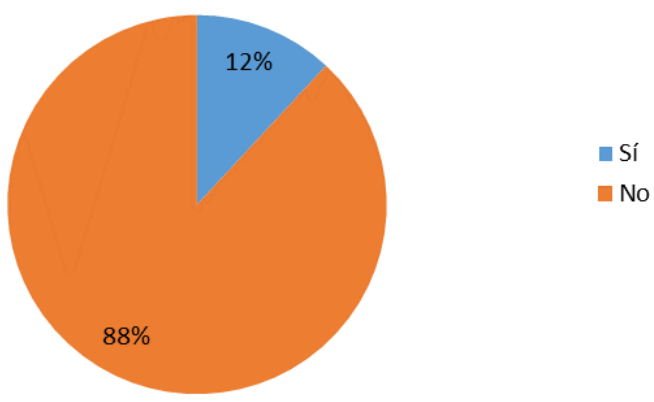

El número de trabajadores de la unidad productiva, incluyendo todas las sedes, es:

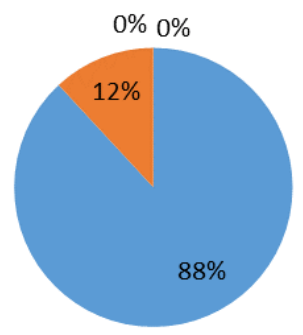

- De 1 a 2

- De 3 a 5

- De 6 a 10

- Superior a 11 
¿Qué tipo de vinculación tiene para la mayoría de empleados de su cultivo?

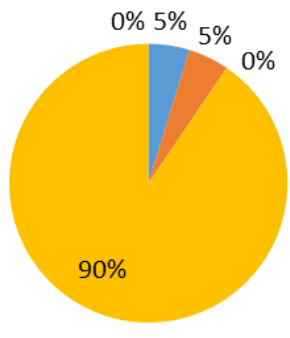

w Tiempo completo

nedio tiempo

a Por jornal

- Prestación de servicios

- Otro

\section{¿Cuáles son los gastos promedio mensuales para el sostenimiento de su hogar?}

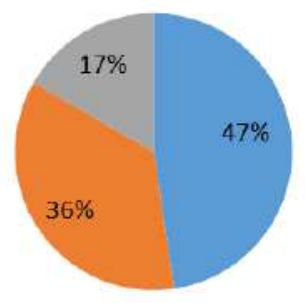

\section{¿Qué nivel educativo tienen los} trabajadores vinculados en su proceso productivo?

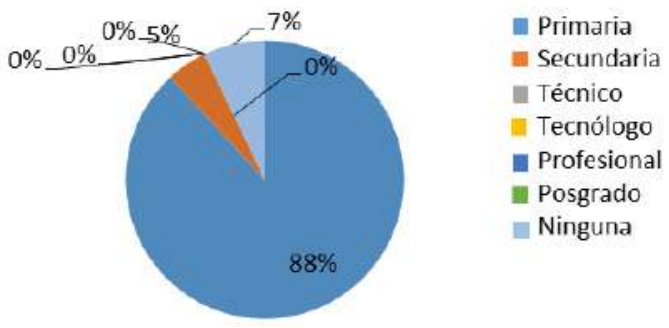




\section{¿Está capacitado el personal de cultivo para realizar las actividades?}

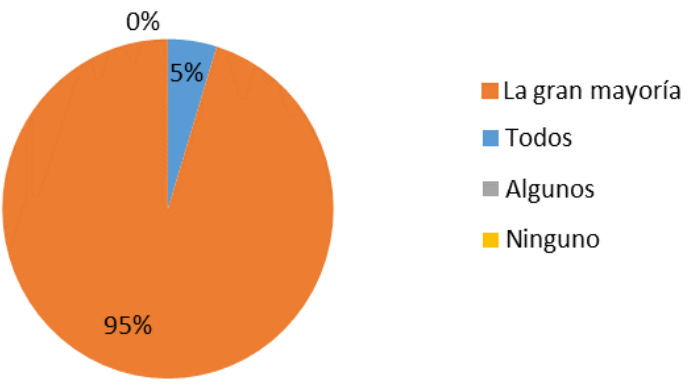

\section{La capacitación del personal es:}

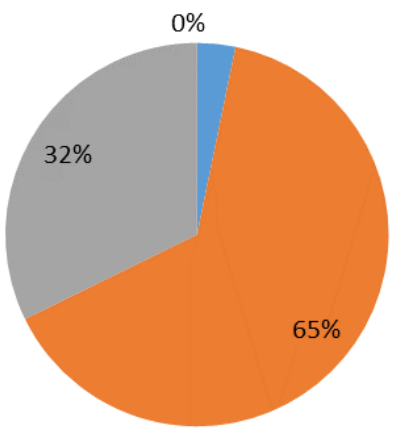
- Dada en el cultivo por otros trabajadores

n Dada en el cultivo por el productor

- Se contratan

capacitadores

notro

\section{¿En qué actividades considera que se requiere capacitación?}

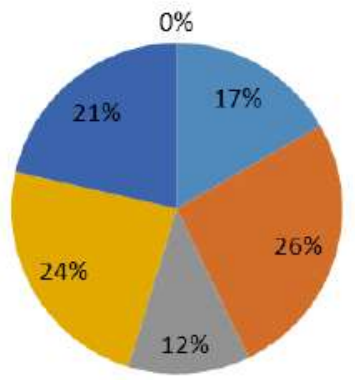

Producción

Mercadeo

- Fluctuación de precios

11 Poscosecha

- Financiamiento

Otro 


\section{¿Tiene proyecciones de ampliar el volumen de producción en su cultivo?}

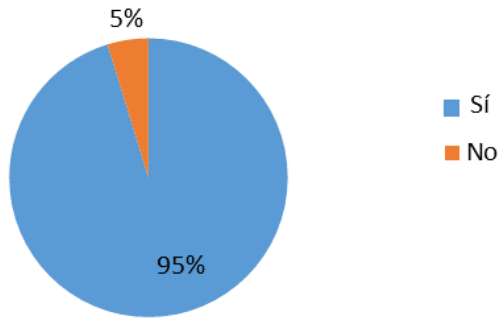

¿Cuáles considera que son las prioridades estratégicas con miras a mejorar la competitividad?

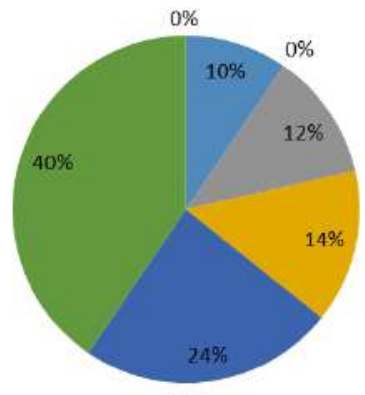

- Minimizar el precio de agroquímicos

- Aumentar productividad de los

empleados mediante reconocimientos

* Conformar formas asociativas

Elizalizar préstamos para aumentar el volumen de producción

- Invertir en investigación y desarrollo

- Realizar transformación de producto

=tro

¿Recibe incentivos del gobierno para desarrollar esta actividad?

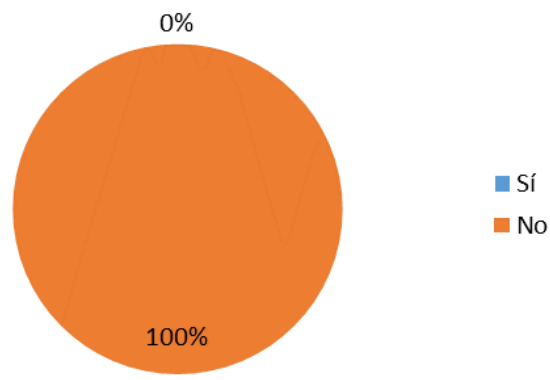




\section{¿Qué tipo de transformación requiere para mejorar su competitividad?}

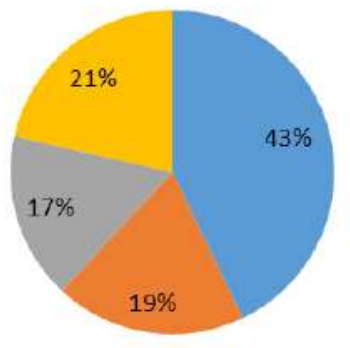

- Transformación del producto

- Transformación del proceso productivo

- Nuevas formas de presentación del producto

no visualiza ninguna

\section{¿Qué incentivos considera usted que debería dar el gobierno para desarrollar mejor su actividad y mejorar su rentabilidad?}

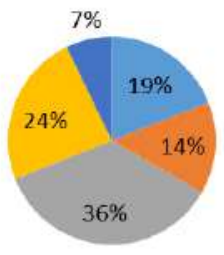

Disminución de precios de los agroquímicos - Prestar asesoría técnica

- Dotar de infraestructura y equipos

Dotar de seguros de cosecha EOtra

¿Cuál cree usted que son los principales factores que afectan el producto en materia de competitividad?

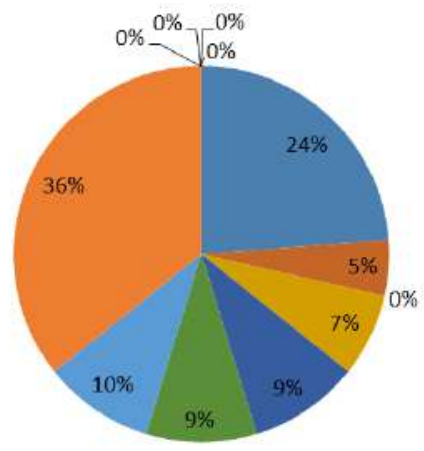

- Baja productividad - Mercados limitados

- Tasa de cambio

= Falta desarrollar producción limpia

- Baja o nula transformación

= Baja calidad del producto

= Falta de agremiación

- Precio de los insumos agricolas

- Falta de agua

- Importación del producto

- Bajos niveles de producción

Otro 


\title{
¿Lleva registros contables de su actividad agrícola?
}

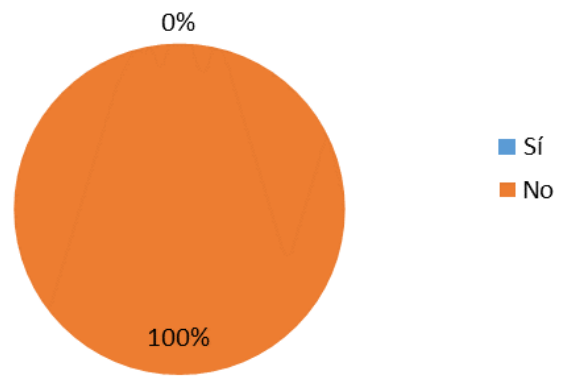

\section{¿Aproximadamente a cuánto} ascienden las ventas por ciclo de producción en su cultivo/ha?

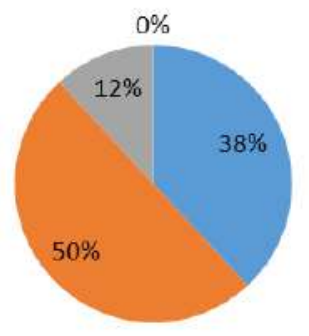

\author{
Entre 100.000 y 5.000 .000 \\ Entre $5.000 .000 \mathrm{a}$ \\ 10.000 .000 \\ = Entre $10.000 .000 \mathrm{a}$ \\ 20.000 .000 \\ = Más de 20.000 .000
}

\section{¿De cuánto es el costo de producción de su cultivo por ha?}

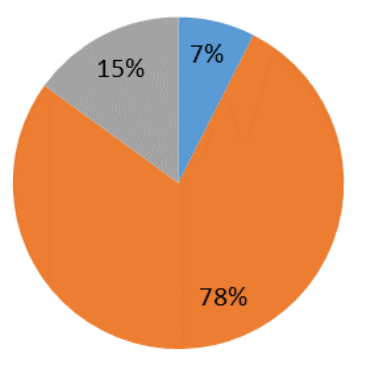

Menos de $\$ 1.500 .000$

Entre $\$ 1.500 .000 \mathrm{y}$ $\$ 3.000 .000$

Entre $\$ 3.000 .000 \mathrm{y}$ $\$ 6.000 .000$ 
¿Cuál es la frecuencia de sembrado de maíz en su unidad productiva?

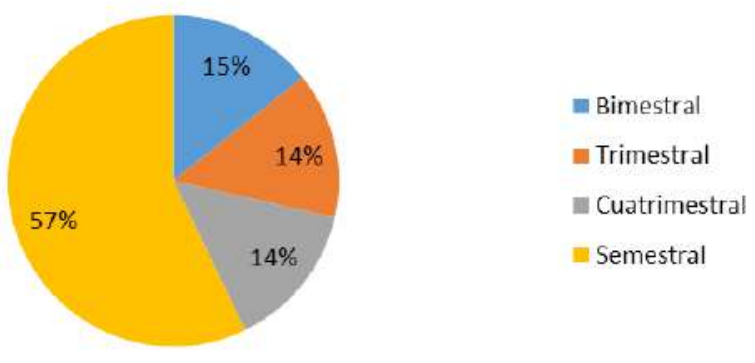

¿Cuáles son los criterios en los que se basa para manejar distintos precios de venta?

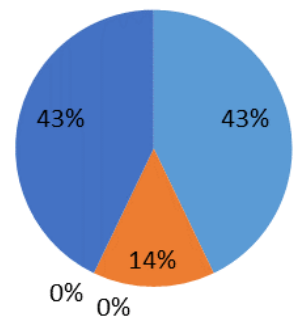

- Venta plaza al por mayor

- Cercanía a centros de consumo

- Formas de pago

- Pago anticipado

- Otro (temporada)

¿A qué mercados están dirigidos los productos que desarrolla su unidad productiva?

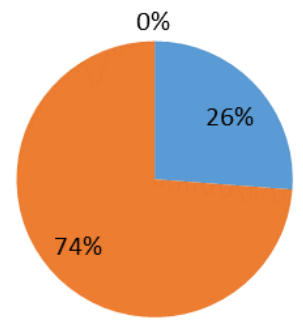

- Local

nacional

- Internacional 


\section{¿A quién le vende su producto con más frecuencia?}

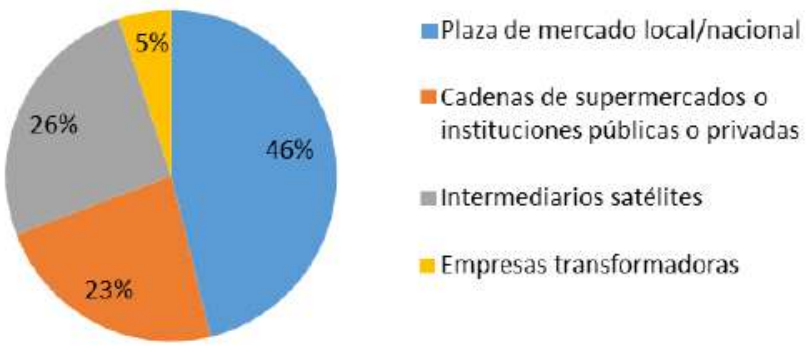

\section{¿Dónde comercializa el producto?}

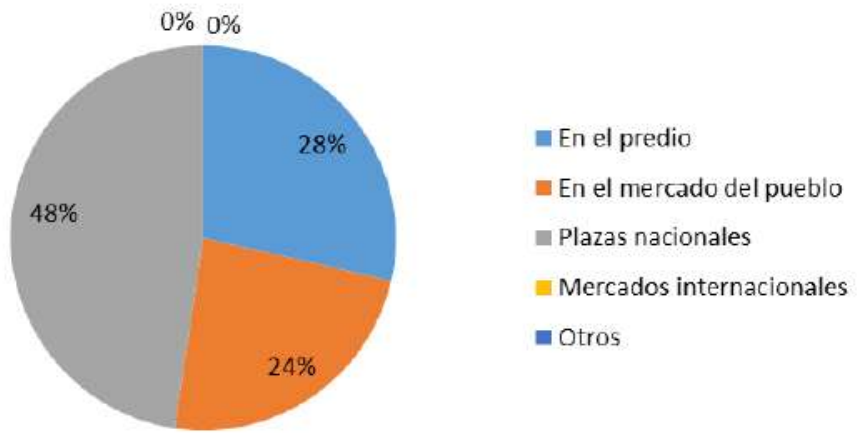

\section{¿Conoce los procesos 0} requerimientos para exportar maíz?

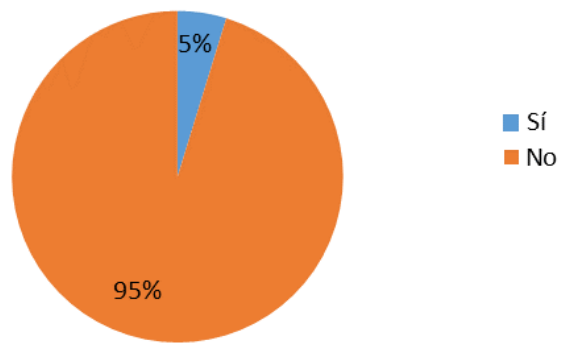




\section{¿Comercializa en el mercado internacional?}

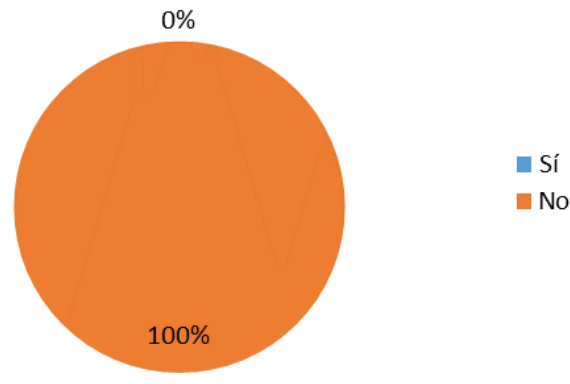

\section{El acceso a los mercados internacionales implica:}

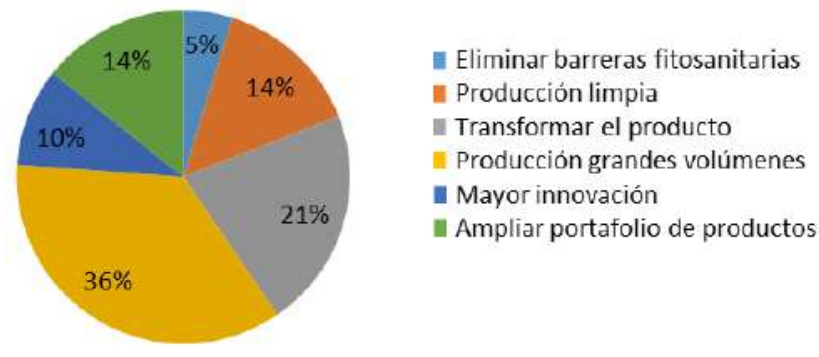

La variación de precios de venta en el año es:

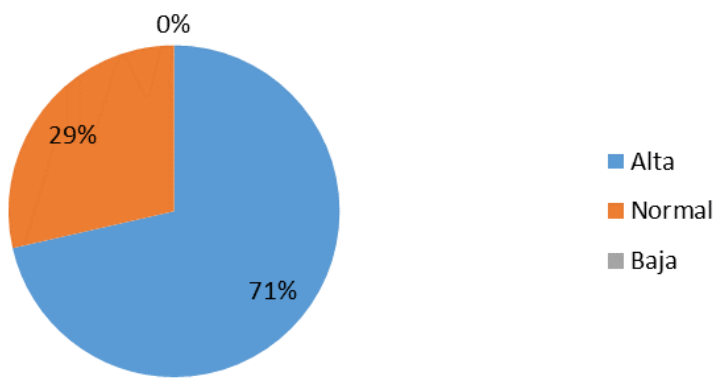


¿Pertenece su unidad productiva a una asociación o cadena productiva reconocida?

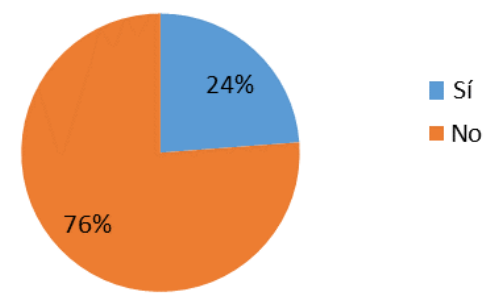

¿Su unidad productiva cuenta con el servicio de asistencia técnica agrícola?

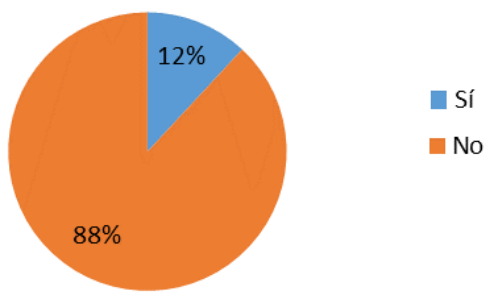

¿La asistencia técnica agrícola ayuda a mejorar la producción de mi unidad productiva?

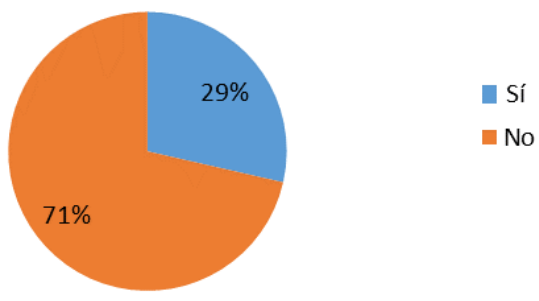


¿Su empresa ha sido certificada por sistemas de calidad?

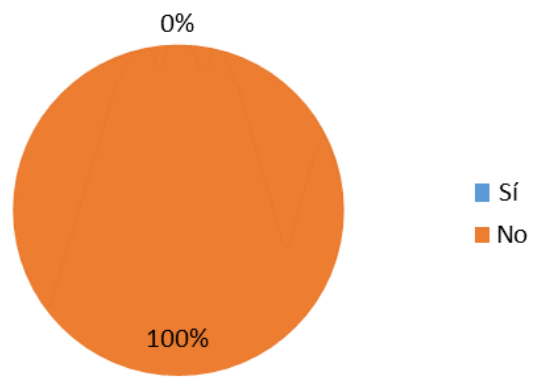

\section{¿Han llevado procesos de certificación del recurso humano por competencias laborales?}

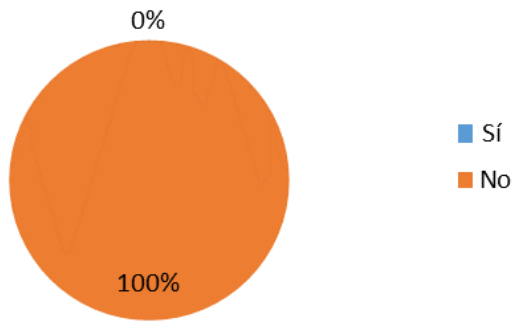

¿Dispone su unidad productiva de marcas propias?

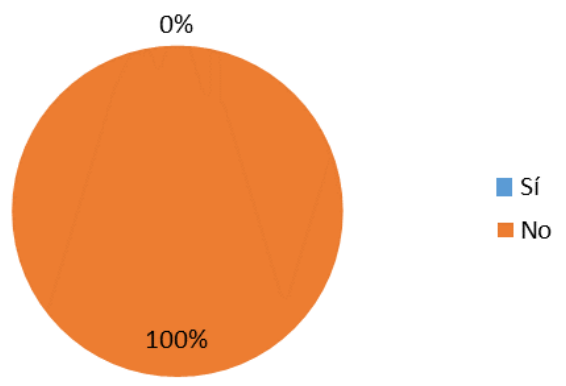


¿Realiza en su unidad productiva actividades de investigaciones y desarrollo tecnológico?

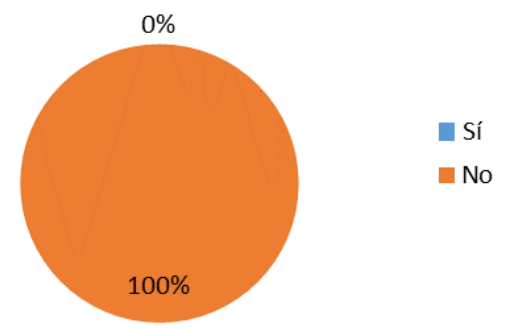

¿En el último año se ha introducido en la empresa alguna innovación en producto o proceso?

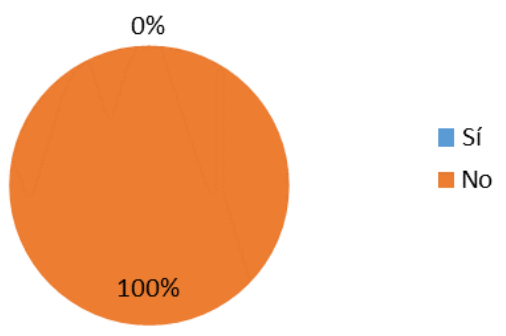

\section{¿Cuáles tecnologías considera que} serán utilizadas en los próximos años?

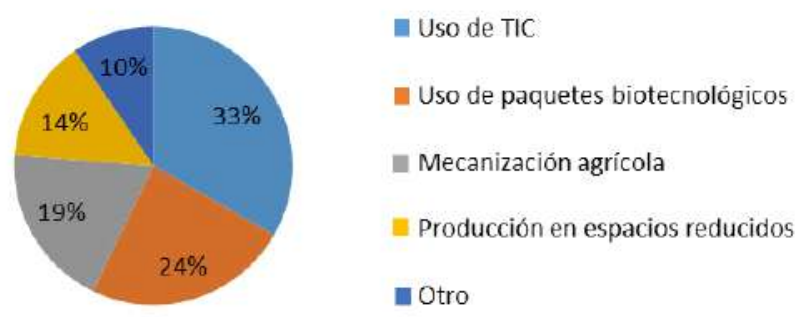


¿En su unidad productiva se ha establecido alguna práctica para contrarrestar la volatilidad de precios del cultivo?

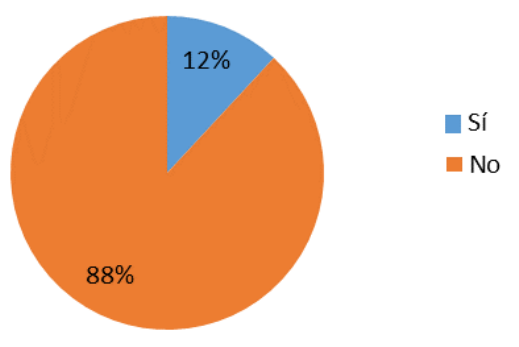

¿En su gremio se han diseñado nuevas políticas de apoyo para promover la seguridad alimentaria?

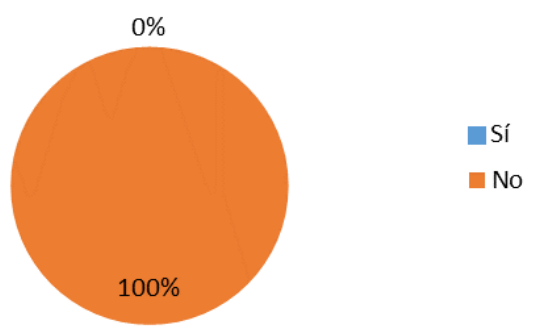

¿En la unidad productiva se han desarrollado acciones para la adaptacion al cambio climático?

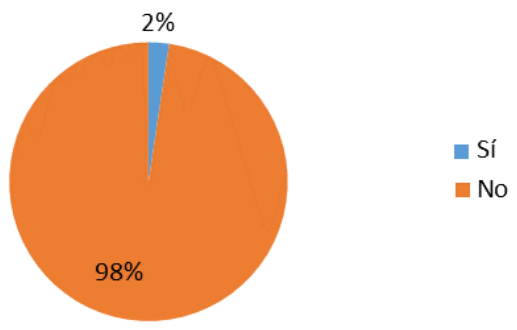


¿Qué estrategia considera importante implementar para mejorar la competitividad de la maíz?

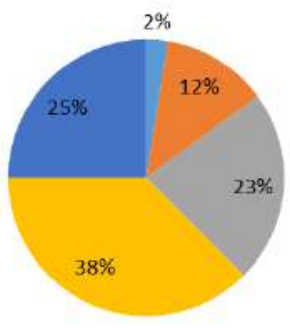

\author{
= Construir centros de acopio locales o regionales \\ almplementar procesos de transformación \\ m Asociarse con otros productores \\ E incursionar en otros mercados \\ = Mejorar la infaestructura productiva
}

\title{
Considera que los rendimientos de su cultivo se
} han visto afectados en los últimos años por:

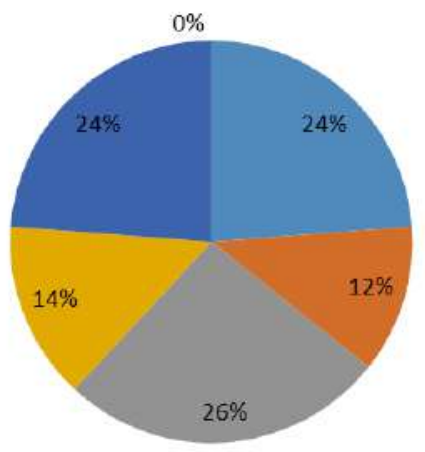

El cambio climático

La erosión de los suelos

II La fatiga de los suelos

- La presencia de hongos, nemátodos y otros

- La urbanización acelerada de los terrenos aptos para agricultura

in Otro 


\section{Anexo 5. Encuesta de caracterización - Lechuga Universidad de Cundinamarca- Universidad Nacional de Colombia} Encuesta de caracterización agrícola

Objetivo: obtener información directa de las unidades productivas de lechuga (Lactuca sativa) de la provincia Sabana Centro, Cundinamarca, en relación con los factores de competitividad: condiciones de los factores de producción, condiciones de la demanda, sectores relacionados y de apoyo y estrategia, estructura y rivalidad, para identificar las condiciones que requiere el cultivo para ser considerado productivo y mejorar su competitividad.

\section{Información de la encuesta}

1. Identificación de la unidad productiva

2. Entorno ocupacional

3. Oferta y demanda

4. Estructura tecnológica e innovación

\section{Contenido de la encuesta}

Instrucciones para su diligenciamiento:

Lea detenidamente las preguntas y responda de acuerdo con las características de su unidad productiva.

Si alguna pregunta no aplica para su unidad productiva, por favor déjela en blanco. 
Fecha (dd/mm/aaaa):

Hora de inicio:

Hora de finalización:

Encuestador:

\section{Identificación de la unidad productiva}

1. Nombre de la unidad productiva:

2. Altura del predio: MSNM

3. Dirección:

4. NIT:

5. Nombre del representante legal:

6. Nombre de la persona entrevistada:

7. Cargo:

8. Teléfonos:

9. Dirección electrónica:

10. Tipo de sociedad:

11. Municipio:

12. El cultivo es:

a. Urbano ( ) 

b. Rural ()
c. Suburbano ( )

13. El tiempo de conformación de la unidad productiva es de (señale con una $\mathrm{x}$ ):

a. Menos de un año ( )

b. Entre 1 y 4 años ()

c. Más de 4 años ()

14. El área del cultivo sembrada (en ha) es de:
a. $0-1$ has
b. 1-5 has
c. 5-10 has
d. De 10-20 has
()
e. Superior a 20 has

15. El área cosechada del cultivo (en ha) es de:
a. $0-1$ has
b. $1-5$ has
c. 5-10 has
d. De 10-20 has
e. Superior a 20 has

16. La producción (ton/ha ciclo) del cultivo es:
a. $0-1$ ton
b. 1-5 ton
c. 5 y 10 ton
d. De 10-20 ton ()
e. Superior a 20 ton

17. ¿Cuál es la periodicidad de la producción de lechuga en su parcela?
a. De 0-1 mes
b. De 1-3 meses ()
c. De 3-6 meses () 

d. De 6 meses a un año ( )
e. Otro ( )

18. Para la caracterización del suelo de su unidad productiva utiliza:

a. Análisis de suelo
b. Ninguna ()

19. ¿Cada cuánto tiempo realiza la caracterización del suelo en su unidad productiva?
a. Cada 1-3 años
b. Cada 3-5 años
c. Cada 5-10 años
d. No realiza
( )

20. El tipo de suelo de su unidad productiva es:
a. Suelo arenoso
()
b. b. Suelo limoso
c. Suelo arcilloso
d. Suelo franco arenoso ()
e. Otro. ¿Cuál?

21. ¿Cuáles son los criterios mediante los cuales fertiliza?
a. Análisis de suelos
b. Ciclos ya estandarizados
c. Situación climática
d. A juicio del cultivador
e. Otro. ¿Cuál?

22. ¿Cuáles son los criterios del uso de agroquímicos?
a. Experiencia ()
b. A calendario () 

c. Incidencia y severidad
d. Por evaluación agronómica ()
e. Cuidado y preservación ambiental

f. Otro. ¿Cuál?

23. ¿Cuáles son los productos más utilizados para el control de plagas y enfermedades en el cultivo?
a. Fungicidas
b. Herbicidas
c. Insecticidas
d. Nematicidas
e. Control orgánico
f. Otro. ¿Cuál?

24. ¿Cuáles son los fertilizantes más utilizados para las etapas de crecimiento, desarrollo y producción en el cultivo?
a. Fertilizantes químicos
b. Fertilizantes de origen orgánico
c. Otro. ¿Cuál?

25. ¿Utiliza en su cultivo productos orgánicos?
a. Sí
¿Cuál?
b. No
( )

26. ¿Qué tipo de agua utiliza en su cultivo?
a. Agua lluvia
b. Agua de acueducto
c. Agua propia
d. Reservorios
e. Distrito de riego
f. Otro. ¿Cuál?

() 
27. ¿Qué tipo de riego utiliza en su cultivo?
a. Por goteo
b. Por aspersión
c. Por gravedad ( )
d. Otro. ¿Cuál?

28. ¿Tiene mecanismos implementados para el manejo de aguas residuales de origen agrícola?
a. Sí
( ) ¿Cuál?

b. No

( )

29. ¿Tiene mecanismos implementados para el manejo de cuencas?
a. Sí
( ) ¿cuál?
b. No
( )

30. ¿Cuál es el uso dado a los envases de agroquímicos utilizados en las prácticas de cultivo?
a. Reutilizados
b. Reciclados
( )
( )
c. Desechados dentro del cultivo
d. Incinerados
e. Otro. ¿Cuál?

\section{Entorno ocupacional}

31. ¿Cuál es el tiempo en horas a la semana destinado por el productor en la unidad productiva?
a. 5-10 horas
b. 11-15 horas
c. $16-20$ horas
d. Otro. ¿Cuál? 
32. ¿Qué otro tipo de actividad laboral realiza el productor?
a. Comerciante
b. Agricultor
c. Profesional dependiente
d. Profesional independiente
e. Otra. ¿Cuál?

33. ¿Cuál es el porcentaje de ingresos aportados por la unidad aqrícola?

\begin{tabular}{llll}
\hline a. Del $1 \%$ al $25 \%$ & () & b. Del $26 \%$ al $50 \%$ & () \\
\hline c. Del $51 \%$ al $75 \%$ & () & d. Del $76 \%$ al $100 \%$ & () \\
\hline 34. ¿Cuál es el porcentaje de ingresos aportados por \\
otras actividades laborales? \\
\begin{tabular}{llll} 
a. Del $1 \%$ al $25 \%$ & () & b. Del $26 \%$ al $50 \%$ & () \\
\hline c. Del $51 \%$ al $75 \%$ & () & d. Del $76 \%$ al $100 \%$ & () \\
\hline
\end{tabular}
\end{tabular}

35. ¿Escolaridad del productor?
a. Primaria
b. Secundaria
c. Técnico
d. Tecnólogo
e. Profesional
f. Posgrado
g. Ninguna

36. ¿Tiene empleados en su cultivo?
a. Sí ( )
b. No ( )

37. El número de trabajadores de la unidad productiva, incluyendo todas las sedes, es (señale con una $\mathrm{x}$ ):

a. 1-2 trabajadores 

b. 3-5 trabajadores
j. 6-10 trabajadores
k. Superior a 11 trabajadores

38. ¿Qué tipo de vinculación tiene para la mayoría de los empleados en su cultivo?
a. Tiempo completo
b. Medio tiempo
c. Prestación de servicios
d. Por jornal
e. Otro. ¿Cuál?

39. Diligencie el siguiente cuadro indicando frente a cada uno de los procesos misionales su nivel educativo, sus principales funciones y el número de trabajadores, según sean permanentes o temporales: 


\begin{tabular}{|c|c|c|c|c|c|c|c|c|c|c|c|c|}
\hline \multicolumn{2}{|c|}{$\begin{array}{l}\bar{\pi} \\
\frac{\pi}{0} \\
\frac{0}{\pi} \\
>\end{array}$} & & & & & & & & & & & \\
\hline \multicolumn{3}{|c|}{ 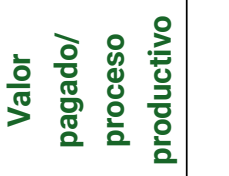 } & & & & & & & & & & \\
\hline \multicolumn{2}{|c|}{ 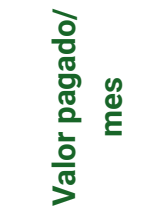 } & & & & & & & & & & & \\
\hline \multicolumn{2}{|c|}{$\frac{\frac{\pi}{0}}{\frac{0}{0}}$} & & & & & & & & & & & \\
\hline \multirow{2}{*}{ 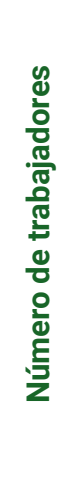 } & 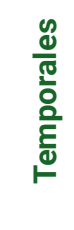 & & & & & & & & & & & \\
\hline & 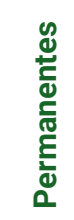 & & & & & & & & & & & \\
\hline \multicolumn{2}{|c|}{ 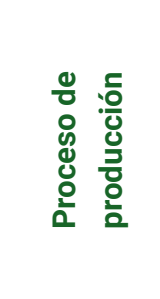 } & 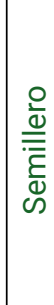 & 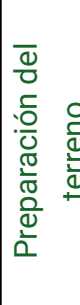 & 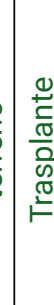 & 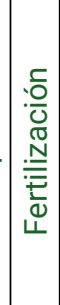 & 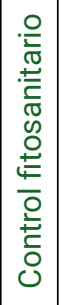 & 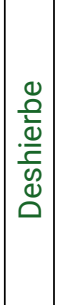 & 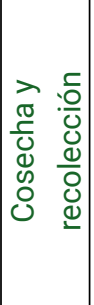 & 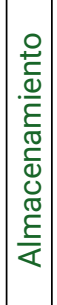 & 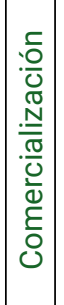 & 은 & 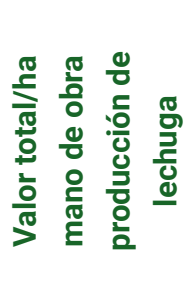 \\
\hline
\end{tabular}




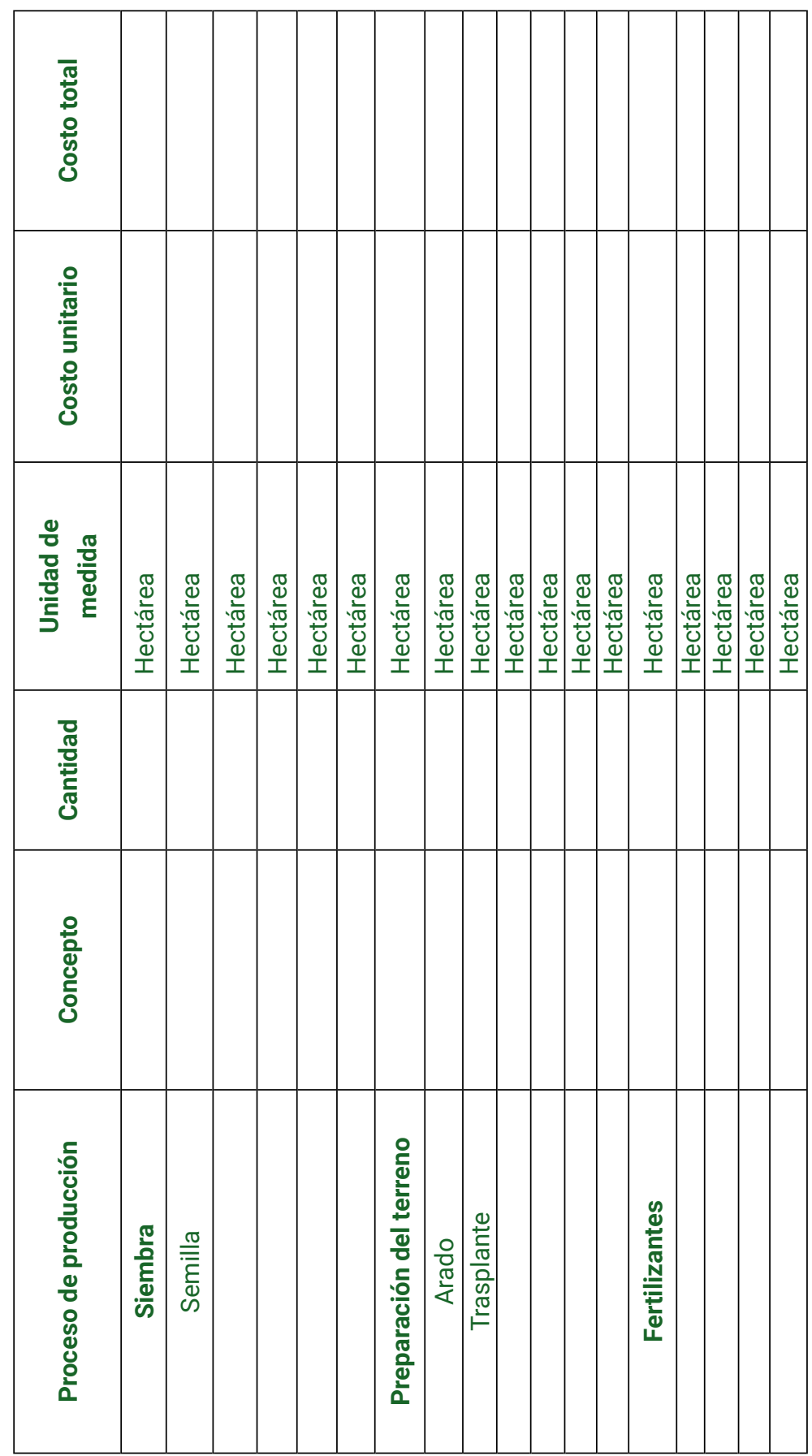




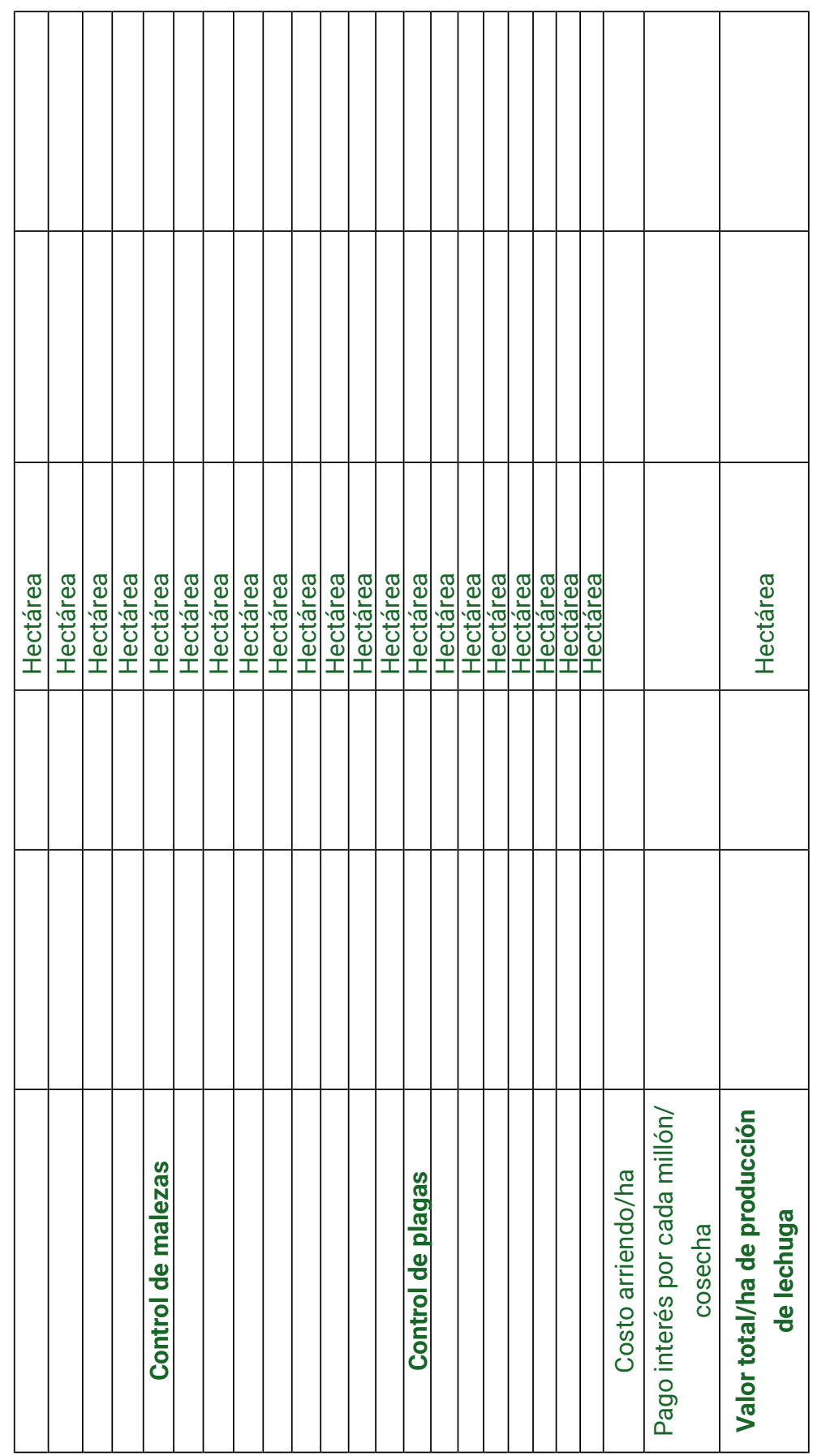


40. Si el terreno es propio, ¿sabe usted cuál es el costo de arriendo de una hectárea de tierra en su vereda o región?

41. Total costo por hectárea (39 y 40):

42. Si usted usa crédito, ¿qué entidad o particular le presta dinero? ¿A qué interés? $\%$

43. ¿Cuáles son los gastos promedio mensuales en el sostenimiento de su hogar?

a. Luz/mes:

b. Agua/mes:

c. Gas/mes:

d. Mercado/mes:

e. Otro. ¿Cuál? Valor /mes:

Total:

44. ¿Qué nivel educativo tienen los trabajadores vinculados en su proceso productivo?
a. Primaria
b. Secundaria
c. Técnico
d. Tecnólogo
e. Profesional
f. Posgrado
g. Ninguno 
45. ¿Está capacitado el personal del cultivo para realizar las actividades?
a. Todos
b. La gran mayoría ()
c. Algunos
d. Ninguno

46. La capacitación del personal es:

a. Dada en el cultivo por otros trabajadores ( )

b. Dada en el cultivo por el productor ( )

c. Se contratan capacitadores

d. Otro. ¿Cuál?

47. ¿En qué actividades considera que se requiere capacitación?
a. Producción ()
b. Mercadeo ()
c. Fluctuación de precios
g. Poscosecha ()
h. Financiamiento ()
i. Otro. ¿Cuál?

\section{III.Visión empresarial}

48. ¿Tiene proyecciones de ampliar el volumen de producción en su cultivo?
a. Sí
b. No
c. ¿En qué área?

49. ¿Cuáles considera que son las prioridades 
estratégicas con miras a mejorar la competitividad?

a. Minimizar el uso de agroquímicos

b. Aumentar la productividad de los empleados mediante reconocimientos, incentivos o bonificaciones

c. Conformar formas asociativas

d. Realizar préstamos para aumentar el volumen de producción

e. Invertir en investigación y desarrollo

f. Realizar transformación del producto

g. Otro. ¿Cuál?

50. ¿Qué tipo de transformación le gustaría realizar en su producto?

a. Transformación del producto

b. Transformación del proceso productivo

c. Nuevas formas de presentación del producto

d. No visualiza ninguna

51. ¿Recibe incentivos del gobierno para desarrollar esta actividad?
a. Sí
( ) ¿Cuál?

b. No

( )

52. ¿Qué incentivos considera usted debería dar el gobierno para desarrollar mejor su actividad y mejorar la rentabilidad?

a. Disminuir precios de agroquímicos ( )

b. Prestar asesoría técnica () 
c. Facilitar infraestructura y dotar de equipos ( )

d. Dotarlo de un seguro de cosecha ()

e. Otro ()

53. ¿Cuál cree usted que son los principales factores que afectan el producto en materia de competitividad?

a. Baja productividad

b. Mercados limitados

( )

c. Tasa de cambio

d. Producción limpia

e. Baja o nula transformación

( )

f. Baja calidad del producto

g. Falta de agremiación

h. Precio de los insumos agrícolas ()

i. Falta de agua

j. Importación del producto

k. Bajos volúmenes de producción

I. Otro. ¿Cuál?

54. ¿Lleva registros contables de su actividad agrícola?
a. Sí
b. No
( ) ¿Por qué?

55. ¿Aproximadamente a cuánto ascienden las ventas por ciclo de producción en su cultivo/ha?

a. Entre $\$ 100.000-\$ 5.000 .000$

b. Entre $\$ 5.000 .000-\$ 10.000 .000$

c. Entre $\$ 10.000 .000-\$ 20.000 .000$

d. Más de $\$ 20.000 .000$ ¿Cuánto? 
56. ¿De cuánto es el costo de producción en su cultivo?

a. Por planta:

b. Por ha/ciclo productivo:

57. ¿Aproximadamente a cuánto ascienden los costos por ha/ciclo productivo en su cultivo?

a. Entre $\$ 1.000 .000-\$ 4.000 .000$

b. Entre $\$ 4.000 .000-\$ 6.000 .000$

c. Entre $\$ 6.000 .000-\$ 10.000 .000$

d. Más de $\$ 10.000 .000$ ¿Cuánto?

58. ¿Cuál es la frecuencia de siembra del cultivo de papa en su unidad productiva?
a. Bimestral
b. Trimestral
c. Semestral
d. Anual
e. Otro

59. ¿Cuáles son los criterios en los que se basa para manejar distintos precios de venta?
a. Venta al por mayor - Plaza
b. Cercanía a centros de consumo
c. Forma de pago
d. Pago anticipado
e. Pago diferido
f. Otro. ¿Cuál? 
60. ¿A qué mercado están dirigidos los productos que desarrolla su unidad productiva?
a. Local
b. Nacional
c. Internacional

61. ¿A quién le vende su producto con mayor frecuencia?
a. Plaza de mercado local/nacional
b. Cadenas de supermercados o instituciones públicas/privadas
c. Intermediarios satélites
d. Empresas transformadoras
e. Otro. ¿Cuál?

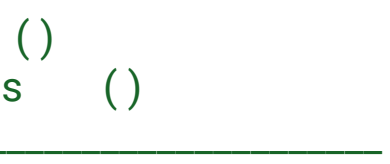

62. ¿Dónde comercializa el producto?
a. En el predio
b. En el mercado del pueblo
c. En plazas nacionales
d. En mercados internacionales
e. Otro. ¿Cuál?

63. ¿Conoce los procesos o requerimientos para poder exportar lechuga?
a. Sí
b. No

64. ¿Comercializa su producto en el mercado internacional?
a. Sí
( )
b. No 
65. Si comercializa en el mercado internacional, especifique en cuáles regiones:

a. Comunidad Andina de Naciones (CAN) ()

b. Mercosur

c. Centroamérica y el Caribe

d. EE. UU. y Canadá

e. Unión Europea

f. Asia

g. África

h. Oceanía

i. Otro. ¿Cuál?

66. El acceso a los mercados internacionales le implica (seleccione máximo 5 opciones y clasifíquelas, teniendo en cuenta que cinco es la mayor puntuación y uno la menor):

a. Eliminar barreras fitosanitarias

b. Producción limpia

c. Transformar el producto

d. Producir grandes volúmenes

e. Producir en cualquier temporada

f. Mayor velocidad de innovación

g. Reducción de los costos de producción

h. Ampliar infraestructura física

i. Capacitación del recurso humano

j. Gestión del talento humano

k. Actualización y renovación tecnológica

1. Vincular especialistas para los procesos misionales

m. Mejorar y ampliar el portafolio de productos ( )

n. Certificar competencias laborales

o. Incorporar procesos logísticos relacionados con almacenamiento, transporte y distribución 
de los productos

p. Otro. ¿Cuál?

67. La variación de los precios de ventas en el año es:

a. Alta (los precios presentaron cambios sustanciales en los diferentes meses)

b. Normal (similar a años anteriores con precios bajos y altos según los meses)

c. Baja (los precios permanecieron estables independientemente de los meses)

68. Con su conocimiento y experiencia, ¿cuál es la oferta del producto por mes?

\begin{tabular}{|l|l|l|l|l|}
\hline & Alta & Media & Baja & $\begin{array}{c}\text { Oferta en } \\
\text { toneladas/ha }\end{array}$ \\
\hline Enero & & & & \\
\hline Febrero & & & & \\
\hline Marzo & & & & \\
\hline Abril & & & & \\
\hline Mayo & & & & \\
\hline Junio & & & & \\
\hline Julio & & & & \\
\hline Agosto & & & & \\
\hline Septiembre & & & & \\
\hline Octubre & & & & \\
\hline Noviembre & & & & \\
\hline Diciembre & & & & \\
\hline
\end{tabular}

69. ¿Pertenece su unidad productiva a una asociación o cadena productiva reconocida? 

a. Sí
( )
b. No
Si su respuesta es "sí", indique cuál:

\section{IV.Estructura tecnológica e innovación}

70. ¿Su unidad productiva cuenta con el servicio de asistencia técnica agrícola?
a. Sí
( )
b. No

71. ¿La asistencia técnica agrícola ayuda a mejorar la producción de mi unidad productiva?
a. Sí
( )
b. No
( )

72. ¿Su empresa ha sido certificada por sistemas de gestión de calidad?
a. Sí
()
b. No
Si la respuesta es "sí", indique cuáles normas:

73. ¿Han llevado a cabo procesos de certificación del recurso humano por competencias laborales?
a. Sí
b. No
Si la respuesta es "sí", indique cuáles normas: 
74. ¿Dispone su unidad productiva de marcas propias?
a. Sí
b. No
Si la respuesta es "si", indique cuáles:

75. ¿Realiza su unidad productiva actividades de investigación y desarrollo tecnológico?
a. Sí
b. No
Si la respuesta es "sí", ¿a qué se enfoca esta investigación?

76. ¿En el último año se ha introducido en la empresa o unidad productiva alguna innovación en producto 0 proceso?
a. Sí
( )
b. No
()

Si la respuesta es "sí", indique cuáles productos o procesos:

78. ¿En su unidad productiva se ha establecido alguna práctica para contrarrestar la volatilidad de precios del cultivo?
a. Sí
b. No
( ) 
Si su respuesta es "sí", indique cuál:

79. ¿En su gremio se han diseñado nuevas políticas de apoyo a los productores para promover la seguridad alimentaria?
a. Sí
b. No
Si su respuesta es "sí", indique cuáles:

80. Considera que los rendimientos de su cultivo se han visto afectados en los últimos 20 años por:
a. El cambio climático
b. La erosión de los suelos
( )
c. La fatiga de los suelos
()
d. Presencia de hongos, nematodos y otros
e. La urbanización acelerada de los terrenos aptos para agricultura
f. Otro. ¿Cuál?

81. ¿En la unidad productiva se han desarrollado acciones para la adaptación al cambio climático?
a. Sí
b. No

Si su respuesta es "sí", indique cuáles: 
82. ¿Qué estrategia considera importante implementar para mejorar la competitividad de la lechuga?

a. Construir centros de acopio locales o regionales ( )

b. Asociarse con otros productores

c. Diversificar las variedades

d. Implementar proyectos de transformación del producto ()

e. Mejorar la infraestructura productiva

f. Incursionar en nuevos mercados

g. Otro. ¿Cuál? 
Anexo 6. Tabulación encuesta de caracterización Lechuga

\section{El cultivo es:}

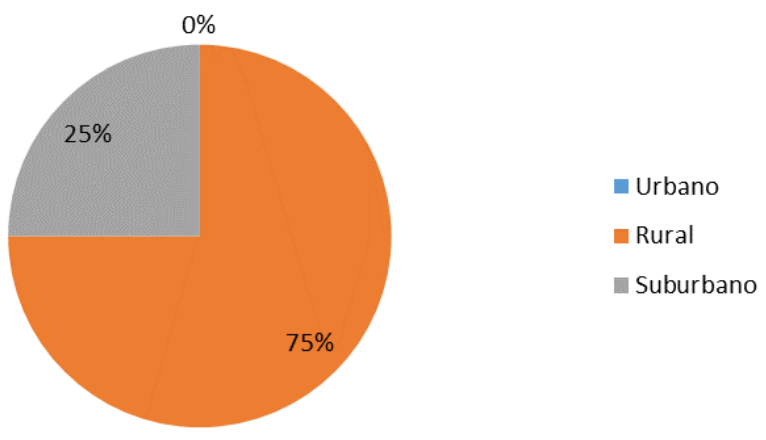

\section{El tiempo de conformación de la unidad productiva es de:}

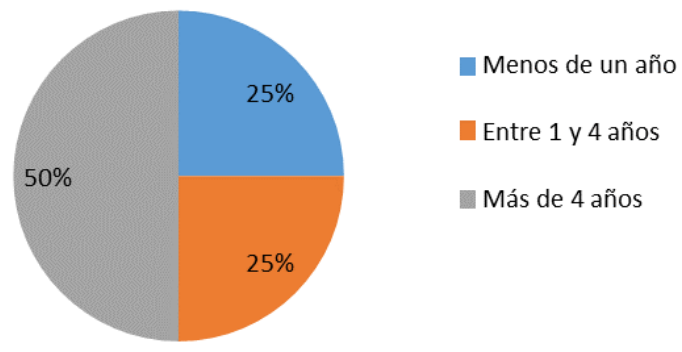




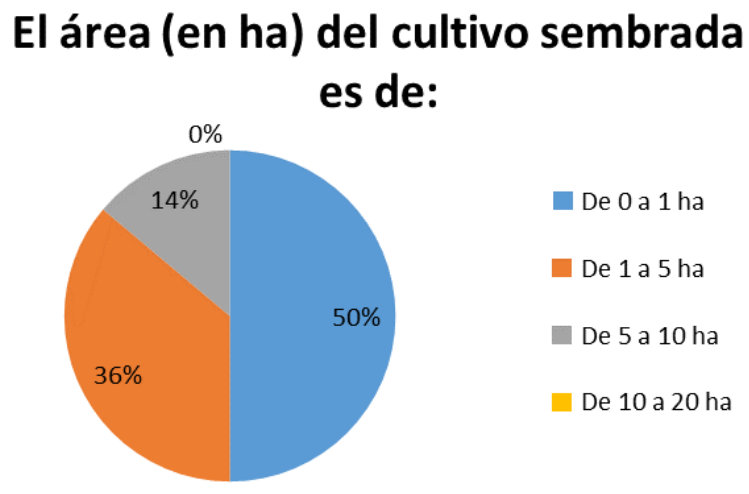

El área (en ha) cosechada del cultivo es de:

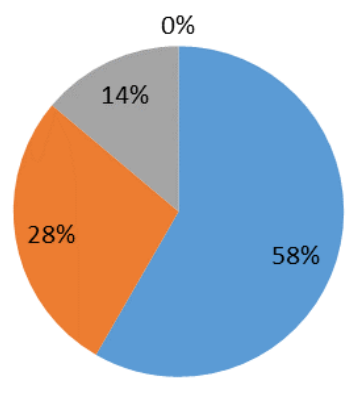

- 0 a 1 ha

1 a 5 ha

5 a 10 ha

Sup. a 10 ha

La producción (ton/ha ciclo) es de:

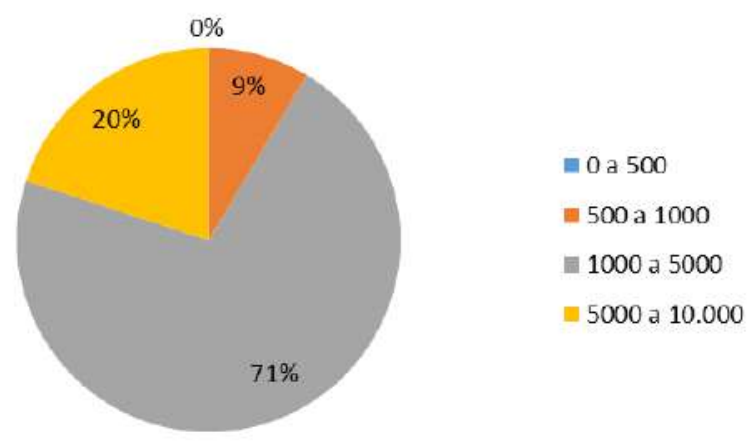




\section{¿Cuál es la periodicidad de la producción de lechuga en su parcela?}

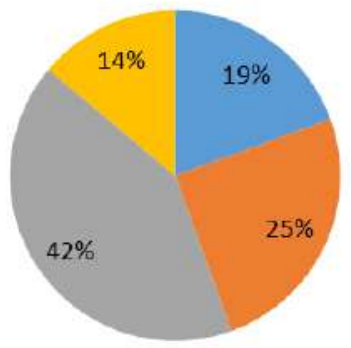

De $0-15$ días

De 15-30 días

- De 30-60 días

De 60 a 90 días

Caracterización del suelo de su unidad productiva:

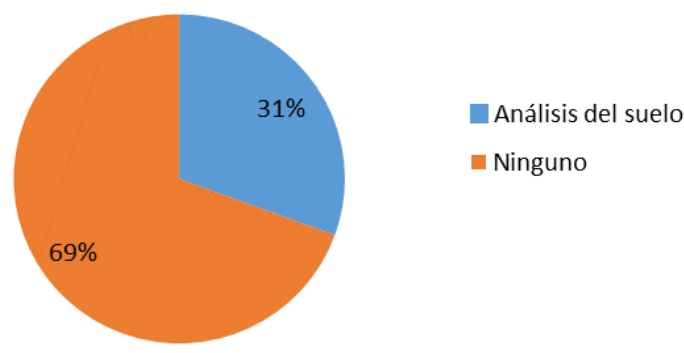

¿Cada cuánto tiempo realiza la caracterización del suelo en su unidad productiva?

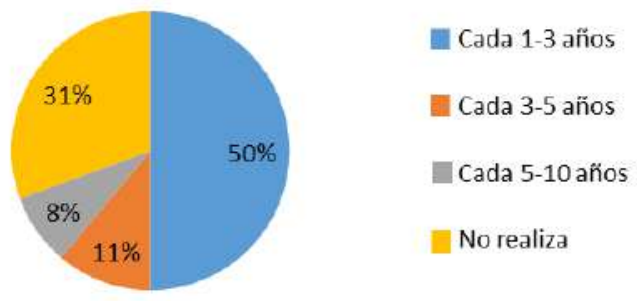




\section{El tipo de suelo de su unidad productiva es:}

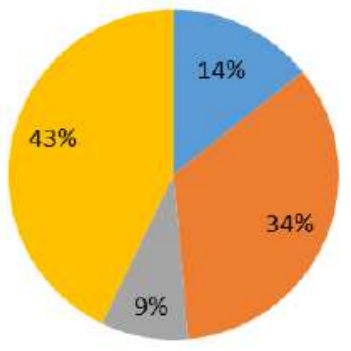

m Suelo arenoso

in Suelo limoso

w Suelo arcilloso

w Suelo franco arenoso

\section{¿Cuáles son los criterios mediantes} los cuales usted fertiliza?

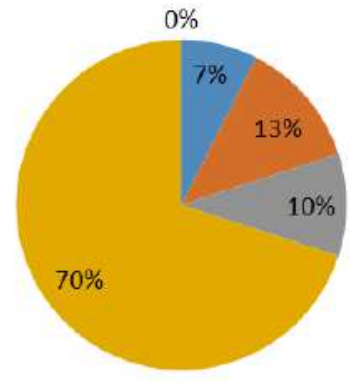

Análisis del suelo

Ciclos estandarizados

Situación climática

A juicio del cultivador

otro

¿Cuáles son los criterios del uso de agroquímicos?

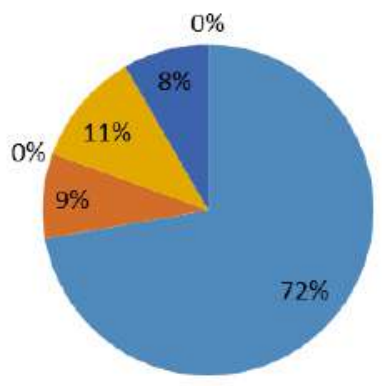

Experiencia

a calendario

n Preservación ambiental

Incidencia y severidad

- Por evaluación agronómica 
¿Cuáles son los productos más utilizados para el control de plagas y enfermedades en el cultivo?

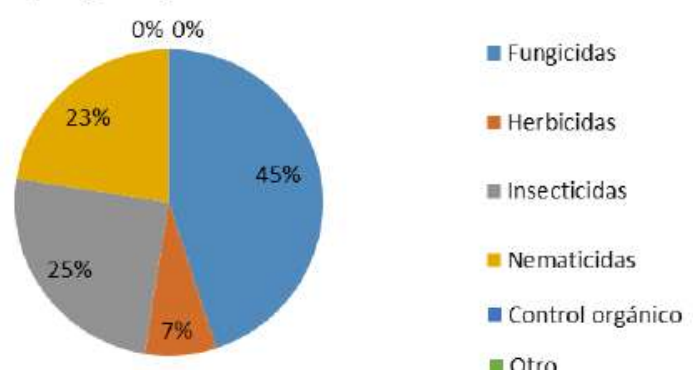

¿Cuáles son los fertilizantes más utilizados para las etapas de crecimiento, desarrollo y producción del cultivo?

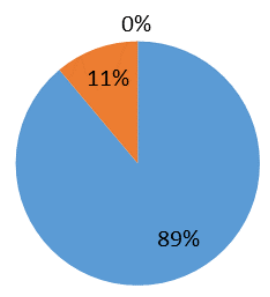

Fertilizantes químicos

Fertilizantes de origen orgánico

Otro

\section{¿Utiliza en su cultivo productos} orgánicos?

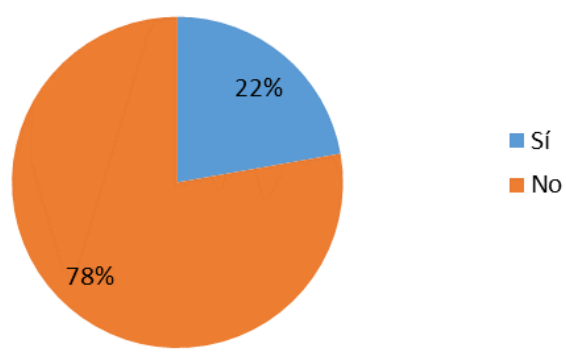


¿Qué tipo de riego utiliza en su cultivo diferente a agua lluvia?

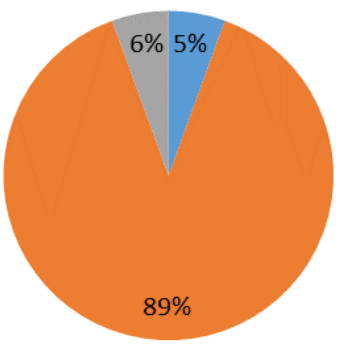

- Distritos de Riego

Reservorios

Acueductos

¿Qué sistema de riego utiliza en su cultivo?

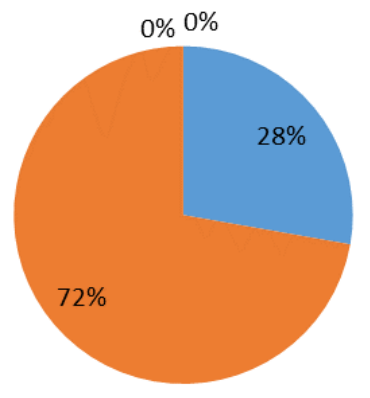

- Por aspersión

- Por goteo

- Por gravedad

Otro

¿Tiene mecanismos implementados para el manejo de aguas residuales de origen agrícola?

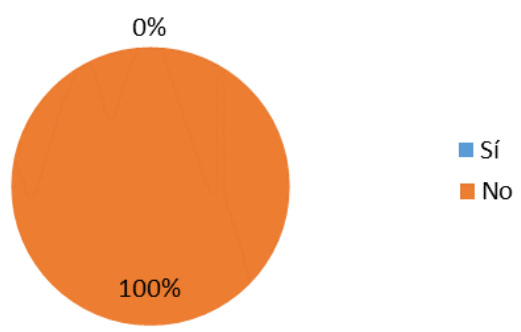


¿Tiene mecanismos implementados para el manejo de cuencas hidrográficas?

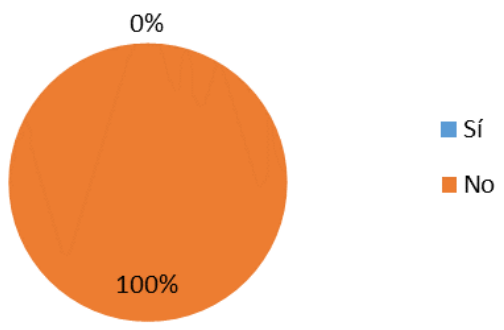

¿Cuál es el uso dado a los envases de agroquímicos utilizados en las prácticas de cultivo?

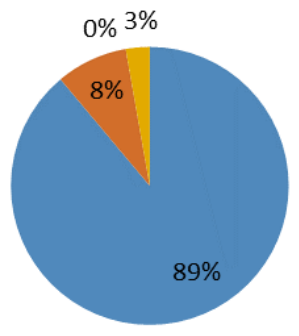

Reciclados

- Desechados dentro del cultivo

Incinerados

Otro

¿Cuál es el tiempo en horas a la semana destinado por el productor en la unidad productiva?

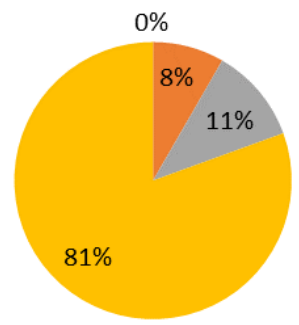

5 a 10 horas

- 11 a 15 horas

- 16 a 20 horas

Más de 20 horas 


\section{¿Qué otro tipo de actividad laboral} realiza el productor?

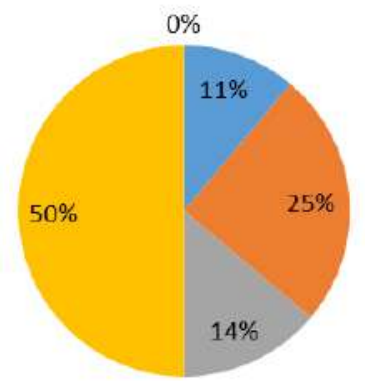

$$
\begin{aligned}
& \text { n Comerciante } \\
& \text { w Jornalero agrícola } \\
& \text { = Profesional dependiente } \\
& \text { = Profesional independiente } \\
& \text { = Otras }
\end{aligned}
$$

¿Cuál es el porcentaje de ingresos aportados por otras actividades laborales?

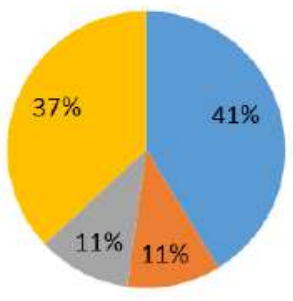

Del $1 \%$ al $25 \%$

Del $26 \%$ al $50 \%$

Del $51 \%$ al $75 \%$

Del $76 \%$ al $100 \%$

¿Cuál es el porcentaje de ingresos aportados por la unidad agrícola?

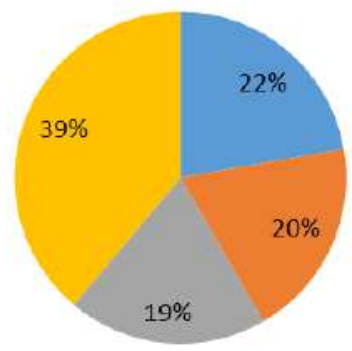

Del $1 \%$ al $25 \%$

Del $26 \%$ al $50 \%$

Del $51 \%$ al $75 \%$

Del $76 \%$ al $100 \%$ 
Nivel educativo de los productores:

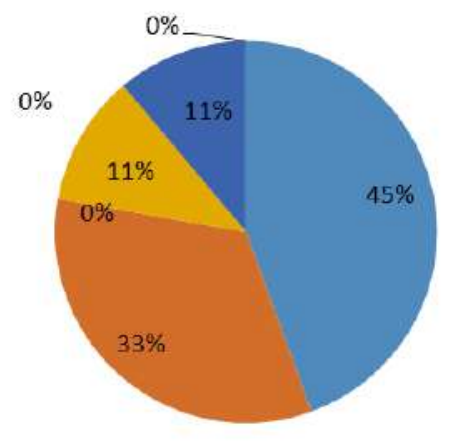

w Primaria

n Secundaria

= Técnico

ㅍecnólogo

- Profesional

-1 Posgrado

= Ninguna

\section{¿Tiene empleados en su cultivo?}

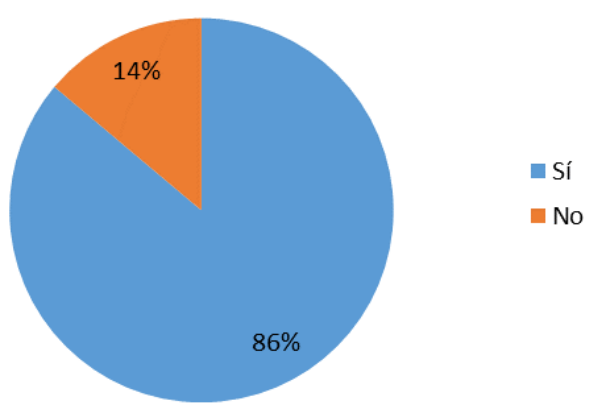

\section{El número de trabajadores de la unidad productiva, incluyendo todas las sedes, es:}

$0 \% 0 \%$

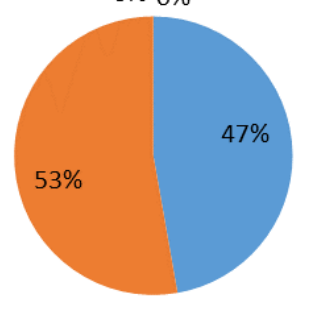

- De 1 a 2

- De 3 a 5

- De 6 a 10

- Superior a 11 
¿Qué tipo de vinculación tiene para la mayoría de empleados de su cultivo?

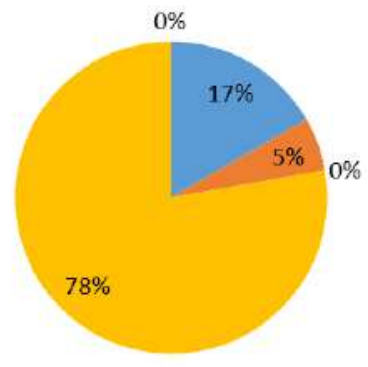

- Tiempo completo

- Medio tiempo

- Por jornal

- Prestación de servicios

atro

\section{¿Cuáles son los gastos promedio mensuales para el sostenimiento de su hogar?}

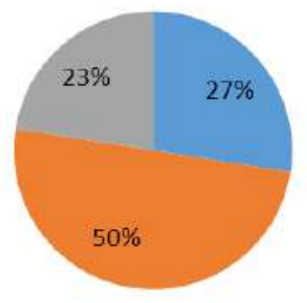

Menos de 1.000 .000

Entre $1.000 .000 \mathrm{a}$

1.500 .000

Más de 1.500.000

\section{¿Qué nivel educativo tienen los trabajadores vinculados en su proceso productivo?}

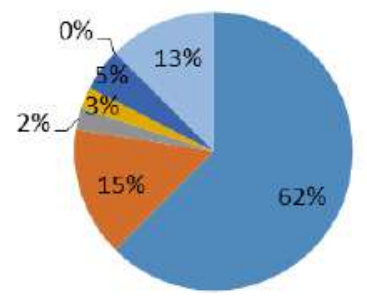

- Primaria

- Secundaria

- Técnico

in Tecnólogo

- Profesional

- Posgrado

Ninguna 


\section{¿Está capacitado el personal de cultivo para realizar las actividades?}

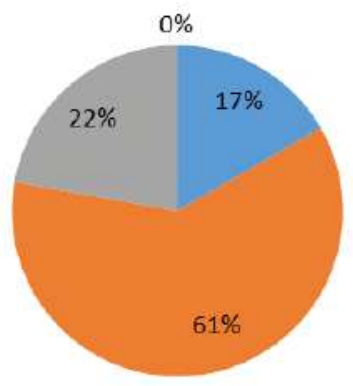

Todos

La gran mayoría

Algunos

Ninguno

\section{La capacitación del personal es:}

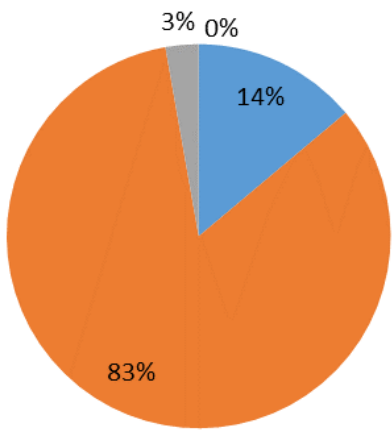

- Dada en el cultivo por otros trabajadores

- Dada en el cultivo por el productor

- Se contratan capacitadores

Otro

\section{¿En qué actividades considera que se} requiere capacitación?

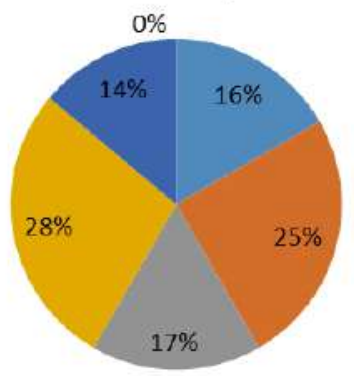

Producción

- Mercadeo

- Fluctuación de precios

Poscosecha

- Financiamiento

Otro 
¿Tiene proyecciones de ampliar el

volumen de producción en su cultivo?

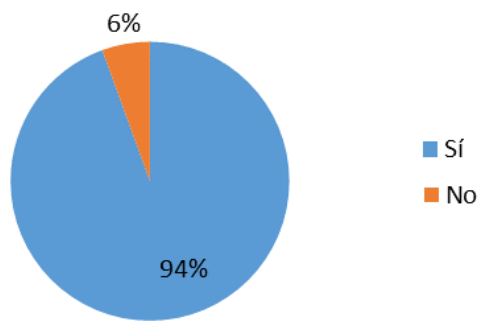

\section{¿Cuáles considera que son las prioridades estratégicas con miras a mejorar la competitividad?}

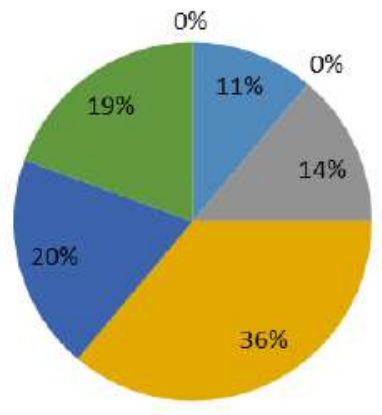

- Minimizar el precio de agroquímicos

- Aumentar productividad de los

empleados mediante reconocimientos

- Conformar formas asociativas

nealizar préstamos para aumentar el volumen de producción

- Invertir en investigación y desarrollo

- Realizar transformación de producto in Otro

\section{¿Recibe incentivos del gobierno para desarrollar esta actividad?}

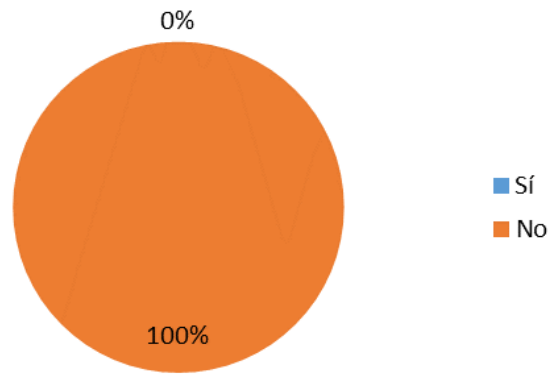


¿Qué tipo de transformación requiere para mejorar su competitividad?

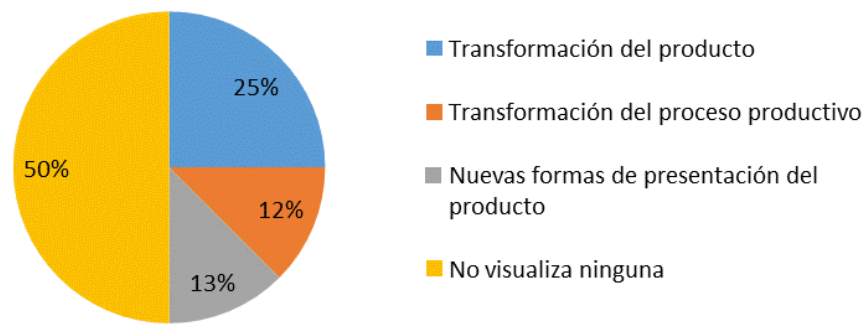

¿Qué incentivos considera usted que debería dar el gobierno para desarrollar mejor su actividad y mejorar su rentabilidad?
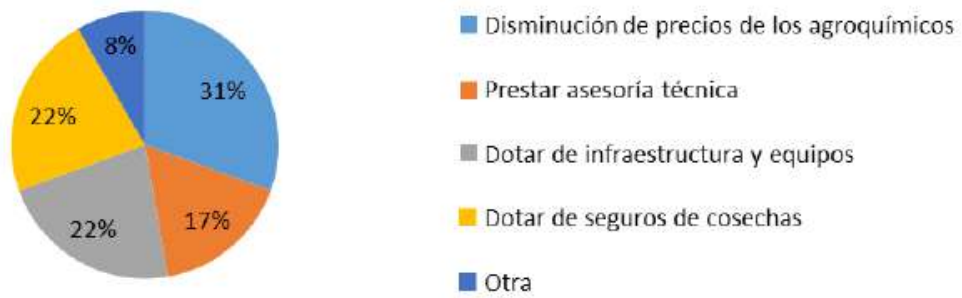

¿Cuál cree usted que son los principales factores que afectan el producto en materia de competitividad?
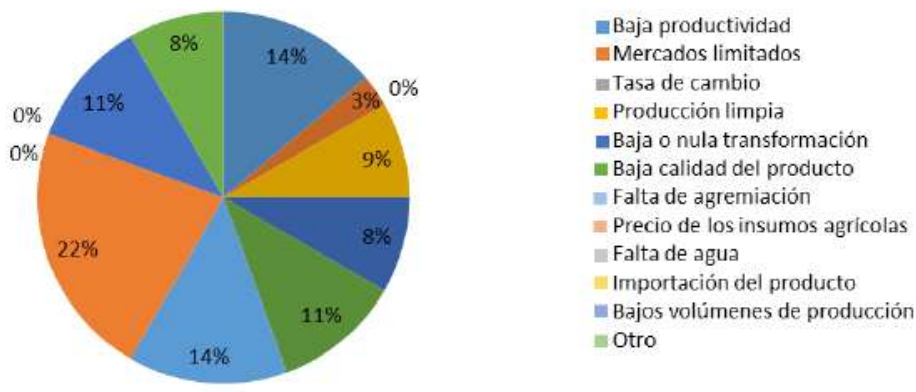


\section{¿Lleva registros contables de su actividad agrícola?}

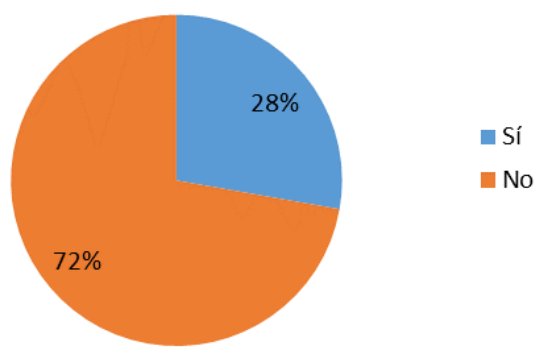

¿Aproximadamente a cuánto ascienden las ventas por ciclo de producción/ha en su cultivo?

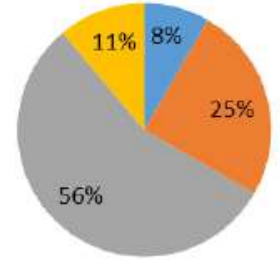

Entre 20 y 30 millones

Entre 30 y 50 millones

Entre 50 y 80 millones

Más de 80 millones

\section{¿De cuánto es el costo de producción de su cultivo por ha?}

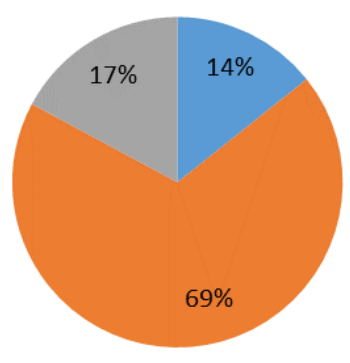

Entre $\$ 1.000 .000$ y $\$ 10.000 .000$

Entre $\$ 10.000 .000$ y $\$ 30.000 .000$

Entre $\$ 30.000 .000$ y $\$ 50.000 .000$ 
¿Cuál es la frecuencia de sembrado de papa en su unidad productiva?

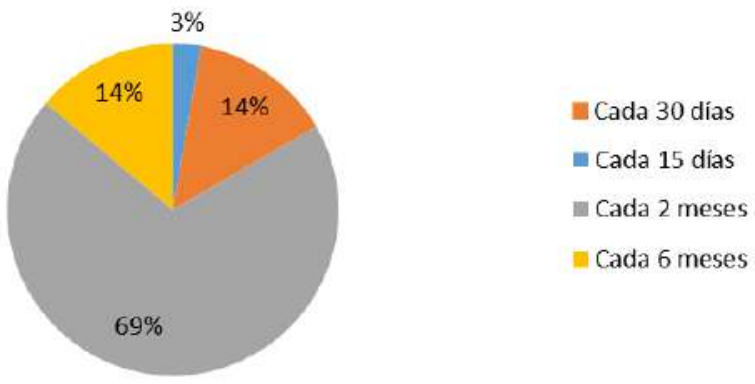

¿Cuáles son los criterios en que se basa para manejar distintos precios de venta?

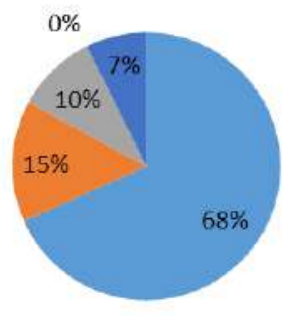

- Venta plaza al por mayor

- Cercanía a centros de consumo

Wormas de pago

- Pago anticipado

atro

¿A qué mercados están dirigidos los productos que desarrolla su unidad productiva?

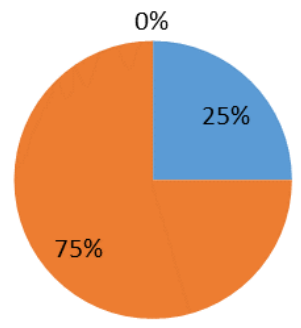

$$
\begin{aligned}
& \text { n Local } \\
& \text { nacional } \\
& \text { n Internacional }
\end{aligned}
$$




\section{¿A quién le vende su producto con más frecuencia?}

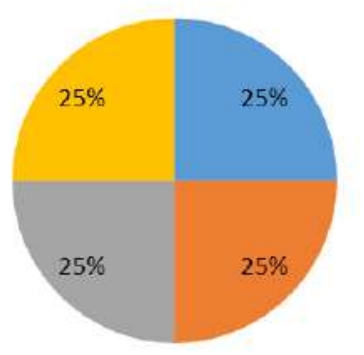

- Plaza de mercado local o nacional

- Cadenas de supermercados o instituciones públicas o privadas

- Intermediarios satélites

Empresas transformadoras

\section{¿Dónde comercializa el producto?}

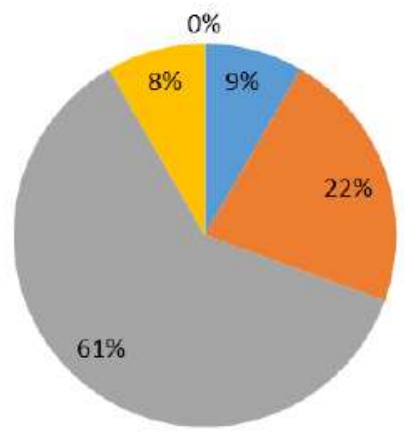

En el predio

En el mercado del pueblo o plaza nacional

m Plazas nacionales

Empresas con convenio de comercialización

motros

¿Conoce los procesos o requerimientos para exportar lechuga?

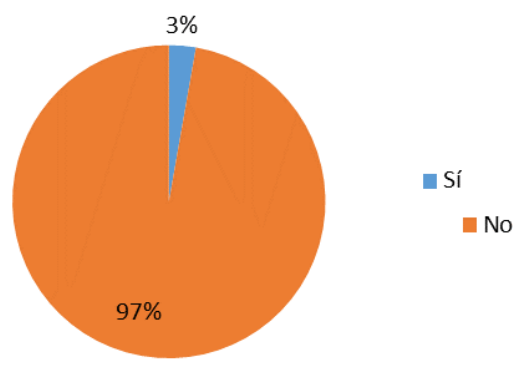




\section{¿Comercializa en el mercado internacional?}

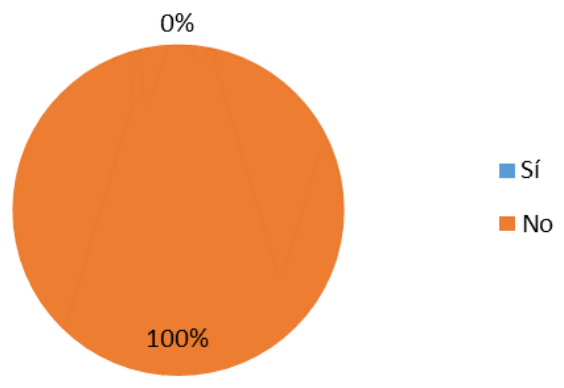

\section{El acceso a los mercados internacionales implica:}

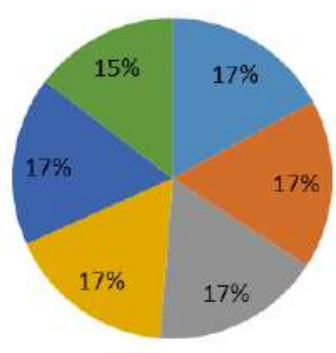

E Eliminar barreras fitosanitarias

- Producción limpia

- Transformar el producto

E Producción grandes volúmenes

Mayor innovación

Ampliar portafolio de productos

La variación de precios de venta en el año es:

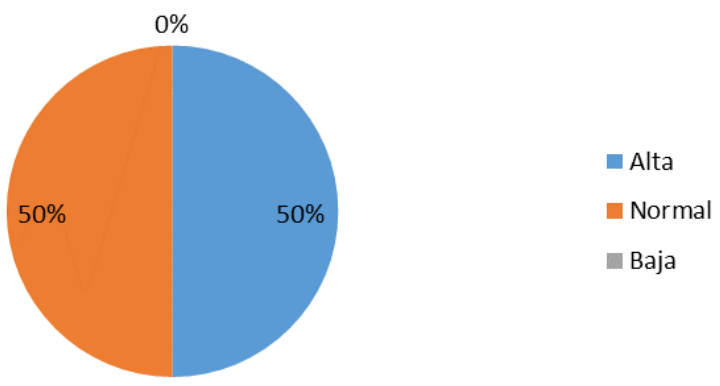


¿Pertenece su unidad productiva a una asociación o cadena productiva reconocida?

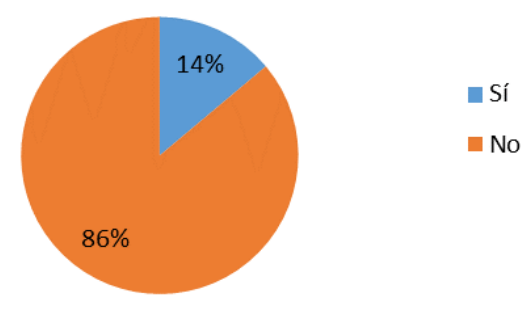

¿Su unidad productiva cuenta con el servicio de asistencia técnica agrícola?

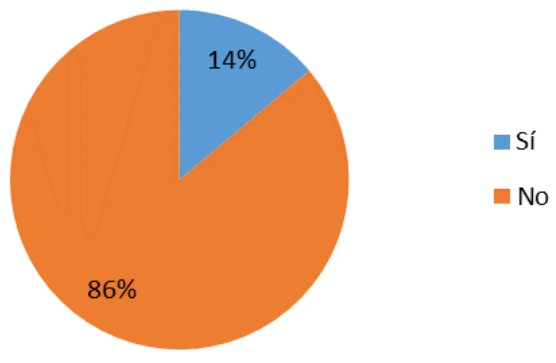

¿La asistencia técnica agrícola ayuda a mejorar la producción de mi unidad productiva?

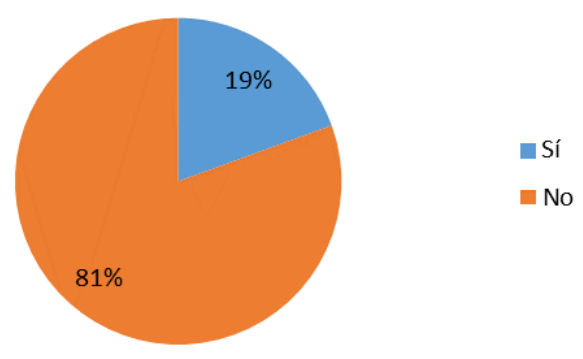


¿Su empresa ha sido certificada por sistemas de calidad?

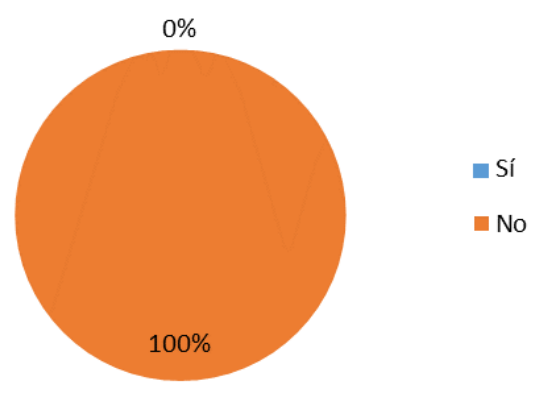

\section{¿Han llevado procesos de certificación del recurso humano por competencias laborales?}

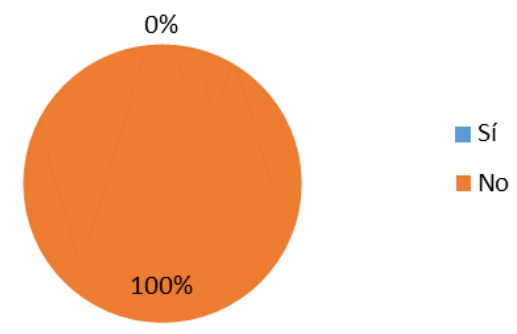

¿Dispone su unidad productiva de marcas propias?

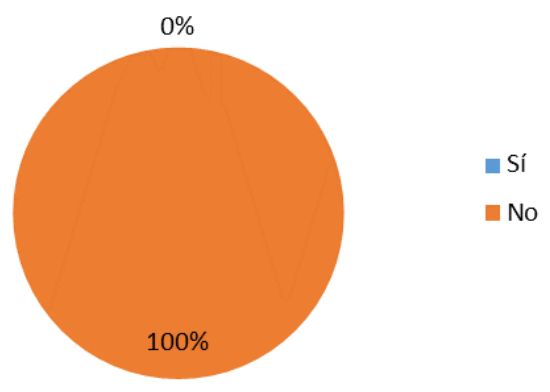


¿Realiza en su unidad productiva actividades de investigación y desarrollo tecnológico?

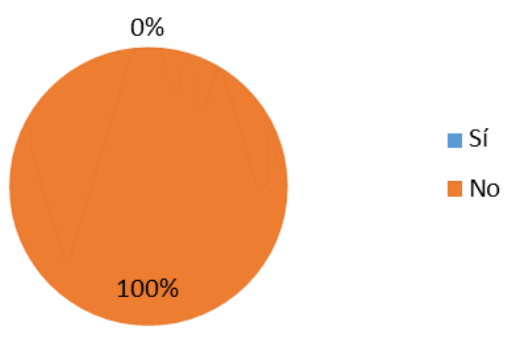

¿En el último año se ha introducido en la empresa alguna innovación en producto o proceso?

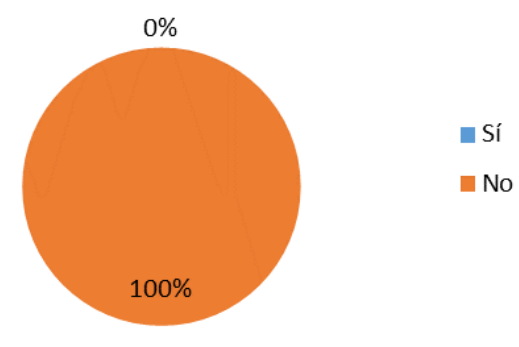

¿Cuáles tecnologías considera que serán utilizadas en los próximos años?

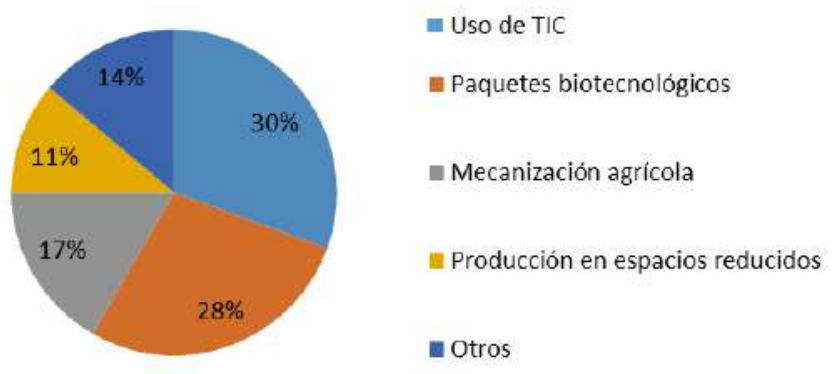


¿En su unidad productiva se ha establecido alguna práctica para contrarrestar la volatilidad del precio del producto?

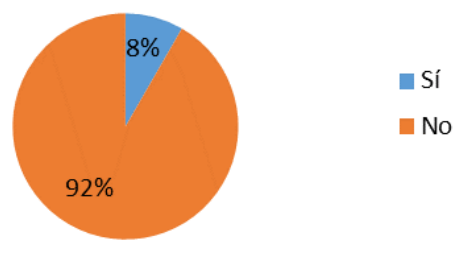

¿En su gremio se han diseñado nuevas políticas de apoyo para promover la seguridad alimentaria?

$0 \%$

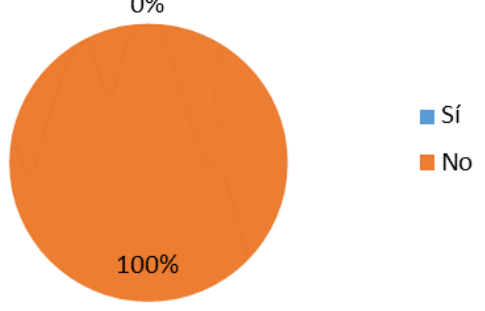

¿En la unidad productiva se han desarrollado acciones para la adaptación al cambio climático?

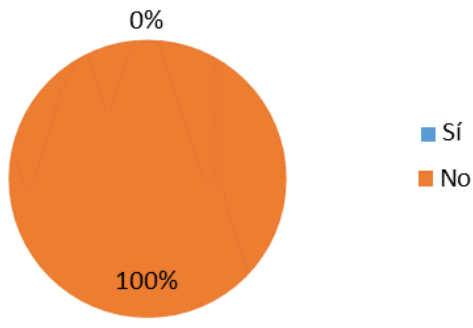




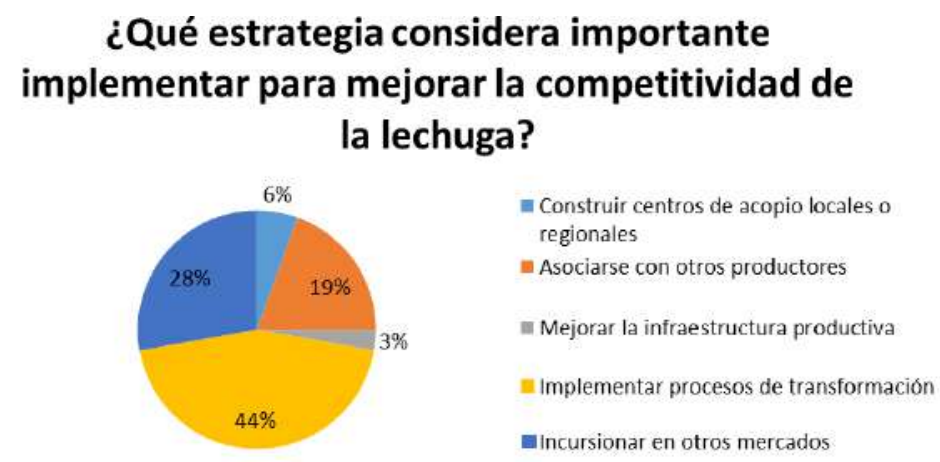

Considera que los rendimientos de su cultivo se han visto afectados en los últimos años por:

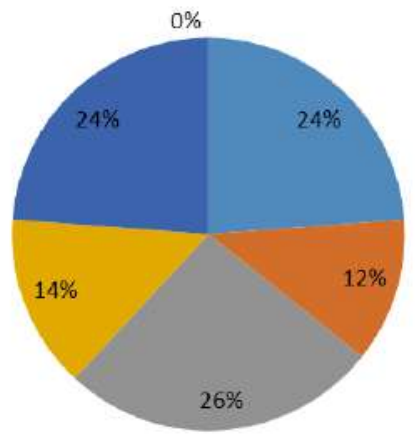

EEl cambio climático

- La erosión de los suelos

La fatiga de los suelos

in La presencia de hongos, nemátodos y otros

- La urbanización acelerada de los terrenos aptos para agricultura

Otro 


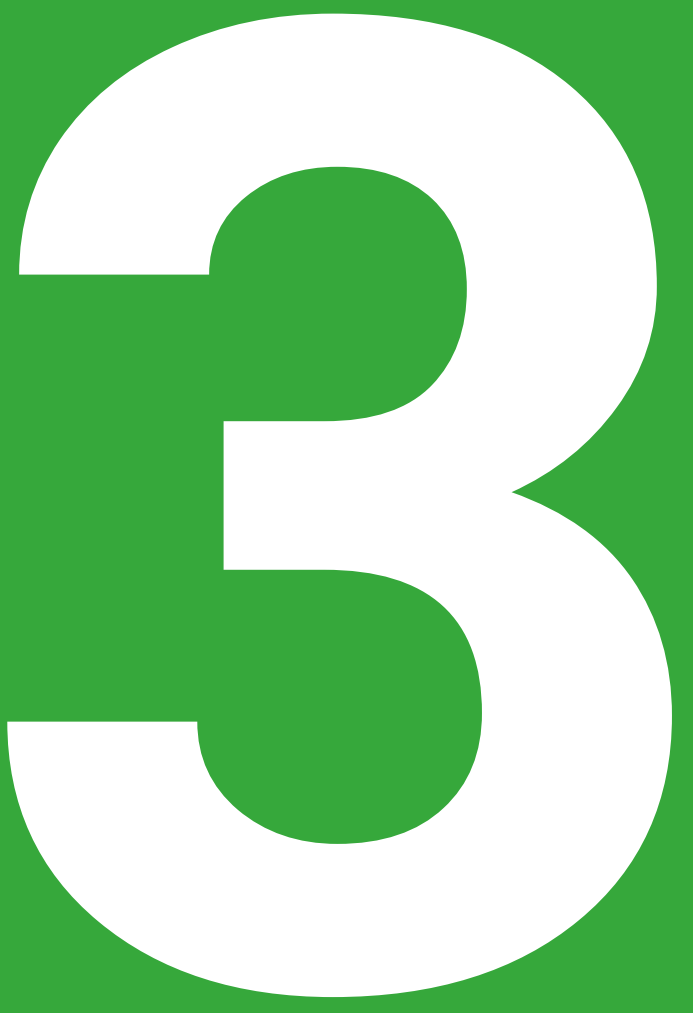

Análisis del emprendimiento turístico en los municipios de Chía y Cajicá 2019-2020. Propuesta metodológica 


\title{
Análisis del emprendimiento turístico en los municipios de Chía y Cajicá 2019-2020. Propuesta metodológica
}

\author{
Luz Deicy Flórez Espinal' ${ }^{16}$ \\ Ana María Balcázar Daza ${ }^{17}$ \\ Jairo Alonso Ávila Moreno ${ }^{18}$
}

\section{Introducción}

Indagar la caracterización del emprendimiento turístico en Chía y Cajicá del 2018 al 2019, con el fin de describir su composición y recoger la percepción que sobre el tema se tiene en las alcaldías y universidades de la región Sabana Centro, es la propuesta de una investigación en curso que contribuya a la consolidación de la gestión empresarial de los

\footnotetext{
$16 \quad$ Estudiante de doctorado en Pensamiento Complejo (Multiversidad Mundo Real, México), magíster en Ciencias Económicas (Universidad Nacional de Colombia), especialista en Evaluación Socioeconómica de Proyectos y administradora de empresas (Universidad de Antioquia, Colombia). Docente investigadora de la Facultad de Ciencias Administrativas, Económicas y Contables (Universidad de Cundinamarca, extensión Chía, Colombia).E-mail: Ideicyflorez@ucundinamarca.edu.co.

17 Magíster en Dirección de Empresas de la Universidad Camilo José Cela de España, economista y administradora de empresas de la Universidad Santo Tomás. Docente investigadora del programa de Administración de Empresas e integrante del Grupo de Investigación DOPyS de la Universidad de Cundinamarca. E-mail: anacoris2@hotmail. com.

18

Magíster en Desarrollo Rural, especialista en Gerencia Informática, especialista en Finanzas y administrador de empresas. Docente investigador del programa de Administración de Empresas e integrante del Grupo de Investigación DOPyS. E-mail: jairo3139@yahoo.es.
} 
emprendimientos turísticos de los dos municipios.

La pregunta articuladora del proyecto es: ¿cuáles son las características del emprendimiento turístico en los municipios de Chía y Cajicá en el periodo 2019-2020? La respuesta que se obtendría sería a partir del análisis de las condiciones de operación de emprendimientos como restaurantes, hoteles y puestos de información turística. Además, se hará la selección de un grupo piloto de emprendimientos para la aplicación de un modelo de formación sobre administración de emprendimientos turísticos. Por último, en el área de soporte web y desarrollo de aplicaciones móviles se acompañarán los emprendimientos del grupo piloto para el diseño de propuestas útiles empleando recursos TIC; la infraestructura de la Universidad de Cundinamarca será el lugar para realizar el modelo de formación y los semilleristas de investigación de la extensión Chía investigarán haciendo el trabajo de campo.

No se trata de una investigación inferencial acerca del total de los emprendimientos turísticos de los dos municipios. Su utilidad puede radicar en coadyuvar a fijar políticas y acciones públicas para el fortalecimiento del emprendimiento en los municipios de Chía y Cajicá, o de la subregión Sabana Centro. También es claro que una investigación de este tipo permite generar un acercamiento de la academia con la realidad empresarial, particularmente la regional. 


\subsection{Estado del arte}

\section{Sabana Centro de Cundinamarca como destino turístico}

La actividad turística en el departamento de Cundinamarca, como mercado potencial y de acuerdo con el Plan de Desarrollo Turístico Departamental, señala 14 provincias con vocaciones turísticas como el turismo cultural, sustentable, de recreación, deportivo, histórico, contemplativo, de descanso, ecoturismo y de aventura (Infante, 2014). De esas vocaciones predominantes se desataca la Sabana Centro con el ecoturismo, turismo cultural y turismo de observación (Infante, 2014).

En cuanto a la concentración de empresas en actividades de turismo, Infante (2014) señala que el $56 \%$ de los prestadores turísticos son empresas para alojamiento, y un 14 \% para gastronomía y guía turística; además, que la Gobernación de Cundinamarca desea para el departamento ser reconocido como destino turístico; este anhelo también lo comparten gremios como la Asociación Colombiana de Agencias de Viajes y Turismo (ANATO) y la Asociación Hotelera y Turística de Colombia (COTELCO).

Dentro de la subregión Sabana Centro se destacan los municipios de Chía y Cajicá. El municipio de Chía, fundado en 1537, se encuentra ubicado en límites con los municipios de Tenjo y Cajicá. Las principales actividades económicas son la agricultura, la floricultura y la ganadería lechera. Existen también algunas manufacturas y artesanías como la pintura, escultura en piedra y bronce, ebanistería, carpintería y trabajo con hierro forjado. La gastronomía y el turismo, asociado con ella, son sectores recientes 
reconocidos dentro de los cuales se destacan bares y restaurantes de alta gama. El municipio cuenta además con una amplia oferta comercial y de entretenimiento mediante centros comerciales, discotecas y restaurantes abiertos al público en las noches, principalmente sobre la Avenida Pradilla y la variante Chía-Cota (Alcaldía Municipal de Chía, 2019).

El municipio de Cajicá, por su parte, fue fundado en 1537 y se encuentra en la subprovincia de la Sabana Centro, al norte de Chía, y en la vía que conduce a Zipaquirá. La economía del municipio cuenta con empresas en industria (lácteos, papel, cementos, huevos), floricultura, agrícola y artesanías. Cajicá se destaca por poseer sitios turísticos como la parroquia Inmaculada Concepción, el centro cultural, la reserva natural de Montepincio y el seminario de San Gabriel. También tiene una de las estaciones del tren de la sabana donde existen diversos restaurantes como parada para los turistas que viajan en el tren. Cuenta con un destacado espacio apto para realizar todo tipo de eventos y ferias, lo mismo que el Autódromo $\mathrm{XRP}$, adecuado para la realización de actividades deportivas y recreativas (Concejo Municipal de Cajicá, 2018).

\section{Política pública de turismo en Colombia e instrumentos de ejecución}

La Ley 300 de 1996 corresponde a la norma que regula la industria turística en Colombia y en la cual señala la necesidad de presentar un Plan Sectorial de Turismo dentro del Plan Nacional de Desarrollo durante el primer año de gobierno de cada presidente de la república (Benavides, 2015). La Ley marco de turismo dio origen al Viceministerio de Turismo, la Dirección 
de Calidad y Desarrollo Sostenible de Turismo, y la Dirección de Análisis Sectorial y Promoción de Turismo; adicionalmente se permite el origen del Plan Sectorial de Turismo (PST) y se crean instrumentos de fomento turístico en materia tributaria, el Fondo de Promoción Turística, el Registro Nacional de Turismo, entre otros (Benavides, 2015).

De otro lado, el Ministerio de Comercio, Industria y Turismo (2018) propone seis temas en los que se debe concentrar la política de competitividad en turismo, como son: (i) gestión; (ii) calidad; (iii) seguridad, higiene y salubridad; (iv) educación y formación del talento humano; (v) desarrollo de infraestructura estratégica; y (vi) facilitación turística, los cuales corresponden a las tareas centrales que el Gobierno Nacional debe impulsar para promover el plan de turismo.

\section{Herramientas de promoción del turismo}

El sector audiovisual está relacionado con el turismo, ya que el turista, al trasladarse de escenarios y destinos geográficos diferentes, puede compartir las sensaciones y movimiento de su experiencia individual mediante imágenes, videos o series audiovisuales. Las actividades audiovisuales están relacionadas con el viajar y con la realización de series audiovisuales que permiten al espectador poder observar otras realidades (Araújo y Fraiz, 2013).

De otro lado, como herramienta de promoción del turismo se encuentra el comercio electrónico por medio de sitios web que actúan como intermediarios con los turistas potenciales, siendo el uso de las páginas web fundamental para el fomento del turismo (Alcántara y Barrio, 2016). 
En cuanto a la gestión de las empresas turísticas, es clave como herramienta de trabajo la adopción de un sistema integrado para la gestión, orientado a las Mipymes como estrategia de fortalecimiento de diferentes destinos turísticos del departamento a un nivel de clase mundial (López, Maldonado, Pinzón y García, 2016). En este sentido, el Plan Sectorial de Turismo 2018-2022 (Ministerio de Comercio, Industria y Turismo, 2018) impulsa el desarrollo de seis líneas estratégicas para promover el turismo en Colombia: (i) generación de condiciones institucionales para el impulso al sector turismo; (ii) gestión integral de destinos y fortalecimiento de la oferta turística del país; (iii) más inversión, mejor infraestructura y conectividad para el turismo; (iv) innovación y desarrollo empresarial en el sector turismo; (v) fortalecimiento del capital humano para la competitividad del turismo; y (vi) promoción de un turismo transformador, incluyente y con equidad.

\section{Emprendimiento e innovación turística}

La definición de emprendedor es tan amplia como literatura existe sobre el tema, pero la mayoría converge en el sentido que el emprendedor decide innovar y tomar riesgos porque es capaz de trabajar bajo incertidumbre (Bucardo, Saavedra y Camarena, 2015). Por otro lado, el sector turístico aumenta considerablemente a nivel mundial, ya que aporta el $11 \%$ del PIB mundial y más del $8.3 \%$ del empleo global (López, Serrano y Gómez, 2009). De acuerdo con lo anterior, el turismo está reflejando cambios en cuanto a la capacidad instalada y al tipo de competencia, por lo que se demandan nuevas orientaciones de actividad turística donde la innovación surge como elemento 
básico para garantizar competitividad y crecimiento para los emprendimientos turísticos (López, Serrano y Gómez, 2009).

López, Serrano y Gómez (2009) señalan que son pocos los estudios que han analizado la innovación en turismo, tanto sobre el análisis del sector en su conjunto como el estudio de industria hotelera; las investigaciones en ese tema se basan principalmente en clasificar los tipos de innovación que se pueden presentar en el sector turístico, mientras que son pocos los trabajos que buscan investigar las tendencias de la actividad innovadora, las variables que determinan la decisión de innovar en turismo y el comportamiento innovador de las empresas turísticas (pp. 169-170).

Los factores que determinan la probabilidad de emprender en la industria turística son diversos, por eso el análisis del emprendimiento turístico requiere la selección de unidades más específicas (Silveira, Cabeza y Fernández, 2016).

\section{Avances tecnológicos para pymes turísticas}

Las Tecnologías de la Información y la Comunicación (TIC) en el sector turístico son clave para la promoción, gestión, comercialización y marketing que toda pyme turística requiere para ser visible, bien a nivel local o global. López y López (2018) citan a Gálvez (2014) en su estudio sobre el impacto de las TIC en la innovación de la mipyme colombiana, en la que asegura que estas nuevas tecnologías son el factor central para alcanzar la competitividad y la sostenibilidad. Como señala Giraldo, "son prioritarias las micro, pequeñas y medianas empresas, que representan $99 \%$ de las empresas del país y son un engranaje vital para la economía colombiana" (2015), 
por lo que al vincularlas con la tecnología y TIC en general en sus procesos impulsan las oportunidades comerciales como la rentabilidad de sus negocios. En este sentido, las pymes del sector turístico aún tienen mucho por hacer en cuanto a la adopción ideal de las TIC, donde Segovia, Bermeo y González (2014) afirman que esto se debe a dos factores: (i) la carencia de una cultura organizacional que considere verdaderamente su uso; y (ii) la limitada disponibilidad de recursos financieros, humanos y tecnológicos dispuestos para este fin.

Frente a estos factores, las pymes se enfrentan a retos y oportunidades encaminados a la gestión empresarial, donde las TIC representan un papel fundamental para su desarrollo, tales como: la distribución, los medios sociales (marketing social), generación de servicios de valor añadido (desarrollo del website, anuncios online) y tecnologías portables o wearables. Cada uno de estos retos y oportunidades asumen un rol importante en el marketing y gestión digital de una empresa (e-mail marketing, marketing de buscador, marketing de afiliados), por lo que su buena administración deriva en nuevas plazas de empleo y crecimiento corporativo, adicional a la buena imagen que se brinda a la comunidad. Es por ello que cada vez es más frecuente encontrar empresas turísticas presentes de forma activa en la red, incluso, se considera extraño si estas no interactúan en este entorno virtual (Daries y Fransi, 2016). Bajo esta perspectiva, la industria de las pymes de turismo en Colombia tiene a su disposición diversos recursos TIC que pueden ser encaminados a promover la imagen de una región potencialmente turística, que a su vez genera cambios que afectan tanto a proveedores 
intermediarios, al consumidor final y economía de la región.

\subsection{Metodología}

La investigación objeto del presente artículo corresponde a un tipo mixto según su paradigma, ya que aborda el análisis socioeconómico del sector del turismo en Cajicá y Chía a partir de información secundaria. Se mide el grado de percepción de la comunidad de estos municipios sobre el emprendimiento mediante entrevistas semiestructuradas. A través de las entrevistas, la investigación es interpretativa, ideográfica y humanística. Adicionalmente, se aplican encuestas para obtener resultados a mayor escala en cuanto al tamaño de muestra poblacional de emprendimientos turísticos.

Según la finalidad de la investigación es aplicada, ya que se podrán comprobar los planteamientos hechos alrededor del tema de emprendimiento turístico.

En cuanto al instrumento de medición referente a las encuestas, se realizan teniendo en cuenta la población de estudio. La primera parte busca conocer las bases de datos de emprendedores turísticos registrados en la Gobernación de Cundinamarca, alcaldías de Cajicá y Chía y Cámara de Comercio de Bogotá. En la segunda parte se efectúa una intervención piloto que contribuye a la consolidación de la gestión empresarial de los emprendimientos turísticos de los dos municipios, mediante el diseño de un soporte web y desarrollo de aplicaciones móviles que permitan la mayor difusión de los servicios que ofrecen los emprendedores turísticos. 
En la tercera y última etapa se recogerá la percepción de académicos y funcionarios públicos encargados de liderar los temas de emprendimiento, turismo e innovación en la región Sabana Centro, y particularmente en los municipios de Cajicá y Chía.

\section{Resultados esperados}

A través de las respuestas dadas por los emprendedores turísticos se podrá diseñar un sistema de investigación en emprendimientos turísticos acorde a las necesidades de la región, lo mismo que el diseño de programas de acompañamientos brindados desde la Universidad de Cundinamarca que, desde ahora, trabaja en la creación y adopción de una línea de profundización en emprendimiento turístico para las subregiones del departamento.

Adicionalmente, se diseña un soporte web y aplicación móvil certificado por el Grupo de Investigación S@R@A, el cual se trasladará a las respectivas alcaldías para su uso, promoción y continuidad

\section{Objetivo general de la investigación}

Indagar la caracterización del emprendimiento turístico en Chía y Cajicá en el periodo 2018 al 2019, con el fin de describir su composición en cuanto a tipos de servicios turísticos ofertados.

\section{Objetivos específicos}

- Identificar la percepción que sobre el 
emprendimiento turístico se tiene en la Sabana Centro.

- Diseñar un programa de formación y apoyo al emprendimiento turístico de la región Sabana Centro del departamento de Cundinamarca.

- Divulgar los resultados de investigación entre la comunidad de emprendedores y directores de turismo del departamento y a nivel nacional.

- Fortalecer la gestión empresarial de los emprendimientos turísticos de los dos municipios en el área de soporte web y desarrollo de aplicaciones móviles para la visibilización.

\subsection{Desarrollo de la investigación}

\section{Problema de investigación}

El turismo es una base de progreso para las comunidades y aporta a la disminución de la pobreza, las desigualdades, evita la migración de los pobladores, fomenta la distribución justa de los ingresos y las utilidades. Para este proyecto se establece la siguiente pregunta: ¿cuáles son las características del emprendimiento turístico en los municipios de Chía y Cajicá en el periodo 2019-2020?

Según Benavides (2015), hablar de turismo implica, de una parte, referirse realmente a un paquete de servicios complejo que, en última instancia, hacen del turismo una experiencia que requiere que varias condiciones sean satisfechas simultáneamente. Es decir, que el turismo no solo implica la prestación de un servicio para satisfacer al cliente, sino que implica varias características.

Con lo mencionado anteriormente, se busca 
tener un dato más completo sobre los meses en los que la actividad turística se desarrolla con mayor demanda y con menor demanda para poder identificar la característica que afecta en este aspecto. ¿Con cuántos funcionarios cuenta la empresa? Este dato permite saber un aproximado sobre lo sostenible que puede ser una empresa que se dedica a los diferentes sectores que abarca el turismo. ¿Su empresa realiza declaración de renta anual? Con esta pregunta se pretende identificar la variable administrativa y contable que abarca el tema de la formalidad de las empresas a las que se les realizará la investigación.

Las diferentes empresas que se tendrán en cuenta en la investigación pertenecen a sectores hoteleros, gastronómicos, informativos y turísticos, y en cuanto a las variables con las que se contaron fueron: servicio turístico, fuentes de financiación, características administrativas y contables.

\section{Metodología de investigación}

Se llevará a cabo una metodología que, según su paradigma, sea cuantitativa porque se examinan los datos recolectados de manera científica y específicamente de forma numérica. Por otra parte, Hernández-Sampieri (2016) define la investigación con enfoque cuantitativo como un conjunto de procesos en secuencia que se pueden probar y tienen un análisis estadístico. Por otra parte, también expone que la investigación cuantitativa es aquella que ofrece la posibilidad de generalizar los resultados que se obtienen por medio de un instrumento de medición para probar una hipótesis. Se deriva de una idea que se va acortando y limitando, seguido de objetivos y las preguntas de investigación; por otra parte, se realizó 
la revisión de la literatura y la realización de un marco teórico.

\section{Tamaño de muestra}

Los resultados se obtendrán teniendo en cuenta un tamaño de muestra probabilística estratificada que indica "el interés del investigador de comparar sus resultados entre segmentos, grupos o nichos de la población, porque así lo señala el planteamiento del problema" (Hernández-Sampieri, 2016).

A través de esto se procederá a aplicar la siguiente tabla para determinar el tamaño de muestra (estratificada) a quien se le aplicaría el instrumento de medición. Para identificar el tamaño de muestra estratificada se utilizaría la siguiente fórmula:

\section{Figura 20. Fórmulas tamaño de muestra}

$$
\begin{aligned}
& \text { Tamaño total de la muestra } \\
& n=\frac{\sum_{i=1}^{1} N_{i} P_{i} Q_{i}}{N D+\frac{1}{N} \sum_{i=1}^{l} N_{i} P_{i} Q_{i}}
\end{aligned}
$$

Tamaño de cada estrato

$$
n_{i}=n\left(\frac{N_{i}}{\sum_{i=1}^{T} N_{i}}\right)=n\left(\frac{N_{i}}{N}\right)=n(W i)
$$

Fuente: Mellado (2012).

Donde:

$n$ es el tamaño de muestra.

$N$ es la población por cada estrato

$P$ es la probabilidad de confianza.

$Q$ es el complemento de valor de $P$, es decir 1-P=Q.

$P \star Q$ representa la variabilidad

cuando estimamos el tamaño de la muestra.

$E$ es el error de estimación o la probabilidad de error; d representa la precisión. 
$W$ representa la fracción de asignación.

$n_{i}$ es el tamaño de muestra para cada estrato.

Los grupos poblacionales de estratificación definidos para hacer la investigación fueron los siguientes:

- Hoteles.

- Operadores.

- Agencias de viajes.

- Atractivos.

- Informadores.

- Restaurantes.

El cálculo del tamaño de muestra estratificado se obtuvo de la siguiente manera:

\section{Variables de análisis}

Las variables para análisis en cada establecimiento turístico serán las siguientes:

- Fuentes de apoyo y emprendimiento: que representa los diferentes entes, ya sean municipales, departamentales, nacionales o internacionales que apoyan estas empresas turísticas.

- Servicios de turismo: que indica la cantidad demandada de turistas mes a mes.

- Características administrativas y contables de los emprendimientos: que contempla la organización y el funcionamiento de cada empresa.

\section{Instrumento de medición y trabajo de campo}

El instrumento de medición contemplará 9 preguntas, las cuales se distribuyen así: 2 para la variable fuentes de apoyo, 2 para la variable de servicios de turismo, y 4 en la variable características 
administrativas y contables de los emprendimientos. La opción de respuestas será cerrada y el trabajo de campo se realizará visitando directamente a cada emprendimiento distribuido en Chía y Cajicá (ver anexo 7).

\section{Conclusión}

El emprendimiento turístico es una actividad que debe involucrar la participación de entidades de orden territorial que permitan fortalecer la economía, lo mismo que los procesos de educación y cultura en materia del sector turismo.

Existe una gran cantidad de empresas de informadores y hoteles pertenecientes al sector hotelero con poca cantidad en cuanto al número de funcionarios, y varios de los negocios aún sin hacer procesos de declaración de renta.

En cuanto a la demanda de turistas, esta varía significativamente en los meses de enero, abril, junio y diciembre, donde se presenta una alta demanda de turistas, y los meses como febrero y mayo la demanda disminuye considerablemente.

Por lo anterior, sería recomendable realizar el presente estudio con el fin de confirmar, entre otros temas, si las empresas reciben apoyo. En este sentido, fortalecer las investigaciones de emprendimiento turístico en los diferentes municipios de la sabana norte y diseñar programas de formación para los emprendedores turísticos de Zipaquirá y de otros municipios, en alianza con la Universidad de Cundinamarca, permitiría dar continuidad a investigaciones que permitanidentificar las diferencias del emprendimiento turístico en los últimos años. 


\section{Referencias}

Alcaldía Municipal de Chía. (2019). Diagnóstico Municipio de Chía. Alcaldía Municipal de Chía. Alcántara, J., y Barrio, S. (2016). El papel moderador del diseño web y la cultura del país en la respuesta del consumidor online. Una aplicación a los destinos turísticos. European Research on Management and Business Economics, (22), 78-87.

Araujo, N., y Fraiz, J. (2013). Las series audiovisuales como herramienta promocional de un destino turístico: el caso de España. Investigaciones Europeas de Dirección y Economía de la Empresa, (19), 8-15.

Armenteros, M., Guerrero, L., Noyola, F., y Molina, V. (2012). Cultura organizacional y organización que aprende un análisis desde la perspectiva de la innovación. Revista Internacional de Administración y Finanzas, 5(1), 33-51.

Benavides, G. (2015). Las políticas públicas del turismo receptivo colombiano. Suma de Negocios, 6(13), 66-73.

Bucardo, M., Saavedra, M., y Camarena, M. (2015).

Hacia una comprensión de los conceptos de emprendedores y empresarios. Suma de Negocios, (13), 98-107.

Concejo Municipal de Cajicá. (2018). Plan Municipal de la Gestión del Riesgo (PMGR). Concejo 
Municipal de Cajicá.

Daries, N., y Fransi, E. (2016). Las TIC como factor clave en la gestión de las empresas turísticas. Estudios Turísticos, (210), 63-74.

Gálvez, E. (2014): Tecnologías de Información y Comunicación, e innovación en las MIPYMES de Colombia. Cuadernos de administración, 30(51), 71-79.

Giraldo, C. (2015). En Colombia el turismo se fortalece gracias a las TIC. https://mintic. gov.co/portal/604/w3-article-11068.html?_ noredirect $=1$

Hernández-Sampieri, R. (2016). Metodología de la investigación. McGraw-Hill Interamericana.

Infante, E. (2014). Elementos determinantes en Cundinamarca para el desarrollo del turismo como actividad estratégica regional. Suma de Negocios, 5(10), 40-48.

López, G.; Maldonado, G.; Pinzón, S y García, R. (2016). Colaboración y actividades de innovación en Pymes. Contaduría y administración, 61(3), 568-581.

López, M., Serrano, A., y Gómez, R. (2009). La decisión de innovar de las empresas turísticas: un análisis empírico de la industria hostelera. Investigaciones Europeas de Dirección y Economía de la Empresa, 15(3), 169-182.

López, R., y López, R. (2018). Impacto de las TIC 
en el turismo: caso colombiano. Cuadernos de Turismo, (41), 399-418. http://dx.doi. org/10.6018/turismo.41.327081

Mellado, J. (2012). Muestreo estratificado. Departamento de Estadística y Cálculo. http:// www.uaaan.mx/ jmelbos/muestreo/muapu2. pdf

Ministerio de Comercio, Industria y Turismo. (2018). Plan Sectorial de Turismo 2018-2022. https:// www.mincit.gov.co/CMSPages/GetFile. aspx? guid=2ca4ebd7-1 acd-44f9-99784c826bab5013

Segovia, C., Bermeo, H., y González, D. (2014). La integración de las tecnologías de la información y la comunicación (TIC) como estrategia para generar competitividad en el sector turismo: una investigación en la región de Tolima (Colombia). Universidad \& Empresa, 16(27), 137-156. dx.doi.org/10.12804/rev.univ. empresa.27.2014.05

Silveira, Y., Cabeza, D., y Fernández, V. (2016). Emprendimiento: perspectiva cubana en la creación de empresas familiares. European Research on Management and Business Economics, (22), 70-77. 
Anexo 7. Instrumento de medición (encuesta)

$$
\text { Emprendimiento turístico }
$$

Nombre:

\section{Encuesta}

\section{Características administrativas y contables:}

1. ¿A qué tipo de sociedad pertenece su empresa?
A. Sociedad anónima
B. Sociedad por acciones simplificadas
C. Sociedad limitada
D. Sociedad colectiva
E. Otra

2. ¿A qué sector pertenece la empresa?
A. Gastronómico
B. Turístico
C. Informativo
D. Hotelero

3. ¿Hace cuánto funciona esta empresa?
A. Menos de 5 años
B. Entre 5-10 años
C. Entre 10-15 años
D. Más de 15 años

4. ¿Su empresa realiza declaración de renta anual? 

A. Sí
B. No

5. ¿Con cuántos funcionarios cuenta la empresa?
A. Menos de 5
B. Entre 5-10
C. Entre 10-15
D. Más de 15

\section{Turismo}

6. Marque con una $\mathrm{X}$ el mes de mayor o menor demanda:

\begin{tabular}{|l|l|}
\hline \multicolumn{1}{|c|}{ Mes } & Mayor Demanda Menor Demanda \\
\hline Enero & \\
\hline Febrero & \\
\hline Marzo & \\
\hline Abril & \\
\hline Mayo & \\
\hline Junio & \\
\hline Julio & \\
\hline Agosto & \\
\hline Septiembre & \\
\hline Octubre & \\
\hline Noviembre & \\
\hline Diciembre & \\
\hline
\end{tabular}

7. ¿Aproximadamente cuántos turistas llegan mensualmente a su empresa?

A. Menos de 500 

B. Entre 500-1000
C. Entre 1000-2000
D. Más de 2000

\section{Fuentes de apoyo y emprendimiento}

8. Recibe su empresa apoyo de:
A. La Cámara de Comercio
B. La Gobernación
C. Alguna universidad
D. Otro ente

9. Marque con una $X$ si el turismo sí o no recibe apoyo por parte de la administración:

\begin{tabular}{|c|c|c|}
\hline Apoyo & Sí & No \\
\hline $\begin{array}{l}\text { ¿La administración apoya el turismo con la defensa y } \\
\text { promoción de la educación y cultura? }\end{array}$ & & \\
\hline $\begin{array}{l}\text { ¿La administración apoya el turismo con la conservación } \\
\text { de monumentos? }\end{array}$ & & \\
\hline $\begin{array}{l}\text { ¿La administración apoya el turismo con el desarrollo del } \\
\text { turismo con criterio sostenible? }\end{array}$ & & \\
\hline $\begin{array}{l}\text { ¿La administración apoya el turismo con promoción de } \\
\text { la recreación? }\end{array}$ & & \\
\hline $\begin{array}{l}\text { ¿La administración apoya el turismo con el } \\
\text { abastecimiento y comercialización de productos? }\end{array}$ & & \\
\hline $\begin{array}{l}\text { ¿La administración apoya el turismo con el transporte } \\
\text { colectivo, circulación y turismo? }\end{array}$ & & \\
\hline $\begin{array}{l}\text { ¿La administración no apoya el turismo con ninguna de } \\
\text { las anteriores? }\end{array}$ & & \\
\hline
\end{tabular}




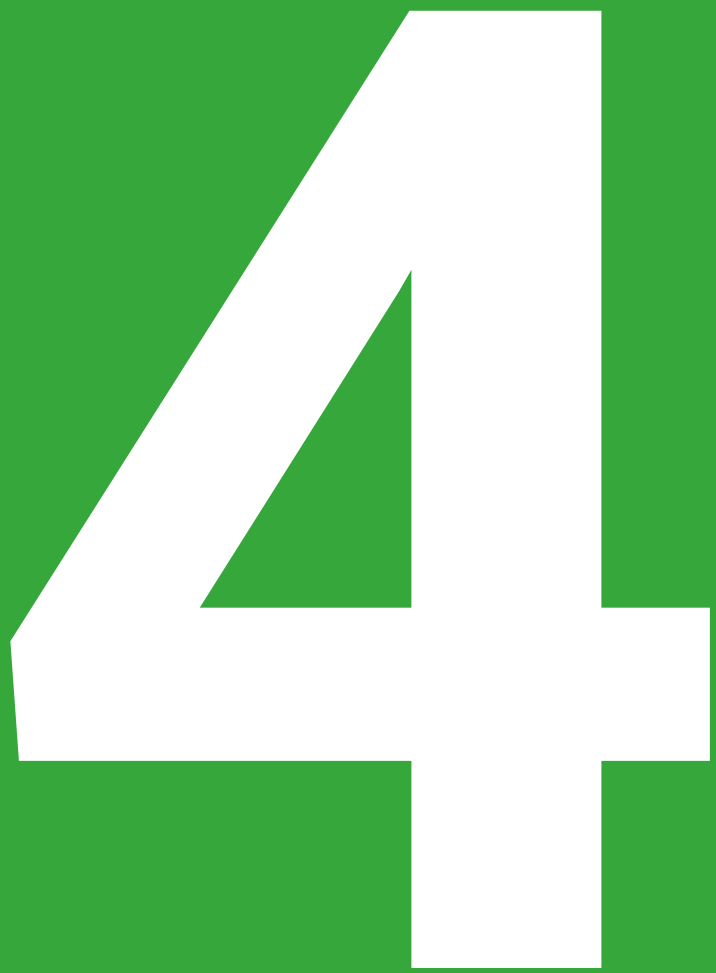

\section{El microcrédito, una alternativa para el desarrollo biotecnológico del agro colombiano}


Capítulo 4

\title{
El microcrédito, una alternativa para el desarrollo biotecnológico del agro colombiano
}

\author{
Ana María Balcázar Daza ${ }^{19}$ \\ Luz Deisy Flórez Espinal ${ }^{20}$ \\ Jairo Alonso Ávila Moreno ${ }^{21}$
}

\section{Resumen}

El sector agrícola colombiano debe estar alineado con las nuevas tendencias de biotecnología marcadas a nivel mundial, habida cuenta que debe abastecer las necesidades alimentarias de la población, la cual aumenta progresivamente. Para cumplir con tal fin, es necesario contar con procesos innovadores y con la infraestructura adecuada. Es por ello necesario contar con los recursos monetarios para estar a la vanguardia dentro del sector.

De acuerdo con las exigencias de la banca tradicional, dentrodelagrocolombianoexistensectores

\footnotetext{
$19 \quad$ Magíster en Dirección de Empresas de la Universidad Camilo José Cela de España, economista y administradora de empresas de la Universidad Santo Tomás. Docente investigadora del programa de Administración de Empresas e integrante del Grupo de Investigación DOPyS, Universidad de Cundinamarca. E-mail: anacoris2@hotmail.com.

20 Magíster en Dirección de Empresas de la Universidad Camilo José Cela de España, economista y administradora de empresas de la Universidad Santo Tomás. Docente investigadora del programa de Administración de Empresas e integrante del Grupo de Investigación DOPyS, Universidad de Cundinamarca. E-mail: Ideisyflorez@ ucundinamarca.edu.co.

$21 \quad$ Magíster en Desarrollo Rural, especialista en Gerencia Informática, especialista en Finanzas y administrador de empresas. Docente investigador del programa de Administración de Empresas e integrante del Grupo de Investigación DOPyS, Universidad de Cundinamarca. E-mail: jairo3139@yahoo.es.
} 
que necesitan acceder a fuentes de financiamiento no tradicionales para su modernización.

El objetivo de la presente investigación es identificar el comportamiento del crédito financiero en el sector agrícola colombiano e identificar las actividades que, de acuerdo con sus características, demandarían los servicios de la banca no tradicional para la modernización y desarrollo biotecnológico.

Para este fin, se efectúa una investigación de tipo cualitativo descriptivo, en la cual se lleva a cabo una revisión de los informes de los últimos de 10 años del Fondo para el Financiamiento del Sector Agropecuario (Finagro), con el fin de determinar las actividades que dentro del sector agropecuario podrían beneficiarse del sector microcrediticio.

De acuerdo con el análisis de la información, se concluye que los sectores que podrían beneficiarse de los productos de la banca no tradicional son las actividades productivas orientadas al cultivo de aguacate, cacao, café, caña panelera, papa, plátano y yuca.

\section{Introducción}

El sector agrícola colombiano debe estar alineado con las nuevas tendencias de biotecnología marcadas a nivel mundial, habida cuenta que debe abastecer las necesidades alimentarias de la población, la cual aumenta progresivamente. Para cumplir con tal fin, es necesario contar con procesos innovadores y con la infraestructura adecuada.

$\mathrm{Si}$ se mantienen las tendencias actuales de crecimiento de la población mundial, industrialización, contaminación ambiental, 
producción de alimentos y agotamiento de los recursos, este planeta alcanzará los límites de su crecimiento en el curso de los próximos cien años. El resultado más probable sería un súbito e incontrolable descenso, tanto de la población como de la capacidad industrial. (Meadows et al., 1972)

En consecuencia, es necesario aplicar la tecnología a sistemas biológicos y organismos vivos para generar nuevos procesos y productos para satisfacer las necesidades básicas del hombre, preservando su medioambiente.

La biotecnología es la ciencia que contribuye a mejorar las actividades dentro del sector agrícola, con el fin de procurar satisfacer las necesidades alimentarias de una población en ascenso, proporcionando mejoras significativas en materia nutricional, mantenimiento de animales y vegetales para el consumo, mejorando sus propiedades en cuanto a preservación y tolerancia a cambios ambientales, como respuesta a la tendencia mundial de cultura saludabley preservación del medioambiente en cualquier proceso productivo.

Colombia proyecta para el 2025 estar dentro de los tres países líderes de biotecnología en Latinoamérica, cuyas estrategias se centran en la producción de alimentos saludables con alto contenido nutricional, libre de químicos, enriquecidos con altos contenidos de fibra, dietéticos y energéticos, producidos con un alto sentido de responsabilidad y preservación del medioambiente (Narváez, 2015).

Es por ello necesario contar con los recursos monetarios para estar a la vanguardia dentro del sector. De acuerdo con las exigencias de la banca tradicional, 
dentro del agro colombiano existen sectores que necesitan acceder a fuentes de financiamiento no tradicionales para su modernización.

El objetivo de la presente investigación es identificar el comportamiento del crédito financiero en el sector agrícola colombiano e identificar las actividades que, de acuerdo con sus características, demandarían los servicios de la banca no tradicional para la modernización y desarrollo biotecnológico.

Los beneficiarios de los microcréditos son mujeres cabeza de familia, pequeños comerciantes, microempresarios, pequeños agricultores y campesinos, los cuales cuentan con bajos niveles de activos, carencia de información personal y comercial confiable, inexistencia contable de sus operaciones y demanda de mano de obra no calificada. (Flórez, Naranjo, Balcázar y García, 2018, p. 37)

Para este fin, se desarrolla un análisis de tipo cualitativo descriptivo a través de la revisión de los informes de los últimos de 10 años del Fondo para el Financiamiento del Sector Agropecuario (Finagro), con el fin de determinar el comportamiento del uso financiero de las actividades dentro del sector agropecuario para identificar los sectores que podrían beneficiarse del sector microcrediticio para el desarrollo biotecnológico.

En la primera parte del documento se muestra la parte teórica del desarrollo biotecnológico en Colombia; en la segunda parte se evidencia el concepto y el papel del microcrédito; finalmente, se muestra la información y los resultados estadísticos de la revisión de los datos de los informes de Finagro 
con las respectivas conclusiones.

De acuerdo con el análisis de la información, se concluye que los sectores que podrían beneficiarse de los productos de la banca no tradicional son las actividades productivas orientadas al cultivo de aguacates, cacao, café, caña panelera, papa, plátano y yuca.

\subsection{Marco teórico}

\section{Concepto de biotecnología}

Biotecnología es el término utilizado para definir el uso de la tecnología en seres vivientes, mejorando los productos derivados de estos como alimentos o medicamentos.

En la antigüedad se mejoraba el proceso de fermentación del vino a través de microorganismos, lo que se denominó biotecnología tradicional. Con el desarrollo de las áreas científicas, en la cual se permite la manipulación del ADN, se origina el uso de técnicas de ingeniería genética, la cual permite mejorar y transferir genes de un organismo al otro, lo que da paso a la biotecnología moderna.

La biotecnología se aplica en casos de infertilidad y de enfermedades a través de la clonación reproductiva y terapéutica (biotecnología médica), aumento de la producción de alimentos nutritivos y con propiedades nutricionales (biotecnología agrícola), producción de productos biodegradables con uso de biorremediación que reducen la contaminación ambiental (biotecnología ambiental). 


\section{Biotecnología a favor del desarrollo sostenible y sustentable en el sector agrícola colombiano}

El creciente aumento de la población enfrenta a la agricultura a un reto enorme: generar procesos para producir alimentos tendientes a abastecer a una población cada vez mayor, la cual se calcula que para el año 2050 se situará en 9200 millones de personas. Este reto incluye, entre otros, el aumento de la productividad, la eficiencia en el uso de los recursos naturales y la disminución de los costos de producción, preservando a su vez la sostenibilidad económica, medioambiental y social (Atehortúa 2018, p. 1).

De acuerdo con el último Censo Nacional Agropecuario (DANE, 2014), el sector agrícola colombiano se desarrolla en 43 millones de hectáreas, de las cuales el $80 \%$, equivalente a 34.4 millones, corresponde a pastos y rastrojo, y 8.6 millones de hectáreas, equivalente al $20 \%$, a cultivos transitorios y permanentes.

Lo anterior indica que existe un $80 \%$ de hectáreas sin cultivar productos alimentarios. Para lograr la capacidad plena en el sector agropecuario es necesario contar con mano de obra calificada, maquinaria y equipos con la tecnología adecuada, y con buena infraestructura en TIC, habida cuenta que el bajo desarrollo tecnológico y de comunicaciones en zonas rurales, la falta de oportunidades económicas y el conflicto armado son los responsables de la migración de jóvenes ubicados en zonas rurales hacia zonas urbanas, lo que en consecuencia impide el desarrollo del agro colombiano.

Es por ello necesario implementar nuevas 
tecnologías en los procesos productivos y generar plataformas de acceso a las TIC, con el fin de manejar eficientemente los recursos, consiguiendo la productividad y sostenibilidad de la producción del sector. En consecuencia, es necesario el fomento de inversión por parte del gobierno y las empresas para la consecución de maquinaria, herramienta, equipo, plataformas y aplicaciones móviles para la producción y comercialización por parte del productor.

El sector agrícola colombiano necesita en consecuencia para su desarrollo del resultado de investigaciones desarrolladas por expertos, formación para los productores, desarrollo e innovación tecnológica.

Según Sasson (1993), las principales preocupaciones concernientes al tema de biotecnología en países como Colombia se centran en la posibilidad o imposibilidad de ayudar a los campesinos pobres a mejorar sus productividad, si es posible generar productos de sustitución sin deteriorar al sector agropecuario, ser el epicentro de prueba de productos no aceptados en países ricos, protección a la propiedad intelectual (generar patentes) y falta de recursos para apoyar la investigación en biotecnología.

\section{La biotecnología en el agro colombiano}

El mercado agrícola ofrece nuevas oportunidades en el mejoramiento de sus productos mediante el uso de bioinsumos, biorremediación de suelos y aguas, aditivos funcionales para la alimentación animal y semillas transgénicas. Colombia permanece en la actual tendencia mundial mediante el apoyo de bancos de germoplasma que están a favor de la conservación de recursos genéticos 
(Cotes et al., 2012).

Colombia tiene como objetivo para 2025 ubicarse entre los tres líderes del sector biotecnológico en América Latina, para lo cual requiere conectarse con las tendencias mundiales enmarcadas en el desarrollo de actividades de bioprospección que actúen en armonía con el entorno ambiental, garantizando la seguridad alimentaria. Por lo tanto, las tendencias de consumo global en el mercado agrícola presentan nuevas oportunidades de negocios alrededor de bioinsumos, aditivos funcionales para alimentación animal, agricultura sostenible, biorremediación de suelos y aguas, reproducción in vitro y semillas mejoradas con biotecnologías de punta, direccionadas a mejorar la calidad, el rendimiento y reducir al mínimo el uso de prácticas agrícolas tradicionales que consumen energía y contaminan el medioambiente. (Montenegro y Hernández, 2015, p. 97)

Según Montenegro y Hernández (2015), Colombia solo cuenta con 20 centros de bioprospección, estadística que lo coloca en desventaja frente a países como Brasil que cuenta con 800 centros y Costa Rica con 43. Es necesario, por lo tanto, el fortalecimiento de la investigación y del fomento de políticas a favor de la regulación de procesos biotecnológicos, con el fin de desarrollar productos innovadores para la consecución de los objetivos planteados por el Gobierno Nacional.

La biotecnología agrícola se enfoca en el mejoramiento del rendimiento y la calidad de los 
productos agrícolas a través del uso de biofertilizantes, biorremediación y geomicrobiología (Da Silva, 2004), reduciendo el uso de energía y contaminación del medioambiente, resultado del uso de prácticas agrícolas tradicionales (Shmaefsky, 2013).

De acuerdo con la Agenda de Conocimiento Universidad Nacional de Colombia, en concordancia con el Ministerio de Investigación, Ciencia y Tecnología de Nueva Zelanda (2005) (Chaparro et al., 2012), las tendencias mundiales en el 2020 en biotecnología en el sector pecuario apuntan a suministrar mayor concentración de aminoácidos y nutrientes, disminuyendo hormonas y antibióticos a los alimentos de los animales para la obtención de razas mejoradas, más resistentes a las enfermedades y cambios climáticos, clonación de especies, mejor rendimiento de carne, leche y sus derivados.

En el campo vegetal, mediante el uso de biofertilizantes y bioplaguicidas se mejoran los atributos nutricionales y de resistencia a plagas, y tensiones ambientales de los cultivos, logrando una mayor conservación de estos a largo plazo, árboles con mejor almidón y aceite para un mejor procesamiento industrial (Cotes et al., 2012).

El gobierno colombiano plantea estrategias para el desarrollo biotecnológico, aprovechando la biodiversidad, exploración e identificación sistémica de los recursos biológicos y uso de la bioprospección con fines comerciales, de acuerdo con las tendencias mundiales (Gómez et al., 2013).

Las tendencias mundiales están enmarcadas hacia el consumo de alimentos saludables, naturales, con buena apariencia y alta calidad nutricional; productos $100 \%$ naturales sin químicos y aditivos; agricultura ecológica, libre de agroquímicos; 
alimentos funcionales, fortificados, enriquecidos, con altos contenidos de fibra, dietéticos y energéticos; productos sofisticados con responsabilidad hacia el medioambiente; utilización de la biotecnología para mejorar características nutricionales y conservación de los recursos a favor del bienestar de los seres vivos (Narváez, 2015).

De acuerdo con los objetivos propuestos por el Gobierno Nacional, es necesario que todas las actividades del sector agrícola cuenten con la infraestructura para tal propósito, pero por las características que presentan algunas actividades del sector, no se cuenta con el acceso a fuentes de financiamiento, es por ello necesario acceder a créditos de la banca no tradicional, para que estos sectores no queden rezagados de los procesos de innovación y desarrollo biotecnológico propuestos dentro del país.

\section{El microcrédito, mecanismo financiero} para el desarrollo biotecnológico de los pequeños agricultores

El Grameen Bank es la institución pionera en la gestión de microcréditos, empezando en Bangladesh en el año 1976. El modelo propuesto por Muhammad Yunus implica romper con los principios de la banca tradicional en cuanto al concepto de riesgo de los usuarios. El modelo implica prestar a personas de escasos recursos o con dificultades de acceso a la banca tradicional. De acuerdo con lo expuesto por el Grameen Bank (2012), desde la implementación del modelo de Yunus se han desarrollado con éxito réplicas del modelo en más de 100 países, generando 
desarrollo y crecimiento económico en los países de la implementación.

De acuerdo con Hernández (2011), el microcrédito nació en Colombia en 2002 como mecanismo de financiación a microempresarios, usuarios de créditos informales, riesgosos y con altos costos por la falta de acceso a la banca tradicional.

Según Navajas y Tejerina (2007), el desarrollo de organizaciones no gubernamentales y entidades multilaterales orientadas a ofrecer servicios financieros para la población de escasos recursos, adaptada a las necesidades de los microempresarios, se denomina microcrédito.

De acuerdo con la Ley 590 de 2000 en Colombia, el microcrédito es el conjunto de préstamos otorgados a la población de escasos recursos, créditos que no superan los 25 salarios mínimos vigentes.

La Ley 590 de 2000 define el sistema de microcrédito como:

El sistema de financiamiento a microempresas, dentro del cual el monto máximo por operación de préstamo es de veinticinco (25) salarios mínimos mensuales legales vigentes sin que, en ningún tiempo, el saldo para un solo deudor pueda sobrepasar dicha cuantía. (Art. 39)

Los beneficiarios de estos créditos son usuarios del sector financiero sin acceso a los créditos otorgados por la banca tradicional, por carecer de activos que respalden la solicitud de créditos tradicionales, mujeres cabeza de hogar, microempresarios, pequeños comerciantes, agricultores, campesinos y desplazados.

Según Balcázar (2019), gran porcentaje de la 
población perteneciente al sector agrícola, no pueden invertir ni en maquinaria ni en equipos especializados, habida cuenta que no cuentan con el capital físico para respaldar sus créditos. Esta condición los deja al margen del cumplimiento de metas que tiene planteado el Gobierno Nacional en cuanto al desarrollo biotecnológico. Es por ello necesario incentivar el uso de los productos ofrecidos por el sector microcrediticio.

Según Stiglitz (1989), los mercados financieros excluyentes, como el de la banca tradicional, son obstáculo para el desarrollo de nuevas industrias, desarrollo de técnicas innovadoras y nuevas iniciativas de negocio, es por ello necesario contar con sistemas alternativos de financiación.

Los resultados encontrados sugieren que el microcrédito tiene grandes posibilidades de expansión, particularmente en zonas rurales y en pequeños centros urbanos. Se sugiere, por lo tanto, crear incentivos que permitan a las entidades financieras hacer presencia en estas áreas, tales como la creación de redes de asistencia técnica que brinden orientación en el proceso de implementación de tecnología microcrediticia, y de la modificación de algunos aspectos en el marco regulatorio en el que actualmente se desarrolla su actividad. (Banco de la República, Ministerio de Agricultura y Finagro, 2010, p. 1)

De acuerdo con el Banco Mundial (2006), las microfinanzas mejoran las condiciones económicas de los usuarios incrementando sus ingresos y contribuyendo al aumento de inversión de los 
microempresarios.

Los programas que promueven el microcrédito se han convertido en uno de los mecanismos de fomento de la actividad empresarial con mayor crecimiento en América Latina. El surgimiento de estos productos financieros responde a las necesidades de financiación de los negocios de pequeños empresarios, los cuales adquieren importancia en la medida en que componen un porcentaje significativo de la actividad económica y pueden contribuir a la generación de empleo. (Banco de la República, Ministerio de Agricultura y Finagro, 2010, p. 2)

Es necesario involucrar a todos los sectores del agro colombiano en el desarrollo de la biotecnología, con el fin de implementar procesos y procedimientos de acuerdo con los lineamientos del Gobierno Nacional para garantizar la seguridad alimentaria del país.

De acuerdo con las características de los participantes de algunas actividades agrícolas, muchos se encuentran excluidos del sector financiero tradicional, lo cual es indispensable para la compra de maquinaria, equipo y el montaje de infraestructura necesario para el desarrollo de estas tecnologías.

Es necesario, en consecuencia, direccionar los servicios del sector microcrediticio a los sectores agrícolas sin acceso a los servicios financieros.

\subsection{Metodología}

La metodología desarrollada en este estudio es de tipo cualitativo descriptivo, en el cual se revisaron 
las estadísticas de los informes de Finagro de la última década.

En la primera etapa del estudio se verifica el comportamiento del sector agrícola en relación con los préstamos otorgados por la banca tradicional. El objetivo del análisis de esta información es fijar un referente de las actividades agrícolas que acceden a la banca tradicional y establecer cuáles podrían ser los sectores potenciales para el uso de los productos del sector microcrediticio.

En la segunda parte se comparan datos estadísticos encontrados para establecer los sectores que podrían ser los usuarios del sector microcrediticio.

En la tercera parte del estudio, de acuerdo con los históricos de los últimos 10 años, se analizan las tendencias del microcrédito frente a los sectores agrícolas seleccionados, en el cual se saca el promedio respectivo para evaluar el monto y el número de créditos que, de acuerdo con los históricos, podría ofrecer el sector microcrediticio a los usuarios potenciales.

La muestra seleccionada para la primera parte del estudio y verificación estadística corresponde a todas las actividades agrícolas evidenciadas en los informes de Finagro, con el fin de verificar el comportamiento crediticio del sector.

La muestra seleccionada para verificar los potenciales clientes del microcrédito y sus montos de crédito corresponde a los sectores que, de acuerdo con sus características, podrían ser los beneficiarios del sector microcrediticio. Estos sectores, de acuerdo con la Ley 590 de 2000, son aquellos que no reporten más de 25 salarios mínimos de solicitud de crédito por usuario.

Los resultados de la investigación se mostrarán 
en tablas, cuyas explicaciones se darán en cada una de ellas.

Se manejarán los datos encontrados en los informes de Finagro para sacar nuevos datos y cumplir con los objetivos de la investigación, a través de cálculos como sumas, divisiones, restas y promedios, los cuales alimentarán las tablas de resultado del estudio.

Según Hernández, Fernández y Baptista (2014), el método descriptivo es uno de los métodos cualitativos utilizados para evaluar las características de una población de acuerdo con la información, describiendo los resultados de un número de variables. El objetivo de este método es obtener datos estadísticos (promedios y cálculos) que reflejen tendencias en el objeto de estudio.

\subsection{Resultados}

\section{Créditos otorgados por actividad productiva}

En la tabla 11, a continuación, se relaciona la cantidad de créditos otorgados de acuerdo con la actividad agrícola. Según la información, las actividades que más demandan los recursos financieros en los últimos 10 años son: agricultura de arroz, con un promedio de 4634 créditos otorgados; cacao, con promedio de 9160 créditos otorgados; café, con un promedio de 69.585 créditos otorgados; caña panelera, con un promedio de 8829 créditos otorgados; frutales, con un promedio de 164.233 créditos otorgados; papa, con un promedio de 6646 créditos otorgados; plátano, con un promedio de 12.665 créditos otorgados; ganadería de carne, con un 
promedio de 52.670 créditos otorgados; ganadería de leche, con un promedio de 18.391 créditos otorgados.

El sector de porcicultura, aunque en los últimos 5 años ha desacelerado las solicitudes de créditos, cuenta con un promedio de 7690 , y el sector productor de aguacate que, contrario al sector de porcicultura, en los últimos 5 años ha dinamizado las solicitudes de créditos con un promedio de 6503 créditos otorgados. 
ลิ่

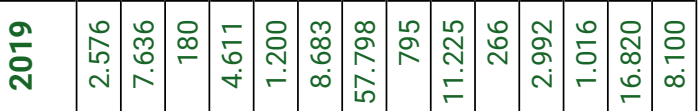

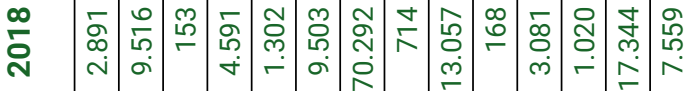

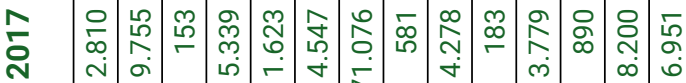

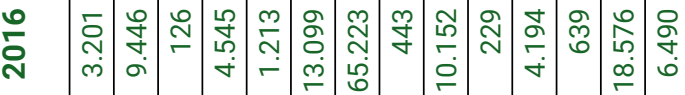

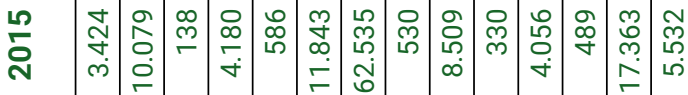

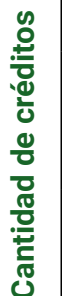

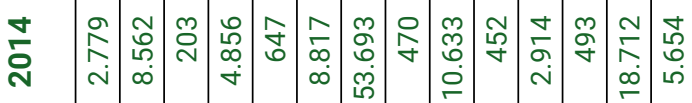

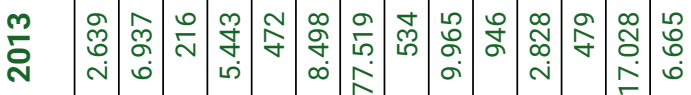

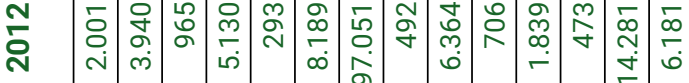

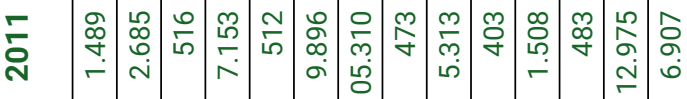

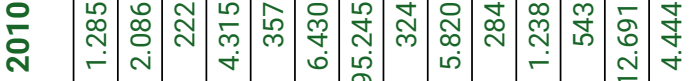

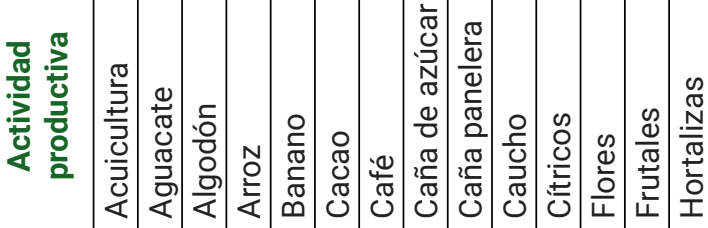




\begin{tabular}{|c|c|c|c|c|c|c|c|c|c|c|}
\hline 요 & $\frac{0}{\sqrt{n}}$ & 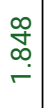 & \begin{tabular}{l}
0 \\
\multirow{2}{\alpha}{} \\
\\
\end{tabular} & $\stackrel{\circ}{N}$ & ষ্ল & ং & $\infty$ & $\begin{array}{l}\bar{N} \\
\tilde{o} \\
\stackrel{\circ}{\circ}\end{array}$ & $\underset{\stackrel{\sim}{\sim}}{\stackrel{\sim}{\sim}}$ & ৯ \\
\hline $\begin{array}{l}\hat{m} \\
\check{\digamma}\end{array}$ & 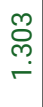 & $\begin{array}{l}\hat{b} \\
\stackrel{+}{ } \\
\sigma\end{array}$ & $\mid \begin{array}{l}5 \\
\\
\\
\end{array}$ & $\stackrel{\infty}{\mp}$ & $\begin{array}{l}\tilde{N} \\
\tilde{O} \\
- \\
-\end{array}$ & ป & $\begin{array}{l}0 \\
\stackrel{\sigma}{d} \\
\text { ì }\end{array}$ & 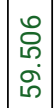 & $\begin{array}{l}\Omega \\
\infty \\
\infty \\
\dot{N}\end{array}$ & 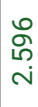 \\
\hline $\begin{array}{c}\stackrel{\circ}{\circ} \\
\text { ஸ़ } \\
-\end{array}$ & 요 & 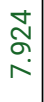 & 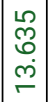 & $\stackrel{+}{\infty}$ & 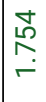 & ָ & 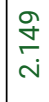 & 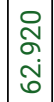 & 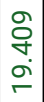 & $\begin{array}{l}\stackrel{N}{N} \\
\tilde{\sigma} \\
\dot{n}\end{array}$ \\
\hline $\begin{array}{l}\text { ำ } \\
\text { mె } \\
\leftarrow\end{array}$ & $\begin{array}{l}\circ \\
\text { ڤั }\end{array}$ & $\begin{array}{l}\circ \\
\varnothing \\
\infty \\
\\
\end{array}$ & $\mid \begin{array}{l}\hat{\sigma} \\
\tilde{n} \\
\sigma \\
\sigma \\
\Gamma\end{array}$ & $\underset{\sim}{\stackrel{\mathscr{P}}{+}}$ & 음 & 으 & 옹 & 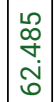 & 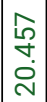 & $\begin{array}{l}10 \\
0 \\
\infty \\
\dot{\sigma}\end{array}$ \\
\hline $\begin{array}{c}\stackrel{v}{\infty} \\
\stackrel{+}{+} \\
\leftarrow\end{array}$ & ปั & $\begin{array}{l}m \\
\stackrel{n}{+} \\
\sim\end{array}$ & $\begin{array}{l}m \\
0 \\
1 \\
\infty \\
\infty \\
-\infty \\
\end{array}$ & $\widehat{\widehat{m}}$ & 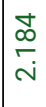 & 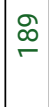 & $\begin{array}{l}m \\
\infty \\
\infty \\
- \\
-\end{array}$ & $\begin{array}{l}0 \\
m \\
m \\
\infty \\
\infty \\
i n\end{array}$ & $\begin{array}{l}m \\
0 \\
\infty \\
\\
- \\
-\end{array}$ & $\begin{array}{l}\text { व } \\
\text { o } \\
\text { + }\end{array}$ \\
\hline $\begin{array}{l}\infty \\
\infty \\
\circ \\
\ulcorner\end{array}$ & ڤo & \begin{tabular}{|c|}
$\infty$ \\
$\infty$ \\
$\stackrel{o}{ }$ \\
$\ddots$
\end{tabular} & \begin{tabular}{|l|}
$m$ \\
$m$ \\
$\dot{\omega}$ \\
\\
\end{tabular} & $\begin{array}{l}0 \\
\infty \\
0\end{array}$ & $\begin{array}{l}\stackrel{N}{\infty} \\
\tilde{m} \\
\sim \\
N\end{array}$ & $\stackrel{\circ}{\circ}$ & $\begin{array}{l}\text { o } \\
\check{ } \\
\text { i }\end{array}$ & $\mid \begin{array}{c}\stackrel{\sim}{\sim} \\
\tilde{n} \\
\tilde{\sigma} \\
\dot{\gamma}\end{array}$ & 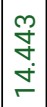 & 穴 \\
\hline $\begin{array}{l}\text { ঠे } \\
\text { ભ̣ } \\
-\end{array}$ & ळू & \begin{tabular}{|l|}
$\infty$ \\
1 \\
$\infty$ \\
$\infty$ \\
$\omega$ \\
\end{tabular} & 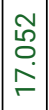 & N & $\begin{array}{l}10 \\
0 \\
0 \\
\text { m. }\end{array}$ & $\stackrel{m}{\sim}$ & $\begin{array}{l}\sigma \\
\stackrel{\sigma}{\sigma} \\
\text { ¿ }\end{array}$ & $\mid \begin{array}{l}0 \\
\infty \\
\infty \\
0 \\
1 \\
1\end{array}$ & 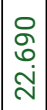 & 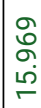 \\
\hline 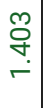 & নু & $\mid \begin{array}{l}\hat{\sigma} \\
\sigma \\
0 \\
0\end{array}$ & 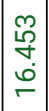 & 志 & \begin{tabular}{l}
$\underset{N}{\sim}$ \\
\multirow{\leftarrow}{*}{} \\
m.
\end{tabular} & $\stackrel{\circ}{\circ}$ & $\begin{array}{l}\stackrel{L}{N} \\
\stackrel{n}{n} \\
\text { N }\end{array}$ & $\mid \begin{array}{c}\bar{\infty} \\
m \\
\bar{\sigma} \\
\end{array}$ & 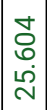 & 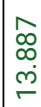 \\
\hline $\begin{array}{l}\stackrel{0}{r} \\
\stackrel{N}{N}\end{array}$ & 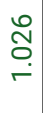 & 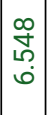 & $\begin{array}{l}m \\
\infty \\
\infty \\
\sigma \\
\sigma\end{array}$ & \begin{tabular}{|l|}
$\stackrel{8}{\circ}$ \\
\hdashline \\
\ulcorner \\
\end{tabular} & $\left|\begin{array}{l}\overline{0} \\
\check{r} \\
\dot{m}\end{array}\right|$ & 음 & $\begin{array}{l}\stackrel{\sim}{\sim} \\
\underset{\sim}{v}\end{array}$ & 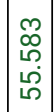 & $\begin{array}{l}\infty \\
\stackrel{\infty}{N} \\
\grave{N} \\
\end{array}$ & مَ \\
\hline ঠ্ণ & ণ & $\stackrel{m}{\sim}$ & $\begin{array}{l}\circ \\
\infty \\
o !\end{array}$ & $\hat{\circ}$ & 움 & 움 & ¿ु & $\underset{m}{+}$ & 只 & L \\
\hline $\begin{array}{l}\nwarrow \\
\infty \\
\check{\digamma} \\
\ulcorner\end{array}$ & 용 & \begin{tabular}{|c|}
0 \\
5 \\
50 \\
0 \\
\end{tabular} & 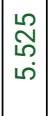 & 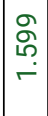 & $\begin{array}{c}1 \\
\tilde{m} \\
o \\
\text { N }\end{array}$ & $\infty$ & $\begin{array}{l}\infty \\
\infty \\
\underset{\sim}{+} \\
\sim\end{array}$ & $\begin{array}{l}20 \\
2 \\
\check{0} \\
8\end{array}$ & $\frac{r}{\stackrel{N}{*}}$ & $\begin{array}{l}\stackrel{2}{N} \\
\text { ㅁ } \\
\stackrel{0}{\circ}\end{array}$ \\
\hline$\stackrel{\frac{N}{\sigma}}{\sum}$ & $\frac{\widetilde{\sigma}}{\underline{\varepsilon}}$ & $\begin{array}{l}0 \\
\stackrel{0}{0} \\
\widetilde{0} \\
0\end{array}$ & $\mid \begin{array}{c}0 \\
\frac{c}{\sigma} \\
\frac{\pi}{\pi} \\
\frac{\pi}{\alpha} \\
\frac{1}{0}\end{array}$ & $\begin{array}{l}0 \\
0 \\
\tilde{D} \\
\tilde{O} \\
\stackrel{\sigma}{\circ}\end{array}$ & $\underset{\mathcal{J}}{\mathcal{J}}$ & 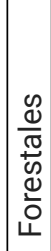 & 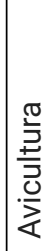 & 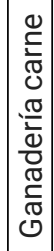 & 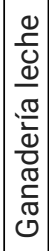 & 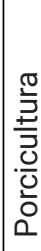 \\
\hline
\end{tabular}


Montos de préstamos otorgados por actividad productiva, banca tradicional

A continuación, se presenta el valor de los créditos otorgados al sector por año. Los sectores que solicitan los montos más altos en los últimos 10 años son: el sector de arroz, café, caña de azúcar, frutales, palma, avicultura, ganadería de carne y ganadería de leche. Estas actividades son las que más acceso tienen a la banca tradicional. 


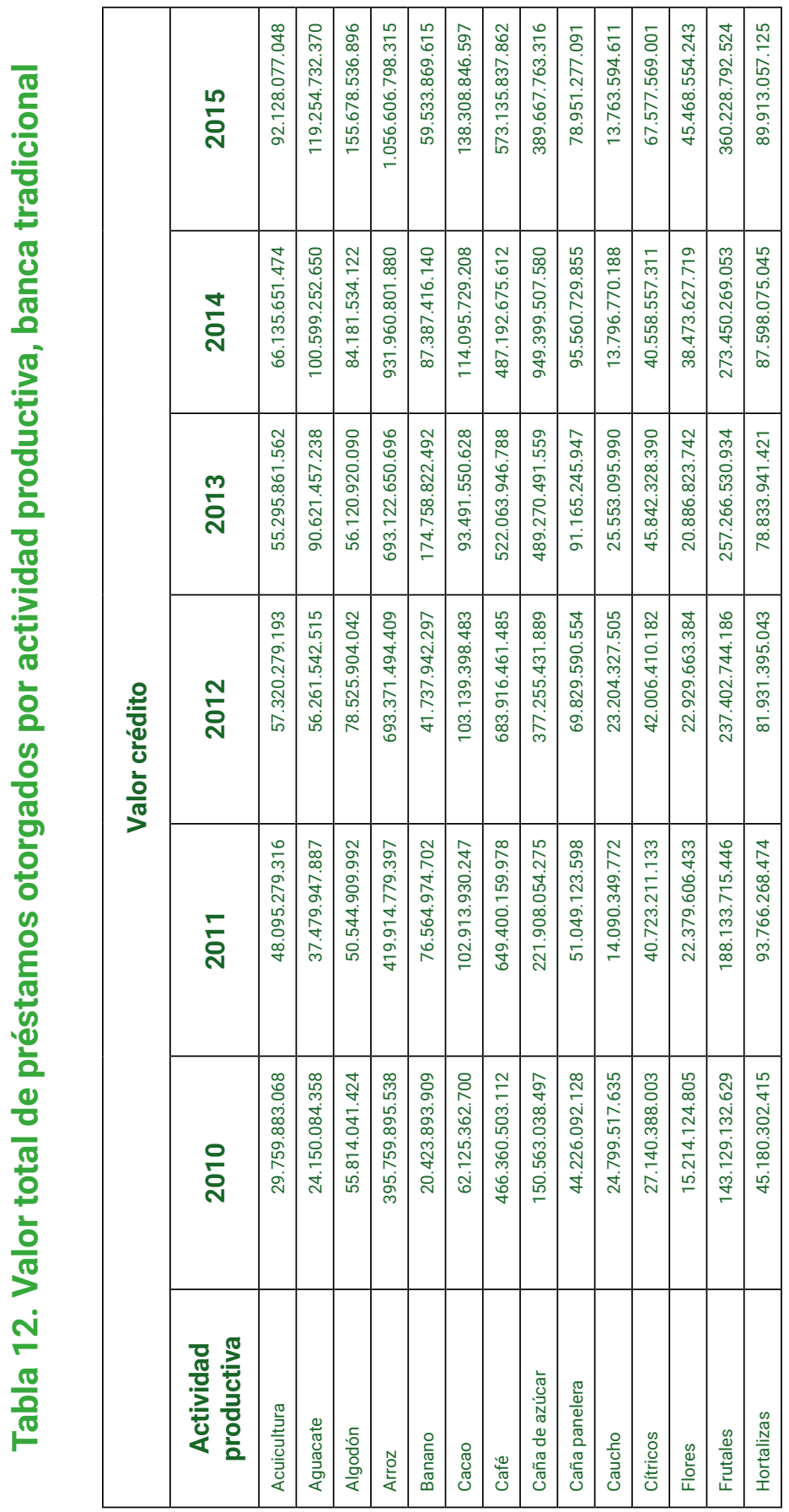




\begin{tabular}{|c|c|c|c|c|c|c|c|c|c|c|c|c|c|c|c|c|c|c|c|c|}
\hline 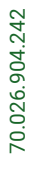 & 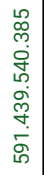 & 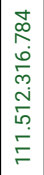 & 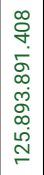 & 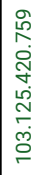 & 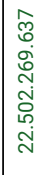 & 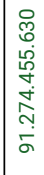 & 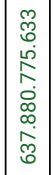 & 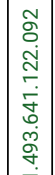 & 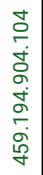 & 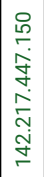 & & & & & & & & & & \\
\hline 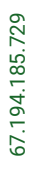 & 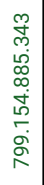 & 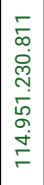 & 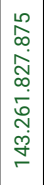 & 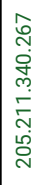 & 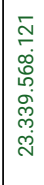 & 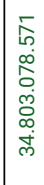 & 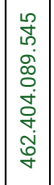 & 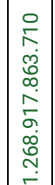 & 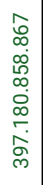 & 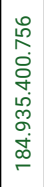 & ণ্ণ & 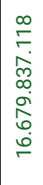 & 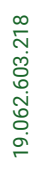 & 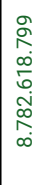 & 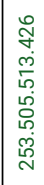 & 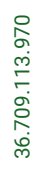 & 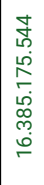 & 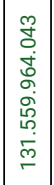 & 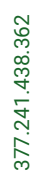 & 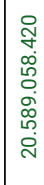 \\
\hline 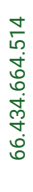 & 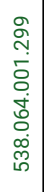 & 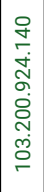 & 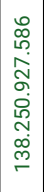 & 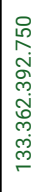 & 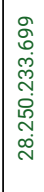 & 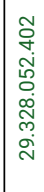 & 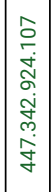 & 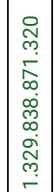 & 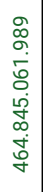 & 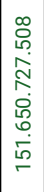 & 뭉 & 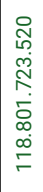 & 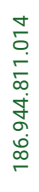 & $\begin{array}{l}m \\
m \\
m \\
0 \\
o \\
o \\
\infty \\
\infty \\
10 \\
\infty \\
\infty \\
\infty\end{array}$ & 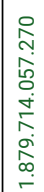 & 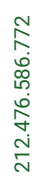 & 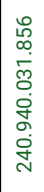 & 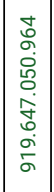 & 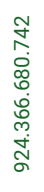 & 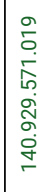 \\
\hline 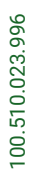 & 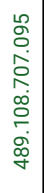 & 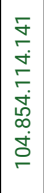 & 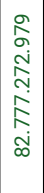 & 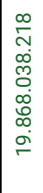 & 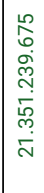 & 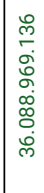 & 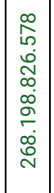 & 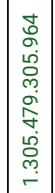 & 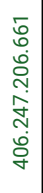 & 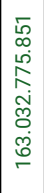 & $\stackrel{\infty}{\infty}$ & 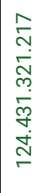 & 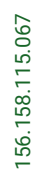 & 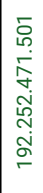 & 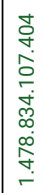 & 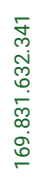 & 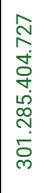 & 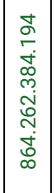 & 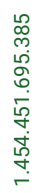 & 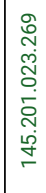 \\
\hline 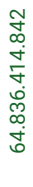 & 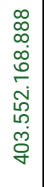 & 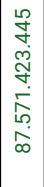 & 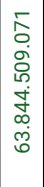 & 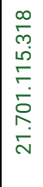 & 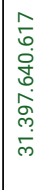 & 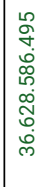 & 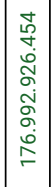 & 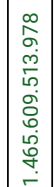 & 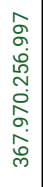 & 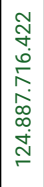 & 동 & 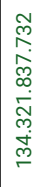 & 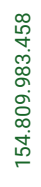 & 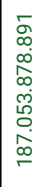 & 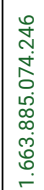 & 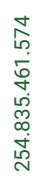 & 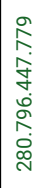 & 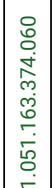 & 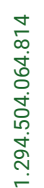 & 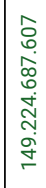 \\
\hline 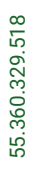 & 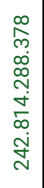 & 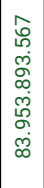 & 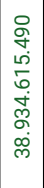 & 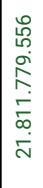 & 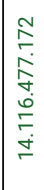 & 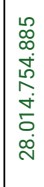 & 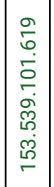 & 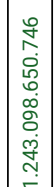 & 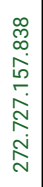 & 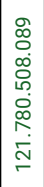 & $\stackrel{0}{\circ}$ & 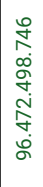 & 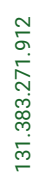 & 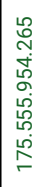 & 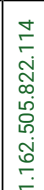 & 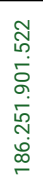 & 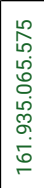 & 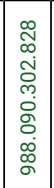 & 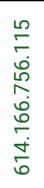 & 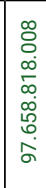 \\
\hline$\sum_{\substack{\mathrm{N} \\
\mathrm{N}}}^{\mathrm{N}}$ & $\frac{\stackrel{\pi}{\frac{\varepsilon}{\sigma}}}{\frac{\sigma}{\alpha}}$ & $\frac{\pi}{\frac{\pi}{0}} \frac{1}{0}$ & $\underset{\substack{\stackrel{0}{0} \\
\frac{\pi}{0}}}{\frac{\pi}{\alpha}}$ & 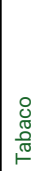 & $\stackrel{\text { \} }{\supset}} &{\text { 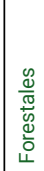 }} &{\text { 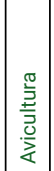 }} &{\text { 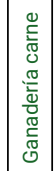 }} &{\text { 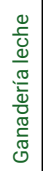 }} &{\text { 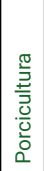 }} &{ } &{\begin{array}{l}\frac{\widetilde{g}}{3} \\
\frac{3}{3} \\
\frac{0}{3} \\
\frac{0}{4}\end{array}} &{\text { 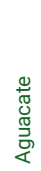 }} &{\begin{array}{l}\frac{}{0} \\
\frac{0}{0} \\
\frac{\mathrm{O}}{4}\end{array}} &{\text { 总 }} &{\text { 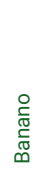 }} &{\begin{array}{l}\text { 尺 } \\
\mathbb{J} \\
\text { ల }\end{array}} &{\frac{\dddot{\pi}}{\pi}} &{\text { 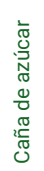 }} &{\text { 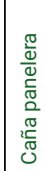 }} \\
$\hline
\end{tabular}




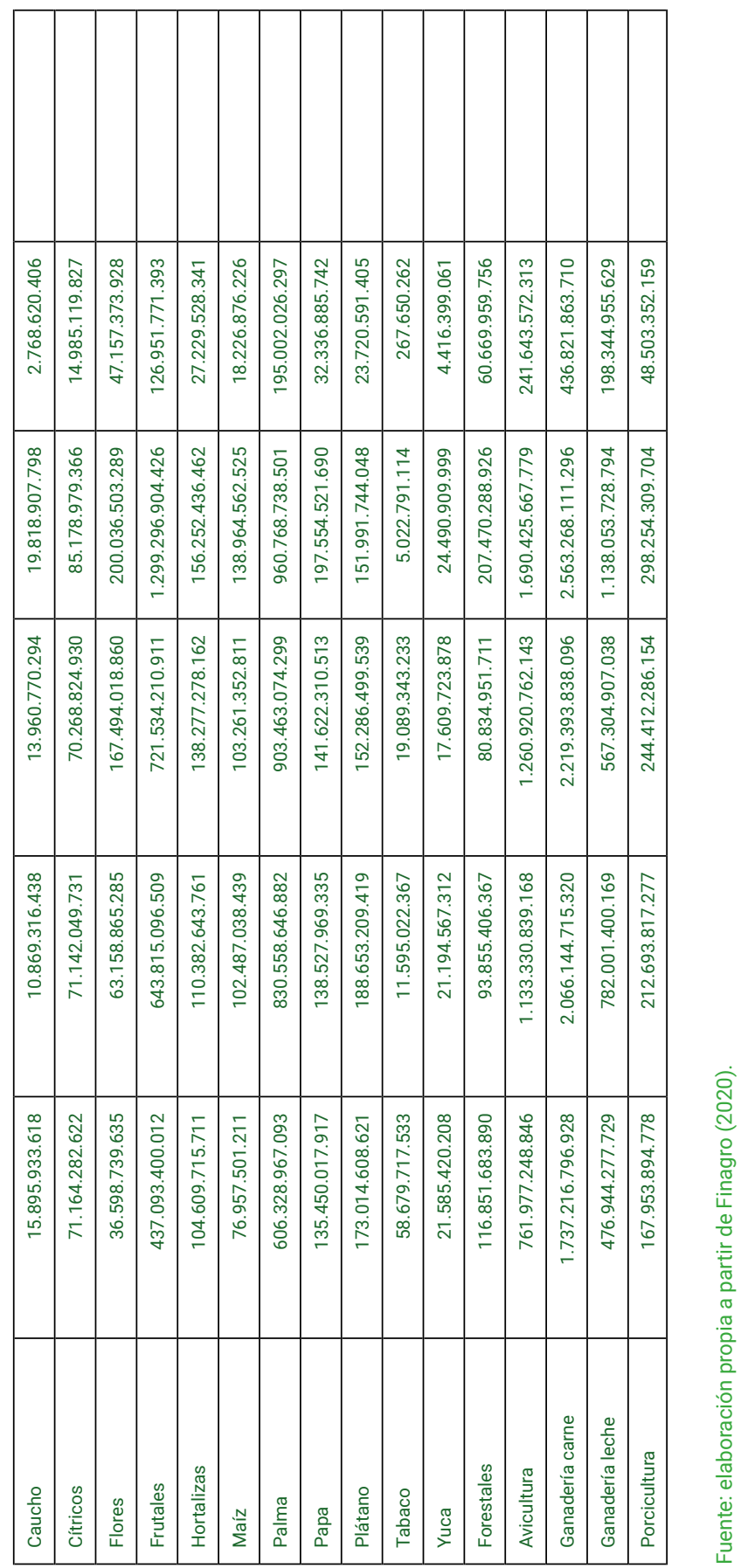




\section{Monto promedio por solicitante del crédito}

\section{por actividad productiva}

En la tabla 13 se relaciona el promedio del monto de los créditos solicitados por actividad productiva. Los datos de la tabla 13 son el resultado de la división de los datos de la tabla 12 "Valor total de préstamos otorgados por actividad productiva, banca tradicional", y la tabla 11 "Cantidad de créditos otorgados por actividad productiva, banca tradicional".

De acuerdo con los resultados, los sectores cuyos montos son los más altos por solicitante del crédito son: el sector de algodón, con un promedio de crédito por usuario de $\$ 690.312 .234$; el de caña de azúcar, con un promedio de crédito por usuario de \$1.316.959.687; el de palma, con un promedio de crédito por usuario de $\$ 682.796 .931$; el forestal, con un promedio de crédito por usuario de \$423.595.014; el avícola, con un promedio de crédito por usuario de \$326.680.455; y en los últimos tres años el de porcicultura, con un promedio de crédito por usuario de $\$ 42.827 .332$.

Los sectores que menos montos piden por beneficiarios del crédito en la banca tradicional son: el de aguacate, con un promedio de crédito por usuario de \$15.309.711; Cacao, con un promedio de crédito por usuario de $\$ 15.676 .374$; café, con un promedio de crédito por usuario de $\$ 10.485 .000$; caña panelera, con un promedio de crédito por usuario de $\$ 10.069 .100$; papa, con un promedio de crédito por usuario de \$16.992.378; plátano, con un promedio de crédito por usuario de \$9.268.873; y yuca, con un promedio de crédito por usuario de $\$ 9.377 .830$. 


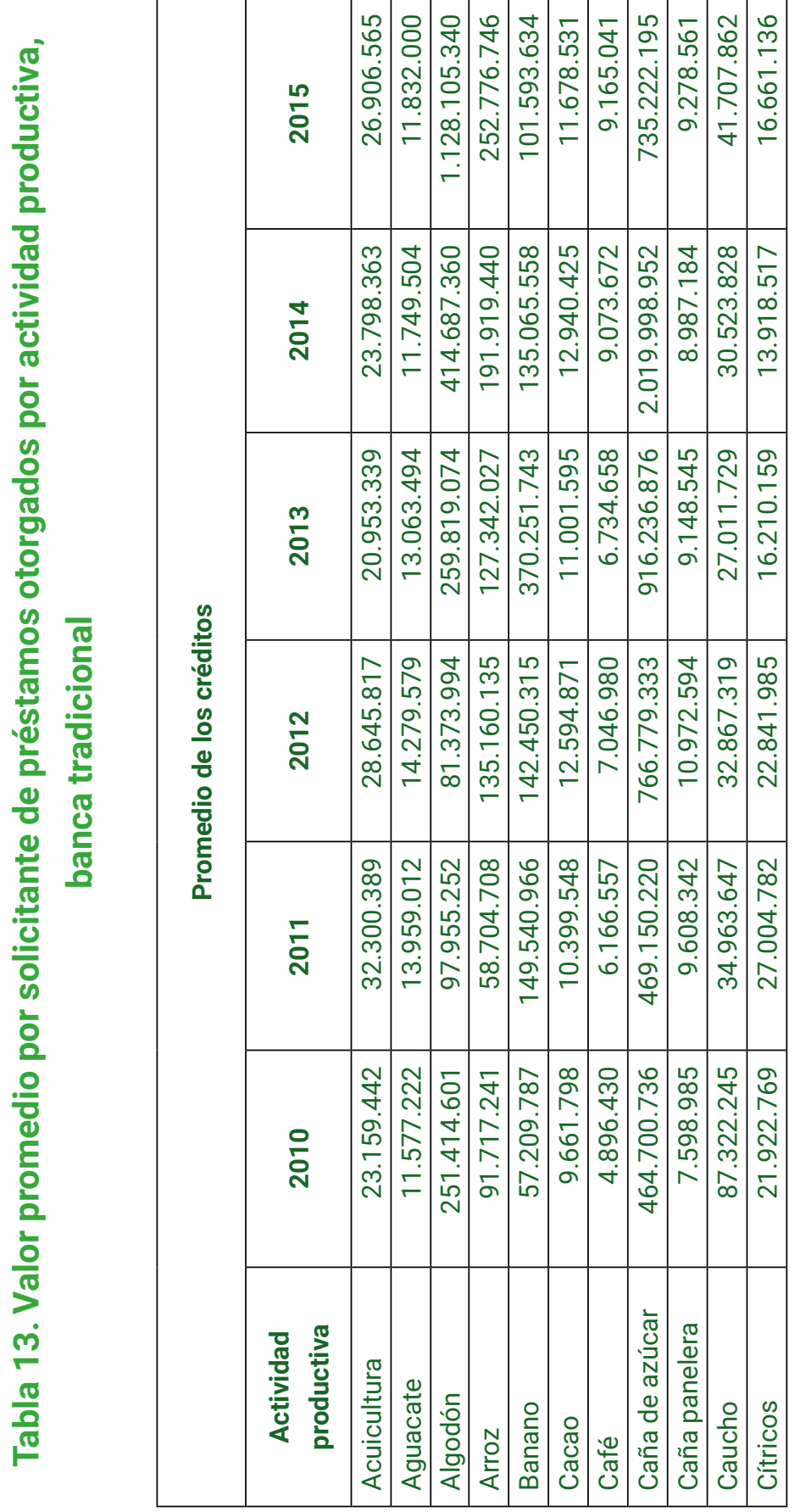




\begin{tabular}{|c|c|c|c|c|c|c|c|c|c|c|c|c|c|c|c|c|c|c|c|}
\hline 2 & 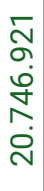 & 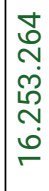 & 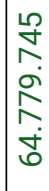 & 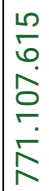 & 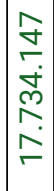 & $\begin{array}{l}m \\
6 \\
\tilde{\sigma} \\
\tilde{\sigma} \\
\tilde{m} \\
\infty\end{array}$ & 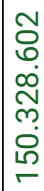 & 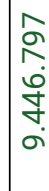 & 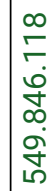 & 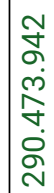 & 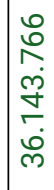 & 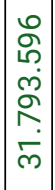 & 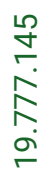 & & & & & & \\
\hline '. & 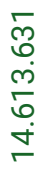 & 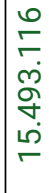 & 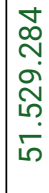 & 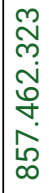 & 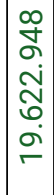 & 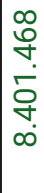 & \begin{tabular}{l}
$\bar{N}$ \\
\multirow{\gamma}{*}{} \\
$\stackrel{2}{\infty}$ \\
$\infty$ \\
$\infty$ \\
$\stackrel{N}{N}$ \\
$\stackrel{N}{N}$
\end{tabular} & 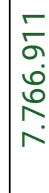 & 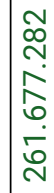 & 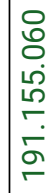 & 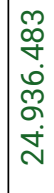 & 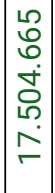 & $\begin{array}{l}5 \\
\circ \\
\circ \\
\infty \\
\infty \\
\check{1} \\
\leftarrow\end{array}$ & 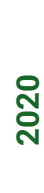 & 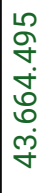 & 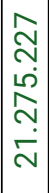 & 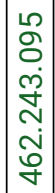 & $\begin{array}{l}\bar{N} \\
\text { in } \\
\infty \\
0 \\
0 \\
0 \\
0 \\
\text { ஸे }\end{array}$ & 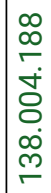 \\
\hline 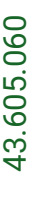 & 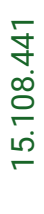 & 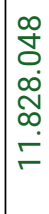 & 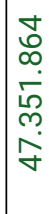 & 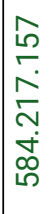 & 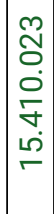 & 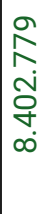 & 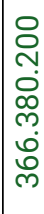 & 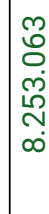 & 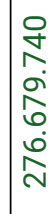 & 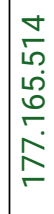 & 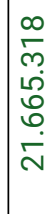 & 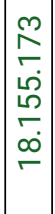 & 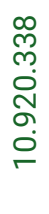 & $\stackrel{a}{\frac{9}{0}}$ & 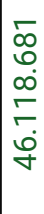 & 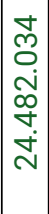 & 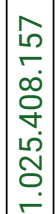 & 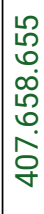 & 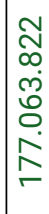 \\
\hline 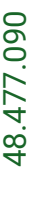 & 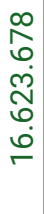 & 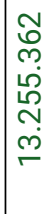 & 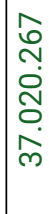 & 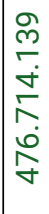 & $\begin{array}{c}\text { 두 } \\
\text { ก் } \\
5 \\
0 \\
6\end{array}$ & $\begin{array}{l}\hat{N} \\
\stackrel{1}{0} \\
\hat{N} \\
\tilde{m} \\
\infty \\
\infty\end{array}$ & $\begin{array}{l}0 \\
\text { m } \\
\infty \\
\text { ம் } \\
0 \\
0 \\
0 \\
\text { ம. }\end{array}$ & 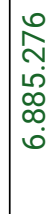 & 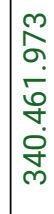 & 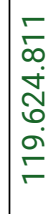 & 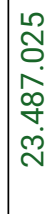 & 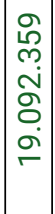 & $\begin{array}{l}\stackrel{\infty}{N} \\
\text { } \\
\stackrel{N}{N} \\
\stackrel{\sim}{\sim} \\
\stackrel{+}{+}\end{array}$ & $\stackrel{\infty}{5}$ & 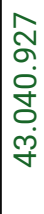 & 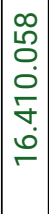 & 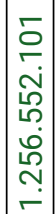 & 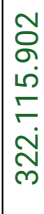 & 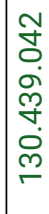 \\
\hline 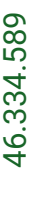 & 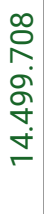 & 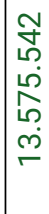 & 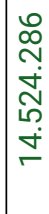 & 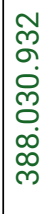 & $\begin{array}{c}N \\
5 \\
0 \\
\infty \\
\infty \\
\sigma \\
\sim \\
\end{array}$ & 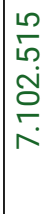 & 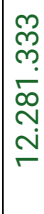 & $\begin{array}{l}0 \\
\sigma \\
\sigma \\
5 \\
\sigma \\
\text { ద் } \\
\text { ம் }\end{array}$ & 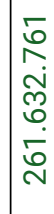 & 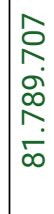 & 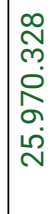 & 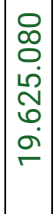 & 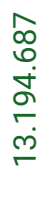 & $\stackrel{N}{\stackrel{0}{0}}$ & 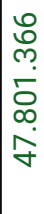 & $\begin{array}{l}9 \\
\circ \\
\infty \\
0 \\
0 \\
\infty \\
1 \\
10 \\
\end{array}$ & 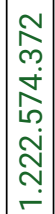 & 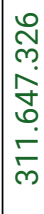 & 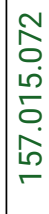 \\
\hline 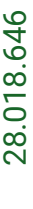 & 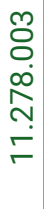 & $\begin{array}{l}10 \\
\infty \\
10 \\
0 \\
0 \\
0 \\
0 \\
0\end{array}$ & $\begin{array}{l}0 \\
1 \\
- \\
0 \\
0 \\
\infty \\
0 \\
0 \\
\dot{\sigma}\end{array}$ & 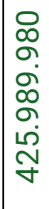 & 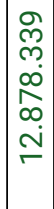 & $\begin{array}{l}0 \\
\infty \\
0 \\
0 \\
0 \\
0 \\
0 \\
1\end{array}$ & $\begin{array}{l}\infty \\
\infty \\
\infty \\
\infty \\
0 \\
\dot{+} \\
0 \\
\dot{m} \\
\dot{m}\end{array}$ & 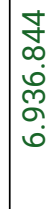 & $\begin{array}{l}\hat{\infty} \\
\infty \\
\dot{\gamma} \\
\text { j} \\
\text { m } \\
\infty \\
\text { m }\end{array}$ & $\begin{array}{l}\infty \\
\infty \\
\infty \\
\Gamma \\
\Gamma \\
\Gamma \\
\sigma \\
\sigma\end{array}$ & 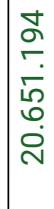 & 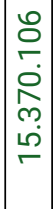 & 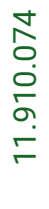 & $\stackrel{0}{\frac{0}{0}}$ & 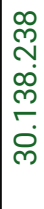 & $\begin{array}{l}\infty \\
\infty \\
\infty \\
\infty \\
\infty \\
\varnothing \\
\dot{m} \\
\dot{m}\end{array}$ & 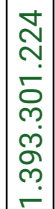 & $\begin{array}{l}0 \\
1 \\
\infty \\
0 \\
1 \\
N \\
10 \\
10 \\
N\end{array}$ & 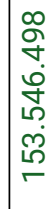 \\
\hline 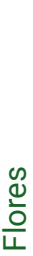 & 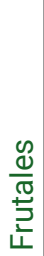 & 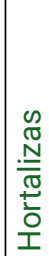 & $\frac{N}{N}$ & $\frac{\stackrel{\sigma}{E}}{\widetilde{\sigma}}$ & $\begin{array}{l}\tilde{\sigma} \\
\stackrel{0}{\sigma} \\
\tilde{\sigma} \\
\end{array}$ & $\mid \begin{array}{l}\frac{0}{\pi} \\
\frac{c}{\pi} \\
\frac{\pi}{\pi} \\
\frac{\pi}{\alpha}\end{array}$ & 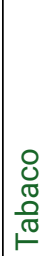 & ల] & 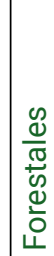 & 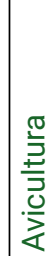 & 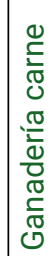 & 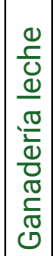 & 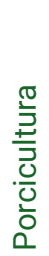 & & 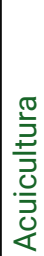 & 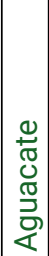 & 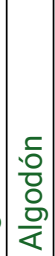 & N & 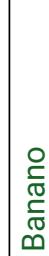 \\
\hline
\end{tabular}




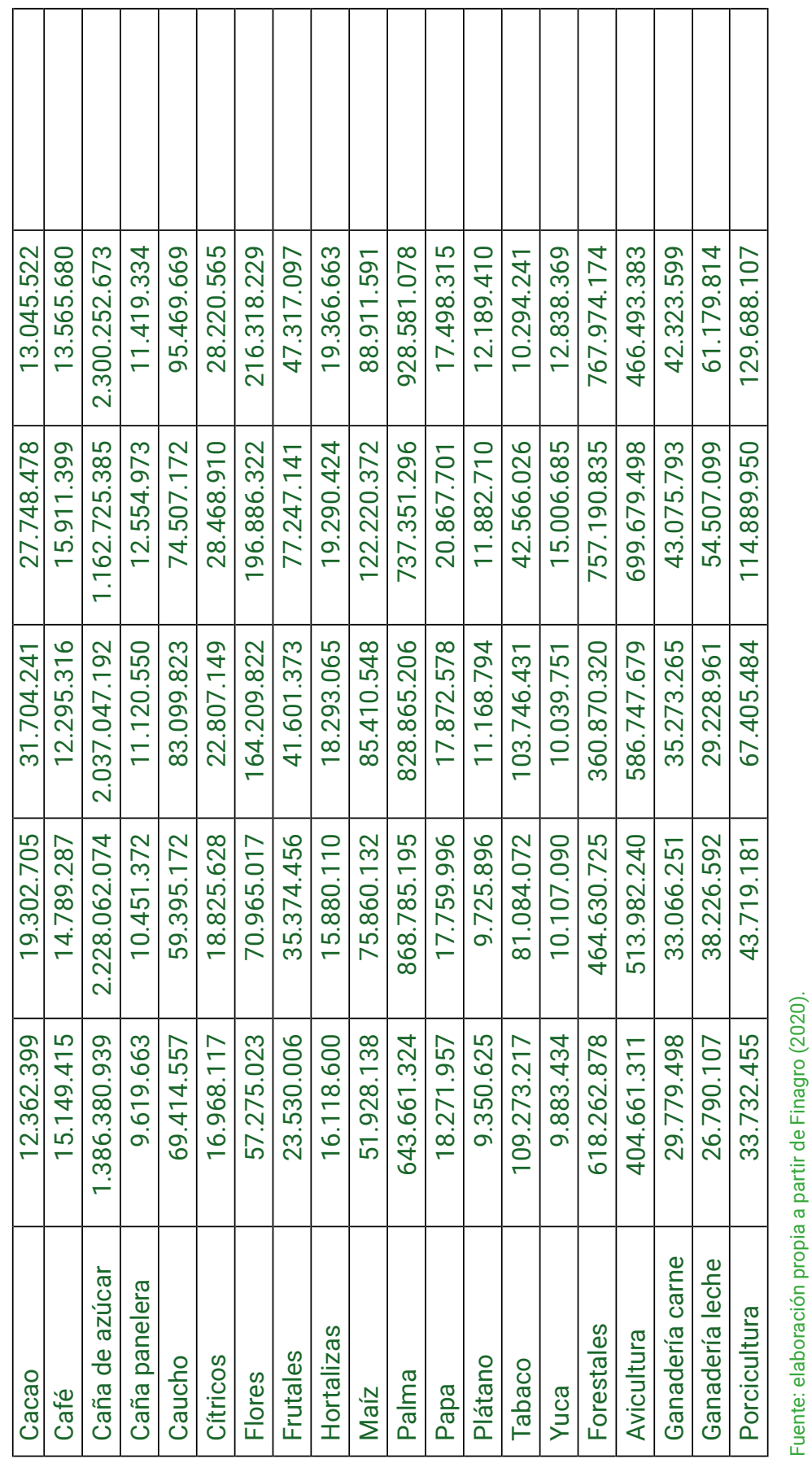




\section{Sector microcrediticio y direccionamiento de los créditos}

A continuación, se relaciona la información del número de créditos y el número de beneficiarios de los microcréditos para el sector agrícola en los últimos años, con sus respectivos usos para el sector agrícola, refinanciación de crédito (Rede) y crédito de sustitución (Sust).

De acuerdo con la información, dentro del sector agrícola la demanda hacia el microcrédito es, en primer lugar, para sustituciones de crédito por condiciones más favorables ofrecidas por estas instituciones; en segundo lugar, para refinanciar créditos adquiridos en otras instituciones financieras; y finalmente, en tercer lugar, para el desarrollo del sector agrícola en cuanto a compra de maquinaria, equipo, mejora en infraestructura y procesos de tecnificación agrícola. 


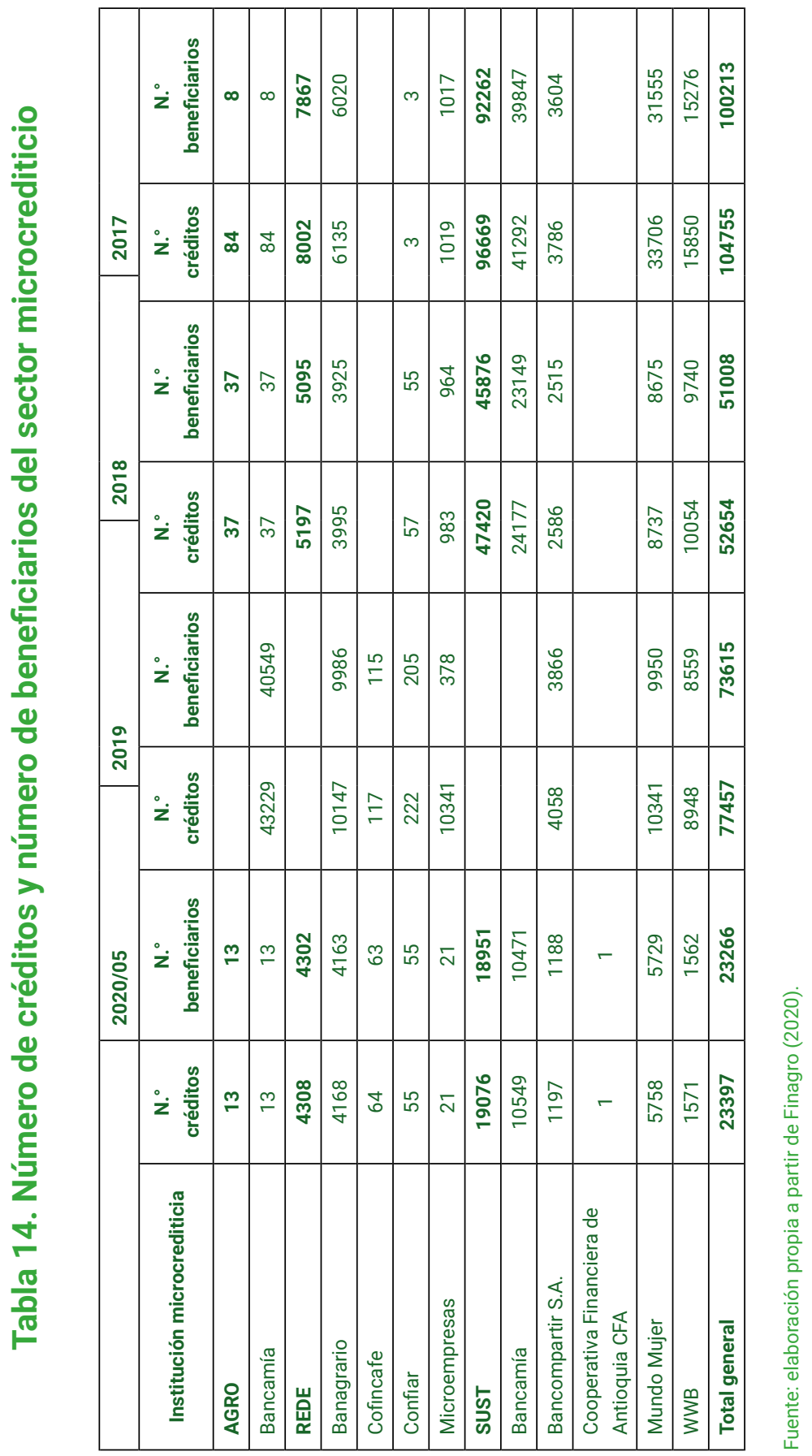




\section{Relación créditos banca tradicional vs. microcrédito}

En la tabla 15 se muestran los datos de los últimos 4 años del comportamiento de los créditos de la banca tradicional y la banca no tradicional para el sector agrícola. De acuerdo con la información, la demanda hacia la banca no tradicional por parte del sector agrícola ha ido incrementándose en los últimos años. En el 2017, la demanda por microcréditos fue de $0.03 \%$, en el 2018 del $0.01 \%$, en el 2019 del 15.37 $\%$ y en lo corrido del 2020 fue de $4.60 \%$.

Tabla 15. Relación créditos banca tradicional vs. microcrédito

\begin{tabular}{|l|c|c|c|c|}
\hline Total de créditos & $\mathbf{2 0 2 0}$ & $\mathbf{2 0 1 9}$ & $\mathbf{2 0 1 8}$ & $\mathbf{2 0 1 7}$ \\
\hline Banca tradicional & 41300 & 238036 & 257333 & 274140 \\
\hline Microcréditos & 19 & 43229 & 37 & 84 \\
\hline Banca tradicional \% & $95.40 \%$ & $84.63 \%$ & $99.99 \%$ & $99.97 \%$ \\
\hline Microcréditos \% & $4.60 \%$ & $15.37 \%$ & $0.01 \%$ & $0.03 \%$ \\
\hline
\end{tabular}

Fuente: elaboración propia a partir de Finagro (2020).

\section{Demanda potencial hacia los microcréditos} por actividades del sector agrícola

La tabla 16 relaciona las actividades productivas que, de acuerdo con el análisis de la información y lo estipulado por la Ley 590 del 2000, podrían acceder al sector microcrediticio según el 
promedio de créditos solicitados y otorgados por beneficiarios en los últimos 10 años.

Los sectores que podrían acceder a los créditos ofrecidos por las instituciones microcrediticias son el sector del aguacate, cacao, café, caña panelera, papa, plátano y yuca.

De acuerdo con los históricos, la demanda potencial del sector agrícola de producción de aguacate al 2020 aproximadamente sería de 6503 solicitudes de crédito; cacao, 9160 solicitudes de crédito; café, 69.585 solicitudes de crédito; caña panelera, 8829 solicitudes de crédito; papa, 6646 solicitudes de crédito; plátano, 12.665 solicitudes de crédito; y yuca, 2472 solicitudes de crédito. 


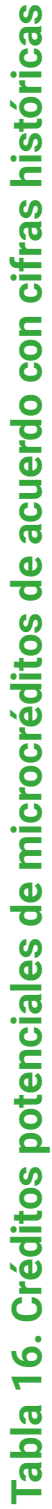

足

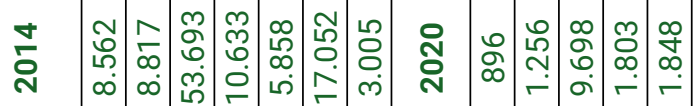

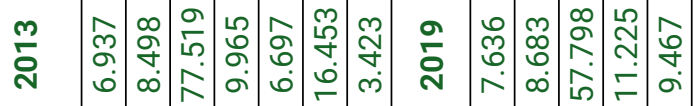

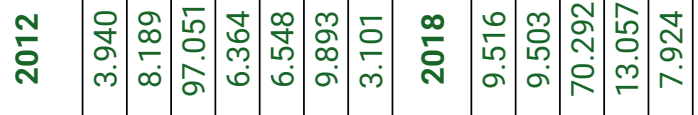

高

言

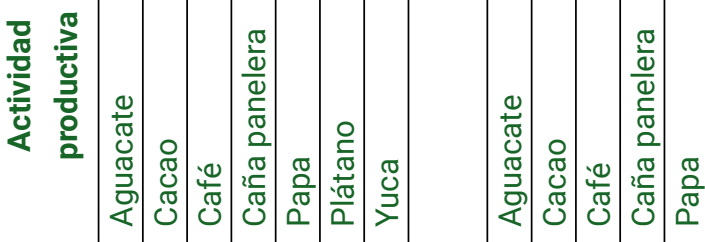




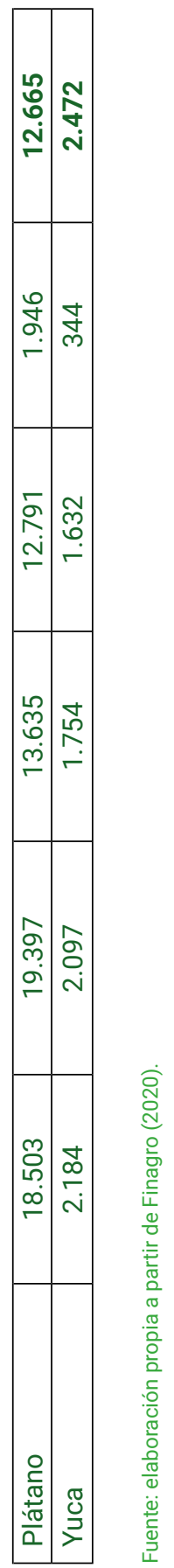




\section{Montos demanda potencial hacia los microcréditos por actividades del sector agrícola}

El siguiente cuadro relaciona el valor promedio de la demanda potencial por actividad productiva, con posibilidades de acceso al microcrédito de acuerdo con el promedio histórico de los últimos 11 años.

El valor de la demanda potencial del sector de aguacate para el 2020 es de $\$ 97.884 .163 .790$; del sector del cacao es de $\$ 146.856 .085 .759 ;$ del sector del café es de \$666.981.150.993; del sector de caña panelera es de $\$ 89.489 .565 .227$; del sector de la papa es de \$113.775.565.227; del sector del plátano es de \$116.602.699.767; y del sector de la yuca es de $\$ 20.932 .222 .671$. 


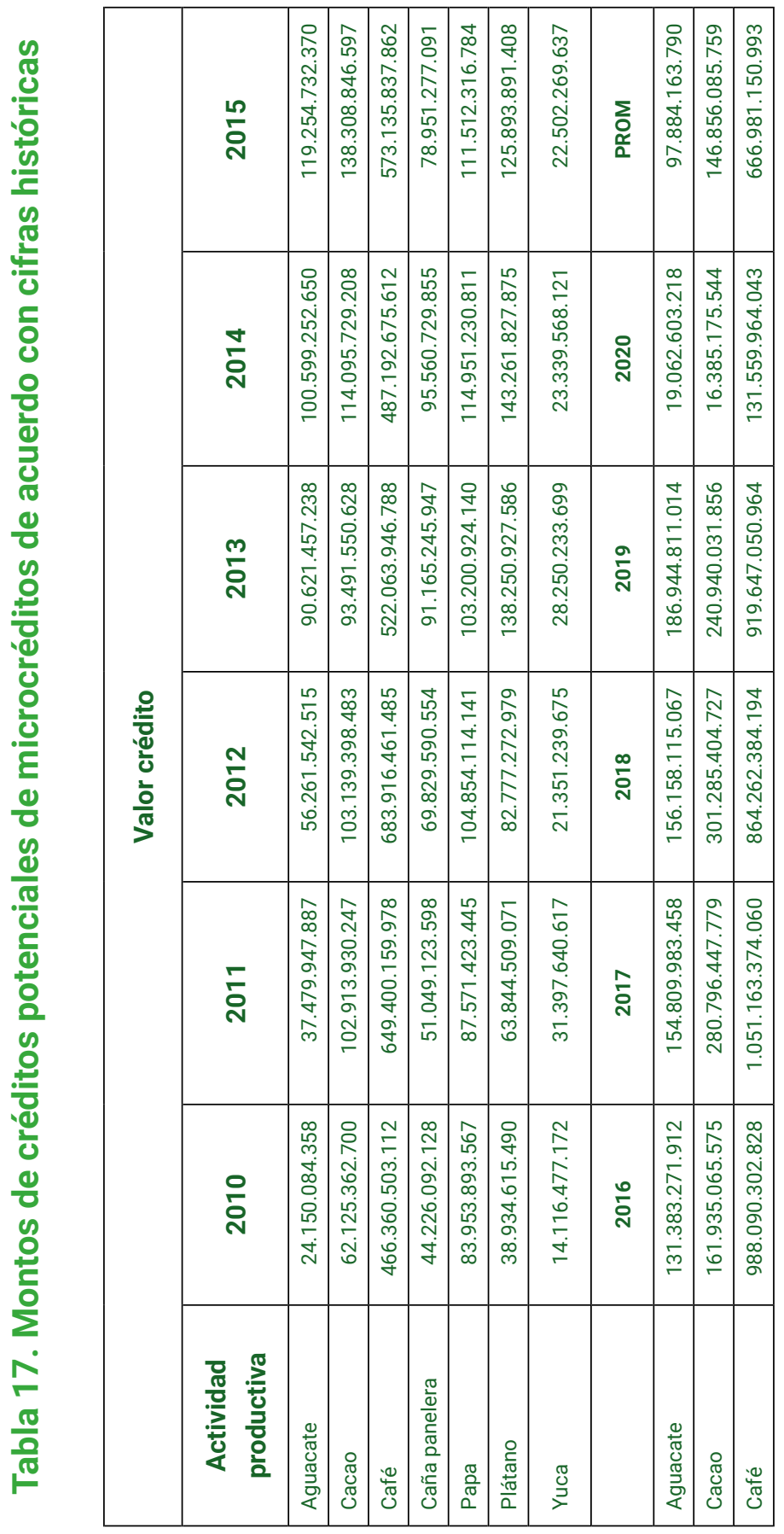




\begin{tabular}{|c|c|c|c|}
\hline 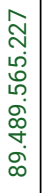 & 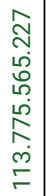 & 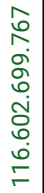 & 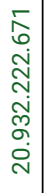 \\
\hline 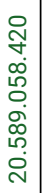 & 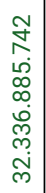 & 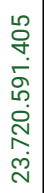 & 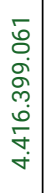 \\
\hline 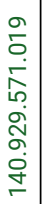 & 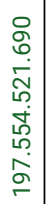 & 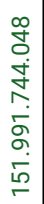 & 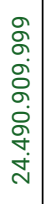 \\
\hline 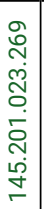 & 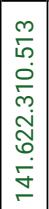 & 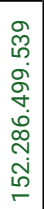 & 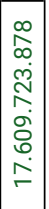 \\
\hline 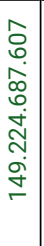 & 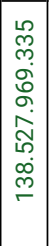 & 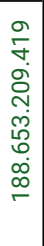 & 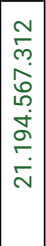 \\
\hline 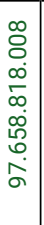 & 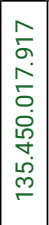 & 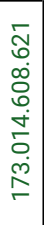 & 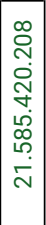 \\
\hline 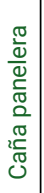 & $\begin{array}{l}\pi \\
\frac{0}{\sigma} \\
\alpha\end{array}$ & $\begin{array}{l}0 \\
\frac{0}{\pi} \\
\frac{\pi}{\pi 0} \\
\frac{\pi}{\alpha}\end{array}$ & $\begin{array}{l}\mathbb{J} \\
\\
\end{array}$ \\
\hline
\end{tabular}




\section{Montos por solicitante demanda potencial hacia los microcréditos por actividades del sector agrícola}

A continuación, se muestran los datos de los montos promedios por beneficios que se demandarían por actividad agrícola. El promedio de solicitud del crédito para el sector de aguacate para el 2020 es de $\$ 15.052 .155$; del sector del cacao es de $\$ 16.032 .324$; del sector del café es de \$9.585.128; del sector de caña panelera es de $\$ 10.135 .866$; del sector de la papa es de \$17.119.405; del sector del plátano es de $\$ 9.206 .688$; y del sector de la yuca es de $\$ 8.467 .728$.

Tabla 18. Promedio montos de créditos potenciales de microcréditos de acuerdo con cifras históricas

\begin{tabular}{|l|c|c|c|}
\hline $\begin{array}{c}\text { Actividad } \\
\text { productiva }\end{array}$ & $\begin{array}{c}\text { Promedio por } \\
\text { monto créditos }\end{array}$ & $\begin{array}{c}\text { Promedio por } \\
\text { solicitantes } \\
\text { crédito }\end{array}$ & $\begin{array}{c}\text { Promedio } \\
\text { monto por } \\
\text { solicitante }\end{array}$ \\
\hline Aguacate & 97.884 .163 .790 & 6.503 & 15.052 .155 \\
\hline Cacao & 146.856 .085 .759 & 9.160 & 16.032 .324 \\
\hline Café & 666.981 .150 .993 & 69.585 & 9.585 .128 \\
\hline $\begin{array}{l}\text { Caña } \\
\text { panelera }\end{array}$ & 89.489 .565 .227 & 8.829 & 10.135 .866 \\
\hline Papa & 113.775 .565 .227 & 6.646 & 17.119 .405 \\
\hline Plátano & 116.602 .699 .767 & 12.665 & 9.206 .688 \\
\hline Yuca & 20.932 .222 .671 & 2.472 & 8.467 .728 \\
\hline
\end{tabular}




\section{Conclusión}

El mejoramiento de procesos y procedimientos es fundamental dentro del sector agrícola colombiano para satisfacer la demanda alimentaria frente al aumento de población. Para canalizar estos procesos es necesario contar con recursos financieros y de vinculación a redes de conocimiento, en las cuales se instruya para tal fin.

En algunos sectores agrícolas se evidencia que sus integrantes no cuentan con el acceso a la banca tradicional por carecer de activos que respalden los créditos. En estos casos, es necesario contar con opciones diferentes a las ofrecidas por la banca tradicional.

La esencia del modelo de microcréditos es ofrecer recursos monetarios a los agricultores que desean tecnificar sus procesos dentro de sus actividades productivas, así como también ofrecer el servicio de capacitaciones y asesorías en temas de tecnificación del campo y, de esta forma, contribuir con el desarrollo y crecimiento económico de los beneficiarios del sector y, por ende, del país.

De acuerdo con los lineamientos del Gobierno Nacional, Colombia busca ser líder en el desarrollo de biotecnología agrícola, es por eso que la banca tradicional como la no tradicional se deben alinear a estos objetivos y contribuir con el otorgamiento de créditos para que los agricultores logren cumplir con los objetivos nacionales.

Es necesario, en consecuencia, desarrollar investigaciones que orienten al sector microcrediticio a identificar clientes potenciales dentro del sector agrícola. De igual forma, es necesario que este sector ofrezca a estos clientes potenciales programas 
de capacitaciones en temas de biotecnología, cumpliendo con la filosofía del modelo.

De acuerdo con el desarrollo de la investigación, dentro del sector agrícola los clientes potenciales del microcrédito lo constituyen los sectores del aguacate, cacao, café, caña panelera papa, plátano y yuca, en cuyos resultados se evidencia la cantidad de microcréditos a ofrecer, el monto a demandar por cada sector y el valor promedio a solicitar por aspirante del crédito.

Esta investigación orienta al sector microcrediticio a ofrecer y direccionar sus créditos a estas actividades agropecuarias, y deja expuesta la necesidad de generar las capacitaciones de biotecnología a dichos sectores. 


\section{Referencias}

Atehortúa, A. (2018). Tecnología e innovación: una apuesta para desarrollar el agro colombiano. Revista Colombiana de Investigaciones Agroindustriales, 5(2), 4-5. https://doi-org.bdigital.sena.edu. co/10.23850/24220582.1797

Balcázar, A., Bonilla, Y., y Balcázar, C. (2019). Microcrédito y competitividad del sector agrícola en Cundinamarca - Colombia. https:// www.ecorfan.org/handbooks/Handbooks_ La_competitividad_como_estrategia_de_ crecimiento_en_las_organizaciones_TI/ Handbooks_La_competitividad_como_ estrategia_de_crecimiento_en_las_ organizaciones_TI_2.pdf

Banco de la República, Ministerio de Agricultura y Finagro. (2010). Situación actual del microcrédito en Colombia. Banrep, Reporte de estabilidad financiera.

Banco Mundial (2006). Finance for all. Banco Mundial. Cotes, A., Barrero, L., Rodríguez, F., Zuluaga, M., y Arévalo, H. (2012). Bioprospección para el desarrollo del sector agropecuario de Colombia. Corpoica.

Chaparro, A., Cardona, C., Orrego, C., Alzate, F., Yepes, L., Serna, L., y Ospina, S. (2012). Agendas 
de conocimiento agenda: biotecnología. Universidad Nacional de Colombia.

Da Silva, E. (2004). The Colours of Biotechnology: Science, Development and Humankind. Electronic Journal of Biotechnology, 7(3), 1-2. http://www. scielo.cl/scielo.php?script=sci_ arttext\&pid=S0717-34582004000300001\&lng= es\&tlng=e.

Departamento Administrativo Nacional de Estadística [DANE]. (2014). Censo Nacional Agropecuario. DANE.

Flórez, L.; Naranjo, R.; Balcázar, A. y García, O. (2018). Competitividad y Desarrollo Regional en Colombia. Universidad de Cundinamarca.

Fondo para el Financiamiento del Sector Agropecuario [Finagro]. (2020). Estadísticas. https:// www.finagro.com.co/estad\%C3\%ADsticas/ estad\%C3\%ADsticas

Grameen Bank. (2012). Grameen Bank. http://www. grameen.com/

Gómez, C., Benavides, C., Osorio, D., y Cuervo, M. (2013) Plan de acción estratégico sector bio de Manizales. Fundación Universidad Empresa Estado del Eje Cafetero.

Hernández, M. (2011). La línea que separa al microcrédito entre el éxito y el fracaso. La República. https://www.larepublica. co/buscar?Term $=\mid \mathrm{a} \% 20$ linea $\% 20$ que $\% 20$ 
separa $\% 20$ al\%20microcredito $\% 20$ entre $\% 20$ el\%20exito\%20y\%20el\%20fracaso\%20121839. php\&Page $=1 \&$ Pagesize $=10$.

Hernández, R., Fernández C., y Baptista M. (2014). Metodología de la investigación. McGraw-Hill. Ley 590 de 2000. Sobre promoción del desarrollo de la micro, pequeña y mediana empresa colombiana y se dictan otras disposiciones. Colombia. Congreso de la República.

Meadows, D., Meadows, D., Randers, J., y Behrens, W. (1972). Los límites del crecimiento: informe al Club de Roma sobre el predicamento de la Humanidad. http://habitat.aq.upm.es/gi/mve/ daee/tmzapiain.pdf

Montenegro, S., y Hernández, Y. (2015). Biotecnología aplicada al desarrollo agropecuario colombiano. Revista de Investigación agraria y ambiental, (6), 97-108.

Narváez, A. (2015). El mercado de la biotecnología en Colombia. Embajada de España en Bogotá.

Navajas, S., y Tejerina, L. (2007). Las microfinanzas en América Latina. ¿Cuál es el tamaño del mercado? Banco Interamericano de Desarrollo. Pérez, B., De la Cruz, H., y Ramírez, J. (2017). Sueldos y salarios: ISR, microcrédito y pobreza. Congreso Internacional de Investigación Academia Journals, 9(3), 2398-2402.

Sasson, A. (1993). Biotechnologies in developing 
countries: present and future. Volume 1:Regional and National Survey. UNESCO Publishing.

Shmaefsky, B. (2013). Agricultural Biotechnology: History, Science, and Society. Bibliographic Essay. Choise. 


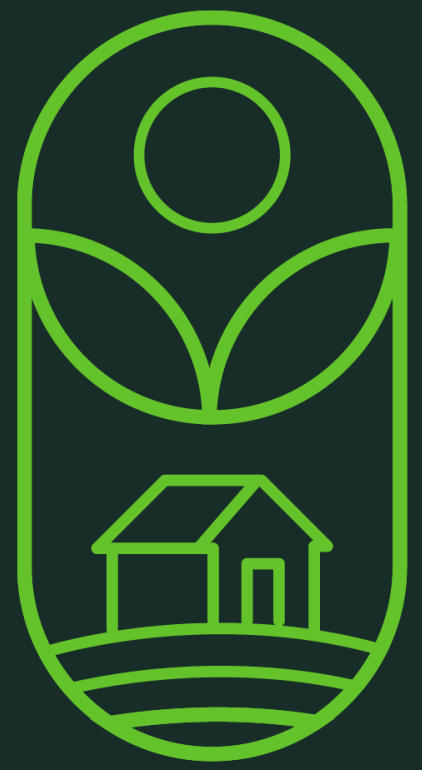

Editorial

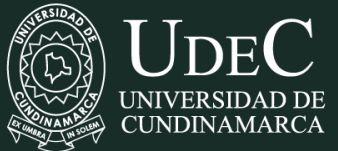

